\title{
Analyse der differentiellen Expression von Transportfaktoren und deren Funktion bei dem nukleocytoplasmatischen Transport von TFIIIA
}

\author{
Dissertation \\ zur Erlangung des Doktorgrades \\ der Mathematisch-Naturwissenschaftlichen Fakultäten \\ der Georg-August-Universität zu Göttingen
}

vorgelegt von

Jörg Wischnewski

aus Hannover

Göttingen 2002 
D7

Referentin: Prof. Dr. M. Schäfer

Korreferentin: Prof. Dr. C. Gatz

Tag der mündlichen Prüfung: 24.04.2002 


\section{INHALTSVERZEICHNIS}

Inhaltsverzeichnis $\quad$ I

Abbildungsverzeichnis $\quad$ VI

Tabellenverzeichnis $\quad$ VII

Abkürzungsverzeichnis $\quad$ IX

$1 \quad$ Einleitung 1

1.1 Mechanismen des richtungsgebundenen nukleocytoplasmatischen Transports 2

1.2 Signalsequenzen vermitteln den nukleocytoplasmatischen Transport 5

1.3 Transportrezeptoren der Karyopherin $\beta$ Familie 5

1.4 Transportadapter, eine Brücke zwischen Substrat und Rezeptor 7

$1.5 \quad$ Karyopherin $\alpha$ im nukleocytoplasmatischen Transport $\quad 8$

1.6 Differentielle Expression und Bindungsaffinität von Karyopherin $\alpha \quad 8$

1.7 5S RNA Transport 9

$1.8 \quad$ Ziel der Arbeit 11

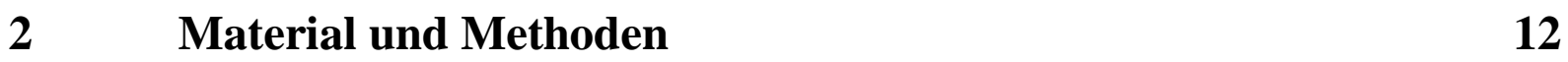

$\begin{array}{lll}2.1 & \text { Material } & 12\end{array}$

2.1.1 Versuchstiere 12

2.1.2 Bakterienstämme 12

2.1.3 Zellinien 12

2.1.4 Genbanken 13

2.1.5 Plasmide aus anderen Laboratorien 13

2.1.6 Vektoren 13

$\begin{array}{lll}2.1 .7 & \text { Oligonukleotide } & 14\end{array}$

2.1.8 Enzyme und Reaktionssysteme (Kits) 17

2.1.9 Antikörper 17

2.1.10 Radioisotope 18

2.1.11 Medien und Lösungen 18

2.1.12 Chromatographiematrices 20

2.1.13 Chemikalien 20

2.1.14 Geräte 21

2.2 Molekularbiologische Methoden 23 
2.2.1 DNA-Methoden 23

2.2.1.1 Plasmidpräparation im präparativen Maßstab 23

2.2.1.2 Plasmidpräparation im analytischen Maßstab 23

2.2.1.3 Konzentrationsbestimmung von Nukleinsäuren durch UV-Spektroskopie 24

2.2.1.4 Agarosegelelektrophorese 24

2.2.1.5 Manipulation von DNA 25

2.2.1.6 Spaltung von DNA mit Restriktionsendonucleasen 25

2.2.1.7 Dephosphorylierung von Vektoren 25

2.2.1.8 Einfügen von Schnittstellen $\quad 25$

2.2.1.9 Ligation 26

2.2.1.10 Reinigung von präparativen PCR-Ansätzen 26

2.2.1.11 Reisolierung von DNA-Fragmenten mit TaKaRa Recochips 27

2.2.1.12 Sequenzierung von DNA 27

2.2.1.13 DNA-Fällung mit Ethanol 28

2.2.2 RNA-Standardmethoden 28

2.2.2.1 Isolierung von Gesamt-RNA aus Xenopus Embryonalstadien 28

2.2.2.2 Isolierung von Gesamt-RNA aus adulten Geweben und Organen 29

2.2.2.3 Total-RNA Präparation von embryonalem Augengewebe 29

2.2.2.4 Poly-A ${ }^{+}$-RNA Isolierung 31

2.2.2.5 Northern Blot 31

2.2.2.6 Reverse-Transkriptase-Polymerase-Kettenreaktion (RT-PCR) 32

2.2.2.7 Smart RACE-Ready cDNA 33

2.2.2.8 In vitro-Synthese markierter RNA-Sonden 33

2.2.2.9 Aufreinigung synthetischer RNA mit "RNeasy Mini Kits" 34

2.2.2.10 Aufreinigung synthetischer RNA mit Sephadex-G50 Säulen 34

2.2.3 Protein-Standardmethoden 35

2.2.3.1 Polyacrylamidgelelektrophorese (PAGE) 35

2.2.3.2 Expression von GST-Fusionsproteinen 36

2.2.3.3 TFIIIA Induktion 37

2.2.3.4 Präparation von Glutathion Agarose und Bindungsprotein 37

2.2.3.5 „Pull-down assay“ für in vitro translatierte Proteine 37

2.2.3.6 Fluoreszenzdetektion von transient transfizierten HeLa Zellen 37

$\begin{array}{lll}2.2 .4 & \text { Bakterien und Zellkultur } & 38\end{array}$ 
2.2.4.1 Elektrokompetente Zellen 38

2.2.4.2 Elektrotransformation 38

2.2.4.3 alpha-Komplementation 39

2.2.4.4 Gewinnung von HeLa Zellen für transiente Transfektion 39

2.2.4.5 Transiente Transfektion von HeLa Zellen durch Elektroporation 39

2.2.4.6 Transiente Transfektion von HeLa Zellen durch Lipofektion 40

2.2.5 Erstellung einer Lamda-cDNA-Bank aus embryonalem Augengewebe 40

2.2.6 Arbeiten mit Phagen 42

2.2.6.1 Phagenfraktionierung 42

2.2.6.2 Phagenplattierung zur Isolierung von Einzelplaques 43

2.2.6.3 Erstellen einer konzentrierten Phagenlösung 43

2.2.6.4 Exzision des Phageninserts 43

2.2.6.5 Bestimmung des Phagentiters 44

2.2.7 Gewinnung von Xenopus laevis Embryonen $\quad 45$

2.2.7.1 Stimulation der Eiablage, Befruchtung und Gewinnung von Embryonalstadien 45

2.2.7.2 Fixierung von Xenopus Embryonen 46

2.2.8 „Whole mount“ in situ Hybridisierung 46

2.2.8.1 Rehydrieren der Embryonen 46

2.2.8.2 Proteinase K-Behandlung 47

2.2.8.3 Refixierung und Hybridisierungsreaktion 47

$\begin{array}{lll}2.2 .8 .4 & \text { Waschen } & 48\end{array}$

2.2.8.5 Antikörper-Inkubation 48

2.2.8.6 Farbentwicklung 49

2.2.8.7 Abstoppen der Färbung und Auswertung 49

2.2.8.8 Gewebeschnitte mit einem Vibratom 50

2.2.8.9 Maschinelle „Whole mount“ in situ Hybridisierung 51

$3 \quad$ Ergebnisse $\quad 55$

3.1 Der Transkriptions-Faktor IIIA

3.1.1 Vorarbeiten zur Eingrenzung der Kernlokalisierungssignalsequenz von dem Transkriptions-Faktor IIIA $\quad 55$

3.1.2 Weitere Arbeiten zur Eingrenzung der Kerntransportsignalsequenzen 56

3.1.3 Analyse von immunfluoreszenzmarkierten TFIIIA Mutanten in HeLa Zellen 61

3.2 Definition einer neuen Synexpressionsgruppe 62 
3.2.1 Karyopherin $\beta 3 \quad 62$

$\begin{array}{lll}3.2 .2 & \text { Isolierung von Karyopherin } \beta 3 & 62\end{array}$

3.2.3 Die nukleocytoplasmatische Verteilung von Xenopus Karyopherin $\beta 3$ in transfizierten HeLa Zellen 63

3.2.4 Karyopherin $\beta 3$ ist ein differentiell exprimierter Transportfaktor 64

3.2.5 Ribosomale Proteine und ihre Transportfaktoren definieren eine neue $\begin{array}{ll}\text { Synexpressionsgruppe } & 66\end{array}$

3.3 Durchmusterung einer cDNA Bank aus embryonalem Augengewebe $\quad 69$

3.3.1 Eine cDNA Bank aus embyonalem Augengewebe 69

$\begin{array}{lll}\text { 3.3.2 Statistische Übersicht } & 70\end{array}$

3.3.3 Sam68, ein Protein, welches möglicherweise am Export von RNA mit CTE $\begin{array}{ll}\text { oder RRE beteiligt ist } & 76\end{array}$

3.3.4 Eingrenzung der Kandidatenklone auf putative Ran bindende Proteine 77

3.3.5 Karyopherin $\alpha 3$ ist ein neues Karyopherin $\alpha$ Homolog 80

3.4 Isolierung der in Xenopus neuen Karyopherin $\alpha$ Homologen $\alpha 4$ und $\alpha 5 \quad 82$

3.4.1 In vitro Translation der Konstrukte $\quad 84$

$\begin{array}{lll}3.5 & \text { TFIIIA und Karyopherin } \alpha & 85\end{array}$

3.5.1 RT-PCR Expressionsanalyse von Xenopus laevis Karyopherin $\alpha$ Varianten im $\begin{array}{ll}\text { Vergleich zu dem Zinkfingerprotein TFIIIA } & 85\end{array}$

3.5.2 Expressionsanalyse mit der ,whole mount“ in situ Methode der Karyopherin $\alpha$ Varianten im Vergleich zu TFIIIA

3.5.3 TFIIIA interagiert mit Karyopherin $\alpha$, aber nicht mit RanBP7, Karyopherin $\beta$, Karyopherin $\beta 3$ oder Transportin $\quad 92$

3.5.4 Interaktionsstudien von verschiedenen Karyopherin $\alpha$ Varianten $\quad 94$

$4 \quad$ Diskussion $\quad 98$

4.1 Die Minimalstruktur der zwei NLS von TFIIIA 98

4.2 TFIIIA bindet spezifisch an Karyopherin $\alpha 1$ und $\alpha 2 \quad 100$

4.3 Definition der Karyopherin $\beta 3$ Synexpressionsgruppe 103

4.4 Die Karyopherin $\alpha$ Varianten 104

4.5 Durchmusterung einer cDNA Bank aus embryonalem Augengewebe 106

$\begin{array}{lll}4.6 & \text { Ausblick } & 109\end{array}$

5 Zusammenfassung 111

$6 \quad$ Literaturverzeichnis $\quad 112$ 
$7 \quad$ Anhang

8 Danksagung

152

9 Lebenslauf

153 


\section{ABBILDUNGSVERZEICHNIS}

Abbildung 1: Grundprinzip des nukleocytoplasmatischen Transports.

Abbildung 2: Modell zum nukleocytoplasmatischen Transport von 5S RNA. 10

Abbildung 3: Analyse zur NLS Identifizierung von N-terminalen Zinkfingern. 58

Abbildung 4: Analyse zur NLS Identifizierung von C-terminalen Zinkfingern. 59

Abbildung 5: Deletionsmutanten zur Eingrenzung der Kernlokalisierungssignalsequenz. 60

Abbildung 6: Subzelluläre Lokalisation der transportkompetenten Minimalstrukturen von TFIIIA in somatischen Zellen.

Abbildung 7: Vergleich von Xenopus Karyopherin $\beta 3$ mit anderen verwandten Proteinen. 63

Abbildung 8: Transfektion von Hela-Zellen mit Xenopus Karyopherin $\beta 3$.

Abbildung 9 : „Whole mount“ in situ Hybridisierung mit Xenopus Karyopherin $\beta 3$ antisense RNA.

Abbildung 10: Vergleichende Expressionsmusteranalyse.

Abbildung 11: Schematische Übersicht der Expressions- und Sequenzdaten der

Durchmusterung einer cDNA-Bank aus embryonalem Augengewebe.

Abbildung 12: Auszug einer Dialign Analyse der abgeleiteten Sequenz des 3p4g2 Klons. 78

Abbildung 13: Sequenzvergleich von Xenopus Karyopherin $\alpha 3$ mit dem humanem $\alpha 1$ Homolog.

Abbildung 14: Phylogenetischer Stammbaum der Karyopherin $\alpha$ Proteinfamilie.

Abbildung 15: Sequenzvergleich von Xenopus Karyopherin $\alpha 4$ mit dem humanen Karyopherin $\alpha 4$ Homolog.

Abbildung 16: Sequenzvergleich von Xenopus Karyopherin $\alpha 5.1$ und 5.2 mit dem humanen Karyopherin $\alpha 7$ Homolog.

Abbildung 17: Analyse der Karyopherin $\alpha 1, \alpha 3, \alpha 4$ und $\alpha 5$ Primärklone.

Abbildung 18: Vergleichende Expressionsanalyse der Karyopherin Varianten $\alpha 1, \alpha 2, \alpha 3$, $\alpha 4, \alpha 5$ und TFIIIA während der Oogenese.

Abbildung 19: Vergleichende Expressionsanalyse der Karyopherin Varianten $\alpha 1, \alpha 2, \alpha 3$, $\alpha 4, \alpha 5$ und TFIIIA während der frühen Embryonalentwicklung von Xenopus laevis.

Abbildung 20: Vergleichende Expressionsanalyse der Karyopherin Varianten $\alpha 1, \alpha 2, \alpha 3$, $\alpha 4, \alpha 5$ und TFIIIA in adulten Geweben von Xenopus laevis. 
Abbildung 21: Expressionsmusteranalyse mit der „whole mount“ in situ Technik zur räumlich-zeitlichen Auflösung in der Oogenese und den frühen Entwicklungsstadien von Xenopus laevis.

Abbildung 22: Zur Interaktion verwendete GST-Fusionsproteine.

Abbildung 23: TFIIIA interagiert mit Karyopherin $\alpha$.

Abbildung 24: Bakterielle Expression der GST-Fusionsproteine mit Nukleoplasmin und TFIIIA- $\Delta 56$.

Abbildung 25: Analyse der Karyopherin $\alpha$ Varianten.

Abbildung 26: Bindungsanalyse von GST-TFIIIA- $\Delta 56$ an verschiedene Karyopherin $\alpha$ Varianten.

Abbildung 27: Die Aminosäuresequenz von TFIIIA.

Abbildung 28: Die TFIIIA Kerntransportsignale überlappen mit der 5S RNA bindenden Domäne.

Abbildung 29: Karyopherin $\beta 3$ Sequenz.

Abbildung 30: Nukleotidsequenz mit abgeleiteter Proteinsequenz der kodierenden Nukleotide von Karyopherin $\alpha 3$ aus Xenopus laevis.

Abbildung 31: Nukleotidsequenz mit abgeleiteter Proteinsequenz der kodierenden Nukleotide von Karyopherin $\alpha 4$ aus Xenopus laevis.

Abbildung 32: Nukleotidsequenz mit abgeleiteter Proteinsequenz der kodierenden Nukleotide von den Karyopherin $\alpha$ Varianten $\alpha 5.1$ und $\alpha 5.2$ aus Xenopus laevis. 


\section{TABELLENVERZEICHNIS}

Tabelle 1: Standard Sequenzierprimer. $\quad 14$

Tabelle 2: TFIIIA spezifische Primer mit eingefügten Schnittstellen. 14

Tabelle 3 : Karyopherin $\beta 3$ spezifische Sequenzierprimer. $\quad 14$

Tabelle 4 : Primer für Transportfaktoren und transportassoziierte Proteine mit $\begin{array}{ll}\text { eingefügten Schnittstellen. } & 15\end{array}$

Tabelle 5 : Karyopherin $\alpha$ spezifische Sequenzierprimer. $\quad 16$

Tabelle 6: Sonstige Oligonukleotide. 16

Tabelle 7 : Exemplarisches Programm für eine maschinelle ,whole mount“ in situ Hybridisierung. 53

Tabelle 8 : Primerkombinationen, Schnittstellen und Matrizen für die Klonierung von Zinkfingerfusionsmutanten.

Tabelle 9: Verteilung der gefundenen Funktionsgruppen. $\quad 72$

Tabelle 10: Identifizierung homologer Sequenzen von Klonen der Karyopherin $\beta 3$ Synexpressionsgruppe und Klonen sonstiger Expressionsmuster. $\quad 75$

Tabelle 11: Tabellarische Auflistung der Kandidatengene. 79

$\begin{array}{ll}\text { Tabelle 12: Mehrfach auftretende Proteine. } & 120\end{array}$

Tabelle 13: Auszug aus der Rohdatentabelle zur Durchmusterung einer cDNA Bank aus embryonalem Augengewebe.

Tabelle 14: Zur Gruppierung der Karyopherin $\beta 3$ Synexpressionsgruppe verwendete Vektoren.

Tabelle 15: Zur Gruppierung von Genen mit anderen Expressionsmustern verwendete Vektoren. 


\section{ABKÜRZUNGSVERZEICHNIS}

\begin{tabular}{|c|c|}
\hline Abb. & Abbildung \\
\hline $\mathrm{bp}$ & Basenpaare \\
\hline $\mathrm{Cy} 3$ & Carboxymethylindocyanin \\
\hline ddNTP & Didesoxyribonukleosidtriphosphat \\
\hline $\mathrm{dH}_{2} \mathrm{O}$ & destilliertes Wasser \\
\hline DNA & „Desoxyribonucleic Acid“ (Desoxyribonukleinsäure) \\
\hline dNTP & Desoxyribonukleotidtriphosphat \\
\hline EDTA & Ethylendiamintetraacetat \\
\hline HEPES & N-2-Hydroxyethylpiperazin-N'-2-ethansulfonsäure \\
\hline IPTG & Isopropyl- $\beta$-D-thiogalactosid \\
\hline $\mathrm{kb}$ & Kilobasen \\
\hline $\mathrm{kd}$ & Kilodalton \\
\hline M & Molar \\
\hline $\min$ & Minuten \\
\hline NP-40 & Nonidet P-40 \\
\hline PAGE & Polyacrylamid-Gelelektrophorese \\
\hline PCR & Polymerase „Chain Reaction““ \\
\hline $\mathrm{pH}$ & pondus Hydrogeni, Protonenaktivitätsexponent \\
\hline PMSF & Phenylmethylsulfonylfluorid \\
\hline Ran & Ras related nuclear protein \\
\hline RanBP & Ran Binding Protein \\
\hline RNA & „Ribonucleic Acid“( Ribonukleinsäure) \\
\hline RT & Raumtemperatur \\
\hline ssDNA & einzelsträngige Didesoxyribonukleinsäure \\
\hline TBE & Tris-Borat-EDTA-Puffer \\
\hline TEMED & N,N,N',N'-Tetramethylethylendiamin \\
\hline Tris & Tri(hydroxymethyl)aminomethan \\
\hline Tween-20 & Polyoxyethylensorbitan-Monolaurat \\
\hline $\mathrm{U}$ & Unit, Einheit für Enzymaktivität \\
\hline Upm & Umdrehungen pro Minute \\
\hline
\end{tabular}


UV

$\mathrm{v} / \mathrm{v}$

$\mathrm{w} / \mathrm{v}$

X-Gal
Ultraviolett

Volumen pro Volumen

Gewicht pro Volumen

5-Brom-4-Chlor-Indolyl- $\beta$-D-galactosid 


\section{Einleitung}

Die Eukaryontenzelle ist in verschiedene membranumhüllte Kompartimente unterteilt, die auch als Organellen bezeichnet werden. Jedes Organell besitzt eine bestimmte Funktion. Für die Ausübung seiner Funktion benötigt es spezifische Enzyme, Substrate oder Milieus, die es Enzymen erlauben, Stoffwechselreaktionen durchzuführen. Der Transport von kleinen Molekülen kann entweder durch Diffusion direkt durch die Membran oder ein Kanalprotein hindurch erfolgen oder wie bei der $\mathrm{Na}^{+} / \mathrm{K}^{+}$Pumpe der Plasmamembran als aktiver energieverbrauchender Transportprozess. Die Energie für Transportprozesse wird wie im Fall von $\mathrm{Na}^{+} / \mathrm{K}^{+}$Pumpen oder auch einigen $\mathrm{Ca}^{+}$Pumpen durch Hydrolyse von ATP gewonnen. Andere Transportsysteme können die für den Transport benötigte Energie auch aus einem Ionengradienten beziehen. Die Synthese von neu gebildeten Proteinen erfolgt fast immer im Cytosol, dem die Organellen umgebenden allgemeinem Zellinnenraum. Eine Ausnahme bilden hier einige Proteine, die von den Ribosomen der Mitochondrien und Chloroplasten synthetisiert werden. Um den verschiedenen Organellen zur Verfügung zu stehen, müssen die Proteine transportiert werden, d. h., sie müssen selektiv in das Innere eines Organells und eventuell wieder hinaus gebracht werden. Generell werden zwei Transportwege von neu synthetisierten Proteinen verwendet, um in das Zielkompartiment zu gelangen. Einer führt vom endoplasmatischen Retikulum über den Golgi-Apparat in die Lysosomen zur Zellmembran, oder zu verschiedenen sekretorischen Vesikeln. Dieser Transportweg beruht auf der selektiven Verschmelzung von Membranen und Transportvesikeln oder deren gerichteter Freisetzung. Hier wird das Transportsubstrat im Inneren des Vesikels gehalten und bei der Verschmelzung der Membranen in das Innere des Lumens oder den extrazellulären Raum freigesetzt. Die Signal- und Rezeptormoleküle für diese Transportprozesse müssen sich, um zugänglich zu sein, auf der Rezeptorseite der Kompartimentmembran befinden. Der zweite Transportweg führt durch das Cytosol und mündet direkt in den von nur einer Membran umgebenen Peroxysomen oder den durch eine Doppelmembran abgegrenzten Mitochondrien, Chloroplasten oder dem Zellkern. Für diesen Transportweg müssen die Transportsubstrate selbst eine Signalsequenz besitzen, welche dann von dem Transportsystem der selektiven Barriere des Zielkompartiments erkannt werden kann. Eine solche selektive Barriere stellt auch die Doppelmembran des Zellkerns dar, der in Eukaryonten den Ort der DNA Replikation, RNA Synthese und der Montage der ribosomalen Untereinheiten vom Cytoplasma abgrenzt. Die Ribosomenbiogenese ist ein komplexer Prozess, der mehrfache Passagen durch die Kernmembran erfordert. Zunächst muss die transkribierte mRNA in das 
Cytoplasma transportiert werden. Dieser Prozess wird Export genannt. Dort findet im Fall von ribosomaler mRNA die Translation an den Orten der Proteinbiosynthese, den Ribosomen, statt. Auch andere Gruppen von RNA Molekülen wie z.B. die meisten U snRNAs (nicht U6) des Spliceosoms werden zunächst als Teil ihres Reifungsprozesses in das Cytoplasma exportiert. Nach dort erfolgter Modifizierung müssen sie wie auch die Proteine der ribosomalen Untereinheiten wieder in den Zellkern transportiert werden. Dieser Transportschritt aus dem Cytoplasma in das Nukleoplasma des Zellkerns wird als Import bezeichnet. Im Nucleolus erfolgt die Montage der ribosomalen Untereinheiten 40S und 60S, die dann exportiert werden. Im Cytoplasma bilden sie zur Proteinbiosynthese das 80S Ribosom aus.

\subsection{Mechanismen des richtungsgebundenen nukleocytoplasmatischen Transports}

Der bidirektionale Transport von Makromolekülen zwischen dem Cytoplasma und dem Zellkern wird von der Kernpore vermittelt. Die Kernpore ist ein Komplex aus ca. 30 Proteinen in Hefe und 50-100 Proteinen in Vertebraten. Das Molekulargewicht wird auf 55 Megadalton in Hefe und 125 Megadalton in Vertebraten geschätzt. Ionen und kleinere Moleküle bis zu einer Größe von 50 kd können die Kernpore durch Diffusion passieren. Größere Moleküle werden aktiv und energieabhängig transportiert. Die Richtung des Transports wird durch einen Konzentrationsgradienten der kleinen GTPase Ran (,Ras-related nuclear protein“, 25 kd) vorgegeben. Ran liegt im Cytoplasma in GDP gebundener Form vor. Im Nukleoplasma ist Ran-GTP die vorwiegend auftretende Form. Karyopherin $\beta$ verwandte Importrezeptoren binden an das NLS präsentierende Transport-substrat und werden oft auch als Importine bezeichnet. Von Transportinen wird aufgrund ihres sauren Charakters angenommen, dass sie auch in den Export von Substraten involviert sein könnten. Der initiale Andockschritt an die Kernpore kann in vitro unabhängig von Ran-GDP vollzogen werden. Um in den Zellkern zu gelangen, wird jedoch Ran-GDP benötigt. Im Zellkern angekommen wird GDP durch den Nukleotidaustauschfaktor RanGEF gegen GTP ausgetauscht, und der Importkomplex zerfällt. Karyopherine, die den Export von Substraten vermitteln, werden auch Exportine genannt. Für die Bindung eines Transportfaktors an ein Exportsubstrat wird im Gegensatz zur Situation im Cytoplasma Ran-GTP benötigt. Auf der cytoplasmatischen Seite wird Ran-GTP vermittelt von RanGAP (GTPase aktivierendes Protein) zu Ran-GDP hydrolysiert und der Exportkomplex zerfällt (Übersicht in Görlich und Kutay, 1999; Mattaj 
und Englmeier, 1998; Moore, 1998; Ohno et al., 1998). Die RanGAP Aktivität wird durch das lösliche und Ran-GTP bindende Protein RanBP1 stimuliert. RanGAP1 ist entweder in unmodifizierter Form im Cytoplasma vorhanden, oder es wird modifiziert durch SUMO-1 (,small ubiquitin-related modifier") an die Kernpore gelenkt (Matunis et al., 1998). Es bindet wahrscheinlich mit SUMO-1 an das Ran bindende Protein RanBP2 (Mahajan et al., 1997). Die Ran-GTPase Aktivität kann auch durch RanBP2 induziert werden. Es ist zur Zeit noch nicht klar, ob RanBP1 alleine oder beide Proteine, RanBP1 und RanBP2, an der Induktion von RanGAP beteiligt sind. Die Lokalisation des Ran-GTP hydrolisierenden Komplexes an der Kernpore legt nahe, dass der Exportkomplex sofort bei dem Eintritt in das Cytoplasma dissoziiert. Die Ran-GTP Konzentration im Nukleoplasma wird durch den Nukleären Transport Faktor 2 (NTF2) aufrecht erhalten. NTF2 importiert Ran-GDP. Der Komplex dissoziiert nach Austausch von GDP gegen GTP durch RanGEF (Ribbeck et al., 1998).

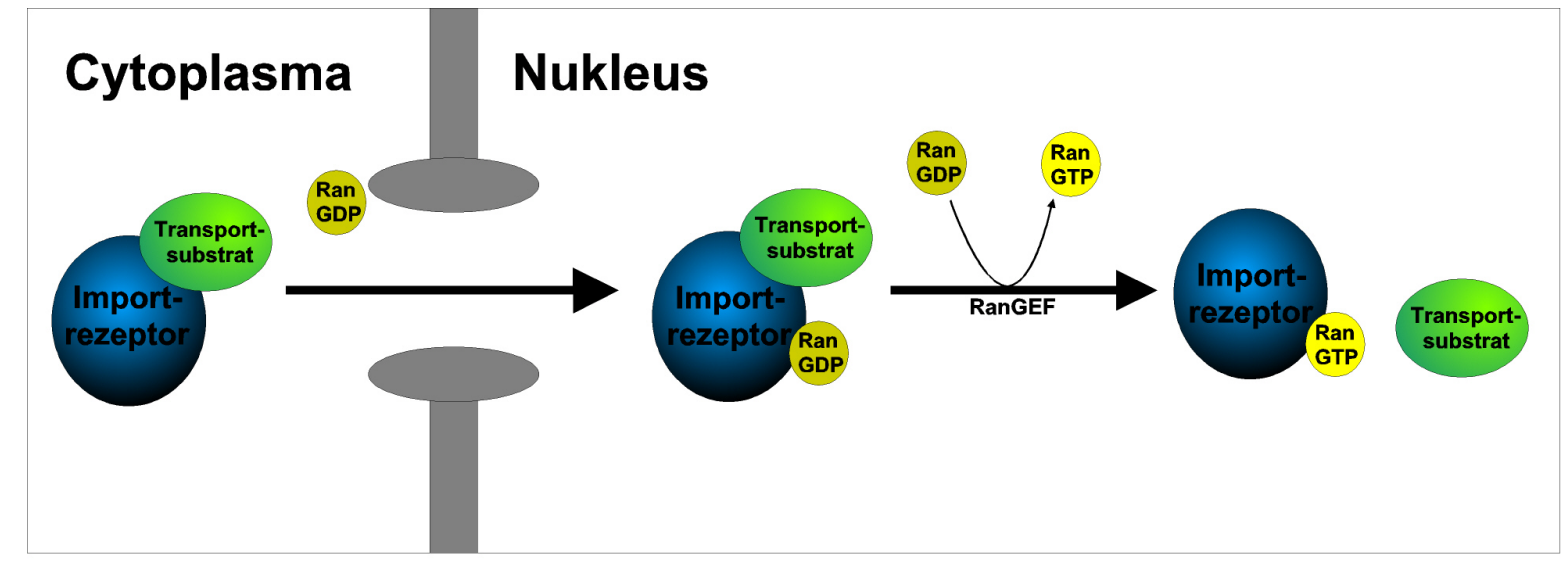

\section{Cytoplasma}

Nukleus

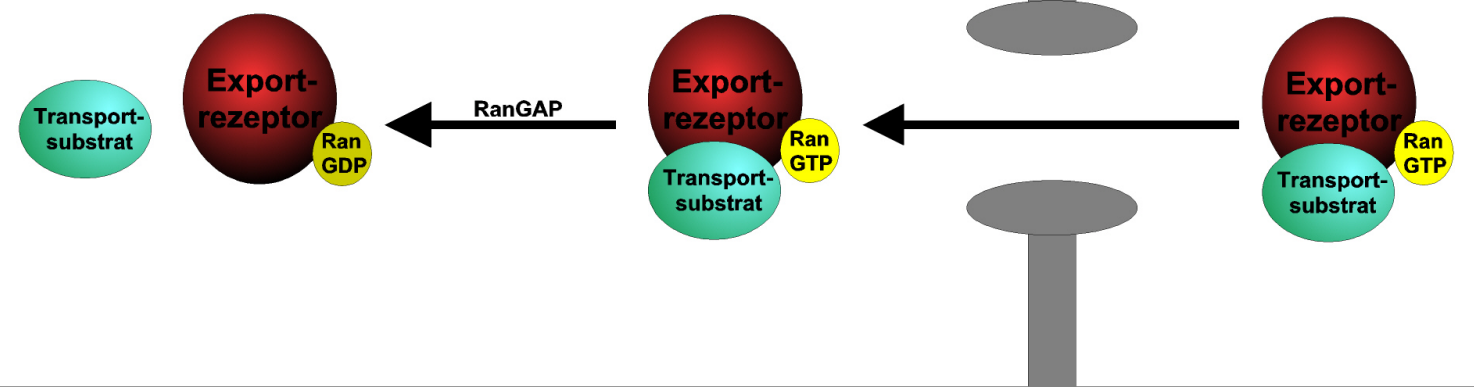

Abbildung 1 : Grundprinzip des nukleocytoplasmatischen Transports.

Im oberen Kasten ist ein Modell des nukleocytoplasmatischen Imports dargestellt. Der Importrezeptor bindet das Substrat. Für die Passage der Kernpore wird Ran-GDP benötigt. Auf der nukleoplasmatischen Seite der Kernpore dissoziiert der Transportkomplex durch Austausch von Ran-GDP gegen Ran-GTP. Der untere Kasten zeigt ein Exportmodell. Die Ausbildung des Exportkomplexes benötigt Ran-GTP. Im Cytoplasma dissoziiert der Exportkomplex durch RanGAP Aktivierung der Hydrolyse von Ran-GTP zu Ran-GDP. 
Ein weiterer Mechanismus des richtungsgebundenen Transports durch die Kernpore basiert vermutlich auf den verschiedenen Bestandteilen der Kernpore. Sowohl die repeathaltigen Nukleoporine der cytoplasmatischen Seite der Kernpore, Nup358 (RanBP2) und Nup214, als auch die Nukleoporine Nup153 und Nup98 der nukleoplasmatischen Seite, die Teil des Kernkorbes sind, binden an Karyopherin $\beta$ (Moroianu et al., 1995). In dem zentralen Teil der Kernpore sind Nup58, Nup54 und Nup45 lokalisiert und bilden den Nup62 Komplex aus. Für den Weg durch die Kernpore wurde eine ansteigende Affinität zu den Nukleoporinen Nup358, dem Nup62 Komplex und Nup153 festgestellt (Ben-Efraim und Gerace, 2001). Dieser zweite Mechanismus könnte eine hohe Bedeutung bei dem in letzter Zeit beschriebenen Ran unabhängigen Import haben. Ran unabhängiger Import kann in in vitro Importversuchen mit permeabilisierten HeLa Zellen mit der RanQ69L Mutante nachgewiesen werden, die nicht mehr in der Lage ist, GTP zu hydrolysieren. Der Inhibitor von kappa B alpha $(\mathrm{I} \kappa \mathrm{B} \alpha)$ kann unabhängig von cytosolischen Faktoren und unabhängig von Ran importiert werden (Sachdev et al., 2000). Ein weiteres Beispiel stellt hier das ribosomale Protein L5 dar, von dem das C-terminale dritte NLS von cytosolischen Faktoren und Ran unabhängigen Import vermitteln kann. Der Import benötigt jedoch Zugriff auf die Kernpore. Bei dem Ran unabhängigen Import könnte eine Komponente der Kernpore den Transport vermitteln (Rudt und Pieler, 2001) und müsste somit auch die Richtung des Transportschritts bestimmen.

Dieser Mechanismus von Assoziations- und Dissoziationsschritten innerhalb der Kernpore mündet in ein Modell, das die generelle Durchquerung des zentralen wässrigen Kanals der Kernpore behandelt. Die Spezifität der Translokation wird durch Interaktionen niedriger Affinität zwischen den Transportrezeptoren und Komponenten des Kernporenkomplexes gewährleistet. Die Bewegung beruht im vorgeschlagenen Modell auf freier Diffusion (Rout et $a l ., 2000)$. Ein zweites Modell geht von einem maschenartigen Netzwerk Phenylalanin reicher Nukleoporine aus, die eine Passage hydrophiler Objekte verhindern, aber die Passage von Transportsubstraten erlauben, deren hydrophile Oberfläche durch Bindung von Transportrezeptoren verdeckt ist und die somit hydrophobe Partikel darstellen (Ribbeck und Görlich, 2001). Beide Modelle erlauben hohe Transportraten und ermöglichen einen energieunabhängigen Transport. 


\subsection{Signalsequenzen vermitteln den nukleocytoplasmatischen Transport}

Der Transport von Proteinen in den Zellkern, auch Import genannt, wird Proteinen ermöglicht, welche eine Kerntransportsignalsequenz (NLS) besitzen. Klassische Signalsequenzen wie SV40-artige (simian virus 40 large T-Antigen) (PKKKRKV, (Kalderon et al., 1984)) oder zweigeteilte Kerntransportsignalsequenzen wie beim Nucleoplasmin (KRPAATKKAGQAKKK, (Robbins et al., 1991)) werden von Karyopherin $\alpha$ auf der cytoplasmatischen Seite der Kernhülle gebunden. Nach Bindung an Karyopherin $\beta$ wird der trimere Komplex unter Energieverbrauch auf die nukleoplasmatische Seite der Kernhülle transportiert, wo er durch Bindung von Ran-GTP zerfällt. Inzwischen sind weitere Signalsequenzen bekannt. RNA bindende Proteine werden über die 38 Aminosäuren umfassende M9-Sequenz innerhalb des hnRNP A1-Proteins (Pollard et al., 1996), sowie über ein aus 40 Aminosäuren bestehendes Signal in hnRNP K, das KNS (hnRNP K nuclear shuttling domain, (Michael et al., 1997)) in den Zellkern gelenkt. Bei dem U snRNP konnte gezeigt werden, dass das Sm-core-Protein und die Trimethylguanosinkappe als komplexes Kernlokalisierungssignal fungieren (Bordonne, 2000; Mattaj und De Robertis, 1985). Mit hoher Wahrscheinlichkeit existieren weitere, bisher unbekannte Kernlokalisierungssequenzen wie beim Transkriptionsfaktor TFIIIA, der die Kernlokalisierungssequenz innerhalb der Zinkfinger trägt (Rudt und Pieler, 1996 und diese Arbeit). Die HIV-1 Rev Aktivierungsdomäne stellt ein Exportsignal dar, welches vorwiegend aus Leucinen besteht und auch in der C-terminalen Sequenz von TFIIIA zu finden ist (Fischer et al., 1995).

\subsection{Transportrezeptoren der Karyopherin $\beta$ Familie}

Die Superfamilie der Karyopherin $\beta$ verwandten Proteine umfasst inzwischen 14 putative Transportfaktoren in Hefe, 9 mit Importfunktion und 4 mit Exportfunktion. Vom Mensch sind bisher 22 potentielle Familienmitglieder identifiziert worden. Das relative Molekulargewicht der Familienmitglieder reicht von 90 bis 130 kd, der isoelektrische Punkt ist in der gesamten Familie sauer, aber die Aminosäureidentität liegt bei weniger als $20 \%$ (Übersicht in Ström und Weis, 2001). Für 7 Transportfaktoren konnte eine Importfunktion nachgewiesen werden, und 4 der Transportfaktoren sind nachweislich Exportrezeptoren. Für drei der Exportrezeptoren konnten einzelne spezifische Exportsubstrate identifiziert werden. CAS vermittelt den Export von Karyopherin $\alpha$. Exportin-4 vermittelt den Export des eukaryotischen Translationsinitiationsfaktors 5A (eIF-5A). Die Exportin-4, eIF-5A 
Interaktion benötigt hypusinierte Sequenzmotive und große Teile des eIF-5A Moleküls (Lipowsky et al., 2000). Exportin-t ist Ran-GTP abhängig und transportiert t-RNA. Die Freisetzung des Exportsubstrates benötigt RanBP1 und RanGAP1, welche auf der cytoplasmatischen Seite der Kernpore lokalisiert sind (Kutay et al., 1998). Für Exportin-1 wurde eine Vielzahl von Exportsubstraten nachgewiesen. So vermittelt Exportin-1 den Export von Proteinen mit leucinreichen Exportsignalen und verschiedenen Adapterproteinen.

Eine Importfunktion konnte für 7 der bisher beschriebenen Ran bindenden Proteine nachgewiesen werden. Importin-11 ist ein Ran abhängiger Importrezeptor des ubiquitinkonjugierten Enzyms UbcM2 (Plafker und Macara, 2000). Transportin-SR bindet Arginin-Serin reiche Importsubstrate (Kataoka et al., 1999). Importin $\beta 13$ bindet spezifisch an den Translationsinitiationsfaktor eIF1a und weitere putative Importsubstrate wie hUBC9, ein dem Ubiquitin konjugierten E2 Enzym verwandtes Protein, oder MGN, das menschliche Homolog von Mago nashi, welches eine wichtige Rolle in der frühen Drosophila Embryogenese spielt. Die Ran-GTP Hydrolyse hat aber nicht automatisch die Freisetzung des Exportsubstrates eIF1a zur Folge. Die Freisetzung scheint die Bindung eines Importsubstrats $\mathrm{zu}$ benötigen (Mingot et al., 2001). Eine Ausnahme im Mechanismus des nukleocytoplasmatischen Transports stellen die Proteine RanBP8, für das noch kein Substrat identifiziert wurde, und RanBP7 (Importin $\beta 7$ ) dar. Beide können an Karyopherin $\beta$ binden (Görlich et al., 1997). RanBP7 kann ribosomale Proteine alleine importieren, aber es ist im Komplex mit Karyopherin $\beta$ auch in der Lage den Import von Histon H1 zu vermitteln (Jäkel et al., 1999).

Einzelne Transportsubstrate können wahrscheinlich auch von verschiedenen Importrezeptoren transportiert werden. Verschiedene Importrezeptoren können in vitro den Import der ribosomalen Proteine L23a, S7 und L5 vermitteln. L23 bindet direkt an RanBP5 (humanes Karyopherin B3) (Jäkel und Görlich, 1998; Yaseen und Blobel, 1997). Zwei Hefe Homologe von Karyopherin 33 , Kap121p und Kap123p sind beschrieben worden. Kap121 kann die Funktion von Kap123 ersetzen und ist vermutlich in den Transport ribosomaler Proteine involviert (Rout et al., 1997; Seedorf et al., 1999). L5 kann, vermutlich über das C-terminale NLS1, spezifisch an Karyopherin $\beta$, Transportin und RanBP7 binden (Claußen et al., 1999).

Die Ran Abhängigkeit des L5-NLS1 Imports konnte auch in vitro nachgewiesen werden (Rudt und Pieler, 2001). 


\subsection{Transportadapter, eine Brücke zwischen Substrat und Rezeptor}

Karyopherin $\beta$ verwandte Proteine interagieren direkt mit dem Kernporenkomplex. Der Import oder Export eines Transportsubstrats kann entweder direkt gebunden an Karyopherin $\beta$ verwandte Proteine erfolgen, oder er wird von einem Adapterprotein vermittelt, welches einerseits an das Transportsubstrat bindet und andererseits an einen Transportrezeptor, der dann den Kontakt zur Kernpore herstellt. Diese Adapterfunktion ist wie in letzter Zeit beschrieben nicht nur auf den Import beschränkt, der durch Karyopherin $\alpha$ verwandte Proteine vermittelt wird, die sich durch gemeinsame strukturelle Merkmale wie die Importin $\beta$ bindende Domäne und mehrere aufeinanderfolgende $\alpha$-helikale Proteindomänen auszeichnen, sondern kann auch von anderen Proteinen wahrgenommen werden.

Der Import von dem ssDNA bindenden Replikationsprotein A (RPA) wird von XRIP $\alpha$, aber nicht von Karyopherin $\alpha$ in Xenopus Eiextrakten vermittelt. XRIP $\alpha$ interagiert direkt mit Karyopherin $\beta$. Eine Depletion von XRIP $\alpha$ blockiert den Import von RPA (Jullien et al., 1999). Indem es die Komplexbildung eines NLS haltigen Substrats mit Karyopherin $\beta$ ermöglicht, dient es somit wie die Karyopherin $\alpha$ Proteine als Adapterprotein für den nukleocytoplasmatischen Transport. Auch der Transport von U snRNPs wird von einem Adapterprotein vermittelt. Snurportin 1 bildet mit Karyopherin $\beta$ und dem Cargo, einem U snRNP, einen heterotrimeren Importkomplex. Snurportin 1 bindet m3G-Cap Strukturen aber nicht m7G-Cap Strukturen (Huber et al., 1998). Der Export von m7G-Cap U snRNAs wird von dem Adapterprotein PHAX vermittelt, welches die Komplexbildung mit CRM1 (Exportin-1), Ran-GTP und dem „,nuclear cap-binding complex “ (CBC) ermöglicht (Ohno et al., 2000).

Die Regulation der nukleocytoplasmatischen Lokalisation ist ein wichtiger Mechanismus bei der Kontrolle der Funktion von dem Tumorsupressor p53. Karyopherin $\alpha 1$ vermittelt den Import von p53, welches dann eine Transaktivierung der p53-Antwort-Apoptose-Faktoren auslöst. Eine Fehlverteilung von p53 konnte in verschiedenen Karzinomen wie Neuroblastomen, Colonkarzinomen und Lungenkarzinomen nachgewiesen werden. In den Lungenkrebszellen ZR-75-1 wurde eine Deletionsmutante von Karyopherin $\alpha 1$ nachgewiesen (Kim et al., 2000). 


\subsection{Karyopherin $\alpha$ im nukleocytoplasmatischen Transport}

Ist der trimere Komplex aus NLS haltigem Substrat, Karyopherin $\alpha$ und $\beta$ über den Kernporenkanal in das Nukleoplasma gelangt, führt eine Ran-GTP Bindung an die $\beta$ Komponente zur Dissoziation. Als Exportfaktor von Karyopherin $\alpha$ wurde CAS identifiziert (Kutay et al., 1997). In Hefe wird das freigesetzte Karyopherin $\alpha$ über die Bindung an das dem CAS homologe Cse1p in das Cytoplasma exportiert. Eine besondere Rolle besitzen hier die beiden FXFG haltigen Nukleoporine Nup2p, welches als einziges Nukleoporin aus Hefe eine RCC1 artige Ran-Bindungsdomäne besitzt, und möglicherweise das verwandte Nup1p. Nup2p wird für die Lokalisation von Cse1p an der inneren Kernhülle benötigt. Eine direkte biochemische Interaktion ist jedoch mit Cse1p bisher nicht nachgewiesen worden, wohl aber mit dem Karyopherin $\alpha$ homologen Srp1p (Kap60p) (Hood et al., 2000). Nup2p kommt eine bidirektionale Funktion im nukleocytoplasmatischen Transport zu (Solsbacher et al., 2000). Nup60p bindet an Nup2p, das Ran homologe Gsp1p-GTP, den RCC1 homologen Guaninnukleotid Austauschfaktor Prp20p und dient als Anlagerungsstelle für Kap95p, Kap60p Heterodimere und Kap123p. Nup60p reduziert die Aktivität von Prp20p und verankert Nup2p an der Kernpore. Gsp1p-GTP steigert die Affinität von Nup2p an Nup60p und ermöglicht die Bindung von dem Nup2p, Kap60p Komplex an Nup60p (Denning et al., 2001). Auch eine spezifische Modifizierung, die Einfluss auf die Importeffizienz haben kann, ist inzwischen von Karyopherin $\alpha$ Varianten nachgewiesen worden. Humanes Karyopherin $\alpha 1$ (Rch 1), Ran BP7 und humanes Karyopherin $\alpha 7$ sind Substrate für die Acetylase CBP (CREB-binding Protein), nicht aber humanes Karyopherin $\alpha 3$. Die Acetylierung des Lys22 (Motiv: G/S K) von Karyopherin $\alpha 1$ kann von CBP oder der nahe verwandten Acetylase p300 erfolgen und fördert die Bindung an den Transportrezeptor Karyopherin $\beta$ (Bannister et al., 2000).

\subsection{Differentielle Expression und Bindungsaffinität von Karyopherin $\alpha$}

In der Maus werden Karyopherin $\alpha 4$ (Q1), $\alpha 3$ (Q2) und $\alpha 5$ (S1) in unterschiedlichen Mengen ubiquitär exprimiert. Die Expression von Karyopherin $\alpha 1$ (P1) und $\alpha 6$ (S2) ist jedoch auf verschiedene Gewebe beschränkt. Karyopherin $\alpha 1$ konnte in Testis, Milz, Leber, Herz, Lunge, schwach in Niere, äußerst schwach in Gehirn und nicht in Skelettmuskel oder Kleinhirn nachgewiesen werden. Karyopherin $\alpha 6$ wurde mit einem 1,8 bp Produkt nur in Testis und mit einem 5,5 bp Produkt in allen untersuchten Geweben, sehr schwach aber in Thymus und 
Skelettmuskel nachgewiesen (Tsuji et al., 1997). Die differentielle Expression der humanen Karyopherin $\alpha$ Varianten $\alpha 3, \alpha 4$ und $\alpha 6$ ist ebenso beschrieben (Köhler et al., 1997), wie unterschiedliche Funktionen der Hefe Homologen Srp1p und Sts1p, die einander funktionell nicht ersetzen können (Tabb et al., 2000). Karyopherin a Varianten zeigen wie die Karyopherin $\beta$ verwandten Transportrezeptoren ein redundantes Bindungsverhalten an Transportsubstrate. Sie können Substrate aber auch spezifisch binden. So zeigen verschieden lange NLS von Helikase Q, in Abhängigkeit von den unterschiedlichen Karyopherin $\alpha$ Varianten unterschiedliches Importverhalten (Miyamoto et al., 1997) oder aber sogar unterschiedliche Bindungsaffinitäten. Humanes Karyopherin $\alpha 3$ (Qip1) und $\alpha 1$ (Rch1) können mit der DNA Helikase Q1 interagieren, nicht aber $\alpha 5$ (hSrp1/NPI1) (Seki et al., 1997).

RanBP3 besitzt ein NLS, welches präferentiell von Karyopherin $\alpha 3$ in Digitonin permeabilisierten HeLa-Zellen in in vitro Import Kompetitionsstudien importiert wird, aber in GST-Bindungsstudien auch von Karyopherin $\alpha 4$ und mit sehr niedriger Effizienz von $\alpha 5$, nicht aber von $\alpha 1$ oder $\alpha 7$, gebunden werden kann. Ein als Kontrolle verwendetes SV40-nls zeigt keine präferentielle Affinität zu einzelnen Karyopherin $\alpha$ Varianten (Welch et al., 1999). Die Abweichungen in den NLS Motiven können sehr gering sein, um unterschiedliches Bindungsverhalten von Proteinen an Karyopherin $\alpha$ Varianten zu zeigen. Das NLS des Lymphoid-Enhancer Faktors-1 (KKKKRKREK) bindet an Karyopherin $\alpha 5$ und $\alpha 1$, das sehr ähnliche Motiv (KKKRRSREK) von dem T-Zell-Faktor-1 jedoch nicht (Prieve et al., 1998).

\subsection{S RNA Transport}

Einen besonderen Fall im nukleocytoplasmatischen Transport stellt die ribosomale 5S RNA, eine Komponente der großen ribosomalen Untereinheit, in Oocyten dar. Während der Oogenese werden die ca. 20000 Kopien von Oocyten spezifischen 5S RNA Genen transkribiert. In somatischen Zellen sind nur die 800 Kopien somatischer 5S RNA Gene aktiv. Von der 5S RNA in Oocyten unterscheidet sich somatische 5S RNA durch 5 Nukleotidsubstitutionen. Im Gegensatz zu den anderen rRNAs (18S, 28S und 5,8S), die von der RNA-Polymerase I transkribiert werden, wird 5S RNA von der RNA-Polymerase III in den Oocyten vor den anderen ribosomalen Komponenten außerhalb der Nukleoli transkribiert. Es können 4 Proteine an 5S RNA binden, p43, das La Protein, das ribosomale Protein L5 und der Transkriptionsfaktor IIIA. Das La Protein interagiert transient mit allen RNA-Polymerase III Produkten und hat eine Rolle bei der Transkriptionsterminierung. TFIIIA bindet an die 5S RNA und sequenzspezifisch an die interne Kontrollregion des 5S RNA Gens, wo TFIIIA für 
die Transkriptionsinitiation benötigt wird. Die 5S RNA wird dann gebunden an L5 (5S RNP) oder an TFIIIA (7S RNP) exportiert. Oocyten spezifische 5S RNA hat eine höhere Affinität zu TFIIIA als zu L5, somatische 5S RNA bindet hingegen präferentiell an L5. Im Cytoplasma liegt die 5S RNA als 7S RNP oder als 42S RNP Vorratspartikel vor. Das 42S RNP ist ein Komplex aus 5S RNA, tRNA und mehreren Proteinen. Das 7S RNP ist ein Partikel im 1:1 Verhältnis aus TFIIIA und 5S RNA. Mit dem Beginn der Vitellogenese beginnt die Ribosomenbiogenese, die L5 Konzentration steigt, und die 5S RNA wird gebunden an L5 in den Zellkern zu den Nukleoli transportiert. Ab diesem Zeitpunkt nimmt die Konzentration der Vorratspartikel ab. Als Teil der großen 60S ribosomalen Untereinheit passiert die 5S RNA dann ein drittes Mal die Kernmembran (Übersicht in Nakielny et al., 1997; Pieler und Rudt, 1997).

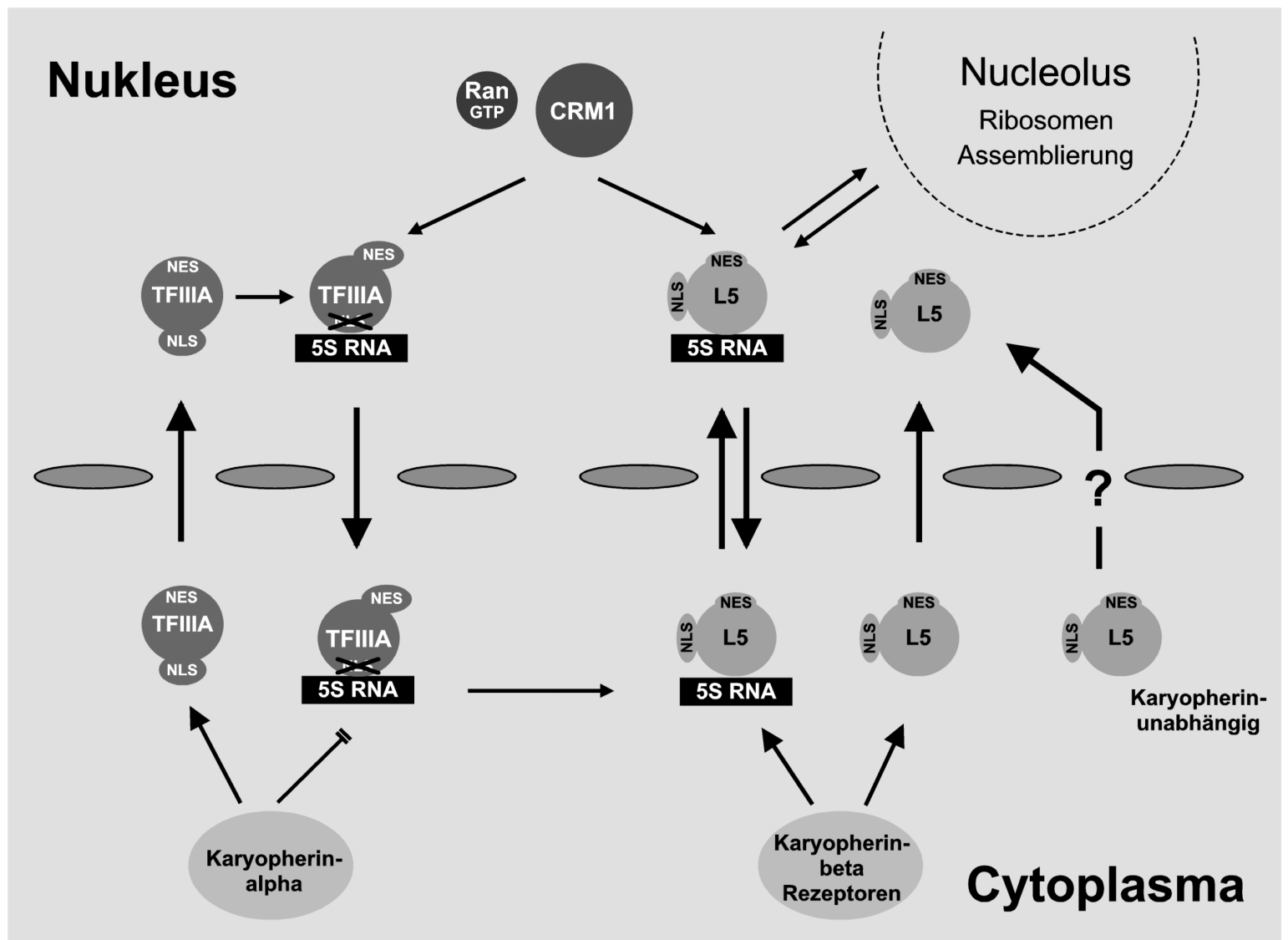

Abbildung 2 : Modell zum nukleocytoplasmatischen Transport von 5S RNA. Aktuelles Modell zum nukleocytoplasmatischen Transport von 5S RNA in Xenopus laevis Oocyten. TFIIIA bildet mit 5S RNA das 7S RNP. Das 7S RNP kann aufgrund einer Maskierung des NLS nicht importiert werden. Der Export von dem 7S RNP und 5S RNP wird von CRM1 vermittelt (K. Murdoch, Publikation in Vorbereitung). 
Die mRNA von TFIIIA liegt während der Entwicklungsstadien I, II und III in den Oocyten von Xenopus laevis in der höchsten Konzentration vor. Die Konzentration sinkt während der Stadien III und IV um das fünffache und bleibt während der Stadien IV-VI konstant. Erst während der späten Blastula und frühen Neurula sinkt die Konzentration dramatisch auf kaum detektierbare Mengen ab (Ginsberg et al., 1984). Im Gegensatz zur mRNA in den Oocyten ist die TFIIIA mRNA in diesen späteren Entwicklungsstadien heterogen und größer. Die Konzentration des TFIIIA-Proteins sinkt von ca. $1 \times 10^{12}$ Molekülen pro Oocyte in den Stadien I-IV über $3 \times 10^{11}$ Moleküle pro Oocyte im Stadium V auf $5 \times 10^{10}$ Moleküle pro Oocyte im Stadium VI. Im Verlauf der Oogenese wird die Anzahl an TFIIIA-Molekülen um das 20fache reduziert. Das somatische TFIIIA (TFIIIA') mit $42 \mathrm{kd}$ tritt erst ab der Neurula mit 7000 Molekülen/Zelle auf (Shastry et al., 1984). Oocyten typische 5S RNA interagiert primär mit TFIIIA, somatische 5S RNA hingegen interagiert vorzugsweise mit L5. Eine Reduktion der TFIIIA Konzentration sollte 5S RNA freisetzen, die dann von L5 gebunden, und im 5S RNP in den Zellkern transportiert werden kann. Dieses Modell beinhaltet auch, dass in somatischen Zellen 5S RNA aufgrund der höheren Affinität zu L5 direkt von L5 gebunden werden kann und so eine Passage der Kernpore überflüssig wird (Übersicht in Pieler und Rudt, 1997).

\subsection{Ziel der Arbeit}

In Fortführung der von mir angefertigten Diplomarbeit sollte die Minimalstruktur der N- und C-terminalen Kernlokalisierungsignalsequenzen von TFIIIA weiter eingegrenzt werden. Ausgehend von einer Expressionsmusteranalyse von Transportfaktoren, Transportfaktor assoziierten Proteinen und ribosomalen Proteinen wurde ein neuer Ansatz entwickelt, neue in den nukleocytoplasmatischen Transport involvierte Proteine zu identifizieren. Im Rahmen der Arbeiten zur Identifizierung neuer Transportfaktoren wurden mehrere Transportadapter isoliert. Die Möglichkeit ihrer Funktion im nukleocytoplasmatischen Transport von TFIIIA wurde geprüft. 


\section{Material und Methoden}

\subsection{Material}

\subsubsection{Versuchstiere}

Der Afrikanische Krallenfrosch (Xenopus laevis) gehört zu der Familie der zungenlosen Froschlurche (Pipidae) der Ordnung Anura. Pigmentierte und Albino-Frösche wurden von Dipl.-Ing. Horst Kähler (Hamburg) und den Firmen Xenopus I (Ann Arbor, USA) und Nasco (Ft. Atkinson, Wisconsin USA) erworben. Die Frösche wurden gemäß der deutschen Tierschutzbestimmungen behandelt und gehalten. Die Bestimmung der Embryonalstadien erfolgte nach Nieuwkoop und Faber (1967).

\subsubsection{Bakterienstämme}

Die verwendeten E. coli-Stämme (Stratagene $\mathrm{GmbH}$, Heidelberg) besaßen folgende Genotypen:

GM2163 F' ara14, leuB6, fhuA31, lacY1, tsx 78, glnV44, galK2, galT22, mcrA, dcm-6, hisG4, rfbD1, rpsL136, dam13::Tn9, xylA5, mtl-1, thi-1mcrB1, hsdR2 NM522 $\mathrm{F}^{\prime} \operatorname{proA}^{+} \mathrm{B}^{+} \operatorname{lac}^{\mathrm{q}} \Delta(\mathrm{lacZ}) \mathrm{M} 15 / \Delta$ (lac-proAB) glnV thi-1 $\Delta($ hsdS-mcrB $) 5$ TG1 $\Delta$ (lac-proAB), supE44, gthi, hsdD5 $\left\{\mathrm{F}^{\prime}\right.$ traD36 proAB+lacIq lacZ $\left.\Delta \mathrm{M} 15\right\}$ Variante des K12-Stamms

XL1-Blue recA1, endA1, gyrA96, thi-1, hsdR17, supE44, relA1, lac $\left\{\mathrm{F}^{\prime} \operatorname{proAB}, \operatorname{lacI}^{\mathrm{q}} \mathrm{Z} \Delta \mathrm{M} 15\right.$, $\operatorname{Tn} 10\left(\right.$ Tet $\left.\left.^{\mathrm{r}}\right)\right\}^{\mathrm{c}}$

XL1-Blue MRF' D(mcrA)183, $\Delta$ (mcrCB-hsdSMR-mrr)173, endA1, supE44, thi-1, recA1, gyrA96, relA1 lac $\left\{\mathrm{F}^{\prime} \text { proAB, } \operatorname{lacI}^{\mathrm{q}} \mathrm{Z} \Delta \mathrm{M} 15, \operatorname{Tn} 10\left(\mathrm{Tet}^{\mathrm{r}}\right)\right\}^{\mathrm{c}}$

XLOLR D(mcrA)183, $\Delta$ (mcrCB-hsdSMR-mrr)173, endA1, thi-1, recA1, gyrA96, relA1 lac \{ $\mathrm{F}^{\prime}$ proAB, $\left.\operatorname{lacl}^{\mathrm{q}} \mathrm{Z} \Delta \mathrm{M} 15, \operatorname{Tn} 10\left(\mathrm{Tet}^{\mathrm{r}}\right)\right\}^{\mathrm{c}}, \mathrm{Su}^{-}, \lambda^{\mathrm{r}}$

BL21 (DE3) plys $\mathbf{S}^{\mathbf{b}} \mathrm{BF}^{-}$, dcm, omp T, hsdS (rb- mb-), gal $\lambda$ (DE3) \{plys S Cam $\left.{ }^{\mathrm{r}}\right\}$

\subsubsection{Zellinien}

Die verwendeten HeLa-Zellen (humane Portiokarzinom-Zellen, Zugriffsnummer: ACC57) wurden in MEM-Medium kultiviert und stammen vom DSMZ aus Braunschweig. 


\subsubsection{Genbanken}

Für die Isolierung der cDNA-Sequenzen von Xenopus Karyopherin $\beta 3$ und der partiellen RanTC4 cDNA-Sequenz wurde eine $\lambda$-Zap Express cDNA-Bank (Stratagene GmbH, Heidelberg) benutzt, welche von T. Hollemann (1998) erstellt wurde und cDNA aus präparierten Köpfen von Xenopus Embryonen (Stadium 28-31) enthielt.

Zur Isolierung von anderen cDNA-Sequenzen wurde aus ca. 4000 präparierten Augen (200 $\mu 1)$ von Xenopus Embryonen (Stadium 30-32) eine $\lambda$-Zap Express cDNA-Bank (Stratagene $\mathrm{GmbH}$, Heidelberg) erstellt. Die Erststrang-Synthese der cDNA erfolgte mit Hilfe von zufällig zusammengesetzten ("random") hexameren Oligonukleotiden.

\subsubsection{Plasmide aus anderen Laboratorien}

Folgende cDNAs wurden von anderen Laboratorien zur Verfügung gestellt: RanBP1 und RanGAP1 von Mary Dasso, XSUMO-1 von Duncan Sparrow, Importin $\alpha 1$ und $\alpha 2$ (Karyopherin $\alpha$ ) von Dirk Görlich und Transportin von Gideon Dreyfuss. Das durch eine zusätzliche Klonierungsstelle modifizierte pSVBeta Plasmid ist von Klaus Schwamborn.

\subsubsection{Vektoren}

PBK-CMV Stratagene GmbH, Heidelberg

pCS2+ Turner und Weintraub, 1994

pCS2+MT Turner und Weintraub, 1994

pGemT Promega Deutschland GmbH, Mannheim

pGex 5x1 Amersham Pharmacia Biotech, Uppsala, Schweden

pGex5x3 Amersham Pharmacia Biotech, Uppsala, Schweden

pSVBeta (modifiziert) Schwamborn et al., 1998 


\subsubsection{Oligonukleotide}

Oligonukleotide wurden von den Firmen NAPS (Göttingen), Eurogentech (Searing, Belgien), MWG-Biotech (Ebersberg) bezogen oder waren Bestandteil der verwendeten Kits. Die Sequenz ist in 5' 3' Orientierung angegeben. Eingefügte Schnittstellen sind unterstrichen dargestellt.

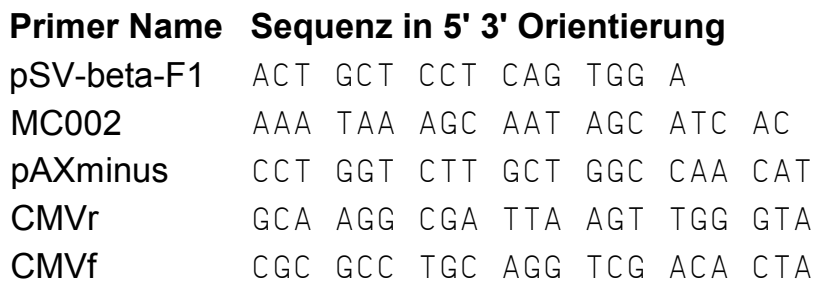

Tabelle 1 : Standard Sequenzierprimer.

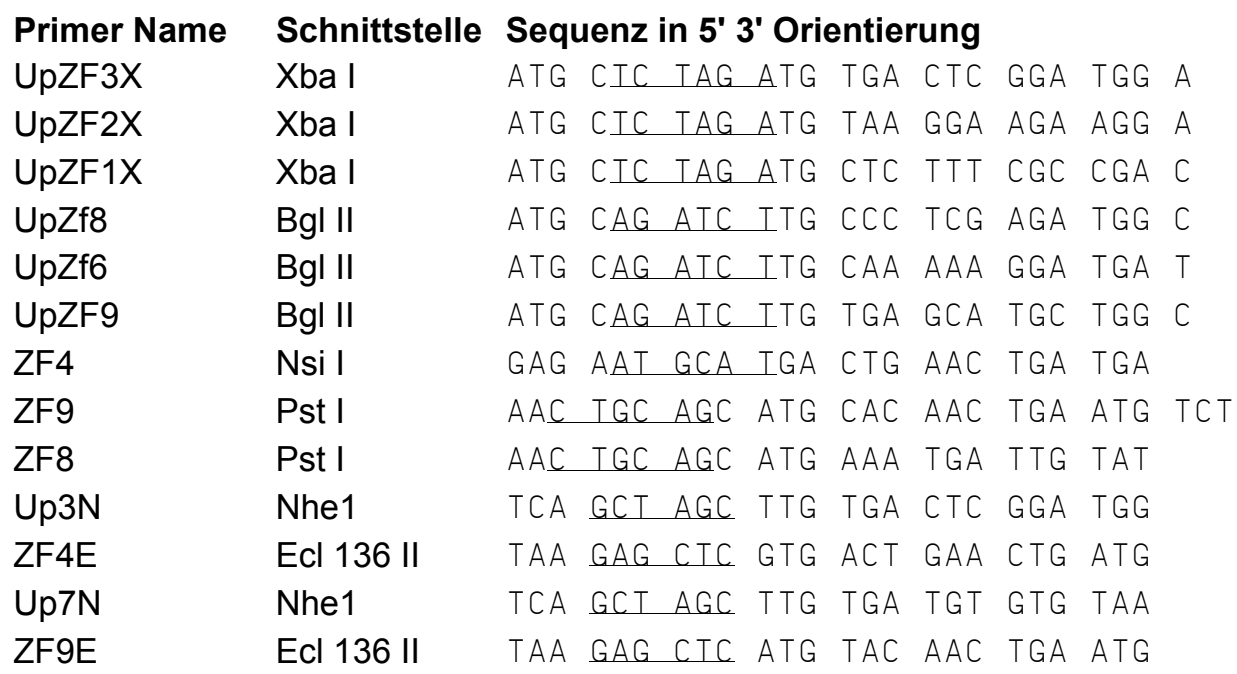

Tabelle 2: TFIIIA spezifische Primer mit eingefügten Schnittstellen.

Die in Spalte zwei angegebenen Schnittstellen sind in der Oligonukleotidsequenz unterstrichen.

Primer Name
B3DF2
B3Seq-f1
B3Seq-r1
B3Seq-r2
B3Uf1
B3Ur1
B3Ur3
B3UTRr1

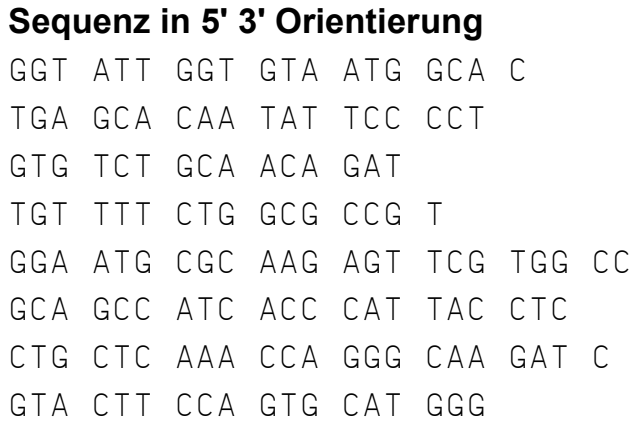

Tabelle 3 : Karyopherin $\beta 3$ spezifische Sequenzierprimer. 


\begin{tabular}{|c|c|c|c|c|c|c|c|c|c|c|}
\hline cDNA & Primer Name & Schnittstelle & Sequenz in $5^{\prime}$ & 3' Orientie & rung & & & & & \\
\hline \multirow[t]{2}{*}{ Karyopherin $\beta 3$} & UpIB3E & Eco R I & ATC GAA TTC & AGC AAT & GGC & GGC & $\mathrm{CGA}$ & & & \\
\hline & IB3X & Xho I & GTG ACT CGA & GTC ACG & CAG & TGC & TGA & G & & \\
\hline \multirow[t]{2}{*}{ p10 } & Upp10E & Eco R I & GCG GAA TTC & AGA TAT & GGC & $A G A$ & AAA & GCC & A & \\
\hline & $\mathrm{P} 10 \mathrm{X}$ & Xho I & GAG CCT CGA & GTC AGC & CAA & $A G T$ & TAT & G & & \\
\hline \multirow[t]{2}{*}{ Ran BP7 } & UpRBP7B & Bst 1107 & CCG TAT ACG & ATA TGG & $\mathrm{ACC}$ & CGG & $\mathrm{CCC}$ & $\mathrm{TG}$ & & \\
\hline & RBP7X & Xho I & TAT CTC GAG & TTA ATT & $\mathrm{CAT}$ & $\mathrm{TCC}$ & TGG & GGC & & \\
\hline \multirow[t]{2}{*}{ SUMO-1 } & UpSUMO1S & Stu I & AGA AGG CCT & GGC ATG & TCT & GAT & CAG & GA & & \\
\hline & SUM01X & Xho I & GAA TCT CGA & GTT AAA & $\mathrm{ATG}$ & TCG & AGT & GGC & $\mathrm{C}$ & \\
\hline \multirow[t]{2}{*}{ RanBP1 } & XIRanBP1E & Eco R I & ATG AAT TCC & GCG ATG & GCC & GAT & ACC & AAG & GAT & \\
\hline & RanBP1X & Xho I & AAT CTC GAG & TTA TTG & $\mathrm{CTT}$ & $\mathrm{TTC}$ & СTC & TGC & $\mathrm{TTT}$ & \\
\hline \multirow[t]{2}{*}{ RanGAP1 } & UpRanGap1E & Eco R I & AAG AAT TCC & GGA ATG & $\mathrm{GCT}$ & $\mathrm{GCT}$ & GAA & GAT & ATC & \\
\hline & RanGap1X & Xho I & CAA CTC GAG & TTA CAG & $\mathrm{ATT}$ & ATG & AAG & $\mathrm{GTT}$ & G & \\
\hline \multirow[t]{2}{*}{ Transportin } & UPTranspE & Eco R I & AAG AAT TCC & GCG ATG & $\mathrm{CCG}$ & GAT & GAA & CAG & GGC & $\mathrm{CTC}$ \\
\hline & TranspX & Xho I & СTT CTC GAG & TTA AAC & TCC & ATA & GTA & GGC & & \\
\hline \multirow[t]{2}{*}{ RanTC4 } & UpRanTC4E & Eco R I & AAG AAT TCC & GTT ATG & GCA & $\mathrm{CCC}$ & AAG & GGA & GGA & \\
\hline & Ran TC41X & Xho I & ATT CTC GAG & TTA GCA & AGC & CAA & AGG & AAG & GGC & \\
\hline \multirow[t]{2}{*}{$\begin{array}{l}\text { Karyopherin } \alpha 1 \\
\text { und } \alpha 2\end{array}$} & UpAlpa1af1E & Ecl 136 II & $\mathrm{AAG}$ GAG CTC & GAA ATG & $\mathrm{CCG}$ & $\mathrm{ACC}$ & $\mathrm{ACA}$ & $\mathrm{AAT}$ & G & \\
\hline & Alpa1ar1X & Xho I & TTC TCG AGT & CAG AAA & TTG & AAA & GAC & $\mathrm{TC}$ & & \\
\hline \multirow[t]{2}{*}{ Karyopherin a3 } & Kalpha3E & Eco R I & $\begin{array}{lll}\text { GGA } & \text { ATT } & \text { CAA } \\
\text { GTC } & \text { TCA } & \text { CTA }\end{array}$ & $\begin{array}{ll}\text { TGT } & \text { CCA } \\
\text { GGT } & \text { TCA }\end{array}$ & $\begin{array}{l}\mathrm{ACA} \\
\mathrm{AG}\end{array}$ & ATG & AGA & ATG & GTG & $\mathrm{CCC}$ \\
\hline & Kalpha3X & Xho I & CGT CTC GAG & TTA GAA & GTT & AAA & TGT & AGT & & \\
\hline \multirow[t]{2}{*}{ Karyopherin a4 } & Kalpha4E & Eco R I & GGA ATT CAA & TGG CGG & $\mathrm{ACA}$ & ACG & CCG & GC & & \\
\hline & Kalpha4X & Xho I & CGT CTC GAG & TTA GAA & GTT & AAA & TTC & СТT & $\mathrm{TG}$ & \\
\hline \multirow[t]{2}{*}{ Karyopherin a5 } & Kalpha5E & Eco R I & GGA ATT CAA & TGG ACA & $\mathrm{CCA}$ & TGG & CAA & GC & & \\
\hline & Kalpha5X & Xho I & CGT CTC GAG & TTA GAG & CTG & AAA & $\mathrm{TCC}$ & TTC & & \\
\hline
\end{tabular}

Tabelle 4: Primer für Transportfaktoren und transportassoziierte Proteine mit eingefügten Schnittstellen. In Spalte eins ist die mit den Primern amplifizierbare cDNA angegeben. Die in Spalte drei angegebenen Schnittstellen für Klonierungen sind in der Oligonukleotidsequenz unterstrichen. 


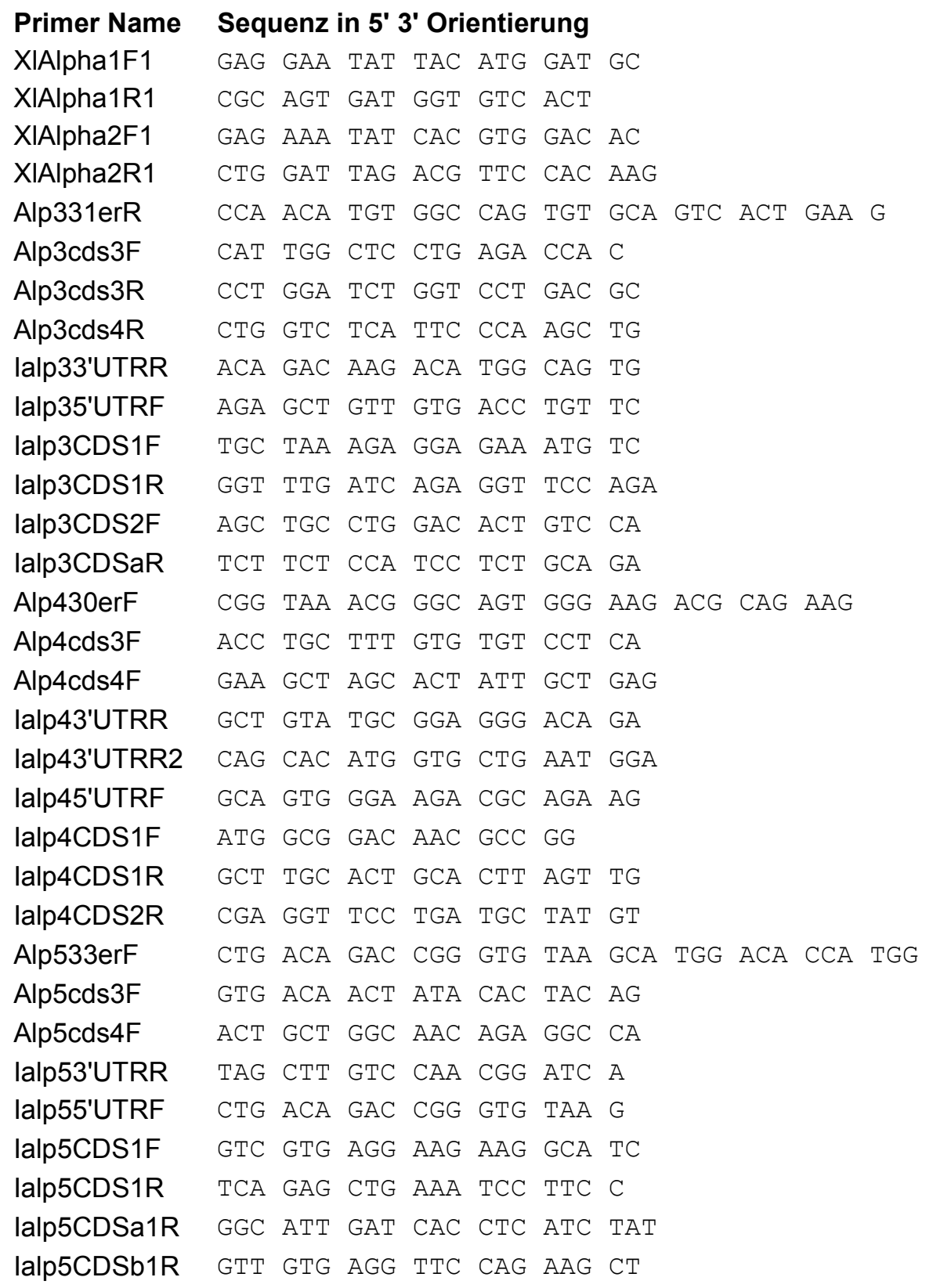

Tabelle 5: Karyopherin $\alpha$ spezifische Sequenzierprimer.

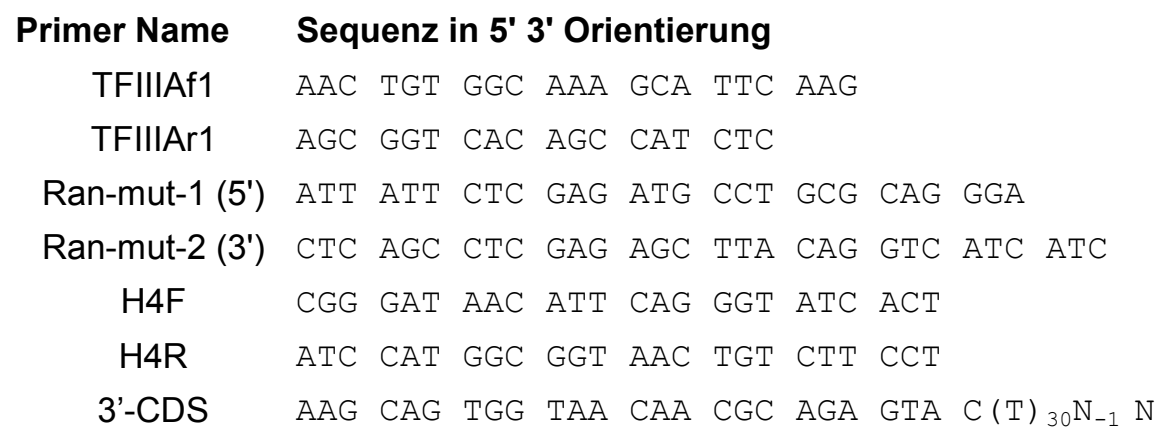

Tabelle 6: Sonstige Oligonukleotide.

$\left(N=A, C, G, \operatorname{oder} T ; N_{-1}=A, G\right.$, oder $\left.C\right)$ 


\subsubsection{Enzyme und Reaktionssysteme (Kits)}

\section{Enzyme:}

Alkalische Phosphatase (1 U/ $\mu$ l) Boehringer Mannheim, Mannheim

Lysozym Biomol GmbH, Hamburg

Proteinase K Merck KGaA, Darmstadt

Restriktionsendonukleasen Boehringer Mannheim, Mannheim

Restriktionsendonukleasen New England Biolabs GmbH, Schwalbach

RNase A Sigma-Aldrich Chemie GmbH, Deisenhofen

RNAsin $(40 U / \mu 1)$ Promega Deutschland GmbH, Mannheim

SP6 RNA-Polymerase (50 U/ $\mu$ l) Stratagene GmbH, Heidelberg

T3 RNA-Polymerase (50 U/ $\mu \mathrm{l})$ Stratagene $\mathrm{GmbH}$, Heidelberg

T7 RNA-Polymerase (50 U/ $\mu$ l) Stratagene GmbH, Heidelberg

$P f u$ DNA-Polymerase $(2.5 \mathrm{U} / \mu \mathrm{l})$ Stratagene $\mathrm{GmbH}$, Heidelberg

Taq DNA-Polymerase (5 U/ $\mu$ l) Perkin-Elmer, Weiterstadt

T4 DNA-Ligase (1 U/ $\mu 1)$ GibcoBRL, Eggenstein

T4-Polynukleotidkinase (10 U/ $\mu$ l) New England Biolabs GmbH, Schwalbach

\section{Kits:}

Dye Terminator Cycle Sequencing Kit Applied Biosystems GmbH, Weiterstadt PCR Purification Kit Qiagen GmbH, Hilden

pGEM-T Kit Promega Deutschland GmbH, Mannheim

QIAEX Gel Extraction Kit Qiagen GmbH, Hilden

RNA Transcription Kit Stratagene $\mathrm{GmbH}$, Heidelberg

RNeasy Mini Kit Qiagen GmbH, Hilden

RT-PCR Kit Perkin-Elmer, Weiterstadt

TNT-Coupled Reticulocyte Lysate System Promega Deutschland GmbH, Mannheim

Rediprime II Amersham Pharmacia Biotech, Uppsala, Schweden

SMART RACE cDNA Amplification Kit Clontech, Palo Alto, USA

\subsubsection{Antikörper}

anti-c-Myc (9E10; Santa Cruz Biotechnology, Santa Cruz, CA, USA): Monoklonaler Antikörper (Maus), welcher spezifisch das Myc-Epitop von Fusionsproteinen bindet. 
anti-Digoxigenin/AP (Boehringer Mannheim, Mannheim): Fab-Fragmente von Digoxigeninspezifischen Antikörpern (aus Ziege), konjugiert mit Alkalischer Phosphatase.

anti-Maus IgG1/Cy ${ }^{\mathrm{TM}_{3}}$ (Jackson Immuno Research Laboratories, Inc., West Grove, Pennsylvania, USA): Fab-Fragmente aus Ziege gegen Maus IgG1-spezifische Antikörper, gekoppelt mit dem Fluoreszenzfarbstoff Cy3.

\subsubsection{Radioisotope}

$\left[\alpha-{ }^{32} \mathrm{P}\right]-\mathrm{dCTP}, 3.000 \mathrm{Ci} / \mathrm{mmol}$ Amersham Buchler, Braunschweig

$\left[{ }^{14} \mathrm{C}\right]$-methylierter Proteinstandard Amersham Buchler, Braunschweig

$\left[{ }^{35} \mathrm{~S}\right]$-Cystein, $1.000 \mathrm{Ci} / \mathrm{mmol}$ Amersham Buchler, Braunschweig

$\left[{ }^{35} \mathrm{~S}\right]$-Methionin, $1.000 \mathrm{Ci} / \mathrm{mmol}$ Amersham Buchler, Braunschweig

\subsubsection{Medien und Lösungen}

Alle nicht gesondert aufgeführten Medien und Pufferlösungen wurden nach Sambrook et al., 1989 hergestellt. Wenn nicht anders beschrieben, wurden die Lösungen mit doppelt destilliertem Wasser angesetzt und durch Autoklavieren für 20 Minuten bei $121^{\circ} \mathrm{C}$ sterilisiert. Hitzelabile Substanzen wurden durch Membranfilter (Porendurchmesser $0.2 \mu \mathrm{m}$, Sartorius) sterilfiltriert. Nährmedien wurden nach dem Autoklavieren bis auf ca. $50^{\circ} \mathrm{C}$ abgekühlt und mit den entsprechenden Selektivantibiotika versetzt.

\section{Nährmedien}

\section{Bakterien}

LB-Agar: 1,5 \% (w/v) Agar (DIFCO) in LB-Flüssigmedium

Luria-Bertani (LB)-Medium: 1 \% (w/v) Bacto-Trypton (DIFCO), 0,5 \% (w/v) Hefeextrakt (DIFCO), $1 \%$ (w/v) NaCl, $\mathrm{pH} 7,5$

NZY-Agar: 1,5 \% (w/v) Agar in NZY-Flüssigmedium

NZY-Medium: $1 \%(\mathrm{w} / \mathrm{v})$ NZ-Amin (Casein Hydrolysat), 0,5 \% (w/v) Hefeextrakt (DIFCO), $0,5 \%(\mathrm{w} / \mathrm{v}) \mathrm{NaCl}, 8,1 \mathrm{mM} \mathrm{MgSO} 4, \mathrm{pH} 7,5$

NZY-Top-Agar: 0,7 \% (w/v) Agar in NZY-Flüssigmedium 


\section{HeLa-Zellmedium}

MEM-Medium: 9,9 g/1 MEM-Medium (MEM Earle's, Biochrom KG, Berlin), 0,001 \% (w/v) Streptomycin, 10 \% FCS (Fötales Kälberserum, PAA Laboratories GmbH, Cölbe; zur Inaktivierung 45 Minuten bei $56^{\circ} \mathrm{C}$ vorinkubiert)

\section{Antibiotika}

Antibiotika-Stammlösungen wurden aliquotiert und bei $-20^{\circ} \mathrm{C}$ aufbewahrt. Ampicillin: $100 \mathrm{mg} / \mathrm{ml}$ in $\mathrm{dH}_{2} \mathrm{O}$, Verdünnung 1:1.000 (Endkonzentration: $100 \mu \mathrm{g} / \mathrm{ml}$ ) Kanamycin: $10 \mathrm{mg} / \mathrm{ml}$ in $\mathrm{dH}_{2} \mathrm{O}$, Verdünnung 1: 200 (Endkonzentration: $50 \mu \mathrm{g} / \mathrm{ml}$ ) Tetracyclin: $5 \mathrm{mg} / \mathrm{ml}$ in Ethanol, Verdünnung 1: 400 (Endkonzentration: 12,5 $\mu \mathrm{g} / \mathrm{ml}$ ) Streptomycin: $10 \mathrm{mg} / \mathrm{ml}$ Streptomycin (Sigma-Aldrich Chemie GmbH, Deisenhofen) Penstrep: 10mg/ml (Biochrom KG, Berlin)

\section{Puffer und Stammlösungen}

DAPI-Einbettungssmedium: $10 \%$ (v/v) PBS, $90 \%$ (v/v) Glycerol, 1 mg/ml Phenylendiamin, $1 \mu \mathrm{g} / \mathrm{ml}$ 4,6-Diamidino-2-Phenylindol (DAPI)

Denhardt's (100 x): 2 \% (w/v) BSA, $2 \%(w / v)$ PVP, $2 \%(w / v)$ Ficoll

Di-Natriumhydrogenphosphat-Lösung: $1 \mathrm{M} \mathrm{Na}_{2} \mathrm{HPO}_{4}$

DNA-Auftragspuffer: 50 \% Glycerin, 0,2\% (w/v) Bromphenolblau oder Xylencyanol

DTT: $1 \mathrm{M}$ DTT, $10 \mathrm{mM}$ Natriumacetat $\mathrm{pH} 5,2 \quad 20{ }^{\circ} \mathrm{C}$ lagern

EDTA: 0,5 M EDTA, pH 8,0

Ethidiumbromid-Lösung: $10 \mathrm{mg} / \mathrm{ml}$ Ethidiumbromid

Ficoll: $10 \%$ (w/v) Ficoll, sterilfiltriert

GST-Pull-Down Bindungspuffer: 20 mM Tris-HCl, pH 8,0, 100 mM NaCl 0,5 mM EDTA, 0,5 $\mathrm{mM} \mathrm{ZnSO}_{4}, 0,05 \% \mathrm{NP}-40$

KCl-Lösung: $1 \mathrm{M} \mathrm{KCl}$

LiCl-Lösung: $8 \mathrm{M} \mathrm{LiCl}$

Maltose-Lösung: $20 \%$ Maltose in $\mathrm{H}_{2} \mathrm{O}$, sterilfiltriert

$\mathrm{MgCl}_{2}$-Lösung: $1 \mathrm{M} \mathrm{MgCl}_{2}$

$\mathrm{MgSO}_{4}$-Lösung: $1 \mathrm{M} \mathrm{MgSO}_{4}$

NaCl-Lösung: $5 \mathrm{M} \mathrm{NaCl}$

Natrium-Acetat-Lösung: $3 \mathrm{M} \mathrm{NaCH}_{3} \mathrm{COO}$ 
Natriumdihydrogenphosphat-Lösung: $1 \mathrm{M} \mathrm{NaH}_{2} \mathrm{PO}_{4}$

PBS (10 x): 8 \% (w/v) NaCl, $2 \%$ (w/v) KCl, $65 \mathrm{mM} \mathrm{Na}_{2} \mathrm{HPO}_{4}, 18 \mathrm{mM} \mathrm{KH}_{2} \mathrm{PO}_{4}, \mathrm{pH}$ 7,2-7,4

PBS-Puffer: $140 \mathrm{mM} \mathrm{NaCL}, 2,7 \mathrm{mM} \mathrm{KCl}, 8 \mathrm{mM} \mathrm{Na}_{2} \mathrm{HPO}_{4}, 1,5 \mathrm{mM} \mathrm{KH}_{2} \mathrm{PO}_{4}$

SDS-Lösung: $20 \%(\mathrm{w} / \mathrm{v})$ Natriumdodecylsulfat

SSC (20 x): $3 \mathrm{M} \mathrm{NaCl}, 0,3 \mathrm{M} \mathrm{Na-Citrat,} \mathrm{pH}$ 7,2-7,4

TBE: 89 mM Tris, $89 \mathrm{mM}$ Borsäure, $2 \mathrm{mM}$ EDTA $\cdot \mathrm{NaOH}$ pH 8,0

Tris-HCl-Puffer (pH 7 - 9): 1 M Tris-HCl, $\mathrm{pH} 7-9$

Tween-20-Lösung: $20 \%$ (v/v) Tween-20

$\mathrm{ZnSO}_{4}$-Lösung: $1 \mathrm{M} \mathrm{ZnSO}_{4}$

Z-Puffer : 25 mM Tris HCl, pH 7,7, 100 mM NaCl, 12,5 mM MgCl 2,20 \% Glycerol, 0,05 \% $\mathrm{NP}-40$

Z-Puffer (für TFIIIA): 25 mM Tris-HCl, pH 7,7, $100 \mathrm{mM} \mathrm{NaCl}, 12,5 \mathrm{MgCl}_{2}, 20 \%$ Glycerol, $0,1 \% \mathrm{NP}-40,1 \mathrm{mM} \mathrm{ZnSO} 4$

SDS-PAGE Probenpuffer: 130 mM Tris-HCl, pH 6,8, 20 \% Glycerol, 4 \% SDS, $10 \% \beta$ -

Mercaptoethanol, 0,002 \% Bromphenolblau

SM-Puffer: $50 \mathrm{mM}$ Tris $\mathrm{HCl} \mathrm{pH}$ 7,5, $8 \mathrm{mM} \mathrm{MgSO}_{4}, 100 \mathrm{mM} \mathrm{NaCl}, 0,01 \%$ Gelatine, sterilfiltriert $(0.45 \mu \mathrm{m})$

\subsubsection{Chromatographiematrices}

Gamabind plus Sepharose Amersham Pharmacia Biotech, Uppsala, Schweden

Ni-NTA Sepharose Qiagen GmbH, Hilden

Glutathion-Agarose Sigma-Aldrich Chemie GmbH, Deisenhofen

Oligo-(dT)-Cellulose Roche Diagnostics GmbH, Mannheim

\subsubsection{Chemikalien}

Biochemische Feinchemikalien wurden von den Firmen Boehringer Mannheim, Fluka, Roth, Serva und Biomol bezogen. Alle anderen Chemikalien stammten von den Firmen Fluka, Baker, Paesel-Lorei, Calbiochem, Gibco, Sigma oder Merck und wiesen den höchsten Reinheitsgrad (p.A.) auf. Die komplexen Medienbestandteile wurden von DIFCO Laboratories (Detroit, Michigan, USA) bezogen. 


\subsubsection{Geräte}

Gebrauchswaren und Geräte wurden, soweit nicht anders erwähnt, von den folgenden Firmen bezogen: Abimed (Hannover), Costar (Bodenheim), Eppendorf (Hamburg), Falcon (Heidelberg), Schütt (Göttingen), Greiner (Frickenhausen), Kranich (Göttingen), Qiagen (Hilden), Sarstedt (Langenhagen), Siemens (Hannover)

\section{Histologie}

Vibratom

\section{Mikroinjektion}

Microinjector 5242

Nadelzieher

\section{Optik}

Stereomikroskop

Stereomikroskop

Kameraaufsatz

Fluoreszenzmikroskop

Fotomikroskop

Digitalkamerasystem

Digitalkamerasystem

Sonstige

Phosphoimager

Zell-Zählgerät CASY 1, Modell TT CAP Innova 4230, temerierbarer Zellschüttler Gyrotory Shaker G25
Typ 1000, Pelco International, Redding, California, USA

Eppendorf, Hamburg

Leitz, Wetzlar

Stemi SV6, Zeiss, Oberkochen

MZFLIII, Leica Microsystems, Wetzlar

MC80, Zeiss, Oberkochen

Axioplan 2, Zeiss, Oberkochen

Axioskop, Zeiss, Oberkochen

JVC 3CCD KY-F58 Kamera

mit Kamera Kontroll Einheit

Sony 3CCD DX950P

Remote Control Unit RM-C950

Kamera Adapter CMA-D2
Molecular Dynamics, Krefeld

Schärfe System, Reutlingen

New Brunswick Scientific, Edison, USA

New Brunswick Scientific, Edison, USA 


\section{Software}

Bild/Grafikverarbeitung: Adobe Photoshop Version 5.5 (Adobe Systems Europe Ltd., Edinburgh, Schottland)

Freehand Version 9.0 (Macromedia Inc., San Francisco, USA)

DNA/Protein-Sequenzverarbeitung:

Lasergene (DNASTAR Inc., Madison, USA)

Blast-Suchsystem für Datenbanken (Altschul et al., 1997)

Textverarbeitung: Microsoft Word 2000® (9.0.3821 SR1)

Adobe Acrobat 4.05a (Adobe Systems Europe Ltd., Edinburgh, Schottland)

\section{Benutzte Datenbanken, DNA- und Protein-Sequenz Analyseprogramme:}

BLAST (Basic Local Alignment Search Tool):

http://www.ncbi.nlm.nih.gov/BLAST/

http://dove.embl-heidelberg.de/Blast2/

http://www.ch.embnet.org/software/BottomBLAST.html?

http://www.celera.com/

\section{PROSCAN (PROSITE SCAN):}

http://npsa-pbil.ibcp.fr/cgi-bin/npsa_automat.pl?page=npsa_prosite.html

Dialign:

http://bibiserv.techfak.uni-bielefeld.de/cgi-bin/dialign_submit

Predict nls:

http://maple.bioc.columbia.edu/predictnls/

PSORT (Prediction of Protein Sorting Signals and Localization Sites in Amino Acid Sequences):

http://psort.nibb.ac.jp/

GeneCards:

http://www.dkfz-heidelberg.de/GeneCards/

Entrez (a retrieval system for searching several linked databases):

http://www.ncbi.nlm.nih.gov/Entrez/ 


\subsection{Molekularbiologische Methoden}

\subsubsection{DNA-Methoden}

\subsubsection{Plasmidpräparation im präparativen Maßstab}

Zur Gewinnung größerer Mengen an Plasmid-DNA (100-600 $\mu \mathrm{g})$ wurden mit $2 \mathrm{ml}$ Vorkultur $50 \mathrm{ml} \mathrm{LB}$ Medium beimpft. Die Kultur wurde 16 Stunden bei $37^{\circ} \mathrm{C}$ und $200 \mathrm{Upm}$ inkubiert. Die Zellen wurden in einem $50 \mathrm{ml}$ Plastikgefäß (Greiner Bio-One $\mathrm{GmbH}$, Solingen) bei $4^{\circ} \mathrm{C}$ und $5000 \mathrm{Upm} 10$ Minuten zentrifugiert (Sorvall CL6B-Kühlzentrifuge mit GSA-Rotor DuPont, Bad Homburg). Das Pellet wurde dem Herstellerprotokoll (Qiagen Plasmid Purification Qiagen GmbH, Hilden oder Nucleobond AX, Macherey-Nagel, Düren) entsprechend aufgearbeitet. Die isolierte Plasmid-DNA wurde in $\mathrm{dH}_{2} \mathrm{O}$ gelöst und auf eine Konzentration von $1 \mu \mathrm{g} / \mu \mathrm{l}$ verdünnt.

\subsubsection{Plasmidpräparation im analytischen Maßstab}

Plasmid-DNA wurde durch alkalische Lyse der Bakterien gewonnen (Birnboim und Doly, 1979). Für die Plasmidpräparation wurden 1,5 ml einer Übernachtkultur 2 Minuten in einem Eppendorf Mikroreaktionsgefäß bei 14000 Upm zentrifugiert. Der Überstand wurde verworfen und das Pellet in $100 \mu$ Lösung 1 resuspendiert. Nach 5 Minuten Inkubation bei Raumtemperatur (RT) wurden $200 \mu \mathrm{l}$ Lösung 2 hinzugegeben, und die Proben durch mehrmaliges Schwenken durchmischt. Nach weiteren 5 Minuten RT erfolgte die Zugabe von $150 \mu \mathrm{l}$ Lösung 3. Die Ansätze wurden kräftig geschüttelt und für 10 Minuten auf Eis inkubiert. Durch 15 Minuten bei 14000 Upm wurden die Zelltrümmer und die genomische DNA pelletiert. Der Überstand wurde in ein neues Mikroreaktionsgefäß überführt. Der Überstand wurde mit $500 \mu \mathrm{l}$ Phenol/Chloroform versetzt und 3-10 s gemischt. Nach 2 Minuten Zentrifugation wurde die wässrige Phase in ein neues Mikroreaktionsgefäß überführt und mit 2 Volumen Ethanol und 1/10 Volumen Natriumacetat $(3 \mathrm{M}, \mathrm{pH} 5,2)$ gefällt. Die Ansätze wurden 15-30 Minuten bei 14000 Upm zentrifugiert. Das Pellet wurde zweimal mit

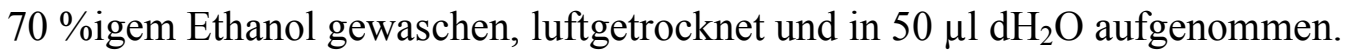

Lösung 1: $50 \mathrm{mM}$ Glucose, $25 \mathrm{mM}$ Tris $\mathrm{HCl}$ pH 8.0, $10 \mathrm{mM}$ EDTA pH 8.0

Lösung 2: 0,2 N NaOH, $1 \%$ SDS

Lösung 3: $60 \mathrm{ml}$ Kaliumacetat, 11,5 ml Eisessig, 28,5 $\mathrm{ml} \mathrm{dH}_{2} \mathrm{O}$ 


\subsubsection{Konzentrationsbestimmung von Nukleinsäuren durch UV-Spektroskopie}

Die Konzentration von DNA und RNA wurde in einem Spektralphotometer (Pharmacia Biotech) mit einer Quarzküvette bei $260 \mathrm{~nm}$ gegen einen Leerwert bestimmt. Gemessen wurden 1:50-Verdünnungen der DNA Lösungen in $\mathrm{H}_{2} \mathrm{O}$. Es gelten folgende Beziehungen:

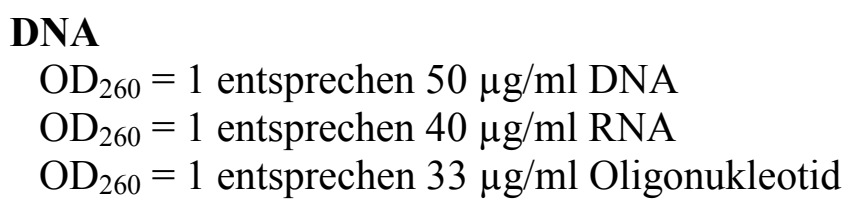

RNA

$$
\mathrm{OD}_{260}=1 \text { entsprechen } 40 \mu \mathrm{g} / \mathrm{ml} \mathrm{RNA}
$$

Als ein Maß für die Qualität der DNA (Reinheit) wurde die OD bei $280 \mathrm{~nm}$ bestimmt und der Quotient aus $\mathrm{OD}_{260} / \mathrm{OD}_{280}$ berechnet.

Für reine DNA gilt: $\mathrm{OD}_{260}: \mathrm{OD}_{280}=2,0$

Für reine RNA gilt: $\mathrm{OD}_{260}: \mathrm{OD}_{280}=1,8$

Eine $\mathrm{OD}_{260}: \mathrm{OD}_{280}<1,8$ zeigt an, dass die Präparation mit Proteinen oder aromatischen Substanzen z.B. Phenol kontaminiert ist. Bei einem Quotienten $\mathrm{OD}_{260}: \mathrm{OD}_{280}>2,0$ ist die Präparation möglicherweise mit RNA kontaminiert.

\subsubsection{Agarosegelelektrophorese}

Die Protokolle zur elektrophoretischen Trennung von DNA-Fragmenten sind bei

Sambrook et al., 1989 beschrieben. Die Agarose hatte je nach Größe der zu trennenden DNAFragmente eine Konzentration von 0,7-2 \% in TBE-Puffer. Das Gel enthielt zusätzlich 1 $\mu \mathrm{g} / \mathrm{ml}$ Ethidiumbromid, um die DNA auf einem UV-Transilluminator (254 $\mathrm{nm})$ sichtbar $\mathrm{zu}$ machen. Als Laufpuffer wurde TBE-Puffer verwendet. Die Proben wurden mit 1/10 Volumen DNA-Auftragspuffer (50 \% Glycerin, 0,2 \% Bromphenolblau oder Xylencyanol) versetzt. Als Größenmarker wurde eine $1 \mathrm{~Kb}$ DNA-Leiter (Life Technologies) verwendet. Die Trennung erfolgte bei ca. $10 \mathrm{~V} / \mathrm{cm}$ Länge des Gels. Um eine Beschädigung der DNA zu vermeiden, wurde bei präparativen Gelen UV-Auflicht (365nm) zur Detektion der DNA-Fragmente benutzt, und die entsprechenden Vektor- und Insertbanden wurden mit einem Skalpell ausgeschnitten. Die Agarosegelstücke wurden mit Qiaex II (Qiagen) nach dem Protokoll des Herstellers behandelt. Die DNA-Fragmente wurden mit 2 x $15 \mu 1 \mathrm{H}_{2} \mathrm{O}$ eluiert. 


\subsubsection{Manipulation von DNA}

Die verwendeten Plasmide wurden durch Restriktion, Bluntending und Ligation modifiziert.

Die Protokolle waren angelehnt an Sambrook et al., 1989 und wurden nach den Herstelleranweisungen bearbeitet.

\subsubsection{Spaltung von DNA mit Restriktionsendonucleasen}

Die Restriktionsenzyme wurden von verschiedenen Herstellern bezogen (Boehringer, Fermentas, Promega, New England Biolabs). Inkubationen wurden bei Raumtemperatur, $25^{\circ} \mathrm{C}$ und $37^{\circ} \mathrm{C}$ für Zeiten zwischen 2 und 18 Stunden durchgeführt. Die Umwandlung von überhängenden DNA-Enden in stumpfe DNA-Enden („Bluntending“) erfolgte entweder durch eine Auffüllreaktion mit dem Klenow-Fragment (NEB), einem proteolytischen Produkt der DNA-Polymerase I, oder durch Nutzung der 3'-5'- Exonukleaseaktivität der DNAPolymerase I (Large Klenow Fragment, Stratagene).

\subsubsection{Dephosphorylierung von Vektoren}

Nach Inaktivierung der Restriktionsendonucleasen wurde der mit ein oder zwei Restriktionsenzymen linearisierte Vektor in einem Gesamtvolumen von $40 \mu 1$ aufgenommen. Um die Anzahl falsch positiver Klone zu reduzieren, wurden die 5'-Phosphatgruppen des Vektors mit Alkalischer Phosphatase entfernt. Hierzu wurde der Vektor mit 1/10 Volumen Phosphatase Puffer und $1 \mu \mathrm{l}$ Alkalischer Phosphatase 30 Minuten bei $37^{\circ} \mathrm{C}$ inkubiert. Anschließend erfolgte eine Enzyminaktivierung durch eine Inkubation von 15 Minuten bei 65 ${ }^{\circ} \mathrm{C}$. Vor Verwendung für eine Ligation wurde der linearisierte und dephosphorylierte Vektor auf ein 0,7 \%iges Agarosegel aufgetragen und nach der Elektrophorese reisoliert.

\subsubsection{Einfügen von Schnittstellen}

Mit der PCR ist es möglich, DNA-Fragmente mit zwei Oligonukleotiden und einer DNAMatrize zu amplifizieren (Mullis und Faloona, 1987; Saiki et al., 1985). Die Oligonukleotide bestimmen das zu amplifizierende DNA-Fragment. Die DNA-Polymerase hat Einfluß auf die Qualität, Eigenschaften der Fragmentenden und die maximale Länge des PCR-Produkts. Die Konstrukte 4, 34, 234 und 678 wurden mit Hilfe dieser Technik erstellt. Die Primer sind so gewählt, dass sie mit ihrem 5'-Ende bei der Hybridisierung mit dem Matrizen-Strang im ersten PCR-Zyklus mit mehreren Basen nicht paaren können. An dieser Position wurde die Sequenz so modifiziert, dass in den folgenden PCR-Zyklen an den Fragmentenden Schnittstellen entstehen. Zwei Reaktionsrunden später konnte so an beiden Enden der amplifizierten Fragmente die Sequenz modifiziert werden. In die 5'- und 3'-Bereiche der 
Zinkfinger kodierenden Sequenzen sind Schnittstellen für Restriktionsenzyme eingefügt worden. Durch Verwendung der Taq-Polymerase wurde gewährleistet, dass bei einigen Fragmenten ein 3'-Adenosin-Überhang vorhanden war.

Für jedes Konstrukt wurde folgender Ansatz erstellt:

$$
\begin{gathered}
1 \mu 110 \times \text { Taq-Puffer } \\
0,9 \mu 1 \mathrm{MgCl} 25 \mathrm{mM} \\
0,8 \mu \mathrm{lNTP} 2,5 \mathrm{mM} \\
0,25 \mu 1 \text { Taq Polymerase } 5 \mathrm{U} / \mu 1 \\
10 \mathrm{ng} \text { Matrizen-DNA } \\
1,25 \mu \mathrm{l} \text { 1. Primer } 2,5 \mu \mathrm{M} \\
1,25 \mu 1 \text { 2. Primer } 2,5 \mu \mathrm{M} \\
\text { ad } 75 \mu \mathrm{l}
\end{gathered}
$$

Folgendes Protokoll wurde für die PCR erstellt : 3 min bei $94^{\circ} \mathrm{C}, 30$ Zyklen: $60 \mathrm{~s}$ bei $95^{\circ} \mathrm{C}, 60$ $\mathrm{s}$ bei $48^{\circ} \mathrm{C}, 60 \mathrm{~s}$ bei $72^{\circ} \mathrm{C}$, und $10 \mathrm{~min} 72^{\circ} \mathrm{C}$. Die PCR-Produkte wurden nach Aufreinigung mit dem PCR-Purification Kit nach Herstellerprotokoll (Qiagen) in den pGEM-T Vektor ligiert (Promega). Dieser Klonierungsvektor zeichnet sich durch seine überhängenden Desoxythymidine aus und ist speziell für den Zweck, PCR-Produkte aufzunehmen, erstellt worden. Die DNA wurde in den E. coli-Stamm TG1 transformiert. Nach Blau-/WeißSelektion auf X-Gal-Platten wurden weiße Kolonien, welche das Insert enthalten können, in 3 ml LB/Ampicillin überimpft. Nach Verifizierung der positiven Klone mittels PCR oder DNAMinipräparation und Restriktionsanalyse wurden sie in $50 \mathrm{ml} \mathrm{LB} /$ Ampicillin vermehrt und die Plasmide präparativ aufgearbeitet.

\subsubsection{Ligation}

Ligationen wurden mit der T4-DNA-Ligase (NEB) in einem $10 \mu 1$ Ligationsansatz durchgeführt. Vektor und Fragment wurden nach Abschätzung auf einem Agarosegel oder photometrischer Bestimmung der DNA Konzentration im molaren Verhältnis 1:3 eingesetzt. Die Ligationsansätze wurden bei $16^{\circ} \mathrm{C}$ für $12-16$ Stunden bei überhängenden Enden oder bei Raumtemperatur für 16 Stunden bei glatten DNA-Enden inkubiert.

\subsubsection{Reinigung von präparativen PCR-Ansätzen}

Die präparativen PCR-Ansätze für die Klonierungen der Konstrukte 4, 34, 234 und 678 wurden nach einem Kontrollgel über eine Silica-Gel-Membran gereinigt. Der PCR-Ansatz wurde ölfrei in ein 1,5 ml Mikroreaktionsgefäß überführt und mit $\mathrm{dH}_{2} \mathrm{O}$ auf $100 \mu 1$ aufgefüllt. 
5 Volumen Puffer PB wurden zugefügt und auf die Säule gegeben. Nach 1 Minute Zentrifugation bei 6000 Upm wurde mit $750 \mu$ Puffer PE gewaschen und zentrifugiert. Die Elution erfolgte mit zweimal $15 \mu \mathrm{dH}_{2} \mathrm{O}$ in ein neues Mikroreaktionsgefäß. $5 \mu 1$ des Eluats wurden auf ein Kontrollgel gegeben, um das molare Verhältnis des PCR-Produktes zum Vektor für die folgende Ligationsreaktion abschätzen zu können.

\subsubsection{Reisolierung von DNA-Fragmenten mit TaKaRa Recochips}

Die Recochip-Technologie basiert auf $0,5 \times 1 \mathrm{~cm}$ großen Cellulose Plättchen, mit denen ohne weitere Reagenzien DNA-Fragmente mit einer Ausbeute von 70-80\% aus Agarosegelen isoliert werden. Zur Reisolierung von DNA-Fragmenten wurde die Probe (Karyopherin $\alpha 4$ Magen-spezifisches PCR Produkt, 450 bp) auf einem $1 \%$ Gel aufgetrennt. Auf einem UVTransilluminator wurde das Gel kurz hinter der zu isolierenden Bande, auf der Anodenseite, eingeschnitten und der Recochip in den Gelschlitz in vorgegebener Orientierung eingeführt. Nach weiterer Elektrophorese für 5 Minuten wurde der Chip in ein $2 \mathrm{ml}$ Reaktionsgefäß überführt. Durch Zentrifugation $5 \mathrm{~s}$ bei $14000 \mathrm{Upm}$ in einer Eppendorf Tischzentrifuge wurden $30 \mu 1$ DNA-Lösung erhalten. Die erhaltene DNA hatte einen Reinheitsgrad der ausreichte, um Sequenzier- oder PCR-Reaktionen zur weiteren Amplifikation des Fragments durchzuführen.

\subsubsection{Sequenzierung von DNA}

Sequenzierungen erfolgten nach einem modifizierten Verfahren der DidesoxyKettenabbruchmethode (Sanger et al., 1977). Im Ansatz sind Didesoxyanaloga der vier verschiedenen dNTP enthalten, die je nach Base, mit unterschiedlichen Fluoreszenzfarbstoffen markiert sind. In der Reaktion führt die Verwendung eines ddNTP zum vorzeitigen Abbruch der Reaktion. Durch Auftrennung der verschiedenen Abbruchprodukte auf einem Polyacrylamidgel können die Farbstoffe der unterschiedlichen Fragmente mit einem Laser angeregt werden. Das emittierte Licht, der verschiedenen Succenylfluorescine hat eine spezifische Wellenlänge. Die über Photomultipier verstärkten und anschließend detektierten Signale werden während des Gellaufs erfasst und mit geeigneter Software ausgewertet. Die Sequenzierungen wurden entsprechend dem mitgelieferten Protokoll zum "Dye Terminator Cycle Sequencing Kit" (Applied Biosystems) in einer Einzelreaktion für jedes Konstrukt angesetzt. In diesem Kit wird eine eine modifizierte Form der Taq-Polymerase verwendet, die keine $5^{\prime} \rightarrow 3^{\prime}$ Exonucleaseaktivität mehr aufweist und zwischen Didesoxy- und Desoxynukleotiden kaum unterscheidet. 
Außerdem wird anstelle von dGTP in diesem Kit dITP verwendet, um Haarnadelschleifenbildung der ssDNA zu vermeiden.

In einem Gesamtvolumen von $20 \mu \mathrm{l}$ wurden $0,2 \mu \mathrm{g}$ DNA, $4 \mu 1$ Terminator Mix und 5 pmol Primer für den Reaktionsansatz verwendet. Die Proben durchliefen im Thermal Cycler (Perkin Elmer DNA Thermal Cycler, TC1/480) folgendes Programm: $96^{\circ} \mathrm{C} 30 \mathrm{~s}, 60^{\circ} \mathrm{C} 15 \mathrm{~s}$, $60^{\circ} \mathrm{C} 4 \mathrm{~min}, 25$ Zyklen. Der Reaktionsansatz wurde mit $10 \mu 13 \mathrm{M}$ Natriumacetat (pH 5,2), 80 $\mu 1 \mathrm{H}_{2} \mathrm{O}$ und 2,5 Volumen Ethanol p.a. versetzt, gemischt und für 30 Minuten bei $14.000 \mathrm{Upm}$ zentrifugiert. Das Pellet wurde mit $250 \mu 170$ \%igem Ethanol gewaschen, getrocknet, in $3 \mu 1$ Formamid $/ 10 \mathrm{mM}$ EDTA resuspendiert und bei $-20^{\circ} \mathrm{C}$ bis zum Gellauf (durchgeführt von einem Mitarbeiter des Instituts) mit dem DNA-Sequenziergerät der Firma ABI (Modell 373A) aufbewahrt.

\subsubsection{DNA-Fällung mit Ethanol}

Die in Lösung befindliche zu fällende DNA wurde mit 1/10 Volumen Natriumacetat und 2,5 Volumen Ethanol versetzt, gemischt und anschließend 30 Minuten bei $4^{\circ} \mathrm{C}$ und $14000 \mathrm{Upm}$ sedimentiert. Nach zweimaligem Waschen mit $70 \%$ Ethanol wurde das Pellet bei RT 5 Minuten luftgetrocknet und anschließend in dem gewünschtem Volumen Wasser resuspendiert.

\subsubsection{RNA-Standardmethoden}

Zur Inaktivierung von RNasen wurden die zum Arbeiten mit RNA bestimmten Gefäße und Lösungen mit $1 \mathrm{ml}$ DEPC pro 1 versetzt und für 2-13 h bei $37^{\circ} \mathrm{C}$ inkubiert. Das DEPC wurde durch anschließendes Autoklavieren für 30 Minuten bei $121{ }^{\circ} \mathrm{C}$ inaktiviert. Hitzelabile Substanzen wurden in DEPC- $\mathrm{dH}_{2} \mathrm{O}$ gelöst. Geräte, welche nicht autoklaviert werden konnten, wurden für $2 \mathrm{~h}$ in $0.5 \mathrm{M} \mathrm{NaOH}$ inkubiert und gut mit DEPC- $\mathrm{dH}_{2} \mathrm{O}$ gespült. Beim Arbeiten mit RNA wurden Einmalhandschuhe getragen.

DEPC- $\mathbf{d H}_{2} \mathrm{O}: 0.1 \%(\mathrm{v} / \mathrm{v})$ Diethylpyrocarbonat in $\mathrm{dH}_{2} \mathrm{O}$, Inkubation für $4-12 \mathrm{~h}$ bei $37^{\circ} \mathrm{C}$ und anschließendes Autoklavieren für 30 Minuten bei $121^{\circ} \mathrm{C}$.

\subsubsection{Isolierung von Gesamt-RNA aus Xenopus Embryonalstadien}

Für Expressionsstudien und cDNA-Klonierungen wurde DNA-freie Gesamt-RNA aus Xenopus Embryonalstadien isoliert. Um Gesamt-RNA aus Xenopus-Embryonen zu extrahieren, wurde in einem 1.5 ml-Eppendorfreaktionsgefäß pro Ansatz je $0.4 \mathrm{ml}$ 
Extraktionspuffer in einem Thermoblock (Gesellschaft für Laborgeräte, Wertheim/Main) auf $45^{\circ} \mathrm{C}$ vorgewärmt. $\mathrm{Zu}$ dem Puffer wurden $20 \mu$ l einer Proteinase K-Lösung $(20 \mathrm{mg} / \mathrm{ml})$ gegeben und diese Mischung sofort auf die gefrorenen Embryonen (je 10 pro Präparation) pipettiert. Durch 8faches Auf- und Absaugen der Probe in einer 1 ml-Einmalspritze mit G24Kanüle wurden die Embryonen homogenisiert. Der Extrakt wurde bei $45^{\circ} \mathrm{C}$ für 45 Minuten inkubiert und phenolextrahiert $(1 \times 1$ Vol. Phenol, 3 x 1 Vol. Phenol/Chloroform, 1 x 1 Vol. Chloroform). Nach der Zugabe von 1 Volumen $8 \mathrm{M} \mathrm{LiCl} \mathrm{wurde} \mathrm{die} \mathrm{RNA} \mathrm{über} \mathrm{Nacht} \mathrm{bei} \mathrm{-}$ $20^{\circ} \mathrm{C}$ gefällt. Das Pellet wurde nach der Zentrifugation (14.000 Upm, $10 \mathrm{~min}$ ) in $100 \mu \mathrm{l}$ DEPC- $\mathrm{H}_{2} \mathrm{O}$ aufgenommen. Die RNA wurde durch Zugabe von 0,1 Volumen $10 \mathrm{M} \mathrm{NH}_{4}$ Acetat und 2,5 Vol. Ethanol durch Zentrifugation in einer Eppendorf-Tischzentrifuge (14.000 Upm, 30 min, RT) gefällt und in $40 \mu \mathrm{DEPC}-\mathrm{dH}_{2} \mathrm{O}$ aufgenommen. Um kontaminierende genomische DNA zu degradieren, wurde die RNA-Lösung nach Zugabe von $2 \mu 1$ RNasefreier DNase (20 U/ $\mu 1$, Boehringer), $5 \mu 110 \times$ DNase-Puffer, $2 \mu 120 \mathrm{mM}$ Dithiothreitol und 1 $\mu \mathrm{l}$ RNasin (40 U/ $\mu$ l, Stratagene) 30 Minuten bei $37^{\circ} \mathrm{C}$ inkubiert. Anschließend wurde die RNA über RNeasy-Säulen aufgereinigt und die Konzentration photometrisch bestimmt.

Extraktionspuffer (1 x): 50 mM Tris- $\mathrm{HCl}(\mathrm{pH} 7,5), 5$ mM EDTA (pH 8), $40 \mathrm{mM} \mathrm{NaCl}$, $0.5 \%$ SDS in DEPC behandeltem $\mathrm{H}_{2} \mathrm{O}$

DNase-Puffer (10 x): 400 mM Tris-HCl (pH 8,0), 60 mM MgCl $2,100 \mathrm{mM} \mathrm{NaCl,}$ $1 \mathrm{mM} \mathrm{CaCl}_{2}$ in DEPC behandeltem $\mathrm{dH}_{2} \mathrm{O}$

\subsubsection{Isolierung von Gesamt-RNA aus adulten Geweben und Organen}

Die entnommenen Gewebe und Organe wurden mit 1 x MBSH gewaschen (blutfrei). Die Gewebe und Organe wurden in Flüssigstickstoff eingefroren und mit einem in Flüssigstickstoff gekühlten Mörser pulverisiert. Das Pulver wurde in vorgekühlten $1.5 \mathrm{ml}$ Eppendorfreaktionsgefäßen in $50 \mu$-Aliquots aufgeteilt und bis zur Extraktion bei $-70^{\circ} \mathrm{C}$ gelagert. Die RNA-Extraktion wurde wie unter 2.2.2.1 beschrieben durchgeführt.

\subsubsection{Total-RNA Präparation von embryonalem Augengewebe}

Da das SDS im Extraktionspuffer ausfallen kann, wurde dieser bei $45^{\circ} \mathrm{C}$ für 1 Stunde vorgewämt. Mit Kanülen verschiedener Größe wurden $200 \mu$ l embryonales Augengewebe in $2 \mathrm{ml}$ Extraktionspuffer homogenisiert und die Resuspension bei $45{ }^{\circ} \mathrm{C}$ für 5 Minuten inkubiert. Nach Zugabe von $1 \mathrm{ml}$ RNase freiem $\mathrm{dH}_{2} \mathrm{O}$ wurden $800 \mu$ l Proteinase $\mathrm{K}$ Lösung 
(Merk 0,1 mol/1 in Tris-HCl pH 7,5) hinzugefügt und der Ansatz für 30 Minuten bei $45^{\circ} \mathrm{C}$ inkubiert. Anschließend wurden dem Ansatz erneut $800 \mu$ 1 Proteinase K Lösung hinzugefügt und der Ansatz für 30 Minuten bei $45^{\circ} \mathrm{C}$ inkubiert. Der Ansatz wurde auf $6 \mathrm{ml}$ mit DEPC behandeltem $\mathrm{dH}_{2} \mathrm{O}$ aufgefüllt und mit 1 Volumen Phenol 5 Minuten bei 12000 Upm (Sorval SS34) zentrifugiert. Anschließend erfolgte eine 5 malige Phenol / Chloroform Extraktion, gefolgt von mehrfacher Chloroform Extraktion bis keine Interphase mehr zu sehen war. Die obere Phase wurde mit 1 Volumen $8 \mathrm{M} \mathrm{LiCl}$ über Nacht bei $-20^{\circ} \mathrm{C}$ gefällt und 20 Minuten bei $12000 \mathrm{Upm}$ und $4^{\circ} \mathrm{C}$ pelletiert. Das luftgetrocknete Pellet wurde in $400 \mu \mathrm{TE}$-Puffer gelöst und mit 1/10 Volumen Natrium-Acetat Lösung und 2,5 Volumen Ethanol bei $-70{ }^{\circ} \mathrm{C}$ für 15 Minuten erneut gefällt. Der Ansatz wurde 30 Minuten bei 14000 Upm zentrifugiert, einmal mit $70 \%$ Ethanol gewaschen und das trockene Pellet in $168 \mu$ DEPC- $\mathrm{dH}_{2} \mathrm{O}$ gelöst. Die DNA wurde durch DNase 30 Minuten bei $37^{\circ} \mathrm{C}$ verdaut und der Ansatz auf $1 \mathrm{ml}$ mit DEPC behandeltem $\mathrm{H}_{2} \mathrm{O}$ aufgefüllt. Nach erneuter Phenol-, zweimaliger Phenol / Chloroform- und Chloroform-Extraktion, bis keine Interphase mehr zu sehen war, wurde die obere Phase von ca. $500 \mu \mathrm{l}$ mit 1/10 Volumen Ammoniumacetat und 2,5 Vol. Ethanol für 2 Stunden bei $-20^{\circ} \mathrm{C}$ gefällt und 15 Minuten bei 14000 Upm pelletiert. Das Pellet wurde einmal mit $70 \%$ Ethanol gewaschen und in $200 \mu \mathrm{l}$ DEPC behandeltem $\mathrm{H}_{2} \mathrm{O}$ aufgenommen.

DNA-Verdau:

DNase-Puffer (10 x):
$168 \mu 1$ DEPC $\mathrm{H}_{2} \mathrm{O}$

$20 \mu 1$ DNase Puffer

$2 \mu 1$ RNAsin $40 \mathrm{U} / \mu \mathrm{l}$ (Promega)

$4 \mu 1$ DTT $20 \mathrm{mM}$

$6 \mu 1$ DNase $10 \mathrm{U} / \mu \mathrm{l}$ (Roche Diagnostics)

$400 \mathrm{mM}$ Tris-HCl (pH 7,9), $100 \mathrm{mM} \mathrm{NaCl}, 60 \mathrm{mM} \mathrm{MgCl}_{2}$, $1 \mathrm{mM} \mathrm{CaCl}_{2}, 1 \mathrm{ml}$ DEPC-d $\mathrm{H}_{2} \mathrm{O}$

Extraktionspuffer (2 x): 20 mM EDTA, $200 \mathrm{mM}$ Tris (pH 7,6), $200 \mathrm{mM} \mathrm{NaCl,}$ $2 \%$ SDS 


\subsubsection{Poly-A ${ }^{+}$-RNA Isolierung}

Die verwendeten Puffer wurden auf $40^{\circ} \mathrm{C}$ vorgewärmt. Für $10 \mathrm{mg}$ Total-RNA wurden $0,5 \mathrm{~g}$ Oligo(dT)-Cellulose mit $0,1 \mathrm{~N} \mathrm{NaOH}$ vorgequollen und anschließend mit DEPC behandeltem $\mathrm{H}_{2} \mathrm{O}$ gewaschen. Eine $1 \mathrm{ml}$ Spritze wurde mit 0,5 ml Oligo(dT)-Cellulose gefüllt und mit 3 Volumen DEPC behandeltem $\mathrm{H}_{2} \mathrm{O}$ gewaschen. Die Säule wurde mit RNA-Säulenpuffer gespült bis der $\mathrm{pH}$ kleiner als 8 war. Präparierte Total-RNA wurde auf $70{ }^{\circ} \mathrm{C}$ für 5 Minuten erhitzt und anschließend auf Eis bis auf Raumtemperatur abgekühlt. Die RNA wurde mit 1 Volumen 2x RNA-Säulenpuffer auf die Säule gegeben und das Eluat aufgefangen. Das Eluat wurde 5 Minuten auf $70^{\circ} \mathrm{C}$ erhitzt und dann erneut auf die Säule geben. Die Säule wurde mit 1x RNA-Säulenpuffer gewaschen bis die gesammelten Fraktionen (0,5-1 ml) eine $\mathrm{OD}_{260}$ von 0 hatten. Anschließend wurde die poly $\mathrm{A}^{+}$-RNA mit $0,5 \mathrm{ml}$ Elutionspuffer von der Säule eluiert. Nach $\mathrm{OD}_{260}$ gesammelte positive $50 \mu$ Fraktionen wurden zusammengefügt und mit 1/10 Volumen $10 \mathrm{M}$ Ammoniumacetat, $1 \mu$ l Glycogen und 2,5 Volumen Ethanol über Nacht bei $-20^{\circ} \mathrm{C}$ gefällt. Das Pellet wurde mit $80 \%$ Ethanol gewaschen und in $200 \mu \mathrm{DEPC}$ behandeltem $\mathrm{H}_{2} \mathrm{O}$ aufgenommen. Die Integität der isolierten RNA wurde durch einen Northern Blot getestet.

RNA-Säulenpuffer (2x): 40 mM Tris $\mathrm{HCl}(\mathrm{pH}$ 7,6), $1 \mathrm{M} \mathrm{NaCl}, 2 \mathrm{mM}$ EDTA (pH 8,0),

$$
0,2 \% \mathrm{SDS}
$$

Elutionspuffer für poly $\mathbf{A}^{+}$-RNA : $10 \mathrm{mM}$ Tris $\mathrm{HCl}(\mathrm{pH} 7,6), 1 \mathrm{mM}$ EDTA $(\mathrm{pH} 8,0)$,

$$
0,5 \% \text { SDS }
$$

\subsubsection{Northern Blot}

Die Probe wurde mit Formamid Loading Dye auf einem $100 \mathrm{ml}$ Formaldehyd-Agarosegel bei 100 V, 200 mA aufgetrennt. Nach Abschluß der Elektrophorese wurde das Formaldehyd durch 15 Minuten DEPC $\mathrm{H}_{2} \mathrm{O}, 15$ Minuten 10x SSC, 15 Minuten 10x SSC Behandlung rausgewaschen. Die RNA wurde in einer gesockelten Wanne mit 20x SSC über Nacht auf eine Hybond-N Membran (Amersham) geblottet. Die Fixierung der RNA erfolgte im UV Crosslinker mit dem Standardprogramm. Die fixierte RNA wurde mit 0,04\% Methylenblau in 0,5 M Natriumacetat (pH 5,2) unter 10-15 minütigem Schwenken angefärbt.

Formaldehydgel-Laufpuffer (5x): 0,1M MOPS (pH 7,0), 40 mM Natriumacetat, 
$100 \mathrm{ml}$ Formaldehyd-Agarosegel: $1 \mathrm{~g}$ Agarose in $60 \mathrm{ml}$ DEPC behandeltem $\mathrm{H}_{2} \mathrm{O}$

kurz aufkochen,

$20 \mathrm{ml} \mathrm{5x}$ Puffer hinzufügen,

wenn die Agarose handwarm ist, wird unter dem Abzug

$22 \mathrm{ml} 37$ \%ige Formaldehydlösung hinzugefügt und das

Gel anschließend gegossen.

\subsubsection{Reverse-Transkriptase-Polymerase-Kettenreaktion (RT-PCR)}

Zur Analyse der Expression klonierter Gene in Embryonalstadien, adulten Geweben und Organen oder zur Klonierung von cDNA wurde mRNA revers transkribiert und die erhaltene cDNA in der PCR amplifiziert. Hierbei wurde mit dem "RT-PCR Kit" (Perkin-Elmer) gearbeitet. Zur Vermeidung von Kontaminationen wurden bei allen Schritten filtergestopfte Pipettenspitzen verwendet. Die reverse Transkription von RNA wurde in einem Ansatz des RT-PCR Kits (Perkin Elmer) durchgeführt, der wie folgt zusammengesetzt war:

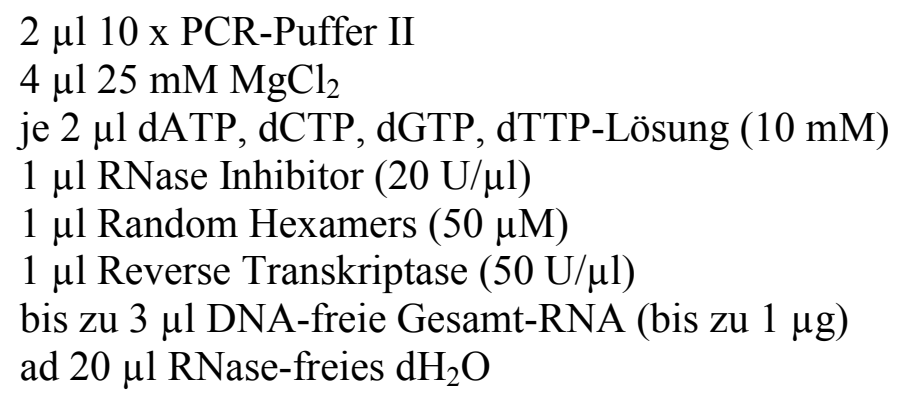

Der Ansatz wurde gemischt und mit $50 \mu 1$ Mineralöl überschichtet. Die reverse Transkription erfolgte in einem PCR-Gerät (Trio, Biometra) mit dem folgenden Temperaturprofil: $10 \mathrm{~min}$ RT (Anlagerung der Oligonukleotide), $30 \mathrm{~min} 42^{\circ} \mathrm{C}$ (reverse Transkription), $5 \min 99^{\circ} \mathrm{C}$ (Inaktivierung der reversen Transkriptase), abkühlen auf $4^{\circ} \mathrm{C}$. Die so erhaltene cDNA wurde anschließend in einer PCR-Reaktion eingesetzt, jedem Ansatz wurden folgende Komponenten hinzugefügt:

$8 \mu 110 \times$ PCR-Puffer II

$2 \mu 125 \mathrm{mM} \mathrm{MgCl}_{2}$ (Endkonzentration 1,5 mM)

$1 \mu 1$ je $15 \mu \mathrm{M}$ "sense"- und "antisense"-Oligonukleotid-Lösung

$0.5 \mu 1$ Taq-Polymerase (5U/ $\mu 1$, Perkin-Elmer)

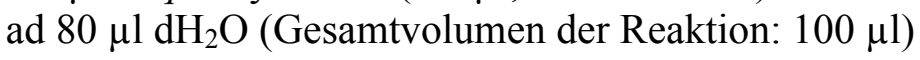


Die gewählte Zyklenzahl der analytischen RT-PCR befand sich möglichst im Bereich des linearen Anstiegs der Produktmenge. Die Produkte wurden im Agarosegel analysiert.

\subsubsection{Smart RACE-Ready cDNA}

Die Karyopherin $\alpha$ Varianten 4, 5.1 und 5.2 wurden mit der 3' RACE Methode auf Testis Gesamt-RNA isoliert. Die Durchführung erfolgte nach Herstellerangaben (Clontech, SMART RACE cDNA Amplification Kit User Manual PT3269-1). Die Karyopherinvariante $\alpha 4$ wurde mit dem Ialp431F und die Karyopherin $\alpha 5.1$ und 5.2 Varianten mit dem Ialp533F Primer in der PCR amplifiziert. Für die Erststrangsynthese wurde folgender Ansatz erstellt:

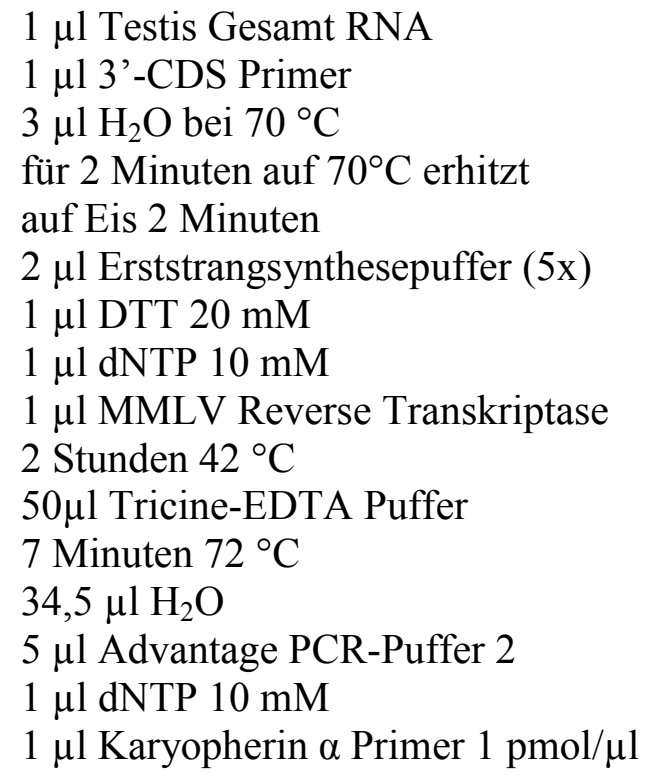

Es wurde folgendes Programm für die PCR verwendet:

5 Zyklen: 5 Sekunden $94^{\circ} \mathrm{C}, 3$ Minuten $72^{\circ} \mathrm{C}$

5 Zyklen: 5 Sekunden $94^{\circ} \mathrm{C}$, 10 Minuten $70{ }^{\circ} \mathrm{C}$

32 Zyklen: 5 Sekunden $94^{\circ} \mathrm{C}, 10$ Minuten $68^{\circ} \mathrm{C}$

3 Minuten $72^{\circ} \mathrm{C}$

Die PCR Produkte wurden in den pGEM-T Klonierungsvektor ligiert und in E. coli TG1 transformiert.

\subsubsection{In vitro-Synthese markierter RNA-Sonden}

Zur Synthese von markierten antisense-RNA-Sonden für in situ Hybridisierungen wurden in vitro Transkriptionen in Anwesenheit von Digoxigenin-markiertem rUTP durchgeführt. Als "template" für die RNA-Polymerase diente linearisierte Plasmid-DNA, die mit dem "RNeasy 
Mini Kit" (Qiagen) aufgereinigt worden war. Ein Transkriptionsansatz (RNA TranskriptionsKit, Stratagene) setzte sich aus den folgenden Komponenten zusammen:

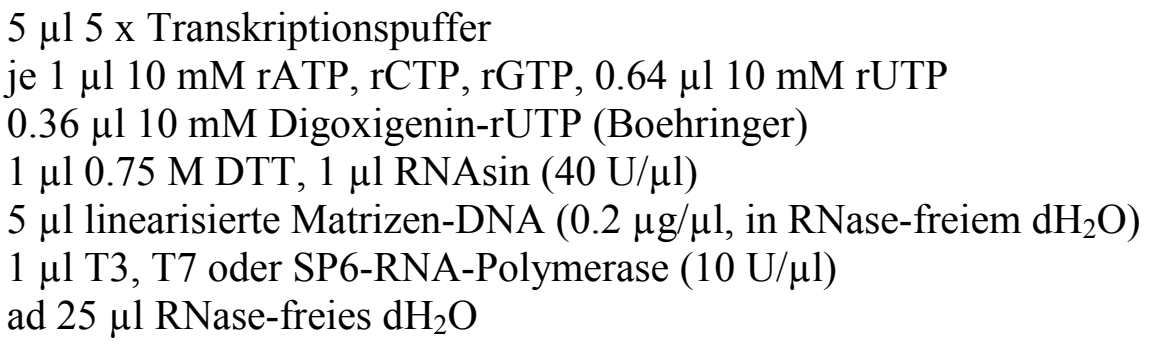

Der Ansatz wurde $2 \mathrm{~h}$ bei $37^{\circ} \mathrm{C}$ inkubiert und anschließend die DNA-Matrize durch Zugabe von $2 \mu \mathrm{l}$ RNase-freier DNase I (Boehringer) 15 min bei $37^{\circ} \mathrm{C}$ verdaut. Die RNA-Sonde wurde mit Hilfe des Reaktionssystems "RNeasy Mini Kit" oder im 96er Maßstab mit Sephadex G50 Säulen aufgereinigt.

\subsubsection{Aufreinigung synthetischer RNA mit "RNeasy Mini Kits"}

Um synthetische RNA von Salzen, Enzymen und Nukleotiden abzutrennen, wurden die Ansätze mit Hilfe des "RNeasy Mini Kits" (Qiagen) aufgereinigt. Der Reaktionsansatz wurde dazu mit RNase-freiem $\mathrm{dH}_{2} \mathrm{O}$ auf ein Gesamtvolumen von $100 \mu$ l aufgefüllt und $350 \mu \mathrm{l}$ Puffer RLT sowie $250 \mu$ Ethanol wurden hinzupipettiert. Nach dem Mischen wurde die Lösung auf eine RNeasy-Säule übertragen und $15 \mathrm{~s}$ bei $10.000 \mathrm{Upm}$ zentrifugiert. Es wurde zweimal mit je $500 \mu 1$ Puffer RPE gewaschen und die Säule trockenzentrifugiert. Die RNA wurde zweimal mit $15 \mu 1 \mathrm{RNase-freiem} \mathrm{dH}_{2} \mathrm{O}$ in ein frisches Eppendorfgefäß eluiert.

\subsubsection{Aufreinigung synthetischer RNA mit Sephadex-G50 Säulen}

Für die Durchmusterung einer cDNA-Bank aus embryonalem Augengewebe wurde synthetische RNA im 96er Platten Maßstab angefertigt und mit Säulen chromatographisch aufgetrennt. Für die Trennung der synthetischen RNA wurden Plastikplatten mit 96, $2 \mathrm{~cm}$ Vertiefungen, die unten mit einem Celluloseflies abschließen, mehrmals mit DEPC behandeltem Wasser gespült und anschließend mit in G50-Lagerlösung vorgequollenem Sephadex-G50 aufgefüllt. Die G50-Matrix wurde bei 1200 Upm für 30 Sekunden sedimentiert und mit je $50 \mu 1$ 1x STE-Puffer äquilibriert. Nach erneuter Zentrifugation für 2 Minuten bei 1200 Upm wurde eine neue Auffangplatte mit 96 Vertiefungen unter die Säulen gestellt und die Proben (ca. $20 \mu$ l) wurden auf die Säulen geladen. Die Elution erfolgte bei 
1200 Upm für 4 Minuten. Das Eluat wurde sofort mit $25 \mu$ Formamid versetzt. Davon wurden $5 \mu$ für ein $1 \%$ iges Agarosekontrollgel verwendet.

G50-Lagerlösung: $0,3 \mathrm{M} \mathrm{NaCl}, 0,1 \% \mathrm{SDS}, 50 \mathrm{mM}$ Tris $(\mathrm{pH} 7,5)$

10x STE Puffer: $20 \mathrm{mM}$ Tris (pH 7,5), 2 mM EDTA, $50 \mathrm{mM} \mathrm{NaCl}$

\subsubsection{Protein-Standardmethoden}

\subsubsection{Polyacrylamidgelelektrophorese (PAGE)}

SDS-Gele wurden nach Laemmli et al., 1970 gegossen. Sie waren 8 x $10 \mathrm{~cm}$ groß und $1 \mathrm{~mm}$ dick. Durch die Verwendung von zwei aufeinanderfolgenden Gelsystemen (Sammelgel und Trenngel) mit unterschiedlichem Vernetzungsgrad kann ein erhöhter Trenneffekt erzielt werden.

Trenngel: $0,375 \mathrm{M}$ Tris- $\mathrm{HCl}(\mathrm{pH} 8,8)$

$$
\begin{aligned}
& 0,1 \% \text { SDS } \\
& 10 \% \text { Acrylamid } \\
& 0,2 \% \text { Bisacrylamid }
\end{aligned}
$$

\author{
Sammelgel: $\quad 0,125 \mathrm{M}$ Tris- $\mathrm{HCl}(\mathrm{pH} 6,8)$ \\ $0,1 \%$ SDS \\ $5 \%$ Acrylamid \\ $0,2 \%$ Bisacrylamid
}

Die Polymerisation fand in Gegenwart von APS (Ammoniumpersulfat) und TEMED bei Raumtemperatur statt. Die Proben wurden in 20 bis $30 \mu$ SDS-PAGE Proben Puffer verdünnt, 3 min gekocht und vor dem Auftragen auf das Gel 4 min in einer Eppendorf Tischzentrifuge zentrifugiert. Die Elektrophorese erfolgte mit $100 \mathrm{~V}$ und $35 \mathrm{~mA}$, bis das Bromphenolblau die Phasengrenze zum Sammelgel erreichte, dann erfolgte die Trennung bei $300 \mathrm{~V}$ und $35 \mathrm{~mA}$. Als Laufpuffer wurde Laemmli-Puffer $(25 \mathrm{mM}$ Tris $\mathrm{HCl}, 192 \mathrm{mM}$ Glycerin und $1 \%$ SDS) verwendet. Gele für die Trennung von radioaktiv markierten Proteinen wurden auf einem Geltrockner unter Vakuum bei $65^{\circ} \mathrm{C}$ getrocknet und zur Exposition in Kassetten für den Phosphoimager (Molecular Dynamics) eingelegt. Gele für unmarkierte Proteinproben wurden mit Coomassie-Färbelösung $1 \mathrm{~h}$ angefärbt. Die Hintergrundfärbung der Gele wurde durch mehrmaliges Erhitzen auf ca. $60^{\circ} \mathrm{C}$ und wechseln der Entfärbelösung (10 \% Essigsäure und 35 \% Methanol) aus dem Gel herausgewaschen. Das Gel mit den jetzt sichtbaren Proteinbanden wurde dann zwischen zwei Zellglasfolien eingespannt und in einem Heißluftofen der Firma Bio-Rad getrocknet. Zur Dokumentation wurden die Gele mit einem handelsüblichen Scanner eingescannt. 


\section{Proteingrößenstandard für Gele mit unmarkierten Proteinproben "Broad Range}

Marker" (Biorad): Myosin 200 kd, ß-Galactosidase 116,25 kd, Phosphorylase B 97,4 kd, BSA 66 kd, Ovalbumin 45 kd, Carboanhydrase 31 kd, Trypsininhibitor 21,5 kd, Lysozym $14,3 \mathrm{kd}$

\section{Proteingrößenstandard für Gele mit radioaktiv markierten Proteinproben ${ }^{14} \mathrm{C}$ -} methyliert: ( $5 \mu \mathrm{Ci} / \mathrm{ml}$, Amersham): Myosin 200 kd, Phosphorylase B 97,4 kd, BSA 69 kd, Ovalbumin 46 kd, Carboanhydrase 30 kd, Lysozym 14,3 kd (0,833 $\mu \mathrm{Ci} / \mathrm{ml}$ Protein)

\subsubsection{Expression von GST-Fusionsproteinen}

Für Interaktionsstudien von Transportfaktoren und verschiedenen Substraten wurden die jeweiligen Gene in den pGex5x3 bzw. pGex5x1 kloniert. Beide Expressionsvektoren besitzen direkt hinter der kodierenden Sequenz von GST eine MCS. Für die Expression der GSTFusionsproteine wurden BL21 (DE3) Zellen verwendet. Zur Induktion der Expression wurde dem Medium 1mM IPTG hinzugefügt. Mit einer frischen Einzelkolonie wurden $10 \mathrm{ml}$ Vorkultur in einem $12 \mathrm{ml}$ PPN-Röhrchen (Greiner) mit LB/Ampicillin und $2 \%$ Glucose inokuliert und in einem Rundschüttelinkubator (New Brunswick Scientific, Edison, NY, USA) bei $37{ }^{\circ} \mathrm{C}$ über Nacht inkubiert. Am nächsten Morgen wurden $100 \mathrm{ml} \mathrm{LB} /$ Ampicillin mit $10 \mathrm{ml}$ der Vorkultur angeimpft und bis zur logarithmischen Wachstumsphase $\mathrm{OD}_{550}=0,7$ unter Schütteln bei $37^{\circ} \mathrm{C}$ angezogen. Durch Zusatz von $1 \mathrm{mM}$ IPTG (200 mM Stocklösung) wurde die Expression der GST-Fusionsmutanten gestartet. Nach weiterer Kultivierung für $3 \mathrm{~h}$ bei $30^{\circ} \mathrm{C}$ wurden die Zellen geerntet und bei $5000 \mathrm{Upm}$ in einer Sorvall CL6B-Kühlzentrifuge mit GSA-Rotor (DuPont, Bad Homburg) 10 min pelletiert. Die Zellen wurden in Z-Puffer mit $1 \mu \mathrm{g} / \mathrm{ml}$ Pepstatin A (Stocklösung: $1 \mathrm{mg} / \mathrm{ml}$ in EtOH), $10 \mu \mathrm{g} / \mathrm{ml}$ Aprotinin (Stocklösung: 10 $\mathrm{mg} / \mathrm{ml}$ in $\mathrm{H}_{2} \mathrm{O}$ ), $1 \mu \mathrm{g} / \mathrm{ml}$ Leupeptin (Stocklösung: $1 \mathrm{mg} / \mathrm{ml}$ in $\mathrm{H}_{2} \mathrm{O}$ ), $1 \mathrm{mM}$ PMSF (frische Stocklösung: $1 \mathrm{M}$ in Isopropanol) und $1 \mathrm{mM}$ DTT resuspendiert. Alternativ zu den einzelnen Proteaseinhibitoren wurde eine Tablette „Complete, EDTA-free“ (ein Proteasen-InhibitorenGemisch der Firma Roche) auf $50 \mathrm{ml}$ Puffer verwendet. Bei einem Resuspensionsvolumen von $5 \mathrm{ml}$ erfolgte die Zugabe von $1 \mathrm{ml}$ Lysozym $(10 \mathrm{mg} / \mathrm{ml}$ frisch angesetzt in 10mM Tris, $\mathrm{pH}$ 8,0), $2 \mu \mathrm{l}$ DNase und $5 \mu \mathrm{l}$ RNase. Nach einer Inkubation von 30 - 60 Minuten auf Eis wurden die Zellen durch Sonifikation (Leistung 3, Puls 60, 4x 30 s) auf EtOH-Eis aufgeschlossen. Die Zelltrümmer wurden durch Zentrifugation bei 10 g (12000 Upm, Sorvall CL6B-Kühlzentrifuge, SS43 Rotor) pelletiert, der Überstand in $2 \mathrm{ml}$ Aliquots aufgeteilt, mit flüssigem $\mathrm{N}_{2}$ Schockgefroren und bis zur Verwendung bei $-70{ }^{\circ} \mathrm{C}$ gelagert. 


\subsubsection{TFIIIA Induktion}

Die Induktion der TFIIIA-GST-Fusionsmutante erfolgte mit $1 \mathrm{mM}$ IPTG und zusätzlich 100 $\mu \mathrm{M} \mathrm{ZnSO}_{4}$.

\subsubsection{Präparation von Glutathion Agarose und Bindungsprotein}

Für die Herstellung von GST-Pellets wurden 20 mg GT-Agarose (Sigma, G4510) pro $100 \mathrm{ml}$ Kulturvolumenäquivalent in $2 \mathrm{ml}$ Z-Puffer pro $10 \mathrm{mg}$ GT-Agarose 1 Stunde bei $4{ }^{\circ} \mathrm{C}$ rotiert. Die aufgequollene GT-Agarose wurde 1 Minute bei $800 \mathrm{Upm}$ und $4{ }^{\circ} \mathrm{C}$ abzentrifugiert und zweimal mit Z-Puffer gewaschen, bevor geeignete Mengen an E. coli Proteinextrakt hinzugefügt wurden. Das Gesamtvolumen wurde mit Z-Puffer (1mM DTT und Proteaseinhibitoren) auf 0,5-1 ml eingestellt. Nach $2 \mathrm{~h}$ Rotation bei $4^{\circ} \mathrm{C}$ wurden die Pellets zweimal mit Bindungspuffer gewaschen und in 1,5 ml Mikroreaktionsgefäße aliquotiert. Je ein Ansatz der aliquotierten Pellets wurde für eine Kontrolle der GST-Fusionsproteinbindung an die GT-Agarose verwendet.

\subsubsection{5 „Pull-down assay" für in vitro translatierte Proteine}

Den Pellets aus 2.2.3.2 wurde $1 \mathrm{ml}$ Bindungspuffer mit $1 \mathrm{mM}$ DTT, Proteinaseinhibitoren und $2 \mathrm{mg} / \mathrm{ml} \mathrm{BSA}$ hinzugefügt. Nach Zugabe von normierten Mengen an in vitro TNT-Ansätzen wurden die Bindungsansätze 1 Stunde bei $4{ }^{\circ} \mathrm{C}$ rotiert. Die Pellets wurden sechsmal mit Bindungspuffer gewaschen, bevor die gebundenen Proteine in $20 \mu$ SDS-PAGE Proben Puffer gelöst wurden. Die Proben wurden bei $100{ }^{\circ} \mathrm{C}$ für 5 Minuten gelöst, abzentrifugiert und der Überstand auf ein 10 \%iges Polyacrylamidgel auftragen.

\subsubsection{Fluoreszenzdetektion von transient transfizierten HeLa Zellen}

Zwei Tage nach der Transfektion erfolgte die Detektion der Genprodukte. Die adhärent auf den Glasplättchen gewachsenen Zellen wurden zweimal in 6-Well-Kulturschalen mit PBSPuffer gewaschen und mit $3 \mathrm{ml} 3 \%$ Paraformaldehyd in PBS für 10 Minuten bei RT fixiert. Nachdem die Zellen zwei mal mit $5 \mathrm{ml}$ PBS gewaschen wurden, erfolgte eine Inkubation mit $3 \mathrm{ml} 0,5 \%$ Triton X-100 in PBS für 10 Minuten bei RT. Die Tritonlösung wurde durch zweimaliges Waschen mit $5 \mathrm{ml}$ PBS entfernt. Anschließend wurden unspezifische Bindungsstellen durch Inkubation in $3 \mathrm{ml} 3 \%$ Bovine Albumin Fraktion $\mathrm{V}$ in PBS (Blocklösung) für 10 Minuten bei RT abgedeckt. Um Verdunstung der Reaktionslösungen während der Antikörperinkubationen zu verhindern, erfolgte eine Überführung der Deckgläser in eine feuchte Inkubationskammer. Der Primär-Antikörper wurde in einer 
Verdünnung von 1:1000 in Blocklösung für $1 \mathrm{~h}$ bei $37^{\circ} \mathrm{C}$ mit einem Volumen von $100 \mu \mathrm{l}$ auf die Zellen gegeben. Nach erneutem zweimaligem Waschen mit PBS erfolgte die Inkubation mit dem sekundären Carboxymethylindocyanin (Cy3) gekoppeltem Antikörper in einer Verdünnung von 1:200. Nach zweimaligem Waschen mit PBS wurden die Zellen in DAPIEinbettungsmedium auf einem Objektträger eingebettet und die Kanten der Glasplättchen mit Nagellack versiegelt. Nachdem der Nagellack ausgehärtet war, erfolgte die Visualisierung am Fluoreszenzmikroskop (Axioplan 2). Das Anregungsmaximum von Cy3 liegt bei $553 \mathrm{~nm}$, das Emissionsmaximum im Bereich der roten Farbe bei $575 \mathrm{~nm}$. Die Zellkerne wurden durch den DNA-bindenden DAPI-Farbstoff sichtbar gemacht.

\subsubsection{Bakterien und Zellkultur}

\subsubsection{Elektrokompetente Zellen}

Die verschiedenen E. coli Stämme wurden auf nicht selektivem Minimal- oder LB-Agar ausplattiert und 16 Stunden bei $37^{\circ} \mathrm{C}$ inkubiert. Von einer Einzelkolonie wurden $5 \mathrm{ml}$ LBMedium beimpft und 16 Stunden bei $37^{\circ} \mathrm{C}$ inkubiert. Mit dieser Vorkultur wurden $800 \mathrm{ml}$ LB-Medium in einem sterilen Erlenmeyerkolben beimpft und bei $37^{\circ} \mathrm{C}$ und $200 \mathrm{rpm}$ geschüttelt, bis die Kultur zu einer $\mathrm{OD}_{600}$ von 0,7 angewachsen war. Die Zellen wurden dann im Eisbad gekühlt und bei $5000 \mathrm{rpm}$ 10min zentrifugiert (Sorvall CL6B-Kühlzentrifuge mit GSA-Rotor DuPont, Bad Homburg). Die Zellen wurden mehrmals mit 10\%igem sterilen Glycerin gewaschen und konzentriert. Für die Waschschritte wurde 1 Volumen, 1/2 Volumen und 1/20stel des Ausgangsvolumens eingesetzt. Die Zellen wurden nach den Waschgängen in

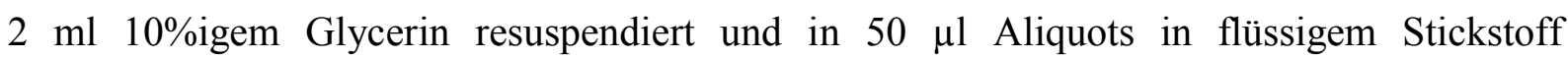
schockgefroren. Die Zellen wurden bis zu ihrer Verwendung bei $-70^{\circ} \mathrm{C}$ aufbewahrt.

\subsubsection{Elektrotransformation}

Die Zellsuspension wurde auf Eis aufgetaut und mit 1/5 Volumen des Ligationsansatzes versetzt. Nach Resuspension wurde der Transformationsansatz luftblasenfrei in Elektroporationsküvetten (Eurogentech) mit einem Elektrodenabstand von $1 \mathrm{~mm}$ überführt. Die Suspension wurde vollständig auf den Küvettenboden zwischen die beiden AluminiumElektroden mit einem Abstand von $2 \mathrm{~mm}$ geklopft. Die Küvette wurde verschlossen in das Elektrotransformationsgerät („E. coli Pulser“, BIORAD Laboratories GmbH München) 
gestellt. Der Strompuls erfolgte bei $2,5 \mathrm{kV}, 25 \mu \mathrm{F}$ und $200 \Omega$ parallel zur Probe. Die Pulsdauer lag zwischen 4,0 und 4,9 ms. Unmittelbar nach erfolgtem Strompuls wurden die transformierten Bakterien mit $500 \mu 1$ LB-Medium aus der Küvette herausgespült und in ein $1,5 \mathrm{ml}$ Eppendorf-Mikroreaktionsgefäß überführt. Die Zellen wurden 15-30 min unter Schütteln bei $37^{\circ} \mathrm{C}$ inkubiert. Auf Selektiv-LB-Agar wurden 50-100 $\mu 1$ ausplattiert und 12-16 Stunden bei $37^{\circ} \mathrm{C}$ inkubiert.

\subsubsection{3 alpha-Komplementation}

Pro Selektiv-Platte (LB-Agar, $100 \mu \mathrm{g}$ Ampicillin/ml) wurde ein Mix aus $30 \mu 1$ IPTG-Lösung und $30 \mu \mathrm{l}$ X-Gal-Lösung ausplattiert. Nach einer Stunde wurden $50 \quad \mu 1$ des Transformationsansatzes auf den Platten ausplattiert. Nach 16 Stunden Inkubationszeit wurden die weißen Kolonien, welche ein Insert aufgenommen hatten und somit das lacZ-Gen des Vektors unterbrochen hatten, mit sterilen Zahnstochern in $3 \mathrm{ml}$ Vorkultur überführt.

IPTG-Lösung: $0,24 \mathrm{~g}$ IPTG / $10 \mathrm{ml} \mathrm{H} \mathrm{H}_{2} \mathrm{O}$ nach Sterilfiltration in $1 \mathrm{ml}$ Aliquots bei $-20^{\circ} \mathrm{C}$ gelagert.

X-Gal-Lösung: 2 \% 5-Chlor-4-Brom-3-Indodyl-b-D-Galactosid in Dimethylformamid gelöst und bei $-20^{\circ} \mathrm{C}$ gelagert.

\subsubsection{Gewinnung von HeLa Zellen für transiente Transfektion}

Um Zellen für Tranfektionen zu gewinnen, wurden zwei Tage alte HeLa-Zellkulturen in 250 $\mathrm{ml}$ Kulturschalen einmal mit $5 \mathrm{ml}$ PBS gewaschen und mit $2 \mathrm{ml}$ Trypsin-Lösung $(0,05 \%$ Trypsin $\mathrm{w} / \mathrm{v}$ und $0,2 \%$ EDTA w/v in PBS, Biochrom KG, Berlin), versetzt. Unter leichten Schwenken wurden die Zellen 2 Minuten lang gelöst und 4 Minuten bei 1000 Upm abzentrifugiert. Die Zellen wurden mit $10 \mathrm{ml}$ PBS gewaschen und auf $1 \times 10^{5}$ bis $1 \times 10^{6}$ Zellen pro ml MEM-Medium eingestellt. Die Zellzahl wurde mit einem Zell-Zählgerät CASY 1 (Schärfe System, Reutlingen) bestimmt. Dazu wurde das Gerät 3 mal vorgespült, anschließend wurden $10 \mu 1$ der Zellsuspension in $10 \mathrm{ml}$ Isoton (Schärfe System) ausgezählt.

\subsubsection{Transiente Transfektion von HeLa Zellen durch Elektroporation}

Durch Elektroporation werden die Zellen, welche DNA aufnehmen sollen, durch einen Stromstoß kurzzeitig permeabilisiert, so dass die Plasmide in die Zelle gelangen können. 20 
$\mu 1$ der zu transfizierenden DNA wurden in einer Konzentration von $0,5 \mu \mathrm{g} / \mu 1 \mathrm{zu} 5 \times 10^{4}$ bis $5 \times 10^{5}$ Helazellen in $500 \mu 1$ MEM-Medium in eine Elektroporationsküvette mit $4 \mathrm{~mm}$ Elektrodenabstand gegeben. Die Elektroporation erfolgte bei $240 \mathrm{~V}$ mit einer Kapazität von $1350 \mu \mathrm{F}$ und einem Ableitungswiderstand von 156 Ohm (Schwamborn, 1998). Lag die Pulsdauer über $20 \mathrm{~ms}$ und die Differenz von Ableitungswiderstand (gemessen) zum Impulswiderstand bei mindestens $25 \mathrm{kOhm}$, wurden die Zellen nach Zugabe von $2 \mathrm{ml}$ MEMMedium auf 4 bis 5 mit UV-Licht sterilisierten Glasplättchen in Kulurschalen (6 Vertiefungen) mit $3 \mathrm{ml}$ vorgelegtem MEM-Medium ausgebracht. Die Zellen wurden bei $37^{\circ} \mathrm{C}$ unter $5 \% \mathrm{CO}_{2}$ Begasung (v/v) inkubiert. Nach $24 \mathrm{~h}$ wurde das Medium mit den toten Zellen abgesaugt. Die Zellen wurden mit $5 \mathrm{ml}$ PBS gewaschen und in MEM-Medium weitere $24 \mathrm{~h}$ inkubiert. Dann wurde die immunologische Fluoreszenzdetektion des Genprodukts der transient mit Plasmiden transfizierten HeLa Zellen wie in 2.2.3.6 durchgeführt.

\subsubsection{Transiente Transfektion von HeLa Zellen durch Lipofektion}

Einführung von DNA mit bis zu $130 \mathrm{~kb}$ in die Zellen mit Liposomen ist ein Verfahren bei dem 0,025 bis $5 \mu \mathrm{m}$ große Phospholipidvesikel mit DNA beladen werden, und die dann bei der Transfektion mit der Zellmembran der Zielzelle fusionieren und ihren Inhalt in das Cytoplasma freisetzen. Wie die DNA in den Zellkern gelangt ist z.Z. noch ungeklärt.

Für die Transfektion wurden am Vortag $5 \times 10^{4} \mathrm{HeLa}$ Zellen auf 4 bis 5 Glassplätchen mit 1 cm Durchmesser in Kulturschalen ausgesäht. Die Zellen wurden einmal mit Medium

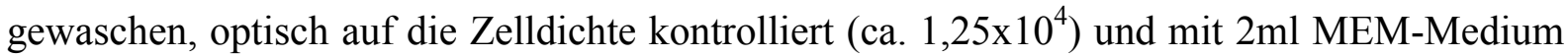
überschichtet. Um die Liposomen zu beladen, wurden $94 \mu$ 1 serumfreies MEM-Medium mit 6 $\mu 1$ Fugene 6 für 5 Minuten bei RT vorinkubiert. Diese Suspension wurde tropfenweise auf die in einem zweiten Mikroreaktionsgefäß vorgelegte DNA $(2 \mu 1,1 \mu \mathrm{g} / \mu \mathrm{l})$ gegeben. Nach 15 Minuten Inkubation bei RT wurden die beladenen Liposomen auf die adhärent auf Glasplättchen gewachsenen Zellen gegeben. Das Medium wurde nach 6 bis 10 h Inkubation bei $37^{\circ} \mathrm{C}$ und $5 \% \mathrm{CO}_{2}(\mathrm{v} / \mathrm{v})$ gewechselt. Nach weiteren $24 \mathrm{~h}$ Inkubation bei $37^{\circ} \mathrm{C}$ wurden die Zellen mit PBS gewaschen und das Genprodukt wie unter 2.2.3.6 beschrieben nachgewiesen.

\subsubsection{Erstellung einer Lamda-cDNA-Bank aus embryonalem Augengewebe}

Zur Erstellung der cDNA-Bank aus embryonalem Augengewebe wurde poly- $\mathrm{A}^{+}$-RNA wie unter 2.2.2.4 angegeben weiterverwendet. Für die Synthese der cDNA und die anschließende Größenfraktionierung, die Überführung in Phagen und folgendem Transfer in Bakterien wurde streng nach Herstellerprotokoll verfahren. Verwendet wurde das ZAP Express cDNA 
Synthesis Kit und das Gigapack III Gold Cloning Kit von Stratagene in der Revision \#200403-12.

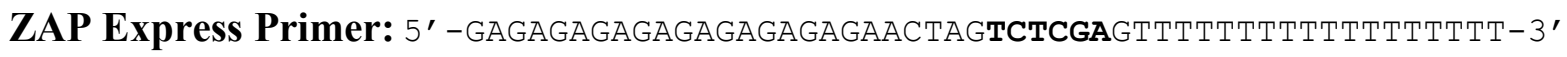

ZAP Express Linker: 5'-OH-AATTCGGCACGAGG-3'

3'-GCCGTGCTCCP-5'

Vorgehensweise: Die Erststrangsynthese erfolgte auf poly- $\mathrm{A}^{+}-\mathrm{RNA}$, die wie in 2.2.2.4 angegeben isoliert wurde, in einer RT-Reaktion mit einem Primer der in 5' $\rightarrow$ 3' Orientierung GA-Sequenzwiederholungen gefolgt von einer Xho I Schnittstelle und einer 18 Basen langen poly dT Sequenz enthält. Der verwendete Nukleotidmix enthielt 5-Methyl-dCTP. In der Zweitstrangsynthese wird dem Ansatz RNase H in geringer Konzentration zugegeben, so dass mehrere Unterbrechungen der an den Erststrang gebundenen RNA entstehen. Die Fragmente dienen der Polymerase I als Primer für die Zweitstrangsynthese („Nick“-Translation). In der Zweitstrangsynthese wird dem Ansatz dCTP zugesetzt, um den Einbau von 5-Methyl-dCTP zu reduzieren. Anschließend wurden die Enden des hemimethylierten DNA Doppelstrangs mit Pfu DNA Polymerase geglättet. Nach Phenol und Phenol / Chloroformextraktion wurde ein Eco RI Oligonukleotid, kompatibel zu einer geschnittenen Eco RI Schnittstelle an die hemimethylierte DNA ligiert. Nach Hitzeinaktivierung der Ligase erfolgte eine Phosphorylierung der Eco RI Enden mit der T4 Polynukleotidkinase. Das Enzym wurde ebenfalls hitzeinaktiviert. Der folgende Xho I Verdau sollte vorwiegend an der Stelle des ersten Primers stattfinden, da nur dort der hemimethylierte Doppelstrang kein 5-Methyl-dCTP enthalten sollte. Die DNA Fragmente mit Xho I und Eco RI kompatiblen überhängenden Enden wurden über eine CL-2B Sepharose (in STE-Puffer) Säule größenfraktioniert, Phenol / Chloroform extrahiert und gefällt. Das luftgetrockene Pellet wurde in $5 \mu \mathrm{ll} \mathrm{dH}_{2} \mathrm{O}$ aufgenommen. Die Fraktionen mit den gewünschten cDNA Fragmenten wurden durch Auftropfen eines $0,5 \mu \mathrm{l}$ Aliquots auf $0,8 \%$ Agarose mit $1 \mathrm{ng} / \mathrm{ml}$ Ethidiumbromid und anschließender Transillumination unter UV-Licht im Vergleich zu einem Standard identifiziert und quantifiziert. Die erhaltenen Mengen (weniger als $10 \mathrm{ng} /$ Fraktion) wurden über Nacht in einem $5 \mu$ Ansatz bei $12^{\circ} \mathrm{C}$ in den pBK-CMV Phagemid Vektor ligiert. Je ein Aliquot von $3 \mu 1$ des Phagemidvektors wurde in die Hüllproteine von Phagen verpackt (2 Stunden, $22^{\circ} \mathrm{C}$ ). Mit den Phagen wurden XL1Blue MRF' Zellen wie unter 2.2.6.1 infiziert. 


\subsubsection{Arbeiten mit Phagen}

\subsubsection{Phagenfraktionierung}

Für dieses Verfahren wurden $5 \mathrm{ml} \mathrm{LB}$, Tetracyclin 12,5 $\mu \mathrm{g} / \mathrm{ml}, 0,2 \%$ Maltose, $10 \mathrm{mM}$ $\mathrm{MgSO}_{4}$ mit einer XL1Blue MRF' Einzelkolonie von einer frischen Kulturplatte inokuliert. Nach $12 \mathrm{~h}$ Inkubation der Vorkultur bei $37^{\circ} \mathrm{C}$ wurden $20 \mathrm{ml} \mathrm{LB}, 0,2 \%$ Maltose, $10 \mathrm{mM}$ $\mathrm{MgSO}_{4}$, Tetracyclin $12,5 \mu \mathrm{g} / \mathrm{ml}$ mit $20 \mu \mathrm{l}$ der frischen Vorkultur inokuliert und bei $37^{\circ} \mathrm{C}$ bis $\mathrm{zu}$ einer $\mathrm{OD}_{600}=1$ inkubiert. Die Kultur wurde in $10 \mathrm{mM} \mathrm{MgSO}_{4}$ auf eine $\mathrm{OD}_{600}$ von 0,5 eingestellt und bis zur Verwendung (maximal 2 Tage) bei $4^{\circ} \mathrm{C}$ gelagert. Für die Phagenanheftung wurden 2,5 $\mu 1$ und $25 \mu$ l einer Phagenverdünnung von 1:100 und 1:1000 auf $200 \mu 1$ SM Puffer gegeben, mit $200 \mu 1$ der eingestellten XL1Blue MRF' Zellen versetzt und für 15 Minuten bei $37^{\circ} \mathrm{C}$ mit $80 \mathrm{Upm}$ geschwenkt. Nach Aufnahme der Zellen in 7,6 ml NZY wurden sie zu je $100 \mu 1$ auf 96-er Mikrotiterplatten aliquotiert und über Nacht bei $37^{\circ} \mathrm{C}$ und 100 Upm geschwenkt. Die Identifikation von Fraktionen mit durch den Verdünnungsschritt angereichertem Phagenmaterial erfolgte durch PCR-Analyse mit geeignet niedriger Zyklenzahl. Um die Fraktionen mit dem anzureicherndem Phagenmaterial zu identifizieren, wurden zunächst die Vereinigungen (Pool) aus 8 Reihen einer Platte für eine PCR-Analyse eingesetzt. Von den vereinigten Fraktionen, die ein positives Signal in der Analyse zeigten, wurde eine PCR-Analyse der Einzelfraktionen vorgenommen. Positive Einzelfraktionen wurden zur Konservierung der Phagen mit $5 \mu$ Chloroform versetzt, gemischt und, um die Zelltrümmer und Bakterien abzutrennen, kurz anzentrifugiert. Die obere phagenhaltige Phase wurde in 1:100 oder nach mehreren Anreicherungsschritten auch in einer 1:1000 Verdünnung für eine weitere Amplifikationsrunde eingesetzt.

Ansatz (1x) für eine PCR-Analyse auf Phagen:

$2,3 \mu 110 \times$ PE-Puffer (Perkin Elmar)

$1,8 \mu \mathrm{dNTP} 2,5 \mathrm{mM}$

$3,4 \mu 1$ Primer $1(1 \mathrm{pmol} / \mu \mathrm{l})$

$3,4 \mu 1$ Primer $2(1 \mathrm{pmol} / \mu \mathrm{l})$

$11,1 \mu 1 \mathrm{H}_{2} \mathrm{O}$

$0,1 \mu 1$ Ampli-Taq-Polymerase (Perkin Elmer)

$0,5 \mu$ l Phagenlösung

$22,5 \mu 1$ Ansatz

PCR-Programm: $2 \min 96^{\circ} \mathrm{C}$, dann 42 Zyklen: $1 \min 96^{\circ} \mathrm{C}, 45 \mathrm{~s} 48^{\circ} \mathrm{C}, 30 \mathrm{~s} 72^{\circ} \mathrm{C}$, abschließend $2 \min 72{ }^{\circ} \mathrm{C}$ 


\subsubsection{Phagenplattierung zur Isolierung von Einzelplaques}

Für die Isolierung einer homogenen Phagenpopulation wurden $2 \mu 1$ einer Phagenverdünnung von 1: $10^{3}, 10^{4}, 2 \times 10^{3}$ oder $2 \times 10^{4}$ in $200 \mu \mathrm{l}$ SM Puffer aufgenommen und mit $200 \mu 1$ vorbereiteter XL1Blue MRF' Zellen $\mathrm{OD}_{600}=0,5$ (siehe 2.2.6.1) versetzt. Nach 15 Minuten Inkubation bei $37^{\circ} \mathrm{C}$ und $80 \mathrm{Upm}$ wurden die Zellen mit $3 \mathrm{ml}$ Topagar $\left(48^{\circ} \mathrm{C}\right)$ versetzt, durch rollen gemischt und auf RT vorgewärmte NZY-Agarplatten $(\mathrm{d}=9.5 \mathrm{~cm})$ gegeben, durch Schwenken gleichmäßig verteilt und nach erstarren des Topagars über Nacht bei $37^{\circ} \mathrm{C}$ inkubiert. Einzelne Phagenplaques von ca. $1 \mathrm{~mm}$ Durchmesser wurden mit der Spitze einer Pasteurpipette ausgestochen und in je $100 \mu \mathrm{SM}$-Puffer überführt und bei $4^{\circ} \mathrm{C}$ über Nacht geschwenkt. Die Plaque-Suspensionen wurde durch PCR getestet. Positive Einzelplaques wurden nach Zugabe von $50 \mu \mathrm{l}$ Chloroform bei $4{ }^{\circ} \mathrm{C}$ in $1,5 \mathrm{ml}$-Eppendorfgefäßen gelagert. Um die Reinheit des Phagen sicherzustellen, wurden Aliquots der positiven Einzelphagensuspension erneut ausplattiert und ausgestochen. Da die ausgestochenen Phagenplaques in der PCR erneut positiv waren, wurde davon ausgegangen, dass ein homogener Klon vorlag.

\subsubsection{Erstellen einer konzentrierten Phagenlösung}

Für die Exzision eines Phagemids samt cDNA-Insertionsfragment aus einem Phagen wurde eine hohe Konzentration des Phagen („high titer“) benötigt. Dazu wurden solche Phagenmengen plattiert, die ein konfluentes Wachstum der Phagenklone erzielten. Zur Isolierung der Phagen aus dem Agar wurden $15 \mathrm{ml}$ SM-Puffer auf den Top-Agar einer Platte gegeben. Um die Phagen zu lösen, wurden die Platten $3 \mathrm{~h}$ bei RT geschwenkt und der Überstand in ein $15 \mathrm{ml}$ Falcongefäß (Falcon 2096) überführt. Nach Zugabe von $450 \mu 1$ Chloroform wurde der Ansatz gemischt und über Nacht bei $4^{\circ} \mathrm{C}$ gelagert. Die Röhrchen wurden für 10 Minuten bei $10.000 \mathrm{Upm}$ zentrifugiert und der Überstand in neue Gefäße überführt. Nach Zugabe von Chloroform zu einer Endkonzentration von 0,3\% wurde der Phagenüberstand bei $4^{\circ} \mathrm{C}$ gelagert.

\subsubsection{Exzision des Phageninserts}

Zur der Exzision des Phageninserts wurden XL1Blue MRF' Zellen wie unter 2.2.6.1 beschrieben vorbereitet. Für die verwendeten XLOLR-Zellen wurde am Vortag NZY Medium mit einer Einzelkolonie inokuliert. Aus der Übernachtkultur wurde eine Hauptkultur angeimpft und bis zum Erreichen von einer $\mathrm{OD}_{600}=1$ kultiviert. In einem 12 ml-PPN- 
Röhrchen wurden $200 \mu \mathrm{l}$ der XL1Blue MRF' Zellsuspension in $10 \mathrm{mM} \mathrm{MgSO} 4$ zusammen mit $250 \mu \mathrm{l}$ der konzentrierten Einzelphagensuspension (2.2.6.3) und $1 \mu 1$ ExAssistHelferphage 15 Minuten bei $37^{\circ} \mathrm{C}$ unter Schwenken inkubiert. Nach Zugabe von $3 \mathrm{ml}$ LBFlüssigmedium wurde $2,5 \mathrm{~h}$ bei $37^{\circ} \mathrm{C}$ geschüttelt. Hierbei wurde ein definierter Bereich des Phagen, welcher die inserierte cDNA enthielt, vom filamentösen M13 Helferphagen einzelsträngig amplifiziert, zirkularisiert und als Phagemid verpackt aus dem Wirtbakterium ausgeschleust. Zum Abtöten des Wirtsbakteriums wurde anschließend der Ansatz für 15 Minuten auf $70^{\circ} \mathrm{C}$ erhitzt, die Bakterien abzentrifugiert und der Phagemid-Überstand in ein neues 12 ml-PPN-Röhrchen überführt. Um den XLOLR E. coli Stamm mit dem Phagemid zu infizieren, wurden $10 \mu 1$ oder $100 \mu 1$ Phagemid-Überstand mit $200 \mu 1$ frischen XLOLR-Zellen $\left(\mathrm{OD}_{600}=1.0\right.$ in NZY-Medium) 15 Minuten bei $37^{\circ} \mathrm{C}$ geschwenkt. Nach Zugabe von $300 \mu 1$ LB-Medium wurde für weiter 45 Minuten unter Schwenken bei $37^{\circ} \mathrm{C}$ inkubiert. Aus jedem Ansatz wurden 2 × $200 \mu$ l auf LB-Agarplatten mit Kanamycin ausplattiert und über Nacht bei $37^{\circ} \mathrm{C}$ inkubiert. Mit den erhaltenen Einzelkolonien wurden Flüssigkulturen angeimpft und das isolierte Plasmid mit der gesuchten cDNA amplifiziert.

\subsubsection{Bestimmung des Phagentiters}

Zur Bestimmung des Titers einer Phagensuspension wurde in SM-Puffer eine Verdünnungsreihe der Phagen erstellt $\left(10^{-1}-10^{-10}\right)$. Diese Verdünnungen wurden auf NZYAgarplatten wie oben beschrieben ausplattiert und bei $37^{\circ} \mathrm{C}$ über Nacht inkubiert. Die entstandenen Plaques (plaque forming units $=$ pfu) wurden ausgezählt und auf die unverdünnte Phagensuspension hochgerechnet (pfu/ml).

SM-Puffer: 10 mM Tris- $\mathrm{HCl}$ (pH 7.5), 8 mM MgSO $4,100 \mathrm{mM} \mathrm{NaCl}, 0.01 \%$ Gelatine, sterilfiltriert $(0.45 \mu \mathrm{m})$ 


\subsubsection{Gewinnung von Xenopus laevis Embryonen}

\subsubsection{Stimulation der Eiablage, Befruchtung und Gewinnung von Embryonal- stadien}

Da die natürliche Pigmentierung von Xenopus laevis die Detektion schwacher Signale in der in situ Hybridisierung unterdrücken würde, wurden Albino-Frösche für die Präparation von Oocyten oder Embryonalstadien verwendet. Um die Frösche künstlich zum Laichen zu stimulieren wurde zu folgenden Zeiten HCG (humanes chorionisches Gonadotropin) in einem Volumen von bis zu $400 \mu 1$ in den abdominal gelegenen dorsalen Lymphsack des Frosches injiziert: $18^{00} 50$ Units (Stock 500 Units/ml) HCG, $24^{00} 500$ Units (Stock 2000 Units/ml) HCG. Nach weiteren acht Stunden konnte mit dem Beginn des Ablaichens gerechnet werden. Zur Vorbereitung wurde von einem männlichen Frosch das Testisgewebe präpariert und auf Eis in 1x MBS bis zur weiteren Verwendung gelagert. Der Frosch wurde durch Massage des dorsalen Lymphsacks zum Ablaichen stimuliert und die Eier in einer Petrischale aufgefangen. Anschließend wurde vorhandenes Spritzwasser abgesaugt. Ein Hodenstück wurde auf Eis in $100 \mu 11$ x MBS mazeriert. Um die Motilität der Spermien zu induzieren, wurde durch Zugabe von $900 \mu \mathrm{l} \mathrm{H}_{2} \mathrm{O}$ der Puffer auf 0,1 x MBS eingestellt. Anschließend wurde die Hodensuspension in mehreren $100 \mu 1$ Portionen mit einer abgeschnittenen $1 \mathrm{ml}$ Pipettenspitze zur Befruchtung über die Eier gegeben. Nach 5 Minuten RT wurden die Eier mit 0,1 x MBS übergossen und weitere 55 Minuten bei RT inkubiert. Durch Inkubation für ca. 3 Minuten in 2 \% Cystein wurde die Gallerthülle der befruchteten Eier entfernt. Anschließend wurden die Embryonen fünfmal mit $0,1 \mathrm{x}$ MBS gewaschen und mit $0,01 \%$ Nilblauchlorid 5 bis 10 Minuten gefärbt. Der ungebundene Farbstoff wurde durch dreimaliges Waschen mit $0,1 \mathrm{x}$ MBS entfernt, und die Embryonen wurden bei $16-18{ }^{\circ} \mathrm{C}$ inkubiert, bis das gewünschte Stadium erreicht war. Um Infektionen zu verhindern, wurde bei der Gewinnung von späteren Stadien zum MBS am zweiten Tag Penicillin / Streptomycin (1:10000) zugesetzt. Die Stadien 16 bis 26 wurden durch Behandlung mit Proteinase K von ihrer Vitellinmembran befreit. Hierzu wurden die Embryonen in $20 \mathrm{ml} \mathrm{0,1} \mathrm{x} \mathrm{MBS} \mathrm{überführt} \mathrm{und} \mathrm{mit} 5 \mu$ einer 20 $\mathrm{mg} / \mathrm{ml}$ Proteinase K Lösung (Merck) versetzt (Endkonzentration $10 \mu \mathrm{g} / \mathrm{ml}$ ). Der Verdau wurde unter einem Binokular kontrolliert. Währenddessen wurde die Vitelinmembran mit Pinzetten entfernt. Die Embryonen wurden dann mehrmals mit 0,1 x MBS gewaschen. Zur

Fixierung wurden die Embryonen anschließend in frischem MEMFA für $1 \mathrm{~h}$ in $5 \mathrm{ml}$ Glasröhrchen auf einem Drehrad bei Raumtemperatur inkubiert, in 100 \% Ethanol entfärbt und bei $-20{ }^{\circ} \mathrm{C}$ in $100 \%$ Ethanol bis zur Verwendung gelagert. 
Benötigte Lösungen: 0,1 x MBS

$1 \times \mathrm{MBS}$

$2 \%(\mathrm{w} / \mathrm{v})$ Cysteinhydrochlorid $\mathrm{pH} 8.0$

MBS (5x): $\quad 88 \mathrm{ml} \mathrm{5M} \mathrm{NaCl}$

$12 \mathrm{ml} 1 \mathrm{M} \mathrm{NaHCO}$

$5 \mathrm{ml} 1 \mathrm{M} \mathrm{KCl}$

$50 \mathrm{ml} 1 \mathrm{M}$ HEPES $\mathrm{pH}$ 7,4

$4,1 \mathrm{ml} 1 \mathrm{M} \mathrm{MgSO}_{4}$

$800 \mathrm{ml} \quad \mathrm{H}_{2} \mathrm{O}$

$2,0 \mathrm{ml} 1 \mathrm{M} \mathrm{CaCl}_{2}$

$3,3 \mathrm{ml} 1 \mathrm{M} \mathrm{KNO}_{3}$

ad 11 sterilfiltrieren

MEM (10 x): 1 M MOPS, $20 \mathrm{mM}$ EGTA, $10 \mathrm{mM} \mathrm{MgSO}_{4}$

MEMFA (1 x): 1 x MEM, 3.7 \% Formaldehydlösung

\subsubsection{Fixierung von Xenopus Embryonen}

Waren die Embryonen für "whole mount" in situ Färbungen bestimmt, wurden sie in $5 \mathrm{ml}$ Schraubdeckelglasröhrchen auf einer Wippe für eine Stunde in 1 x MEMFA fixiert und anschließend in $100 \%$ Ethanol bei $-20^{\circ} \mathrm{C}$ gelagert. Wurde eine größere Anzahl an Embryonen benötigt, konnten sie wie unter 2.2.8.1 bis 2.2.8.3 beschrieben bis zur Prähybridisierung vorbereitet und bis zu zwei Monate verwendet werden.

\subsection{8 „Whole mount" in situ Hybridisierung}

Um die räumliche und zeitliche Expression von Genen zu analysieren, wurde die endogene mRNA von Xenopus-Embryonen oder Oocyten in situ mit komplementären, Digoxigeninmarkierten ,antisense"-RNA (Gegenstrang-RNA) Sonden hybridisiert und in einer Färbereaktion detektiert. Zur Kontrolle der Spezifität wurde markierte "sense"-RNA eingesetzt. Für die Durchmusterung der cDNA-Bank aus embryonalem Augengewebe wurden die Embryonen nach der Prähybridisierung 2.2.8.3 bis zum Start der Färbereaktion maschinell behandelt.

\subsubsection{Rehydrieren der Embryonen}

Soweit nicht anders erwähnt, wurden bei jedem Schritt $5 \mathrm{ml}$ Lösung verwendet. Pro $5 \mathrm{ml}-$ Schraubdeckelröhrchen wurden nicht mehr als 30 Embryonen gleichzeitig behandelt. 


\begin{tabular}{|c|c|c|c|c|}
\hline & Ethanol $(\%)$ & Puffer $(\%)$ & Dauer (min) & Anzahl \\
\hline 1. & Ethanol $100 \%$ & & 5 & $1 x @$ \\
\hline 2. & Ethanol $75 \%$ & $\mathrm{dH}_{2} \mathrm{O} 25 \%$ & 5 & $1 \times @$ \\
\hline 3. & Ethanol $50 \%$ & $\mathrm{dH}_{2} \mathrm{O} 50 \%$ & 5 & 1 x@ \\
\hline 4. & Ethanol $25 \%$ & PTw $75 \%$ & 5 & 1 x@ \\
\hline 5. & & PTw $100 \%$ & 5 & 4 x@ \\
\hline
\end{tabular}

\subsubsection{Proteinase K-Behandlung}

Um die Embryonen oder Oocyten durchlässig für die RNA-Hybridisierungssonden zu machen, wurden sie bis zu 25 Minuten bei RT in $1 \mathrm{ml}$ PTw-Puffer inkubiert, dem $0.5 \mu 1$ Proteinase K-Lösung (Merck, $20 \mathrm{mg} / \mathrm{ml}$ ) zugegeben wurde (Endkonzentration $10 \mu \mathrm{g} / \mathrm{ml}$ ). Zeigten sich unter optischer Kontrolle leichte Schäden, wurde die Behandlung sofort abgebrochen.

\subsubsection{Refixierung und Hybridisierungsreaktion}

Die durch Proteinase K-Behandlung fragilen Embryonen und Oocyten wurden durch Acetylierung und Inkubation in PTw/Formaldehydlösung refixiert. Die Embryonal- und Oocyten-Stadien wurden in $0.1 \mathrm{M}$ Triethanolamin-Lösung ( $\mathrm{pH}$ 7.5) umgepuffert, durch zweimalige Zugabe von Acetanhydrid acetyliert und anschließend in PTw $+3,7 \%$ Formaldehyd refixiert.

\begin{tabular}{|l|l|c|c|c|}
\hline & Puffer & Zugabe von & Dauer (min) & Anzahl \\
\hline 1. & $0.1 \mathrm{M}$ Triethanolamin & & 5 & $2 \mathrm{x} @$ \\
\hline 2. & $0.1 \mathrm{M}$ Triethanolamin & $12.5 \mu$ l Acetanhydrid & 5 & $1 \mathrm{x} @$ \\
\hline 3. & & $12.5 \mu$ l Acetanhydrid & 5 & $1 \times 9$ \\
\hline 4. & PTw & & 5 & $2 \times 9$ \\
\hline 5. & PTw $+3,7 \%$ FA & & 20 & $1 \times 9$ \\
\hline 6. & PTw & & 5 & $5 \times @$ \\
\hline
\end{tabular}

Anschließend wurde der PTw-Puffer bis auf $1 \mathrm{ml}$ entfernt und $250 \mu 1$ Hybridisierungs-Lösung zugegeben. Nach dem Absinken der Stadien in die Hybridisierungslösung wurde der 
Überstand abgenommen, durch $500 \mu$ Hybridierungslösung ersetzt und 10 min bei $65^{\circ} \mathrm{C}$ im Wasserbad inkubiert. Die Hybridisierungslösung wurde erneut ausgetauscht und die Embryonen für mindestens $6 \mathrm{~h}$ bei $60^{\circ} \mathrm{C}$ prähybridisiert. Nach dem Abnehmen des Überstands und Zugabe der RNA-Sonde (Endkonzentration $1 \mu \mathrm{g} / \mathrm{ml}$ ) in $500 \mu \mathrm{l}$ Hybridisierungslösung wurde über Nacht unter leichtem Schütteln bei $60^{\circ} \mathrm{C}$ hybridisiert.

\subsubsection{Waschen}

Um unspezifisch gebundene, einzelsträngig vorliegende Sonden-RNA zu entfernen, wurden die Embryonen unter stringenten Bedingungen gewaschen und bei manueller Behandlung mit $10 \mu \mathrm{g} / \mathrm{ml}$ RNase A und $10 \mathrm{U} / \mathrm{ml}$ RNase T1 verdaut. Die Sonden-RNA konnte bei $-20^{\circ} \mathrm{C}$ gelagert und mehrfach verwendet werden.

\begin{tabular}{|c|l|c|c|c|}
\hline & Puffer & Temperatur $\left({ }^{\circ} \mathrm{C}\right)$ & Dauer $(\mathrm{min})$ & Anzahl \\
\hline 1. & Hybridisierungspuffer $(500 \mu \mathrm{l})$ & 60 & 10 & $1 \mathrm{x}$ \\
\hline 2. & $2 \times \mathrm{SSC}$ & 60 & 20 & $3 \mathrm{x}$ \\
\hline 3. & $2 \times \mathrm{SSC}$ mit RNasen & 37 & 30 & $2 \mathrm{x}$ \\
\hline 4. & $2 \times \mathrm{SSC}$ & $\mathrm{RT}$ & 10 & $1 \mathrm{x}$ \\
\hline 5. & $0.2 \times \mathrm{SSC}$ & 60 & 30 & $2 \mathrm{x}$ \\
\hline 6. & $\mathrm{MAB}$ & $\mathrm{RT}$ & 15 & $2 \mathrm{x}$ \\
\hline
\end{tabular}

\subsubsection{Antikörper-Inkubation}

Die Hybride aus digoxigeninmarkierter Sonden-RNA und endogener mRNA konnten mit einem Digoxigenin-spezifischen Antikörper, an den alkalische Phosphatase gekoppelt war, nachgewiesen werden. Zur Blockierung unspezifischer Bindungsstellen wurden die Embryonen vor Zugabe des Detektions-Antikörpers in einer Block-Lösung aus $2 \%$ Boehringer Mannheim Blockierungs-Reagenz und $20 \%$ hitzeinaktiviertem Pferdeserum (Biochrom KG, Berlin) inkubiert. 


\begin{tabular}{|c|c|c|c|c|}
\hline & Puffer & Temperatur $\left({ }^{\circ} \mathrm{C}\right)$ & Dauer (min) & Anzahl \\
\hline 1. & $\mathrm{MAB}+2 \% \mathrm{BMB}$ & RT & 60 & $1 \mathrm{x}-$ \\
\hline 2. & $\begin{array}{l}\mathrm{MAB}+2 \% \mathrm{BMB} \\
20 \% \text { Serum }\end{array}$ & RT & 60 & $1 \mathrm{x}-$ \\
\hline 3. & $\begin{array}{l}\mathrm{MAB}+2 \% \mathrm{BMB} \\
20 \% \text { Serum }+ \text { AK } \\
(1: 5.000)\end{array}$ & RT & 240 & $1 \mathrm{x}-$ \\
\hline 4. & MAB (Waschen) & RT & 30 & $2 x-$ \\
\hline 5. & MAB (Waschen) & 4 & über Nacht & $1 \mathrm{x}-$ \\
\hline
\end{tabular}

\subsubsection{Farbentwicklung}

Alkalische Phosphatase setzt die Substrate NBT/BCIP zu einem dunkelvioletten Farbstoff um. Die Färbereaktion wurde im Dunkeln durchgeführt bis der gewünschte Kontrast mit einer hohen Signalintensität bei schwacher Hintergrundfärbung erreicht wurde.

\begin{tabular}{|l|l|c|c|c|}
\hline & Puffer & Temperatur $\left({ }^{\circ} \mathrm{C}\right)$ & Dauer (min) & Anzahl \\
\hline 1. & MAB & RT & 60 & $1 \mathrm{x}$ \\
\hline 2. & APB & RT & 5 & $2 \mathrm{x}$ \\
\hline 3. & APB + NBT/BCIP & RT & 5 min $-24 \mathrm{~h}$ & $1 \mathrm{x}$ \\
\hline
\end{tabular}

\subsubsection{Abstoppen der Färbung und Auswertung}

Nach dem Erreichen der gewünschten Farbintensität wurde die Färbereaktion durch Spülen mit $\mathrm{dH}_{2} \mathrm{O}$ abgestoppt. Durch Inkubation in Methanol konnte die Hintergrundfärbung unter optischer Kontrolle reduziert werden. Anschließend wurden die Stadien in einer absteigenden Methanolreihe rehydriert und in 1 x MEMFA fixiert und bei $4^{\circ} \mathrm{C}$ gelagert. Zur Dokumentation wurde die MEMFA Lösung gegen 1 x MEM-Puffer ausgetauscht. 


\begin{tabular}{|l|l|c|c|c|}
\hline & Lösung & Temperatur $\left({ }^{\circ} \mathrm{C}\right)$ & Dauer (min) & Anzahl \\
\hline 1. & $\mathrm{dH}_{2} \mathrm{O}$ & $\mathrm{RT}$ & 1 & $1 \mathrm{x}$ \\
\hline 2. & Methanol $100 \%$ & $\mathrm{RT}$ & $1-5$ & $1 \mathrm{x}$ \\
\hline 3. & Methanol $75 \%$ & $\mathrm{RT}$ & 1 & $1 \mathrm{x}$ \\
\hline 4. & Methanol $50 \%$ & $\mathrm{RT}$ & 1 & $1 \mathrm{x}$ \\
\hline 5. & Methanol $25 \%$ & $\mathrm{RT}$ & 1 & $1 \mathrm{x}$ \\
\hline 6. & $\mathrm{dH} \mathrm{H}_{2} \mathrm{O}$ & $\mathrm{RT}$ & 1 & $1 \mathrm{x}$ \\
\hline 7. & MEMFA & RT & über Nacht & $1 \mathrm{x}$ \\
\hline
\end{tabular}

Mit Hilfe eines Stereomikroskops (Stemi SV6, Zeiss) mit Kameraaufsatz wurden die Ergebnisse zu Beginn der Arbeit auf Ektachrome 64T Kunstlichtdiafilmen (Kodak) dokumentiert. Später erfolgte die Dokumentation mit einer Digitalkamera.

\subsubsection{Gewebeschnitte mit einem Vibratom}

Der Embryo wurde zunächst in Gelatine-Albumin Einbettungsmedium ca. 10 Minuten äquilibriert. In einem Wägeschälchen wurden auf Eis 1,5 ml Einbettungsmedium mit $105 \mu 1$ $25 \%$ Glutaraldehyd-Lösung (Sigma) vermischt und möglichst luftblasenfrei in eine Silikonform gegossen. Nach dem Verfestigen wurde der Embryo auf dem Sockel ausgerichtet. Erneut wurden 1,5 ml Einbettungsmedium und $105 \mu 125 \%$ GlutaraldehydLösung gemischt und der Embryo mit der Mischung überschichtet. Nach 10 Minuten wurde der verfestigte Block aus der Form gelöst und mit einer Rasierklinge getrimmt. Das Objekt wurde mit Sekundenkleber in der entsprechenden Orientierung auf einen Metallblock aufgeklebt. Der Objekthalter mit dem Präparat wurde in ein Vibratom (Typ 1000, Pelco International) eingespannt. Die in $\mathrm{H}_{2} \mathrm{O}$ angefertigten Schnitte in $30 \mu \mathrm{m}$ Dicke wurden mit Hilfe eines feinen Pinsels auf mit Seife gespülte Objektträger überführt und bis zum Abschluss des Schneidens mit $\mathrm{H}_{2} \mathrm{O}$ feucht gehalten. Nach kurzem Trocknen wurden die Schnitte in Moviol-Lösung eingebettet.

Gelatine-Albumin Einbettungsmedium: 1 x PBS, $4.88 \mathrm{mg} / \mathrm{ml}$ Gelatine, $0.3 \mathrm{~g} / \mathrm{ml}$ Albumin, $0.2 \mathrm{mg} / \mathrm{ml}$ Sucrose. Zunächst wurde die Gelatine durch Erhitzen auf ca. $60^{\circ} \mathrm{C}$ gelöst und nach dem Abkühlen Albumin und Sucrose zugefügt. Die Lösung wurde filtriert (0.45 $\mu \mathrm{m})$ aliquotiert und bei $-20^{\circ} \mathrm{C}$ gelagert. 
Moviol-Lösung: 9.6 g Moviol in $19.35 \mathrm{ml} 100$ \% Glycerin lösen, 1 h Rühren. Zugabe von 24

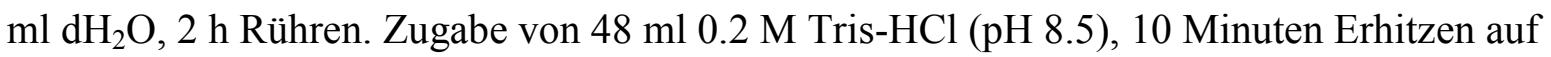
$50^{\circ} \mathrm{C}, 15$ Minuten bei $5.000 \mathrm{Upm}$ abzentrifugieren. Überstand aliquotiert bei $-20^{\circ} \mathrm{C}$ lagern.

\subsubsection{Maschinelle „Whole mount" in situ Hybridisierung}

Die maschinelle „Whole mount“ in situ Hybridisierung wurde das Insitu pro Gerät von Abimed verwendet. Die Maschine besteht aus einem Reservoirschlauch, der an einer Hebelpumpe mit vorgeschaltetem Verteilerelement angeschlossen ist. Über den Schlauch werden Flüssigkeiten aufgenommen und über eine doppelwandige Nadel in das Inkubationsgefäß, in dem sich die Embryonen befinden, gegeben. Die Inkubationsgefäße tauchen mit einer nadelförmigen Verlängerung in ein flüssigkeitsgefülltes Sammelbecken ein (zu Beginn mit Wasser gefüllt). Durch den Wasserdruck wird die Füssigkeit im Inkubationsgefäß gehalten. Das Sammelbecken ist mit einem Überlaufabfürungsschlauch versehen, der in einem Abfallsammelgefäß mündet. Soll ein Wechsel der Inkubationslösung erfolgen, wird die Lösung aus dem entsprechenden Vorratsgefäß in den Reservoirschlauch gesaugt, das Reaktionsgefäß mit dem Roboterarm angesteuert, die im Gefäß vorhandene Flüssigkeit über Luftzufuhr durch die äußere Nadel und den so entstehenden Überdruck nach unten in das Sammelbecken ausgeblasen. Die äußere Nadel schließt mit der Öffnung der Inkubationsgefäße ab. Die innere längere Nadel hat einen geringeren Durchmesser, so dass über sie definierte Flüssigkeitsmengen in den Inkubationsraum gegeben werden können. Da die Embryonen sehr fragil sind, wird zunächst eine geringe Flüssigkeitsmenge mit niedrigem Druck in das Inkubationsgefäß gegeben. Sind die Embryonen vollständig bedeckt, kann das Gefäß mit höherem Druck bis zum angestrebten Volumen gefüllt werden. Um den Temperaturbereich für Hybridisierungsreaktionen einstellen $\mathrm{zu}$ können, sind die Inkubationsgefäße in einen Heizblock mit 8 mal 12 Vertiefungen eingefasst. Die Steuerung von Hebelpumpe, Heizblock und Roboterarm erfolgt über eine vom Hersteller mitgelieferte Software (Abimed in situ Software 4.0), die entweder über eine zum Gerät gehörende DOS basierte Steuerkonsole oder über eine Windows basierte Eingabeoberfläche angepasst werden kann.

Vor Benutzung des Gerätes wurde frisches, destilliertes Wasser in das Vorratsgefäß für Spülschritte gegeben. Wurde die Anlage längere Zeit nicht benutzt, erfolgte eine Reinigung des Systems mit 3 \% Wasserstoffperoxidlösung und zweimaligem Spülen mit frischem, destilliertem Wasser unter Verwendung eines Herstellerprogramms. Vorrats- und 
Inkubationsgefäße wurden bei erstmaliger Benutzung mit $3 \%$ Wasserstoffperoxidlösung und zweimaligem Spülen mit frischem, destilliertem Wasser gereinigt. Nach Verwendung in einer „whole mount“ in situ Hybridisierungsprozedur wurden die Gefäße 5 x mit deionisiertem Wasser gespült und anschließend zur Inaktivierung möglicher RNase Kontaminationen für 24 Stunden in 0,1 N Natronlauge eingelegt. Nachdem die Natronlauge durch fünfmaliges Spülen mit deionisiertem Wasser vollständig entfernt wurde, erfolgte eine weitere Spülung mit $3 \%$ Wasserstoffperoxidlösung. Anschließend wurde verbleibende Flüssigkeit durch dreimaliges Waschen der Gefäße mit technischem Ethanol entfernt und die Gefäße bei $80^{\circ} \mathrm{C}$ für 30 bis 60 Minuten getrocknet.

Für die maschinelle ,whole mount“ in situ Hybridisierung wurden bei $-20^{\circ} \mathrm{C}$ gelagerte prähybridisierte Embryonalstadien wie unter 2.2.8.3 beschrieben verwendet. Der Transfer der Embryonen in die Inkubationsgefäße erfolgte mit einer aufgeschmolzenen Pasteurpipette in Prähybridisierungslösung. Anschließend wurde nach folgendem exemplarischem Programm verfahren: 


\begin{tabular}{|c|c|c|c|}
\hline Schritt & Funktion & Aktion & Erklärung \\
\hline 1 & SetTempReg & T0 (OFF) & Heizblock der Gefäßhalterung aus \\
\hline 2 & Rinse & $5000 / 5000 \mu \mathrm{l}$ & Spülen des Reservoirs mit $5 \mathrm{ml} \mathrm{dH} 2 \mathrm{O}$ \\
\hline 3 & SetTempReg & $\mathrm{T} 2(\mathrm{HIGH})$ & Erhitzen der Gefäßhalterung auf $65^{\circ} \mathrm{C}$ \\
\hline 4 & Incubate & 1 h 150 C-SAMPLE_A & $\begin{array}{l}\text { Wechseln der Hybridisierungslösung } 150 \mu \mathrm{l} \text { und } \\
\text { Inkubation für } 1 \mathrm{~h}\end{array}$ \\
\hline 5 & Incubate & $16 \mathrm{~h} 150$ Probe-SAMPLE_A & Inkubation mit der RNA Sonde $150 \mu \mathrm{l}$ für $16 \mathrm{~h}$ \\
\hline 6 & Incubate & 15 min 150 C-SAMPLE_A & $\begin{array}{l}\text { Waschen mit } 150 \mu \mathrm{l} \text { Hybridisierungslösung und Inkubation } \\
\text { für } 15 \text { min }\end{array}$ \\
\hline 7 & Incubate & 15 min 150 D-SAMPLE_A & Waschen mit $150 \mu \mathrm{l} 2 \times \mathrm{SSC}$ und Inkubation für $15 \mathrm{~min}$ \\
\hline 8 & Incubate & 20 min 150 D-SAMPLE_A & Waschen mit $150 \mu \mathrm{l} 2 \times \mathrm{SSC}$ und Inkubation für $20 \mathrm{~min}$ \\
\hline 9 & Incubate & 20 min 150 E-SAMPLE_A & Waschen mit $150 \mu \mathrm{l} 0,2 \times \mathrm{SSC}$ und Inkubation für $20 \mathrm{~min}$ \\
\hline 10 & Incubate & 20 min 150 E-SAMPLE_A & Waschen mit $150 \mu \mathrm{l} 0,2 \times$ SSC und Inkubation für $20 \mathrm{~min}$ \\
\hline 11 & SetTempReg & T0 (OFF) & Heizblock der Gefäßhalterung aus \\
\hline 12 & Wait & $20 \mathrm{~min}$ & Abkühlen des Heizblocks der Gefäßhalterung auf RT \\
\hline 13 & Incubate & $15 \min 150$ A-SAMPLE_A & Waschen mit $150 \mu$ l MAB-Puffer und Inkubation für $15 \mathrm{~min}$ \\
\hline 14 & Incubate & 15 min 150 A-SAMPLE_A & Waschen mit $150 \mu \mathrm{l}$ MAB-Puffer und Inkubation für $15 \mathrm{~min}$ \\
\hline 15 & Incubate & 20 min 150 A-SAMPLE_A & Waschen mit $150 \mu \mathrm{l}$ MAB-Puffer und Inkubation für $20 \mathrm{~min}$ \\
\hline 16 & Incubate & 60 min 150 L-SAMPLE_A & $\begin{array}{l}\text { Abdecken unspezifischer Bindungsstellen mit } 150 \mu \mathrm{l} \\
\text { Block-Lösung und Inkubation für } 1 \mathrm{~h}\end{array}$ \\
\hline 17 & Incubate & 6 h 150 M-SAMPLE_A & Antikörperinkubation mit $150 \mu \mathrm{l}$ für $6 \mathrm{~h}$ \\
\hline 18 & Incubate & 20 min 150 A-SAMPLE_A & Waschen mit $150 \mu \mathrm{l}$ MAB-Puffer und Inkubation für $20 \mathrm{~min}$ \\
\hline 19 & Incubate & 20 min 150 A-SAMPLE_A & Waschen mit $150 \mu$ l MAB-Puffer und Inkubation für $20 \mathrm{~min}$ \\
\hline 20 & Incubate & 20 min 150 A-SAMPLE_A & Waschen mit $150 \mu \mathrm{l}$ MAB-Puffer und Inkubation für $20 \mathrm{~min}$ \\
\hline 21 & Incubate & 40 min 150 A-SAMPLE_A & Waschen mit $150 \mu \mathrm{l}$ MAB-Puffer und Inkubation für $40 \mathrm{~min}$ \\
\hline 22 & Incubate & 40 min 150 A-SAMPLE_A & Waschen mit $150 \mu \mathrm{l}$ MAB-Puffer und Inkubation für $40 \mathrm{~min}$ \\
\hline 23 & Incubate & $40 \min 150$ A-SAMPLE_A & Waschen mit $150 \mu$ l MAB-Puffer und Inkubation für $40 \mathrm{~min}$ \\
\hline 24 & Incubate & 60 min 150 A-SAMPLE_A & Waschen mit $150 \mu \mathrm{l}$ MAB-Puffer und Inkubation für $60 \mathrm{~min}$ \\
\hline 25 & Incubate & $60 \min 150$ A-SAMPLE_A & Waschen mit $150 \mu$ l MAB-Puffer und Inkubation für $60 \mathrm{~min}$ \\
\hline 26 & WaitForKey & APB in Position F & $\begin{array}{l}\text { Vorratsgefäß mit frischem APB-Puffer auf Position F } \\
\text { Stellen und Programm fortsetzen }\end{array}$ \\
\hline 27 & Incubate & 15 min 150 F-SAMPLE_A & Waschen mit $150 \mu \mathrm{l}$ APB-Puffer und Inkubation für $15 \mathrm{~min}$ \\
\hline 28 & Incubate & 15 min 150 F-SAMPLE_A & Waschen mit $150 \mu \mathrm{l}$ APB-Puffer und Inkubation für $15 \mathrm{~min}$ \\
\hline 29 & Rinse & $5000 / 5000 \mathrm{ul}$ & Spülen des Reservoirs mit $5 \mathrm{ml} \mathrm{dH} 2 \mathrm{O}$ \\
\hline 30 & SetTempReg & T0 (OFF) & Ende des Programms \\
\hline
\end{tabular}

Tabelle 7: Exemplarisches Programm für eine maschinelle „whole mount“" in situ Hybridisierung. Spalte eins gibt den jeweiligen Programmschritt an. In Spalte zwei ist die aufgerufene Funktion aufgelistet. Hier bedeutet SetTempReg: Ansteuerung des Temperaturreglers der Heizplatte, Rinse: Spülvorgang ohne Ansteuerung von Inkubationsgefäßen, Wait: Warteposition für einen bestimmten Zeitraum, WaitForKey: eine Tastatureingabe ist zur Programmfortführung notwendig, Incubate: Wechsel der Inkubationslösung. In Spalte drei ist die auszuführende Aktion in Folgender Reihenfolge aufgelistet: Zeit in Minuten oder Stunden, das hinzugefügte Volumen der Inkubationsflüssigkeit, die Position des Vorratsgefäßes der Puffer (A, C, D, E, F, oder Probe), die anzusteuernden Proben (hier wurde nur ein Bereich von 1-96 Inkubationsgefäßen definiert) in dem jeweiligen Programmschritt. In Spalte vier ist eine kurze Erklärung der jeweiligen Programmschritte aufgelistet. Die verwendeten Lösungen sind anhand ihrer Positionsangabe unten aufgelistet. 


\section{Lösungen für "whole mount" in situ Hybridisierung:}

A: MAB-Puffer (Maleinsäurepuffer):

$\begin{array}{lrcc} & & 500 \mathrm{ml} & 5 \times \text { Stock } 1 \mathrm{~L} \\ \text { Maleinsäure } & 100 \mathrm{mM} & 5,8 \mathrm{~g} & 58 \mathrm{~g} \\ \mathrm{NaCl} & 150 \mathrm{mM} & 4,4 \mathrm{~g} & 44 \mathrm{~g} \\ & \mathrm{pH} \mathrm{7,5} & & \end{array}$

D: $2 \times \mathrm{SSC}$

E: $0,2 \times \mathrm{SSC}$

F: APB-Puffer (Alkalischer Phosphatase Puffer):

$\begin{array}{lcc}\text { Tris- } \mathrm{HCl} \mathrm{pH} 9,5 & 100 \mathrm{mM} & 50 \mathrm{ml} \mathrm{Tris} 1 \mathrm{M} \\ \mathrm{MgCl}_{2} & 50 \mathrm{mM} & 25 \mathrm{ml} \mathrm{MgCl} 21 \mathrm{M} \\ \mathrm{NaCl} & 100 \mathrm{mM} & 10 \mathrm{ml} \mathrm{NaCl} 5 \mathrm{M} \\ \text { Tween } 20 & 0,1 \% & 2,5 \mathrm{ml} 20 \% \text { Tween } \\ & & \text { ad } 500 \mathrm{ml}\end{array}$

$\mathrm{pH} 9,5$; bei $4^{\circ} \mathrm{C}$ maximal 14 Tage aufbewahren

L: Block-Lösung: MAB + $2 \% \mathrm{BMB}+20 \%$ Pferde-Serum 1 Teil 5 x MAB +1 Teil $10 \%$ BMB +1 Teil Serum +2 Teile $\mathrm{H}_{2} \mathrm{O}(6,6 \mathrm{ml} 5$ x MAB $+6,6 \mathrm{ml} 10 \%$ BMB $+6,6$ $\left.\mathrm{ml} \mathrm{Serum}+13,2 \mathrm{ml} \mathrm{H} \mathrm{O}_{2}=33 \mathrm{ml}\right)$

M: Anti Digoxygenin- oder Fluorescin-Antikörper: 15 ml Block-Lösung + $3 \mu 1$ AK (1/5000)

C: Hybridisierungs-Lösung:

$\begin{array}{llr}\text { Formamid } & 50 \% & 500 \mathrm{ml} \text { deionisiert (BRL 5515UB) } \\ \text { SSC } & 5 \mathrm{x} & 250 \mathrm{ml} 20 \times \text { Stock-Lsg. } \\ \text { Torula RNA } & 1 \mathrm{mg} / \mathrm{ml} & 20 \mathrm{ml} 50 \mathrm{mg} / \mathrm{ml} \text { Stock-Lsg. (SIGMA R6625) } \\ \text { Heparin } & 100 \mu \mathrm{g} / \mathrm{ml} & 100 \mathrm{mg} 10 \mathrm{mg} / \mathrm{ml} \text { (Sigma H-9399) } \\ \text { Denhart's } & 1 \mathrm{x} & 1 \mathrm{ml} 100 \mathrm{x} \text { Stock-Lsg. } \\ \text { Tween-20 } & 0.1 \% & 1 \mathrm{~g} 20 \% \text { Stock-Lsg. (Sigma P-1379) } \\ \text { CHAPS } & 0.1 \% & 1 \mathrm{~g} \text { Einwaage (Sigma C-3023) } \\ \text { EDTA } & 10 \mathrm{mM} & 20 \mathrm{ml} 0.5 \mathrm{M}-\text { Stock-Lsg. (MW 292,2) } \\ \text { DEPC- } \mathrm{H}_{2} \mathrm{O} & & \text { ad } 1 \mathrm{~L} \\ \text { Die Hybridisierungslösung wurde bis zur Verwendung bei }-20^{\circ} \mathrm{C} \text { gelagert. }\end{array}$

Probe: Digoxygenin oder Fluorescin markierte RNA-Sonde: $20 \mu$ RNA Probe (in Formamid, $\mathrm{H}_{2} \mathrm{O}$ 1:1) $150 \mu 1$ Hybridisierungslösung

RNasen: $20 \mu \mathrm{g} / \mathrm{ml}$ RNase A, $10 \mathrm{U} / \mathrm{ml}$ RNase T1 (manuelle „whole mount“ in situ Hybridisierung) 


\section{Ergebnisse}

\subsection{Der Transkriptions-Faktor IIIA}

TFIIIA ist ein Zinkfingerprotein mit neun aufeinanderfolgenden Zinkfingern. In der frühen Phase der Oogenese wird der Transkriptionsfaktor bei der 5S RNA-Synthese benötigt. Diese Funktion erfordert den Kernimport von TFIIIA und damit ein Kernlokalisierungssignal. In der Oogenese hat TFIIIA im Cytoplasma eine Speicherfunktion für 5S RNA. Diese Funktion erfordert die Inaktivierung des Kerntransportsignals von TFIIIA. Vermutlich führt die 5S RNA-Bindung an TFIIIA zu einer Maskierung des Kernlokalisierungssignals. An TFIIIA gebundene 5S RNA liegt im Cytoplasma von Oocyten als 7S-Vorratspartikel vor. In somatischen Zellen tritt solch ein Vorratspartikel nicht auf. Nach Deletion der 5S RNA bindenden Zinkfinger 5 und 6 wird TFIIIA in den Zellkern transportiert. Eine Maskierung des NLS durch 5S RNA Bindung könnte die zugrunde liegende Transporthemmung erklären (Rudt et al., 1996; Rudt und Pieler, 1996). In den Zinkfingersequenzen könnte ein weiteres neues Motiv für den Import von Proteinen lokalisiert sein, welches durch die Bindung von 5S RNA an TFIIIA maskiert wird. In diesem Projekt sollen als Beitrag zur Aufklärung des nukleocytoplasmatischen Transports von 5S RNA die NLS-Funktion innerhalb der Sequenz von TFIIIA lokalisiert werden und potentielle Importfaktoren von TFIIIA identifiziert werden.

\subsubsection{Vorarbeiten zur Eingrenzung der Kernlokalisierungssignalsequenz von dem Transkriptions-Faktor IIIA}

Im Rahmen der von mir angefertigten Diplomarbeit wurden verschiedene Fusionsmutanten von TFIIIA mit einem $\beta$-Galaktosidaseanteil erstellt und die Importkompetenz dieser Mutanten durch Mikroinjektion in das Cytoplasma von Oocyten der Stadien V und VI ermittelt. Durch verschiedene Mutationen konnten die N- und C-terminalen Sequenzen, welche keine Zinkfinger kodierenden Sequenzen enthalten, als Träger einer Kerntransportsignalsequenz ausgeschlossen werden. Durch weitere Deletionsmutanten der Zinkfinger kodierenden Sequenz wurde je eine $\mathrm{N}$ - und C-terminal lokalisierte Kerntransportsignalsequenz nachgewiesen. Deletionsmutanten, denen zusätzlich zu den Fingern 5 und 6 ein weiterer Finger fehlte, wiesen auf eine besondere Bedeutung der Zinkfinger 4 und 9 hin. Deletionsmutanten, denen zusätzlich innerhalb der N- bzw. Cterminalen Kerntransportsignalsequenz der vierte oder neunte Zinkfinger fehlte, wurden 
schlechter in den Zellkern transportiert als Mutanten, denen zusätzlich andere Zinkfinger fehlten. Bis zum Abschluss der Arbeit wurden die Zinkfinger 789 für das C-terminale NLS und die Zinkfinger 1 bis 4 mit N- und C-terminaler Sequenz von TFIIIA (N1234C) als kürzeste importkompetente TFIIIA Sequenzen identifiziert. Unter diesem Aspekt wurde in der vorliegenden Arbeit die NLS-Sequenz von TFIIIA weiter eingegrenzt und die strukturelle Einbettung der NLS Funktion analysiert.

\subsubsection{Weitere Arbeiten zur Eingrenzung der Kerntransportsignalsequenzen}

Zur weiteren Eingrenzung des essentiellen Sequenzelementes für den Kerntransport von TFIIIA wurden neue Fusionsmutanten bestehend aus sechs myc-Epitopen, einem $\beta$ Galaktosidaseanteil und den jeweiligen TFIIIA Deletionsmutanten erstellt. Die myc-Epitope dienten der Präzipitation injizierter Proteine. Der $\beta$-Galaktosidaseanteil wurde verwendet, um das Protein zu vergrößern und so passive Diffusion in den Zellkern zu verhindern (Wischnewski, 1997).

Die den Zinkfingern 124, 234, 34, 4, 678, 789, 89 und 9 entsprechenden Sequenzen wurden über PCR (,polymerase chain reaction“) amplifiziert. Die Produkte wurden mit dem Qia quick PCR Purification Kit gereinigt und soweit nicht anders angegeben in den pGemT Vektor kloniert. Durch Verwendung von eingefügten Schnittstellen wurden die Sequenzen mit einem Restriktionsverdau geschnitten und nach Reinigung (siehe Material und Methoden) in den 1/3-beta-Gal Vektor (Wischnewski, 1997) kloniert. Für Klonierungen mit dem Restriktionsenzym Xba I wurde das aus E. Coli TG1 stammende 1/3-beta-Gal Vektorplasmid mit Xba I verdaut, die Schnittstelle mit Klenow Polymerase aufgefüllt, das Plasmid religiert und in dam und dem Methylase negative E. Coli GM2163 transformiert. Durch Zerstörung der 3' von der Pst I gelegenen Xba I Schnittstelle konnte so die jetzt nicht mehr methylierte 5' Xba I Schnittstelle in dem resultierenden 1/3-beta-Gal-X ${ }^{2}$ Vektor verwendet werden.

Für die Klonierung von Konstrukten mit der Sequenz des vierten Fingers wurden neben Xba I, die Schnittstellen Nsi I für die Inserts und Pst I für den Vektor benutzt. Aus einem Verdau mit diesen Restriktionsenzymen gehen überhängende Enden hervor, die zueinander kompatibel sind. Die verwendeten Matrizen, Primerkombinationen und Schnittstellen sind in Tabelle 8 angegebenen. Die verwendeten Oligonukleotide sind in Tabelle 2 aufgelistet. Die Mutante mit dem Zinkfinger 4 wurde durch Bgl II Verdau der 34 Mutante aus dem pGemT Vektor, anschließender Auffüllreaktion mit Klenow Polymerase und folgendem Nru I, Nsi I Verdau in den Nru I, Nsi I geschnittenen 1/3-beta-Gal-X² Vektor kloniert. Zur Überprüfung 
der korrekten Integration der Sequenzelemente wurden Sequenzierungen mit den Primern pAXminus und MC002 durchgeführt.

\begin{tabular}{|c|c|c|c|c|c|}
\cline { 3 - 5 } \multicolumn{2}{c|}{} & \multicolumn{2}{c|}{ Schnittstellen } & \multicolumn{1}{c}{} \\
\hline Kodierende Sequenz & Matrize & Insert & Vektor & 5' Primer & 3' Primer \\
\hline 34 & T3pmTFIIIA & Xba I / Nsi I & Xba I / Pst I & UpZF3X & ZF4 \\
\hline 234 & T3pmTFIIIA & Xba I / Nsi I & Xba I / Pst I & UpZF2X & ZF4 \\
\hline 124 & pAX4C+ TFIIIA- $\Delta 3$ & Xba I / Nsi I & Xba I / Pst I & UpZF1X & ZF4 \\
\hline 89 & T3pmTFIIIA & BgI II / Pst I & Bgl II / Pst I & UpZf8 & ZF9 \\
\hline 678 & T3pmTFIIIA & Bgl II / Pst I & Bgl II / Pst I & UpZf6 & ZF8 \\
\hline 9 & T3pmTFIIIA & Bgl II / Pst I & Bgl II / Pst I & UpZF9 & ZF9 \\
\hline
\end{tabular}

Tabelle 8: Primerkombinationen, Schnittstellen und Matrizen für die Klonierung von Zinkfingerfusionsmutanten.

In der ersten Spalte ist der jeweilige Klon aufgelistet. Spalte 2 gibt das Matrizen-Plasmid an, in Spalte vier sind die für das Insert verwendeten Restriktionsenzyme und in Spalte fünf die für den Vektor verwendeten Schnittstellen aufgelistet. Die Sequenz der verwendeten 5' und 3' Primer ist in Tabelle 2 angegeben.

Innerhalb der N-terminalen Zinkfingersequenzen sind die Fusionsmutanten zu einem hohen Anteil im Kern lokalisiert, welche den vierten Zinkfinger als Sequenzelement besitzen. Eine Mutante mit den Zinkfingern 123 wird nicht in den Zellkern importiert. Ein 234 Zinkfingerelement besitzt ein starkes Kernlokalisierungssignal. Eine Reduktion dieses Dreifingerelementes auf die Finger 34 ist transportkompetent. Im Gegensatz zu den Mutanten mit den Zinkfingern 34, 234 bzw. 124 mit einem starken NLS tritt bei einer Fusionsmutante mit dem vierten Zinkfinger alleine oder den Zinkfingern 123 keine signifikante Kernlokalisierung auf. 


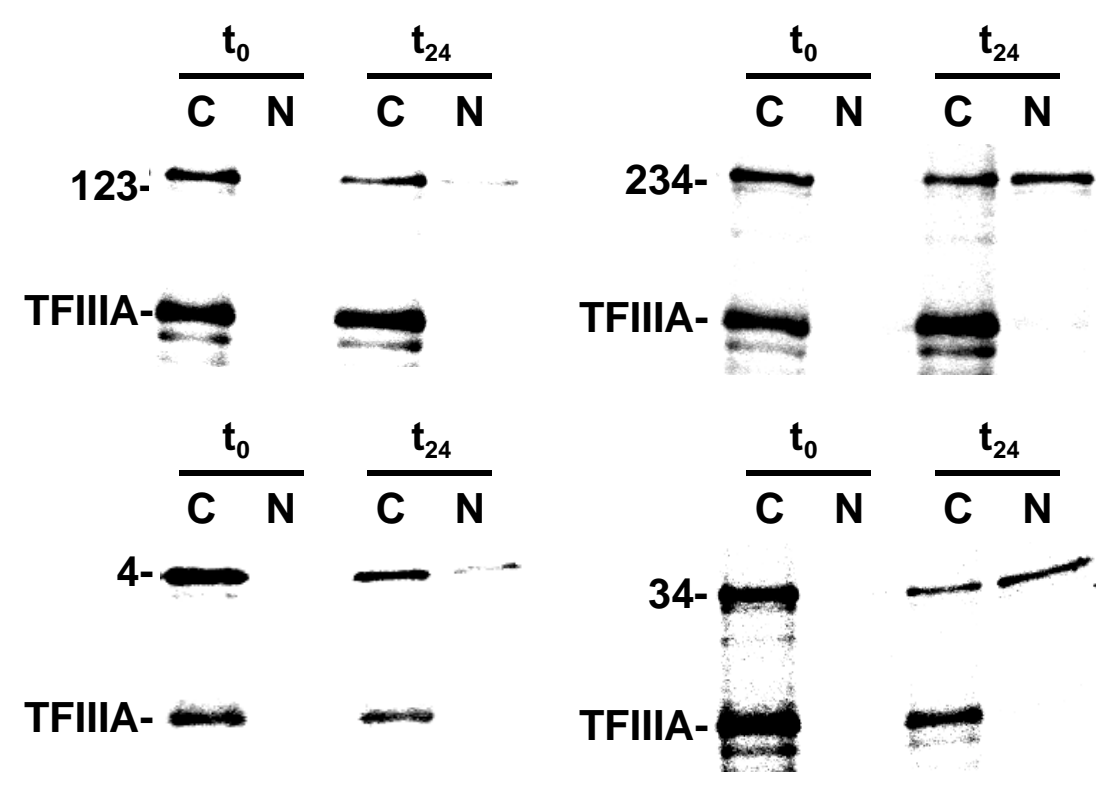

Abbildung 3: Analyse zur NLS Identifizierung von N-terminalen Zinkfingern.

Radioaktiv markiertes Xenopus TFIIIA und Deletionsmutanten mit $\beta$-Galaktosidase und myc Fusionsanteil wurden in das Cytoplasma von Stadium VI Oocyten injiziert. Kern und Cytoplasmafraktionen wurden sofort $\left(\mathrm{t}_{0}\right)$ oder 24 Stunden $\left(\mathrm{t}_{24}\right)$ nach der Injektion manuell separiert. Die eingesetzten Proteine wurden immunpräzipitiert und elektrophoretisch auf einem PAGE-Gel aufgetrennt. Die myc-tag Fusionsmutanten mit den Zinkfingern 234 oder 34 werden importiert. Die Zinkfinger 123 oder der Zinkfinger 4 alleine sind nicht kernlokalisierungskompetent. Die myc-Fusionsmutanten mit der vollständigen TFIIIA-Sequenz werden nicht importiert und dienen als Injektionskontrolle. Links von den Gelabbildungen ist die jeweilige Mutante angegeben, die Bahnen zeigen von links nach rechts: $\mathrm{Ct}_{0}$ Cytoplasma- und $\mathrm{Nt}_{0}$ Kernfraktion unmittelbar nach der Injektion, $\mathrm{Ct}_{24}$ Cytoplasma- und $\mathrm{Nt}_{24}$ Kernfraktion 24 Stunden nach der Injektion.

Durch den Austausch des dritten Zinkfingers der 123 Mutante gegen den vierten Zinkfinger wurde eine importkompetente Mutante erzeugt. Eine 124 Mutante (70 \% kernlokalisiert, nicht gezeigt) wird in vergleichbarer Qualität wie die 234 Mutante importiert. Mit der 124 Mutante konnte die Funktion des NLS vom vierten Zinkfinger unabhängig von der Identität des Vorfingers dargestellt werden. Der vierte Zinkfinger alleine ist allerdings nicht transportkompetent. Da der vierte Zinkfinger alleine nicht mehr importiert wird, besteht für die Integrität der Kerntransportsignalsequenz die strukturelle Notwendigkeit eines Vorfingers. 


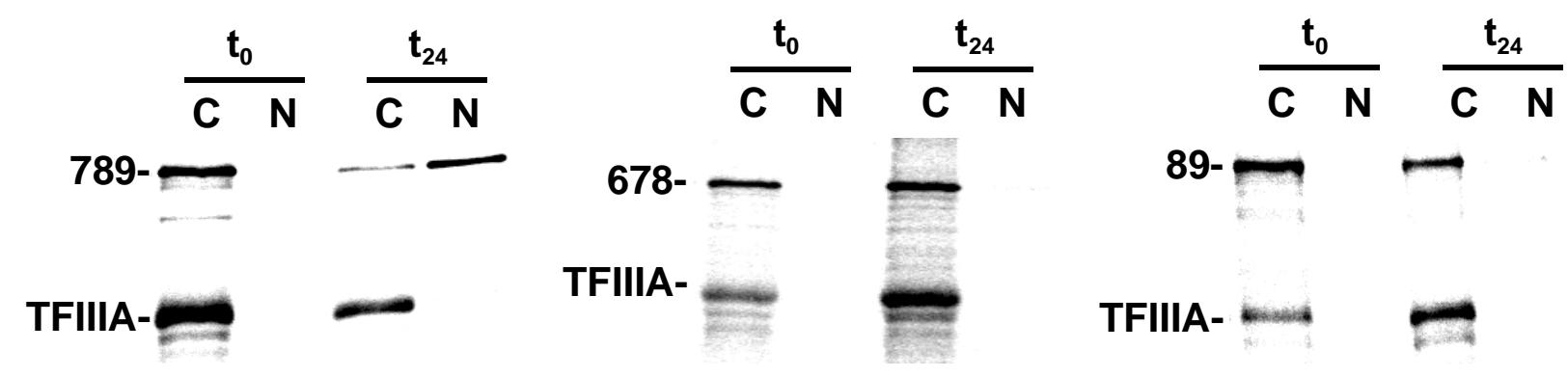

\begin{abstract}
Abbildung 4 : Analyse zur NLS Identifizierung von C-terminalen Zinkfingern.
Radioaktiv markiertes Xenopus TFIIIA und Deletionsmutanten mit $\beta$-Galaktosidase und myc Fusionsanteil wurden in das Cytoplasma von Stadium VI Oocyten injiziert. Kern und Cytoplasmafraktionen wurden sofort $\left(\mathrm{t}_{0}\right)$ oder 24 Stunden $\left(\mathrm{t}_{24}\right)$ nach der Injektion manuell separiert. Die eingesetzten Proteine wurden immunpräzipitiert und elektrophoretisch auf einem PAGE-Gel aufgetrennt. Die myc-tag Fusionsmutante mit den Zinkfingern 789 ist nach 24 Stunden kernlokalisiert. Die Zinkfinger 123 oder der Zinkfinger 4 alleine sind nicht kernlokalisierungskompetent. Die myc-Fusionsmutanten mit der vollständigen TFIIIA-Sequenz werden nicht importiert und dienen als Injektionskontrolle. Links von den Gelabbildungen ist die jeweilige Mutante angegeben, die Bahnen zeigen von links nach rechts: $\mathrm{Ct}_{0}$ Cytoplasma- und $\mathrm{Nt}_{0}$ Kernfraktion unmittelbar nach der Injektion, $\mathrm{Ct}_{24}$ Cytoplasma- und $\mathrm{Nt}_{24}$ Kernfraktion 24 Stunden nach der Injektion.
\end{abstract}

Das C-terminale NLS unterscheidet sich von dem N-terminalen NLS durch die für die Kernlokalisierung minimal notwendige Anzahl an Zinkfingern. Eine Reduktion der 789 Mutante auf den achten und neunten Zinkfinger führt zu einem vollständigen Verlust der Importkompetenz. Das N-terminale NLS lässt sich im Gegensatz zum C-terminalem NLS, welches in seiner Minimalstruktur aus den Zinkfingern 34 besteht, nur auf ein Dreifingerkonstrukt reduzieren. Eine Gegenüberstellung der Mutanten 678 mit cytoplasmatischer Lokalisation und 789 mit starker Lokalisation im Zellkern zeigt, dass innerhalb der Zinkfinger 6 bis 8 kein eigenständiges NLS vorhanden ist. 


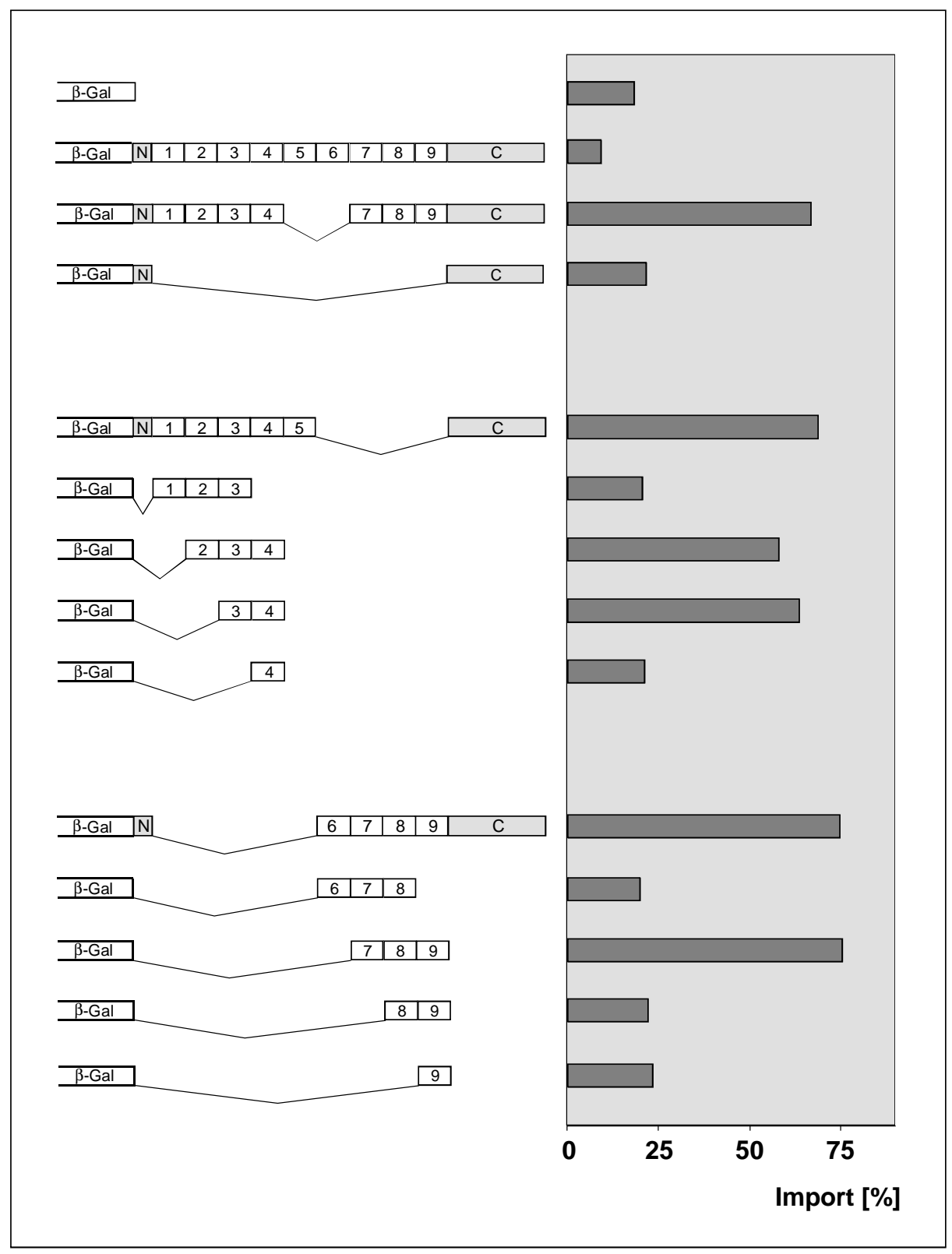

\section{Abbildung 5: Deletionsmutanten zur Eingrenzung der Kernlokalisierungssignalsequenz.}

Zusammenfassende Übersicht der Deletionsmutanten zur Eingrenzung der Kernlokalisierungssignalsequenz. Schematisch dargestellt sind die verschiedenen TFIIIA- Fusionsmutanten mit den zugehörigen Kern / Cytoplasma-Verteilungen nach 24 Stunden Inkubation. Die experimentellen Werte der Mutanten N1-9C, NC, N1-5C, 123 und N6-9C stammen aus meiner Diplomarbeit. Die Werte für die Mutanten 234, 34, 4, 678, 89 und 9 sind im Rahmen dieser Arbeit erstellt worden. Die Werte für die Mutanten 123 und 789 sind in den experimentellen Ansätzen dieser Arbeit erneut verifiziert worden.

Der vierte und der neunte Zinkfinger besitzen beide eine hohe Anzahl von basischen Aminosäuren. Die Aminosäuresequenz der beiden Finger beinhaltet jedoch keine Sequenzfolge, die einem SV40-NLS oder einem zweigeteiltem NLS entspricht. Bisher beschriebene Importsignalsequenzen sind basischer Natur. Eine NLS Datenbankanalyse (Cokol et al., 2000) führt nicht zu vergleichbaren Kernlokalisierungssignalsequenzen. Die 
hier eingegrenzten Kernlokalisierungssignalsequenzen 789 und 34 stellen somit ein neues weiteres Motiv dar, welches in Xenopus Oocyten Kernimport vermitteln kann.

\subsubsection{Analyse von immunfluoreszenzmarkierten TFIIIA Mutanten in HeLa Zellen}

In Injektionsexperimenten mit Oocyten wurden die Zinkfinger 34 und 789 als minimal Struktur der NLS Funktion von TFIIIA identifiziert. Beide Zinkfingermodule haben in ihrer Sequenz ein kurzes basisches Motiv, welches keinem bisher beschriebenen NLS entspricht. Um zu testen, ob die NLS Funktion dieser Minimalstrukturen auf Oocyten beschränkt oder auch in somatischen Zellen wirksam ist, wurde das Importverhalten von Fusionsmutanten der Zinkfinger 34 und 789 mit $\beta$-Galaktosidase in HeLa Zellen in einer transienten Transfektionsanalyse untersucht.

Die kodierende Sequenz der Zinkfinger 34 wurde mit den Primerpaaren Up3 N und ZF4E, die Sequenz der Zinkfinger 789 mit den Primerpaaren Up7N und ZF9 E in einer PCR Reaktion amplifiziert, mit den Restriktionsenzymen Nhe I und Ecl 136 II verdaut und in den Nhe I, Nru I geschnittenen + psv beta Vektor (Schwamborn et al., 1998) vor die $\beta$-Galaktosidase kodierende Sequenz kloniert. Die Integration der Zinkfingersequenzen in die resultierenden Plasmide wurde mit dem pSV-beta-F1 Primer durch Sequenzierung der Insert Vektorübergänge überprüft und die Plasmide wie in 2.2.4.5 beschrieben in HeLa Zellen transfiziert. Der Nachweis der nukleocytoplasmatischen Verteilung der Mutanten erfolgte mit geeigneten primären und Cy3 markierten sekundären Antikörpern. Der Fusionsanteil für die Teilkonstrukte von TFIIIA, $\beta$-Galaktosidase ( + psv beta), ist alleine nicht fähig in den Zellkern zu gelangen. Sowohl das N-als auch das C-terminale NLS von TFIIIA, die Zinkfinger 34 und 789 verhalten sich in HeLa Zellen wie in den Oocyteninjektionsexperimenten. Fusionsmutanten mit den Zinkfingern 34 und 789 und $\beta$-Galaktosidase sind in HeLa Zellen kernlokalisierungskompetent, der Fusionsanteil alleine wird nicht importiert (Abbildung 6). 


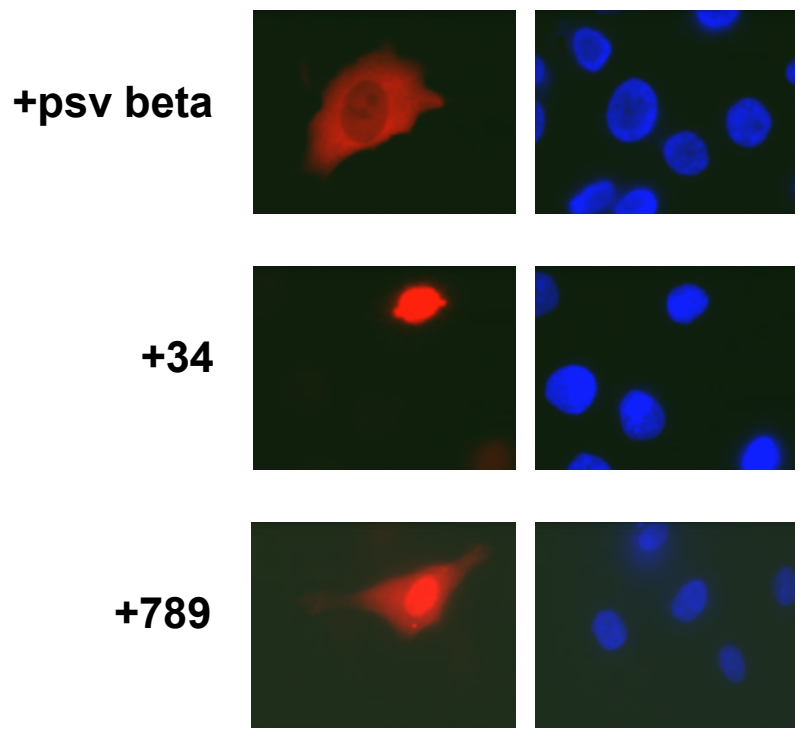

\begin{abstract}
Abbildung 6: Subzelluläre Lokalisation der transportkompetenten Minimalstrukturen von TFIIIA in somatischen Zellen.

HeLa Zellen wurden transient mit Plasmiden + psv beta ( $\beta$-Galaktosidase), + psv beta mit den einklonierten Zinkfingersequenzen 34 oder 789 transfiziert und 2 Tage bei $37^{\circ} \mathrm{C}$ unter $5 \% \mathrm{CO}_{2}$ inkubiert. Anschließend wurden die HeLa Zellen mit $3 \%$ Paraformaldehyd fixiert und mit 0,5 \% Triton-X-100 permeabilisiert. Die intrazelluläre Verteilung wurde mit einem anti- $\beta$-Galaktosidase Primär-Antikörper (aus Maus, Verdünnung 1:1000) und einem fluoreszenzmarkierten Cy3-anti-Maus-IgG-Antikörper (Verdünnung 1:200) nachgewiesen. Die Zellkerne wurden mit DAPI visualisiert. Der Fusionsanteil, $\beta$ Galaktosidase, ist im Cytoplasma lokalisiert. Fusionsmutanten aus $\beta$-Galaktosidase und den Zinkfingern 34 bzw. 789 sind kernlokalisiert.
\end{abstract}

\title{
3.2 Definition einer neuen Synexpressionsgruppe
}

\subsubsection{Karyopherin $\beta 3$}

Karyopherin $\beta 3$ ist ein Transportfaktor, der in den Import von ribosomalen Proteinen involviert sein könnte. Das isolierte humane Karyopherin $\beta 3$ ist ein Karyopherin $\beta$ verwandtes Protein von 123 kd mit zwei putativen Ran-Bindungsdomänen. Es bindet an verschiedene Nukleoporine mit repetitiven Sequenzmustern (Nup358, Nup214, Nup153, Nup98 und p62) und interagiert in einem „Blot overlay assay“ mit den ribosomalen Proteinen L23 und L13 (Yaseen und Blobel, 1997). Karyopherin $\beta$ verwandte Proteine, wie RanBP5, RanBP7, Transportin oder Karyopherin $\beta$ selbst, können direkt an ihre Transportsubstrate binden (Claußen et al., 1999; Jäkel und Görlich, 1998; Pollard et al., 1996).

\subsubsection{Isolierung von Karyopherin $\beta 3$}

Bei der Durchmusterung einer Xenopus-Schwanzspitzen-cDNA-Bank wurde ein partieller Karyopherin $\beta 3$ Klon (Sölter, 1999) von ca. 1,6 kb isoliert. Anhand der mit den Primern 
CMV-F und CMV-R erhaltenen Teilsequenz des partiellen Karyopherin $\beta 3$ Klons wurden die Primer B3Uf1 (5') und B3Ur1 bzw. B3Ur3 (3') entworfen. Über wiederholte Phagenanreicherung (Dürr, 1997) mit wechselnden 5' 3' Primerkombinationen wurde ein Phage isoliert, der die vollständige kodierende Sequenz enthält. Das Phageninsert wurde wie unter 2.2.6.4 beschrieben excisiert und das resultierende Plasmid für weitere Analysen und Klonierungen verwendet. Zur Sequenzierung des vollständigen Klons verwendete Primer sind in Tabelle 3 angegeben. Karyopherin $\beta 3$ aus Xenopus laevis zeigt hohe Homologie zu dem humanen Karyopherin $\beta 3$ (94 \% Ähnlichkeit und 89 \% Identität) und zu Kap121 aus Hefe. Die 4062 Basenpaare der Sequenz kodieren 1094 Aminosäuren, aus denen sich ein Molekulargewicht von 122775,43 Dalton ableitet.

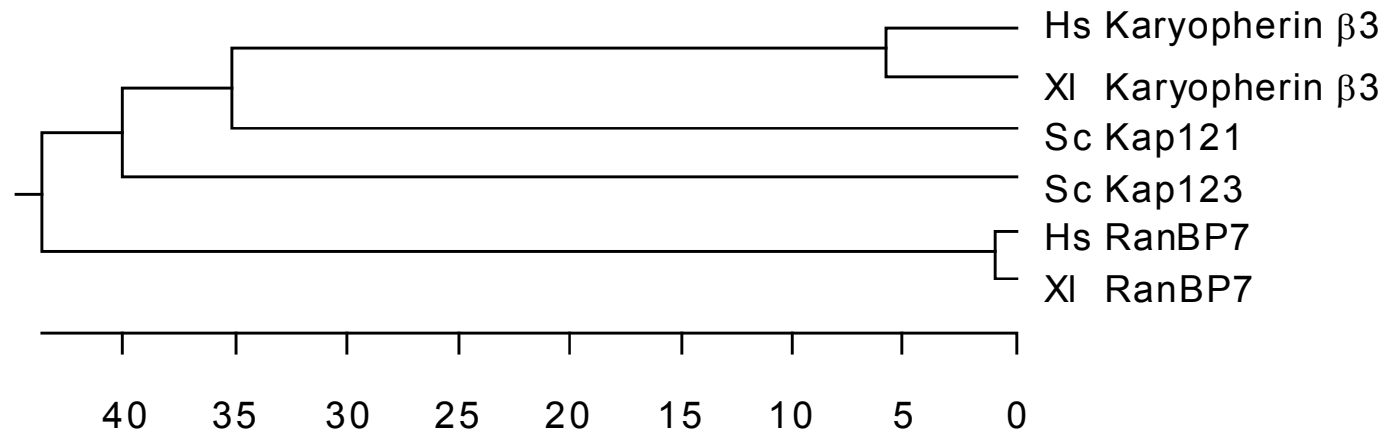

\begin{abstract}
Abbildung 7: Vergleich von Xenopus Karyopherin $\beta 3$ mit anderen verwandten Proteinen.
Der phylogenetische Baum stellt die Verwandtschaftsbeziehungen von Xenopus Karyopherin $\beta 3$ und anderen nahen verwandten Proteinen aus Hefe und dem Menschen dar. Die Analyse wurde mit der „Clustal“" Methode (DNASTAR Lasergene99 Software) mit einem PAM Wert von 250 durchgeführt. Die Länge der Verzweigungen repräsentiert die Distanz zwischen den Sequenzpaaren. Die Einheiten der Skalierung geben die Substitutionsereignisse pro 100 Aminosäuren an. Die aus der GenBank verwendeten Sequenzen haben folgende Zugriffsnummern: Sc Kap121p, emb|Z49212.1; Sc Kap123p, sp|P40069; Hs RanBP7, gb|U71082.1; Xl RanBP7, gb|U71082.1). Abkürzungen: Hs Homo sapiens, Sc Saccharomyces cerevisiae, Xl Xenopus laevis.
\end{abstract}

\title{
3.2.3 Die nukleocytoplasmatische Verteilung von Xenopus Karyopherin $\beta 3$ in transfizierten HeLa Zellen
}

Um die biologische Aktivität des aus Xenopus isolierten Karyopherin $\beta 3 \mathrm{zu}$ überprüfen, wurde ein geeignetes Expressionsplasmid erstellt und transient in HeLa Zellen wie in 2.2.4.6 beschrieben transfiziert. Für die Klonierung wurde die kodierende Sequenz von Karyopherin $\beta 3$ mit den Primern UpIB3E und IB3X in die Schnittstellen Eco RI und Xho I des pCS2+MT Vektors überführt. Die Immunfluoreszenz von Xenopus Karyopherin $\beta 3$ in transfizierten HeLa Zellen zeigt im Gegensatz zu humanem Karyopherin $\beta 3$ (Yaseen und Blobel, 1997) eine ausgeprägtere Anreicherung im Cytoplasma. Wie bei dem humanem Homolog tritt im Nukleoplasma eine perinukleoläre Akzentuierung auf (Abbildung 8). Das Xenopus Protein ist 
also auch in der Lage die Kernmembran in HeLa Zellen in Teilen zu passieren. Neben der hohen Homologie zu dem humanen Karyopherin $\beta 3$ zeigt Xenopus Karyopherin $\beta 3$ in HeLa Zellen also ein ähnliches Verhalten und ist als das nächste Homolog zu humanem Karyopherin $\beta 3$ als Xenopus Karyopherin $\beta 3$ zu bezeichnen.
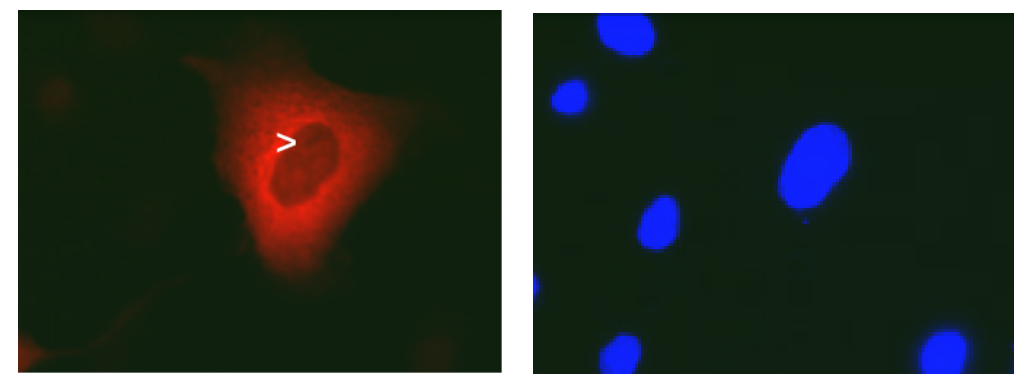

\begin{abstract}
Abbildung 8 : Transfektion von Hela-Zellen mit Xenopus Karyopherin $\beta 3$.
HeLa Zellen wurden mit pCS2+MT Karyopherin $\beta 3$ transfiziert und auf $0,5 \mathrm{~cm}$ Glassplättchen ausgesät. Nach $24 \mathrm{~h}$ Inkubation erfolgte die Fixierung in $2 \%$ Formaldehyd. Anschließend wurden die permeabilisierten Zellen mit dem primären 9E10 anti-myc Antikörper und dem immunfluoreszenzaktiven sekundären Cy3-konjugierten anti Maus Antikörper inkubiert. Die weiße Pfeilspitze markiert eine perinukleoläre Akzentuierung.
\end{abstract}

\title{
3.2.4 Karyopherin $\beta 3$ ist ein differentiell exprimierter Transportfaktor
}

Die Teilsequenz von Karyopherin $\beta 3$ wurde aufgrund eines spezifischen Expressionsmusters in einer Durchmusterung einer Xenopus-Schwanzspitzen-cDNA-Bank (Sölter, 1999) auffällig. Die vollständige Sequenz von Karyopherin $\beta 3$ wurde aus einer Xenopus-KopfcDNA-Bank isoliert. Für eine detaillierte Expressionsanalyse wurde die vollständige Karyopherin $\beta 3$ kodierende Sequenz in einen Vektor kloniert, der es mit einem T7 Promotor ermöglichte, Digoxygenin markierte RNA in ,antisense“ (Gegenstrang) Richtung zu synthetisieren und diese in einer anschließenden "whole mount“ in situ Analyse (2.2.8) einzusetzen. Nach Überführung der kodierenden Sequenz mit den Primern UpIB3EcoR I und IB3Xho I in die Schnittstellen Eco RI und Xho I des pCS2+ Vektors wurde (aus T7 Richtung) Digoxygenin markierte ,antisense“ RNA für eine „whole mount“ in situ Analyse synthetisiert. Mit späten Gastrula / frühen Neurulastadien kann Karyopherin $\beta 3$ vorwiegend in der anterioren Neuralplatte im Bereich vom Augenfeld detektiert werden. Eine schwächere, weiter posterior gelegene Expression ist auf die sensorische Schicht des Neuroektoderms beschränkt. Während der Schwanzknospen- und Schwanzspitzen-Stadien ist eine starke Expression in den Augen, Regionen des Mittelhirns und den Kiemenbögen zu beobachten. In den dorsal gelegenen Bereichen des zentralen Nervensystems ist die Expression von Karyopherin $\beta 3$ generell höher als in den ventralen Bereichen. Die stärkste Expression ist in Vorder- und Mittelhirn zu finden. Eine Ausnahme stellt hier die Hypophyse und das ventrale 
Gewebe des Rückenmarks dar, in denen keine Transkripte detektiert wurden. Im Mes/Metencephalon, dem Pronephros und den terminalen Bereichen des Embryos ist eine schwächere Expression detektierbar.
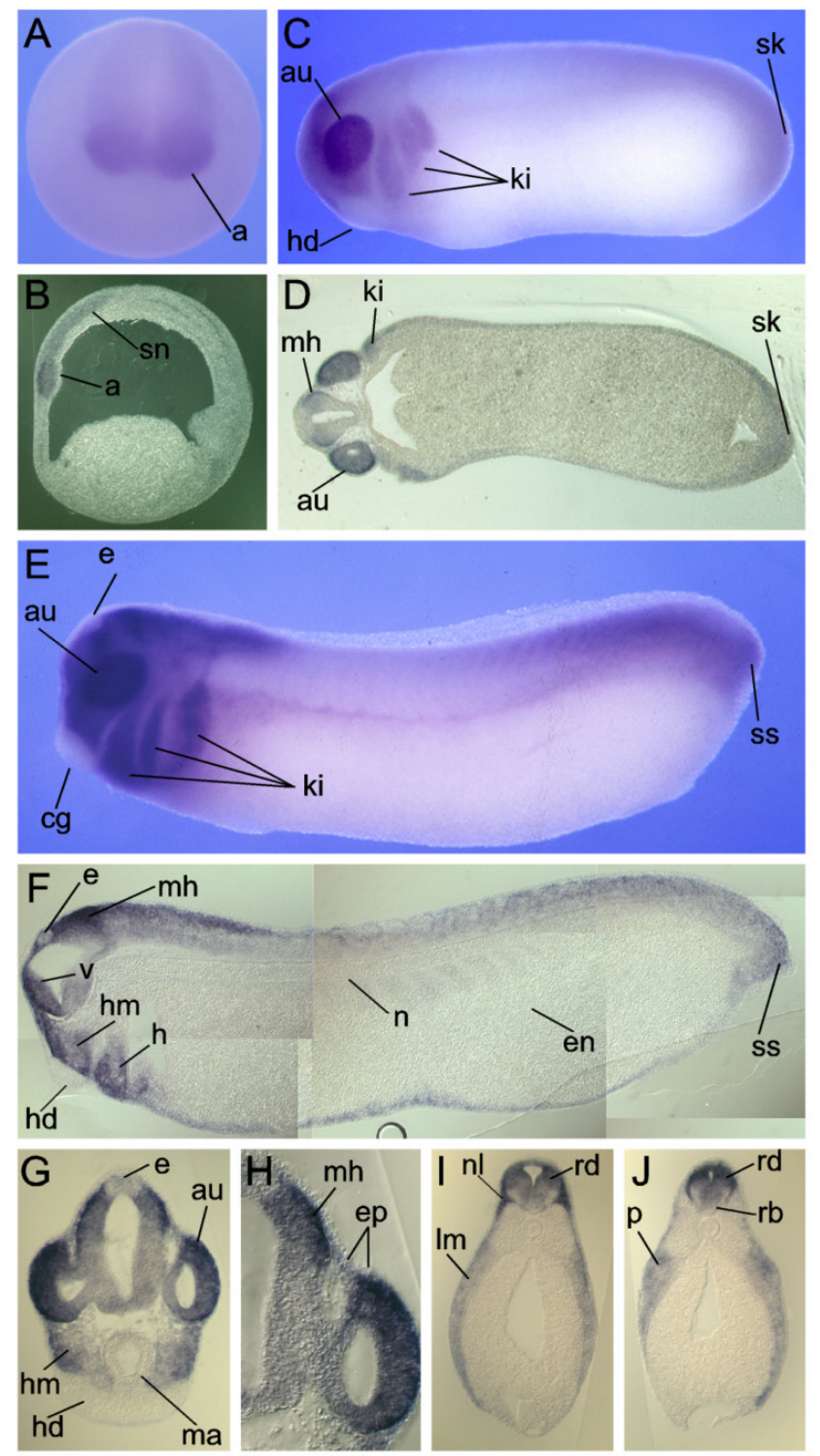

Abbildung 9 : „Whole mount“ in situ Hybridisierung mit Xenopus Karyopherin $\beta 3$ antisense RNA.

Karyopherin $\beta 3$ Transkripte wurden in einer „whole mount“ in situ Hybridisierung mit Digoxigenin markierten Gegenstrang-RNA Sonden von Karyopherin $\beta 3$ in Neurula-, Schwanzknospen- und Schwanzspitzenstadien von Albino-Embryonen detektiert. Geeignete Embryonen wurden in GelatineAlbumin eingebettet und $30 \mu \mathrm{m}$ Vibratomschnitte angefertigt. (A) Die Frontalansicht und (B) der Parasagittalschnitt des Neurulastadiums (Stadium 16) zeigen eine starke Expression von Karyopherin $\beta 3$ in der a, Augenanlage und schwache Expression in der sn, sensorischen Schicht des Neuroektoderms. (C) In der Seitenansicht des Stadiums 23 treten Karyopherin $\beta 3$ Transkripte in dem au, Auge, den ki, Kiemenbögen und in der sk, Schwanzknospe auf. In der hd, embryonalen Haftdrüse ist keine Expression nachweisbar. (D) Im horizontalen Schnitt des Stadiums 23 ist eine starke Expression in dem Auge und den Kiemenbögen zu sehen. Schwächere Expressionslevel sind in dem mh, Mittelhirn und der sk, Schwanzknospe detektierbar. (E) Im Stadium 29 Embryo (auch gezeigt in F-J) sind Karyopherin $\beta 3$ Transkripte in dem Auge, den Kiemenbögen, der ss, Schwanzspitze und in der Region von Vorder- und Mittelhirn stark exprimiert. 
Ausgenommen ist die e, Epiphyse, hier treten keine Transkripte auf. (F) In dem Parasagittalschnitt eines späten Schwanzknospenstadien Embryos ist die Karyopherin $\beta 3$ Expression sichtbar in h, Herz, Schwanzspitze, v, Vorderhirn, Mittelhirn und km, Kopfmesenchym. Keine Expression tritt auf in $\mathrm{n}$, Notochord, en, Endoderm und der embryonalen Haftdrüse. (G) Der Frontalschnitt der Augen/Mittelhirnregion zeigt eine starke Expressionssteigerung in den Augen und der dorsalen Region des Mittelhirns, ein schwächeres Signal wird im Mittelhirnboden und km, Kopfmesenchym detektiert. Keine Expression ist in der embryonalen Haftdrüse, ma, Anlage des Magens und der Epiphyse zu sehen. (H) Die partielle Vergrößerung von G zeigt eine differentielle Verteilung des Signals im Mittelhirn und kein Signal in der ep, Epidermis. (I) Frontaler Schnitt direkt hinter dem Kopf mit starker Expression in der nl, Neuralleiste, dem rd, Rückenmarksdach, und dem lm, lateralen Mesoderm. (J) Posteriorer Schnitt des Embryos. Die Expression in den Rückenmarkszellen ist schwach. Eine stärkere Expression ist sichtbar in der p, Pronephrosregion und in dem rd, Rückenmarksdach. Eine schwache Expression ist in dem rb, Rückenmarksboden detektierbar.

\subsubsection{Ribosomale Proteine und ihre Transportfaktoren definieren eine neue} Synexpressionsgruppe

Expressionsmusteranalysen mit zufällig ausgewählter cDNA zeigten die Existenz von Gengruppen mit stark koordinierter Expression. Gene dieser Gruppen stehen innerhalb der Zelle in einem funktionellem Zusammenhang und werden als Synexpressionsgruppen beschrieben. Die biologischen Prozesse, in die solche Gene involviert sind, reichen von generellen zellulären Aktivitäten wie Transportprozessen des endoplasmatischen Reticulums bis hin zu spezifischen, regulatorischen Prozessen wie beim BMP-4 oder Delta-1 Signalweg (Niehrs und Pollet, 1999). Die differentielle Expression von Proteinen, welche in den nukleocytoplasmatischen Transport involviert sind, ist bisher nur von einigen Karyopherin $\alpha$ Varianten in RT-PCR Analysen oder Northern-Blots beschrieben worden (Kamei et al., 1999; Köhler et al., 1999; Nachury et al., 1998; Tsuji et al., 1997). Karyopherin $\beta 3$ zeigt ein differentielles Expressionsmuster (siehe 3.2.4) und ist vermutlich in den Import ribosomaler Proteine involviert (Yaseen und Blobel, 1997). Die Existenz einer Synexpressionsgruppe bestehend aus ribosomalen Proteinen, ihren Transportfaktoren und assoziierten Proteinen wäre nach den oben angegebenen Beobachtungen naheliegend. Um die Existenz eines solchen gemeinsamen Expressionsprofils nachzuweisen, wurde die Expression verschiedener ribosomaler Proteine, verschiedener putativer Transportfaktoren und verschiedener transportassoziierter Proteine in einer ,whole mount“ in situ Analyse untersucht.

Für die Analyse wurden cDNA Fragmente von L3, L6, L7A, S8 und S3A aus einer homogenen Phagenfraktion, die aus der Durchmusterung einer Xenopus-SchwanzspitzencDNA-Bank (Sölter, 1999) stammen, mit den Primern CMV-F und CMV-R amplifiziert. Die PCR Produkte enthielten einen T7 Promotor. L5 pCS2+ stammt aus unserem Labor (Claußen et al., 1999). Ausgehend von einer in unserem Labor vorhandenen RanTC4 Sequenz wurden 
RanTC4 spezifische Primer entworfen. Das aus einer RT-PCR auf Testis RNA hervorgegangene 500 bp RanTC4 Transkript wurde EcoR I/Xho I in den pCS2+ Vektor überführt. Plasmide mit den Sequenzen von RanBP1 und RanGAP1 wurden von Mary Dasso, XSUMO-1 von Ducan Sparrow, Karyopherin $\alpha 1$ und $\alpha 2$ von Dirk Görlich und Transportin von Gideon Dreyfuss bezogen und wie in Tabelle 4 angegeben in den pCS2+ Vektor überführt.

Indirekt in den nukleocytoplasmatischen Transport involvierte Proteine wie RanTC4 und RanBP1 verhalten sich hinsichtlich ihres Expressionsmusters wie Karyopherin $\beta 3$. Expressionsmuster von Proteinen der großen ribosomalen Untereinheit (L3, L6, L7A und L5) zeigen dasselbe Muster wie Karyopherin $\beta 3$. Für die Expression von ribosomalen Proteinen der kleinen Untereinheit wie S8 und S3A lässt sich ein vergleichbares Muster nachweisen (Abbildung 10 und nicht gezeigt). Das Expressionsmuster aller oben genannten Gene im Xenopus Embryo lässt sich wie folgt beschreiben: Mit der Neurulation tritt ein starkes Expressionssignal in der embryonalen Augenanlage auf. Eine erhöhte Expression ist in der sensorischen Schicht des Neuroektoderms festzustellen. In Schwanzknospen- und frühen Schwanzspitzenstadien tritt ein starkes Signal in Augen, Kiemenbögen, Vorder-, Mittelhirn, den terminalen Embryobereichen und der Schwanzknospe auf. Für andere dem nukleocytoplasmatischen Transport assoziierte Gene, die nicht direkt in den Proteintransport ribosomaler Proteine involviert sind, wie SUMO-1 und p10 (NTF2), konnte ein entsprechendes Expressionsmuster nicht nachgewiesen werden (nicht gezeigt). Interessanterweise zeigten auch die Transportadapter Karyopherin $\alpha 1$ und $\alpha 2$, welche die klassischen NLS binden, in dieser Analyse keine differentielle Expression. Das weist zum einen auf einen anderen funktionellen Zusammenhang für $\alpha 1$ und $\alpha 2$ hin, zum anderen können an dieser Stelle weitere Transportadapter vermutet werden, die den Import von Proteinen mit klassischem Kernlokalisierungssignalsequenzen übernehmen und ein den ribosomalen Proteinen vergleichbares Expressionsmuster zeigen. 


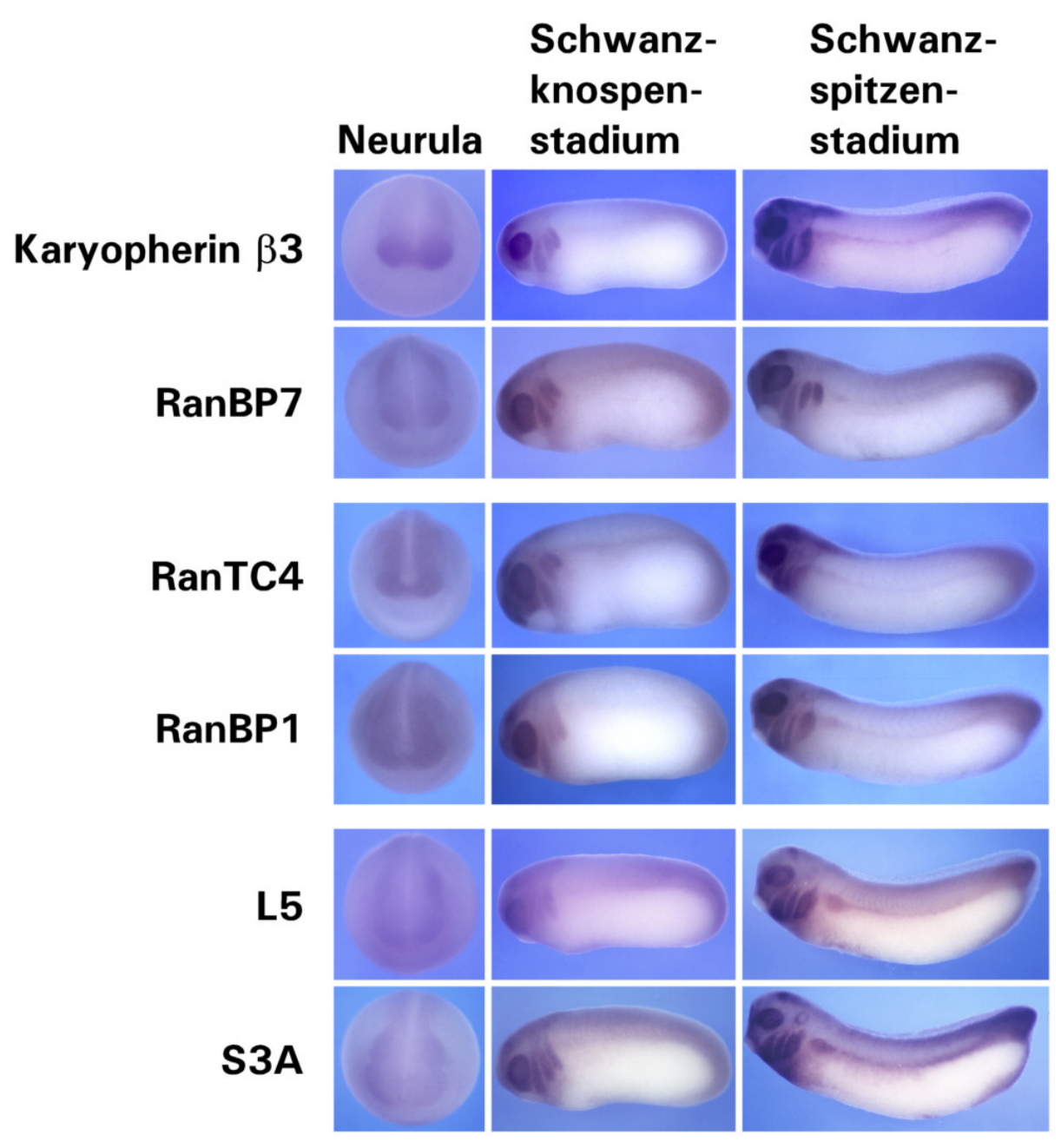

\begin{abstract}
Abbildung 10: Vergleichende Expressionsmusteranalyse.
Gemeinsame Expressionsmerkmale von Transportrezeptoren, transportassoziierten Proteinen und ribosomalen Proteinen. Für Karyopherin $\beta 3$, RanBP7, RanBP1 und L5 wurde in der „whole mount“ in situ Hybridisierung antisense RNA eingesetzt, die komplementär zur gesamten Länge der kodierenden Sequenz war. Partielle antisense Sequenzen wurden für die in situ Hybridisierung von RanTC4 und S3A verwendet. Die dargestellten Beispiele sind in drei Gruppen angeordnet: Transportfaktoren (Karyopherin $\beta 3$ und RanBP7), Transportfaktor assoziierte Proteine (RanTC4 und RanBP1) und ribosomale Proteine (L5 und S3A). Neurulastadien sind in frontaler Ansicht, Schwanzknospen und -spitzenstadien in lateraler Ansicht dargestellt.
\end{abstract}

Für die ribosomalen Proteine L5, L3, L6, L7A, S8, S3A, die transportassoziierten Proteine RanTC4, RanBP1 und die Transportfaktoren Transportin, Karyopherin $\beta 3$ und RanBP7 konnte ein gemeinsames Expressionsprofil nachgewiesen werden. Diese Proteine stehen hinsichtlich ihrer Funktion im nukleocytoplasmatischen Transport bei der Ribosomenbiogenese in einem funktionellen Zusammenhang. Die ribosomalen Proteine sind das Substrat, welches von den Transportfaktoren in das Zielkompartiment, den Zellkern, transportiert wird. Während der Embryonalentwicklung von Xenopus laevis zeigen sowohl ribosomale Proteine als auch die für den Import notwendigen Faktoren beginnend ab dem 
Neurulastadium eine starke Expression in der Region der anterioren Neuralplatte, besonders im Augenfeld. In späteren Stadien tritt neben der starken Expression im Auge eine hohe Expression in Teilen des Gehirns, den Kiemenbögen und der Schwanzspitze auf. Diese Beobachtung des gemeinsamen Expressionsprofils von Proteinen, die in einem funktionellen Zusammenhang stehen, führt $\mathrm{zu}$ der Definition einer neuen Synexpressionsgruppe von ribosomalen Proteinen und ihren putativen Transportfaktoren. Für andere bisher noch nicht identifizierte Transportfaktoren würde man nach dieser Definition ein vergleichbares Expressionsmuster erwarten. Eine optische Selektion auf solche Muster sollte somit die Identifizierung weiterer in den nukleocytoplasmatischen Transport involvierter Gene ermöglichen.

\subsection{Durchmusterung einer cDNA Bank aus embryonalem Augengewebe}

Ribosomale Proteine bilden mit ihren Transportfaktoren eine Synexpressionsgruppe (s.o.). Basierend auf Expressionsmustern in Xenopus Embryonen sollten neue Gene mit einer Funktion im ribosomalen Proteinimport oder Ribosomenexport identifiziert werden. Da eine starke Expression der Gene dieser Synexpressionsgruppe in embryonalen Augen auftritt, wurde eine ZAP-Express cDNA Phagenbank aus poly-A ${ }^{+}$RNA von embryonalem Augengewebe der Stadien 29-34 durch ,whole mount“ in situ Hybridisierung nach optischen Kriterien durchgemustert. Die Sequenzanalyse der resultierenden Klone diente der Eliminierung redundanter Sequenzen und sollte eine funktionelle Zuordnung ermöglichen. Die Expression der Klone in einzelnen Geweben wurde nach ihrer Intensität bewertet. Mit den erhaltenen Werten wurden die Klone in Anlehnung an ein von Eisen und Spellman benutztes Verfahren (Eisen et al., 1998; Spellman et al., 1998) in mehreren Durchläufen anhand von verschiedenen Expressionsvektoren sortiert.

\subsubsection{Eine cDNA Bank aus embyonalem Augengewebe}

Aus mehr als 4000 embryonalen Xenopus Augen, ca. $200 \mu 1$ Gewebe, wurden $347 \mu \mathrm{g}$ GesamtRNA isoliert. Nach Reinigung der messenger-RNA über eine Oligo-dT-Cellulose Säule wurden $6,8 \mu \mathrm{g}$ poly $\mathrm{A}^{+}$RNA erhalten. Für die Synthese von cDNA, welche für die Anfertigung eine cDNA-Phagenbank eingesetzt wurde, wurden $5 \mu \mathrm{g}$ mRNA verwendet. Von der größenfraktionierten cDNA wurden 4 Phagenfraktionen mit 438.000, 170.000, 220.000 und 57.000 Pfu (Plaque formende Einheiten) erhalten. Durch eine PCR auf Einzelphagen und anschließende Bestimmung der Produktgrößen konnte die durchschnittliche Größe in den 
einzelnen Phagenfraktionen ermittelt werden. Die erhaltenen primären Phagenbanken hatten $876 \mathrm{Pfu} / \mu \mathrm{l}$ mit einer durchschnittlichen Insertgröße von 1325 Basenpaaren, $340 \mathrm{Pfu} / \mu 1$ (Insertgröße nicht bestimmt), $440 \mathrm{Pfu} / \mu 1$ mit einer durchschnittlichen Insertgröße von 1212 Basenpaaren und $114 \mathrm{Pfu} / \mu 1$ mit einer durchschnittlichen Insertgröße von 894 Basenpaaren. Da möglichst vollständige Klone isoliert werden sollten wurde die fraktionierte Phagenbank mit $876 \mathrm{Pfu} / \mu \mathrm{l}$ weiterverwendet. Nach Massenexzision der Fraktion mit den größten inserierten Fragmenten wurde die durchschnittliche Insertgröße mit 1470 Basenpaaren bestimmt. Mit PCR-Fragmenten von Einzelklonen aus diesem Bakterienpool wurde Digoxygenin markierte RNA synthetisiert und für eine maschinell durchgeführte „whole mount“ in situ Analyse (siehe 2.2.8.9) zur optischen Detektion von Karyopherin $\beta 3$ ähnlichen Expressionsmustern eingesetzt.

\subsubsection{Statistische Übersicht}

Von 1152 analysierten Klonen wurde bei 989 Klonen ein Expressionssignal nachgewiesen. Das fehlende Signal bei den verbleibenden 168 Klonen ist auf die technische Limitierung der „whole mount“ in situ Prozedur zurückzuführen (Gawantka et al., 1998; Sölter, 1999). 284 Klone zeigen ein starkes differentielles Expressionsmuster und wurden von ihrem 5' Ende aus zum Teil sequenziert. Die erhaltenen Sequenzdaten wurden mit Hilfe der verschiedenen BLAST („Basic Local Alignment Search Tool“) Programme analysiert. 47 dieser Klone traten mehrfach auf und repräsentierten 16 verschiedene Gene (Tabelle 12). Von den 253 nicht redundanten Sequenzen entsprachen 93 (37\%) Sequenzen, die aus Xenopus bekannt sind, für 106 (42\%) der Sequenzen konnten Homologe aus anderen Organismen gefunden werden, und $54(21 \%)$ der Sequenzen waren sowohl auf Protein- als auch auf Nukleotidsequenzebene unbekannt. 


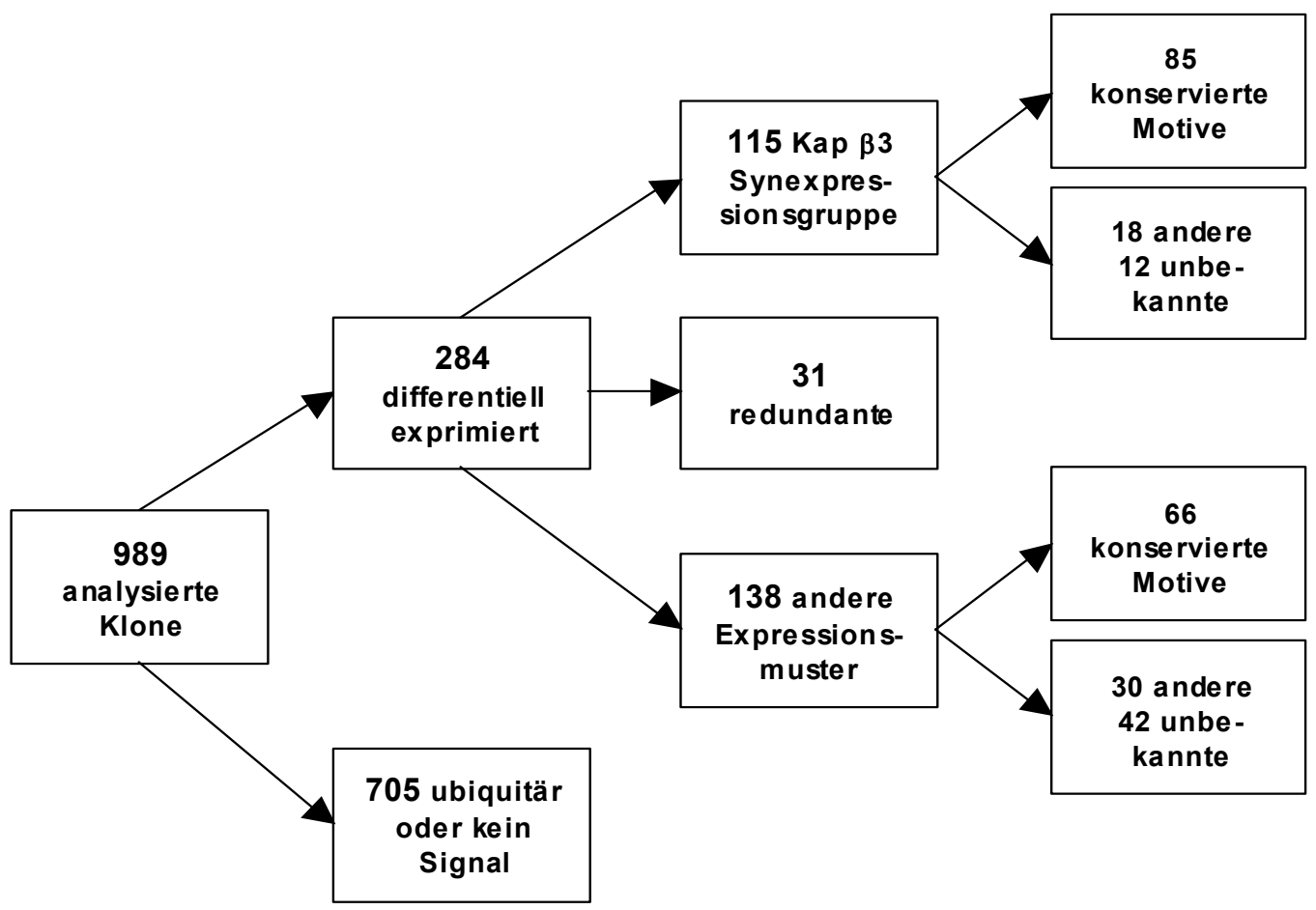

\begin{abstract}
Abbildung 11 : Schematische Übersicht der Expressions- und Sequenzdaten der Durchmusterung einer cDNA-Bank aus embryonalem Augengewebe.

Die Klassifizierung der Klone mit einem Expressionssignal erfolgte zunächst nach ihrem Expressionsmuster, anschließend nach ihrer angenommenen Funktion. Angegeben ist die jeweilige Anzahl der Klone innerhalb der verschiedenen Gruppen. Die Gruppe der Redundanten beinhaltet bekannte, mehrfach isolierte Gene (Tabelle 12), die sowohl der Karyopherin 33 Synexpressionsgruppe zuzuordnen sind als auch andere Expressionsmuster aufweisen. Anderen und unbekannten Klonen konnte keine Funktion zugeordnet werden.
\end{abstract}

Die Gruppierung der Klone nach dem auftretenden Expressionsmusterprofil ergibt als größte Gruppe 115 Klone mit einem Profil, das dem von Karyopherin $\beta 3$ (Wischnewski et al., 2000)entspricht. Innerhalb dieser Gruppe traten Homologe $\mathrm{zu}$ aus Xenopus bekannten Sequenzen mit einem Anteil von 48 \% (55) und Homologe zu Sequenzen aus anderen Organismen mit $42 \%$ (48) auf. Unbekannt waren $10 \%$ (12). Von den 138 Anderen wurden $33 \%$ (45) als homolog zu Sequenzen aus Xenopus und 37 \% (51) als homolog zu Sequenzen aus anderen Organismen eingestuft. Unbekannte innerhalb dieser Gruppe treten mit einem gegenüber der Karyopherin $\beta 3$ Gruppe erhöhten Anteil von $30 \%$ (42) auf (Tabelle 10). Bei Betrachtung der Verteilung von Funktionsgruppen fällt auf, dass DNA-bindende Sequenzmotive innerhalb der Karyopherin $\beta 3$ Synexpressionsgruppe halb so oft auftreten wie im Durchschnitt der anderen Gruppen. Sequenzmotive von Chromatinproteinen sind hingegen mit einem deutlich höheren Anteil in der Karyopherin $\beta 3$ Synexpressionsgruppe als im Durchschnitt der anderen Gruppen zu finden (Tabelle 9). Signifikante Unterschiede in der Verteilung der Sequenzhomologen von RNA bindenden Proteinen zeigen einen um $8 \%$ 
höheren Anteil in der Karyopherin $\beta 3$ Synexpressionsgruppe gegenüber der Summe der anderen Gruppen.

$\begin{array}{lcc} & \mathrm{N}=85 & \mathrm{~N}=66 \\ & \text { Karyopherin } \beta 3 \text { Gruppe } & \text { Andere Gruppen } \\ \text { DNA-bindende Proteine } & 14 \% & 26 \% \\ \text { Chromatin Proteine } & 13 \% & 1,5 \% \\ \text { RNA-bindende Proteine } & 22 \% & 14 \% \\ \text { Kerntransport } & 2 \% & 0 \% \\ \text { Ribosomal } & 16 \% & 0 \% \\ \text { Translation } & 2 \% & 1,5 \% \\ \text { Vesikulärer Transport } & 1 \% & 1,5 \% \\ \text { Strukturprotein } & 4 \% & 18 \% \\ \text { Eisenspeicher Proteine } & 0 \% & 4,5 \% \\ \text { Sonstige } & 25 \% & 33 \%\end{array}$

Tabelle 9: Verteilung der gefundenen Funktionsgruppen.

Prozentuale Verteilung von zugeordneten Sequenzfunktionen innerhalb der Karyopherin $\beta 3$ Synexpressionsgruppe im Vergleich zu der Summe aus anderen Gruppen. Eine Zuordnung der Klone erfolgte zunächst über ihre Nukleinsäurebindungsfähigkeit anschließend wurde soweit möglich nach anderen Funktionen zugeordnet. In der Karyopheringruppe tritt ein Rundungsfehler von $1 \%$ auf.

In Übereinstimmung mit unserer Ausgangshypothese bilden Sequenzhomologe ribosomaler Proteine (14) und Sequenzhomologe transportprozeßbezogener Proteine, wie das in Xenopus neue Karyopherin- $\alpha$ Homolog und Sam68 (siehe unten), mit einem Anteil von $18 \%$ einen Teil der Karyopherin $\beta 3$ Synexpressionsgruppe. Die beiden funktionellen Gruppen (Transport involvierte Proteine und ribosomale Proteine) treten ausschließlich in der Karyopherin $\beta 3$ Synexpressionsgruppe auf.

Für Sequenzmotivhomologe, die in den vesikulären Transport involviert sind, ist im Gegensatz zu Homologen kerntransportassoziierter Proteine kein erhöhter Anteil in der Karyopherin $\beta 3$ Synexpressionsgruppe festzustellen. Der Anteil homologer Sequenzen von Struktur- und Eisenspeicher Proteinen in der Karyopherin $\beta 3$ Synexpressionsgruppe ist deutlich geringer als der Anteil in der Summe der anderen Gruppen (Tabelle 9 und 10). Beide Funktionsgruppen bilden in Bezug auf ihre Expression in Cilienzellen eine Synexpressionsgruppe (Sölter, 1999). 
Karyopherin $\beta 3$ Synexpressionsgruppe

\section{Strukturprotein (3)}

AW158401

Fascin

Tubulin alpha chain (alpha T6)

Translation (2)

Eukaryotic translation initiation factor 2

Translation elongation factor EF-1 gamma

RNA-bindende Proteine (19)

AF302423

AW158433

CG9253 gene product

Cold-inducible RNA-binding protein

DsRNA-binding protein 4F.1 mRNA

Elongation factor 1-alpha

Eukaryotic translation initiation factor 3

HEL117

HnRNP AO protein: A0

HnRNP L

KIAA0099

Non-histone chromosome protein 2

Nucleolin

PolyA binding protein

RNA helicase

Splicing factor

Splicing factor, arginine/serin-rich 2

Translation initiation factor 4

Translation initiation factor elF3 p66 subunit

Ribosomal (14)

12sRNA

$60 S$ acidic ribosomal protein $\mathrm{P} 1$

Ribosomal protein L10

Ribosomal protein L13A

Ribosomal protein $\mathrm{L} 15$

Ribosomal protein L18A

Ribosomal protein $\mathrm{L} 1 \mathrm{a}$

Ribosomal protein L4A (L1A)

Ribosomal protein L8

Ribosomal protein S2

Ribosomal protein S27

Ribosomal protein S3A

Ribosomal protein SA

Ribosomal protein SA (P40)

DNA bindende Proteine (12)

ATF4 (AB013138)

Chromatin remodelling factor SWI1Lalpha

COUP transcription factor $1 \mathrm{mRNA}$

$\mathrm{H} 3$

HMG1

HnRNP A/B homology (Transkriptionsrepressor)

\section{Sonstige Expressionsmuster}

\section{Strukturprotein (12)}

X. I. Cofilin 1

X. I. EG5

X. I.

T. m. Lamin B1

X. I.

X.I.

H. s.

H. s. Targeting protein for Xklp2; TPX2 X. I.

X.I. Tubulin alpha $1 \quad$ M. m. Tubulin alpha $6 \quad$ M. m.

X. I. Tubulin alpha chain X.I.

X.I. Tubulin alpha chain X.I.

D. $m$. Tubulin beta $5 \quad$ M. m.

X. I. Tubulin beta-2 chain X. I.

X.I. Tubulin-alpha M. mu.

X. I. Translation (1)

H. s. AW642277 X.I.

R. n. RNA-bindende Proteine (9)

H. s. AF092565 H. s.

H. s. DKFZP564M2423, mRNA H. s.

H. s. L10911 splicing factor H.s.

H. s. Nrp-1B X.I.

X. I. RNA helicase Gu - human (fragment) H. s.

X. I. RNA polymerase II, elongation factor H. s.

H. s. tRNA-ribosyl-transferase O.c.

H. s. U1 SNRNPA X.I.

M. m. XFG 5-1 and XFG 5-2 X. I.

H. s. Eisenspeicher (3)

H. s. Ferritin heavy chain 1 X. I. Ferritin heavy chain $2 \quad$ H. s.

X. I. Iron storage protein $\mathrm{H}$-ferritin $\quad$ T. v.

M. m. DNA bindende Proteine (17)

H. s. AK027067 H.s.

S. s. ATONAL protein HOMOLOG 3 X.I.

X.I. DNA methyltransferase 1 X.I.

R. n. EGR1 X.I.

X.I. H2A H.s.

X.I. Homeobox protein SMOX-3 S. m.

X.I. Hypothetical protein HES6 H. s.

M. m. KIAA1341 protein H.s.

X. I. LIM domain-containing homeodomain LH-2A G. g.

O. I. Neurogenic differentation factor $1 \quad X . I$.

U. c. Otx-2 X.I.

G. g. Pax6 X.I.

Ribonucleotide reductase R1 class I D. $r$.

G. g. Ribosomal transcription factor xUBF X. I.

H. s. SSB1 X.I.

X. I. Transcription elongation factor TFIIS X.I.

H. s. TXz.1 transposase pseudogene P.p.

G. g. Chromatin Proteine (1)

G. g. Heterochromatin protein 1 gamma X.I. 
Karyopherin $\beta 3$

Synexpressionsgruppe (Fortsetzung, DNA bindende Proteine)

Hypothetical protein DKFZp761D081

Q61412 homeobox protein

Q9UN16 protein inhibitor of activated STAT

SSB2

Xath-3.

Zygotic DNA replication factor MCM6b

\section{Chromatin Proteine (11)}

14-3-3 protein epsilon

AF109733

BE189131

Histone deacetylase 1-2

HMG-17

KIAA1047

Probable histone deacetylase 1-1 (HD1)

SSXT protein

TCF-3 co-repressor CTBP

WS-betaTRP

XCAP-C

Vesikulärer Transport (1)

KIAA0755 gene product

Kerntransport (2)

Karyopherin $\alpha 3$

Sam68deltaKH

Sonstige (21)

Acetolactate synthase

ADE2

Apoptosis inhibitor survivin

CDC47-2p

FK506-binding protein

Glutamine synthetase

HEC

methylenetetrahydrofolate dehydrogenase

$\mathrm{NADH}$ dehydrogenase subunit 4

Ornithine decarboxylase (ODC)

PGLa

Phospholipase C-gamma-1a

Progesterone receptor complex P23

Proteasome subunit $\mathrm{L}$

Proteasome theta-chain, -component C10-II

Q9NPJ1

RACK1

Radical fringe

Ubc9p

Ubiquitination factor E4B

Uridine kinase

Unbekannte Funktion (12)

WDR 3

P4.1 TFF gene

Nucleolar phosphoprotein

\section{Sonstige Expressionsmuster}

(Fortsetzung)

H. s. Vesikulärer Transport (1)

M. m. COP-coated vesicle membrane protein P24 C. g.

H. s. Sonstige (22)

X. I. Adenosylhomocysteinase 2 X. I.

X. I. AF218007

X. I. Alkyldihydroxyacetonephosphate synthase

H. s.

C. p.

B. t.

X.I. CIDE-A M. m.

H. s. Creatine kinase G. g.

X. I. Creatine kinase (EC 2.7.3.2) isozyme IV X. I.

X.I. Cullin 3 H. s.

X.I. Cytochrome B X.I.

H. s. Cytochrome C oxidase polypeptid I X.I.

X. I. Disabled H. s.

H. s. HIRA interacting protein $4 \quad H . s$.

X. I. IdX X.I.

H. s. KIAA1564 H.s.

X. I. Methionine adenosyltransferase II, alpha H. s.

NADH dehydrogenase H. s.

H. s. NADH dehydrogenase subunit $5 \quad X . I$. P75NTRa X. I.

H. s. Pterin-4-alpha-carbinolamine dehydratase X.I.

H. s. REM 1 sequence X.I.

H. s.

H. s. Ubiquitin specific protease 8 H.s.

G. g. Unbekannter Funktion (18)

H. s. AB015330 H.s.

X.I. AC004982 H.s.

X.I. AE003524, CG6479 gene product

X. I. AL035289 hypothetical protein H. s.

H. s. Arginine-rich protein H.s.

X.I. AW147681 X.I.

X. I. Beta-B1 crystallin M. m.

X.I. Exostosin-1 M. m.

X.I. FLJ00069 H.s.

X. I. FLJ10142 hypothetical protein H. s.

H. s. KIAA0874 protein H. s.

R. n. Ndr1 M. m.

O. m. Nonsyndromic hearing impairment protein M. m.

H. s. Phosphoneuroprotein 14 R. n.

X. I. Syntrophin, beta 2 H. s.

X.I. Tanabin X.I.

X.I. XP_001712.1 H.s.

H. s. Zinc finger protein $147 \quad H . s$.

D. r. Homologie zu EST-Sequenzen (12)

AW633329

X.I. AW636607 X.I.

X.I. AW640142 X.I. 


Karyopherin $\beta 3$
Synexpressionsgruppe (Fortsetzung,
unbekannte Funktion)
Mab21
KIAA1726
L32987
X05025
DKFZP564M2423 protein
CG11103 gene product
ARS2
AK022728
AF312865
Homologie zu EST-Sequenzen (6)
BG161660
BF612543
AW646388
AW637346
AW637133
AW634714
Unbekannte (12)
12 x -

Sonstige Expressionsmuster (Fortsetzung, Homologie zu ESTSequenzen)

$\begin{array}{lll}\text { X.I. } & \text { AW640241 } & \text { X.I. } \\ \text { H. s. } & \text { AW640420 } & \text { X.I. } \\ \text { P.w. } & \text { AW640554 } & \text { X.I. } \\ \text { X.I. } & A W 643835 & \text { X.I. } \\ \text { H.s. } & \text { AW645913 } & \text { X.I. } \\ \text { D. m. } & \text { BE507779 } & \text { X.I. } \\ \text { H. s. } & \text { BF231815 } & \text { X.I. } \\ \text { H. s. } & \text { BF614695 } & \text { X.I. }\end{array}$

H. S. Unbekannte (42) $42 x-$

X. I.

X. I.

X. I.

X. I.

X. I.

X. I.

Tabelle 10: Identifizierung homologer Sequenzen von Klonen der Karyopherin $\beta 3$ Synexpressionsgruppe und Klonen sonstiger Expressionsmuster.

Nach molekularer Funktion geordnete Liste der in der Durchmusterung aufgetretenen ähnlichen Datenbanksequenzen mit der zugehörigen Spezies. Die homologen Motive stammen aus folgenden Spezies: B. t. Bos taurus, D. r. Danio rerio, D. m. Drosophila melanogaster, M. m. Mus musculus, M. mu. Macaca mulatta, C. p. Cavia porcellus, C. g. Cricetulus griseus, G. g. Gallus gallus, H. s. Homo sapiens, O. 1. Oryzias latipes, O. m. Oncorhynchus mykiss, O. c. Oryctolagus cuniculus, P. w. Pleurodeles waltlii, P. p. Pleuronectes platessa, R. n. Rattus norvegicus, S. m. Schistosoma mansoni, S. s. Sus scrofa, T. m. Torpedo marmorata, T. v. Trichosurus vulpecula, U. c. Urechis caupo, X. 1. Xenopus laevis, - bisher unbekannte Sequenzen.

Aus der von embryonalem Augengewebe erstellten cDNA Bank konnten 115 Klone isoliert werden, die nach optischen Kriterien ein Karyopherin $\beta 3$ artiges Expressionsmuster zeigen. Klone von Genen, die in den nukleocytoplasmatischen Transport involviert sind, wie auch Klone ribosomaler Gene wurden ausschließlich in der Karyopherin $\beta 3$ Synexpressionsgruppe gefunden. Klone, die Sequenzen enthielten, die in andere Transportwege involviert sind, zeigten im Gegensatz zu Klonen des nukleocytoplasmatischen Transports keine spezifische Verteilung. Die Sequenzanalyse der Klone mit Karyopherin $\beta 3$ artigem Expressionsmuster zeigt eine signifikante Anreicherung von Sequenzen ribosomaler Proteine (16\% gegenüber 0 \%). Dieser erhöhte Anteil ribosomaler Klone, der auf die optische Selektion in der vorgestellten Analyse zurückzuführen ist, zeigt, dass es möglich ist, Gengruppen, welche in einem funktionellem Bezug zueinander stehen, nach der hier vorgestellten Methode anzureichern. Putative Transportfaktoren ribosomaler Proteine und Transport assoziierte 
Proteine zeigen dasselbe Expressionsmuster wie ribosomale Proteine und sollten, da sie für den Import ribosomaler Proteine benötigt werden und somit in einem funktionellem Zusammenhang mit den ribosomalen Proteinen stehen, in mit dem hier vorgestellten Verfahren ebenfalls isoliert werden können. In der Tat konnten 2 Klone, Sam68 und Karyopherin $\alpha 3$, isoliert werden, die in den nukleocytoplasmatischen Transport involviert sind. Die Anreicherung von Klonen mit einer Funktion bei dem nukleocytoplasmatischen Transport läge somit bei $2 \%$.

Karyopherin $\beta$ verwandte Proteine weisen eine hohe Diversität auf. Somit kann in einer Datenbankanalyse mit einfachen BLAST Algorithmen nicht davon ausgegangen werden, dass Homologien von bisher unbekannten Transportfaktoren zu bekannten Transportfaktoren identifiziert werden. Verwendet wurden hier auch nur Teilsequenzen der isolierten Klone. Eine Erfassung von putativen Transportfaktoren ist somit immer dann ausgeschlossen, wenn der homologe Bereich vom jeweiligen Klon außerhalb der im BLAST eingesetzten Sequenz liegt. 30 Klonen mit Karyopherin $\beta$ artigem Expressionsmuster konnte keine Funktion zugeordnet werden. Möglicherweise können sich unter den 30 Klonen weitere, in den nukleocytoplasmatischen Transport involvierte Gene befinden (siehe unten), was dann auch zu einer Anreicherung der in den Kerntransport involvierten Klone von mehr als $2 \%$ führen würde.

\subsubsection{Sam68, ein Protein, welches möglicherweise am Export von RNA mit CTE oder RRE beteiligt ist}

Einer der beiden in der Durchmusterung der cDNA Bank aus embryonalem Augengewebe isolierten Klone ist homolog zu Sam68. Retrovirale mRNA kann über zwei verschiedene Wege exportiert werden. Eine Möglichkeit ist der CRM-1 abhängige Export über das HIV-1 Rev-Protein und das RRE (Rev Response Element) der RNA, ein anderer Exportweg ist CRM-1 unabhängig. Über das CTE (Constitutive Transport Element) binden zwei in den Export verwickelte Proteine, Tap und die RNA Helicase A. Expression von RNA mit RRE kann ebenfalls Rev unabhängig von Sam68 vermittelt werden. Sam68 ist ein Protein mit ungewöhnlichem, C-terminalem, 24 Aminosäuren langem Kerntransportsignal, das ein in verschiedenen RNA-bindenden Proteinen konserviertes Motiv, PPXXR, enthält, welches beispielsweise auch in hnRNP Proteinen zu finden ist (Ishidate et al., 1997). Die RNA Helicase A bindet in vivo und in vitro an Sam68 und Tap. In Gegenwart von Tap führt eine Überexpression von Sam68 zur Aktivierung CTE- oder RRE-regulierter ReporterGenexpression (Reddy et al., 2000). In Übereinstimmung mit seinem Expressionsmuster und 
der Bindung an Tap und Helicase A ist Sam68 ein Protein, welches aufgrund seiner putativen Funktion in die Gruppe der Kerntransportproteine einzuordnen ist.

\subsubsection{Eingrenzung der Kandidatenklone auf putative Ran bindende Proteine}

Von den durchgemusterten Klonen der cDNA Bank aus embryonalem Augengewebe konnte 85 Klonen nach der Sequenzanalyse mit dem Blast Programm eine eindeutige Funktion zugeordnet werden. Die verbleibenden 30 Klone mit Karyopherin $\beta 3$ artigem Expressionsmuster zeigten in den Resultaten des Blast Programms keine auffälligen Homologien zu bekannten Transportfaktoren. Um eine weitere Eingrenzung von Kandidatengenen vorzunehmen, wurde mit verschiedenen Sequenzanalyseprogrammen nach Ähnlichkeiten zu verschiedenen Mustern von bekannten, in den Kerntransport involvierten Proteinen gesucht.

Die Gruppe der Karyopherin $\beta$ artigen Transportrezeptoren wird von einer Anzahl von Proteinen gebildet, die sich durch ihre Fähigkeit, Ran $\mathrm{zu}$ binden, auszeichnen. Phylogenetische Analysen der Karyopherin $\beta$ verwandten Proteine beschränken sich oft auf einen bis zu 300 Aminosäuren erstreckenden Bereich in der Umgebung der Ran bindenden Domäne (RanBD) der einzelnen Proteine, da sonst der Abstammungsbaum an Konsistenz verlieren würde (Görlich et al., 1997; Ohno et al., 1998). Die Ran Bindung erfolgt über die Ran bindende Domäne (RanBD). Die RCC1 Signaturen sind abgeleitet von dem Ran bindenden Protein RCC1 und erfassen auch die Karyopherin $\beta$ artigen Transportrezeptoren (siehe unten). Neben der Ran bindenden Domäne oder der RCC1 Signatur gibt es keine weiteren Sequenzmotive, die eine Gruppenzuordnung erlauben würden. Ziel der Durchmusterung war die Identifizierung von Transportrezeptoren, die vermutlich eine RanBD enthalten. Mithilfe der RCC1 Signatur sollte die Gruppe der Kandidaten für eine detailliertere Analyse ihrer Funktion hinsichtlich des nukleocytoplasmatischen Transports weiter eingegrenzt werden.

Das PROSCAN Programm ist ein Werkzeug mit dem Sequenzen fehlertolerant gegen die PROSITE Datenbank abgesucht werden können. In der PROSITE Datenbank sind biologisch signifikante Muster und Profile formuliert, die es mit geeigneten Computerprogrammen erlauben eine Verwandtschaft von der Sequenz eines unbekannten Proteins zu Domänen bekannter Proteinfamilien aufzudecken. Bei Sequenzen, denen keine putative Funktion zugeordnet werden konnte (30 von 115), wurde mit dem PROSCAN Programm nach verschiedenen Signaturen gesucht, die ebenfalls in den bekannten Transportfaktoren zu finden sind. Humanes Karyopherin $\beta$ z. B. besitzt eine zu $52 \%$ der RCC1 Signatur ähnliche 
Sequenz. Ähnlichkeiten zu der ABC-Transportersuperfamiliensignatur (ATP binding cassette superfamily) können mit bis zu 77 \% gefunden werden. Zu 38 Signaturen von ribosomalen Proteinen besteht eine Ähnlichkeit von 50-72 \%. Von den 30 Klonen sind 7 zu mindestens 50 $\%$ der RCC1 Signatur ähnlich, 9 der ABC-Transporterfamiliensignatur und 12 den Signaturen ribosomaler Proteine. Alle drei Klassen von Signaturen weisen 5 der abgeleiteten Sequenzen (bzw. der Homologen) auf. Sie könnten Gene von Proteinen repräsentieren, die mit Ran interagieren und in den nukleocytoplasmatischen Transport involviert sind.

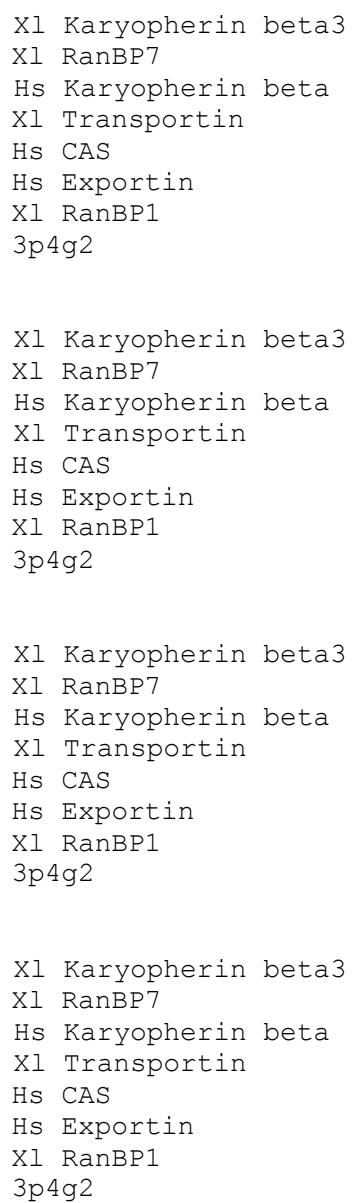

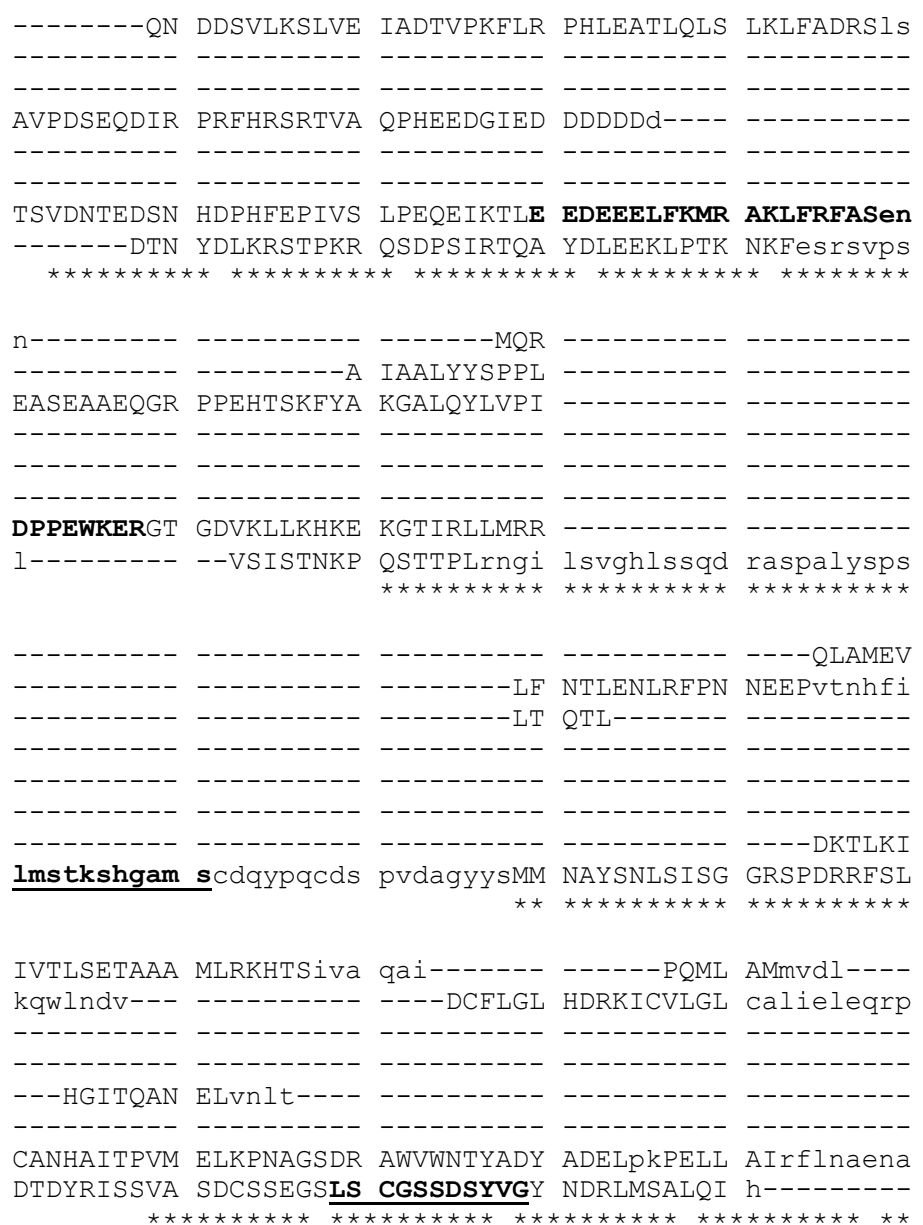

\begin{abstract}
Abbildung 12: Auszug einer Dialign Analyse der abgeleiteten Sequenz des 3p4g2 Klons.
Dargestellt ist ein ausgewählter Abschnitt einer Dialign Analyse mit der abgeleiteten Sequenz des 3p4g2 Klons. Verwendet wurde der größte in der partiellen Sequenz ermittelte Leserahmen. Fett markiert ist die Ran bindende Domäne von RanBP1. Fett markiert und unterstrichen sind Sequenzen, die in der PROSCAN Analyse eine Homologie zur RCC1 Signatur aufwiesen. Die Sterne unter den jeweiligen Sequenzabschnitten geben die Qualität der Homologie an. Maximal 5 Reihen Sterne werden von dem Programm vergeben, wenn bei 6 von 8 der zur Analyse eingereichten Proteinsequenzen ein homologer Bereich identifiziert wurde. Abkürzungen: Hs Homo sapiens, X1 Xenopus laevis.
\end{abstract}

Das Dialign Programm erkennt Homologien in entfernt miteinander verwandten Proteinen, auch wenn sie über eine längere Sequenz keine Sequenzähnlichkeiten aufweisen. Eine Homologie über mehrere längere Aminosäuresequenzen konnte mit dem Dialign Programm 
(Morgenstern, 1999) bei 5 Sequenzen festgestellt werden. Zur Veranschaulichung der mit dieser Art der Analyse gewonnenen Daten ist in Abbildung 12 das exemplarische Beispiel ausgewählter Abschnitte einer Dialign Analyse mit integrierten PROSCAN Resultaten der abgeleiteten Sequenz von dem 3p4g2 Klon dargestellt. Auffällig ist in diesen dargestellten Abschnitten auch das Fehlen von gefundenen Homologien zu dem Superfamilienmitglied Exportin, welches in der Analyse generell nur kurze Abschnitte homologer Bereiche aufwies, was die oben erwähnte hohe Diversität in der Superfamilie verdeutlicht.

Von den 30 Klonen mit einem Expressionsmuster, das dem von Karyopherin $\beta 3$ entspricht, und bei denen mit ihrer abgeleiteten Sequenz keine Funktionszuordnung getroffen werden konnte, wurde bei 5 eine RCC1 Signatur festgestellt. Eine weitere Bestätigung der Eingrenzung der Kandidaten auf 5 Klone erfolgte mit dem Dialign Programm, das eine Homologie der Kandidaten zu Karyopherin $\beta$, RanBP7 und Karyopherin $\beta 3$ über einen größeren Bereich mehrerer Proteindomänen aufdecken konnte. Eine gesicherte Aussage über die Funktion der Klone 3p4g2, 3p6g11, 3p11a6 und 3p21e7 ist aufgrund der Homologie zur RCC1 Signatur nicht möglich, da eine theoretische Analyse mit dem Prosite Programm nur Hinweise auf die mögliche Einordnung einer Sequenz in eine Superfamilie geben kann. Die Homologie zur RCC1 Signatur liegt bei allen 5 Klonen jedoch über 52 \%, d.h., sie ist größer als die Homologie von Karyopherin $\beta$ zur RCC1 Signatur. Diese 5 Klone könnten somit Ran binden. Mit der Dialign Analyse wurden für die 5 Klone mehrere Bereiche mit Sequenzähnlichkeiten zu Mitgliedern der Karyopherin $\beta$ Superfamilie gefunden.

\begin{tabular}{|l|l|l|}
\hline Klon & RCC1 Signaturen (\% Homologie) & Dialign (As Anzahl) \\
\hline 3p4g2 & $59,45,52,51$ & 51, in Folge 44, 48 und 63 \\
\hline 3p6g11 & $53,52,55,56,69,57,51$ & $40,22,51$ und 29 \\
\hline 3p11a6 & 62 & $47,36,27$ \\
\hline 3p21e7 & $75,52,53$ & $61,37,34$ \\
\hline 3p19a3 & 57 & 21,40 mit großer Lücke \\
\hline
\end{tabular}

Tabelle 11: Tabellarische Auflistung der Kandidatengene.

Die mit dem PROSCAN Programm ermittelten Homologien zur RCC1 Signatur sind in Teilen von Hundert angegeben. Die Länge der vom Dialign Programm ermittelten homologen Bereiche von Klonen unbekannter Funktion ist im Vergleich zu X. 1. Karyopherin $\beta 3,1093$ As, X. 1. RanBP7, 1038 As, H. s. Karyopherin $\beta$, 876 As, X. 1. Transportin, 717 As, H. s. CAS, 971 As, H. s. Exportin, 962 As, X. 1. RanBP1, 209 As dargestellt. Angegeben ist in Spalte zwei in Prozent die Homologie zur RCC1 Signatur. In Spalte drei ist die Anzahl, der mit dem Dialign gefundenen homologen Aminosäuren über eine Sequenzlänge von mindestens 20 Aminosäuren angegeben. 
In der Karyopherin $\beta$ Superfamilie ist eine konsistente Darstellung der Verwandtschaftsbeziehungen aufgrund der hohen Diversität der Karyopherin $\beta$ artigen Proteine kaum möglich. Am besten wird dies durch die Ran bindenden Proteine Exportin 4, RanBP16 und Ran BP17 verdeutlicht, deren Einordnung in ein Verwandtschaftsdiagramm der Superfamilie nur mit dem Dialign Programm gelungen ist (Kutay et al., 2000). Aufgrund der starken Sequenzabweichungen innerhalb der Karyopherin $\beta$ Superfamilie wurde eine Verwandschaftsanalyse, die von Karyopherin $\beta$ bis CAS reicht, bisher nur mit den ersten 300 Aminosäuren durchgeführt, da der phylogenetische Baum andernfalls an Konsistenz verlieren würde (Görlich et al., 1997). Selbst unter den in der Referenz verwendeten Bedingungen ist die Sequenzverwandtschaft zwischen den Mitgliedern der Superfamilie nur schwer nachvollziehbar. Eine Homologie kann demzufolge mit den klassischen Mitteln nicht unbedingt nachgewiesen werden.

Vor diesem Hintergrund sind die ermittelten Daten als Hinweis auf eine mögliche Funktion $\mathrm{zu}$ bewerten, welche die Kandidatenklone 3p4g2, 3p6g11, 3p11a6 und 3p21e7 deutlich von den verbleibenden 26 Klonen abhebt. Eine Einordnung in die Gruppe der möglicherweise in den nukleocytoplasmatischen Transport involvierten Proteine kann erst nach Vervollständigung der Sequenz der verbleibenden Kandidaten und einer Analyse der Ran Bindungsfähigkeit erfolgen.

\subsubsection{Karyopherin $\alpha 3$ ist ein neues Karyopherin $\alpha$ Homolog}

Der zweite Klon, der durch die Durchmusterung der cDNA Bank aus embryonalem Augengewebe isoliert werden konnte, ist Xenopus Karyopherin $\alpha 3$. Der erhaltene Klon war in seiner 5' Sequenz nicht vollständig. Anhand der zu Karyopherin $\alpha 3$ passenden EST Sequenzen BE506353, BF427949 und AW147413 wurde der 5' Primer Kalpha3E entworfen und die Sequenz in anschließenden Klonierungen um die fehlenden 24 Nukleotide vervollständigt. Mit den Primern Kalpha3E und Kalpha3X wurde die Karyopherin $\alpha 3$ Sequenz in den pCS2+ Vektor in die Schnittstellen EcoR I und Xho I überführt. Das resultierende Plasmid wurde für weitere Experimente eingesetzt. Karyopherin $\alpha 3$ besitzt eine relative Molekülmasse von 57552 Dalton. Das Protein besteht aus 526 Aminosäuren. Xenopus Karyopherin $\alpha 3$ ist zu $62 \%$ identisch mit dem Xenopus $\alpha 1$ und zu $78 \%$ ähnlich. Die ersten 102 N-terminalen Aminosäuren repräsentieren nach Homologie die Karyopherin $\beta$ Bindungsdomäne. Der C-terminale Rest des Proteins besteht nach Homologie aus 10 Armadillo artigen Sequenzmotiven. Karyopherin $\alpha 3$ ist aus der Durchmusterung der cDNA Bank aus embryonalem Augengewebe hervorgegangen und wird im Gegensatz zu 
Karyopherin $\alpha 1$ in Neurula- und Schwanzspitzenstadien differentiell exprimiert (s.o.). Im Vergleich zu humanem Karyopherin $\alpha 1$ besteht eine Identität von $74 \%$ und eine Ähnlichkeit von $87 \%$. Es ist als nächstes verwandtes Karyopherin $\alpha$ zu humanem Karyopherin $\alpha 1$ und den Xenopus Varianten $\alpha 1$ und $\alpha 2$ in die erste Klasse der $\alpha$ Karyopherine einzuordnen (siehe Abbildung 14).

H.S. Karyopherin $\alpha 1$ MSTNENANTPAARLHRFKNKGKDSTEMRRRR IEVNVELRKAKKDDQMLKRRNVSSFPDDA 60

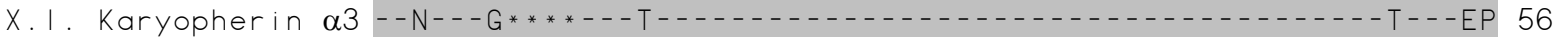

TSPLQE*NRNNQGTVNWSVDD I VKG INSSNVENQLQATQAARKLLSREKQPP I DNI IRAG 119 - - - - - K-Q-G-TSSQ---EE--R-VANPSLDI-- - - - - - - - RE- - - R- -K- - 116

LIPKFVSFLGRTDCSPI QFESAWALTNIASGTSEQTKAVVDGGA IPAF ISLLASPHAHIS 179

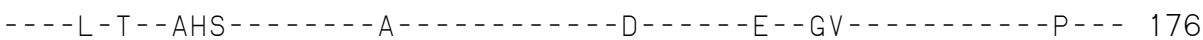

EQAVWALGNI AGDGSVFRDLVIKYGAVDPLLALLAVPDMSSLACGYLRNLTWTLSNLCRN 239

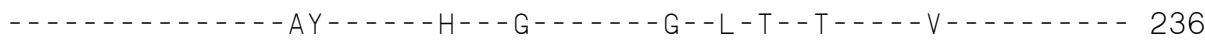

KNPAPP I DAVEQ I LPTLVRLLHHDDPEVLADTCWA I SYLTDGPNER I GMVVKTGVVPQLV 299

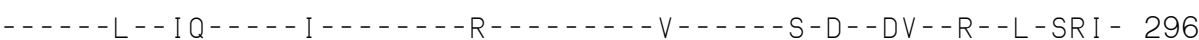
KLLGASELP I VTPALRA I GN IVTGTDEQTQVVIDAGALAVFPSLLTNPKTNIQKEATWTM 359

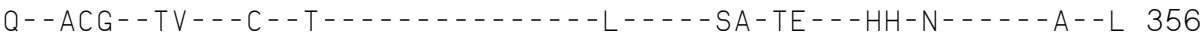
SNITAGRQDQ I QQVVNHGLVPFLVSVLSKADFKTQKEAVWAVTNYTSGGTVEQIVYLVHC 419

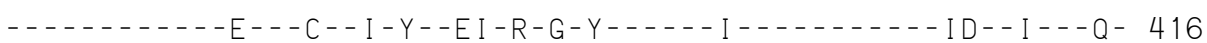
G I IEPLMNLLTAKDTK I I LVILDA I SN IFQAAEKLGETEKLS IMIEECGGLDK IEALQNH 479

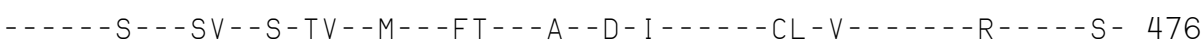
ENESVYKASLSL IEKYFSVEEEEDQNVVPETTSEGYTFQVQDGAPGTFNF 529 - - - Q-- - - AA-- - - A-DG- -ESLA-- - AD--A-- EG-THT-- - 526

\footnotetext{
Abbildung 13: Sequenzvergleich von Xenopus Karyopherin $\alpha 3$ mit dem humanem $\alpha 1$ Homolog. Aminosäuresequenzvergleich von Xenopus Karyopherin $\alpha 3$ mit dem humanen $\alpha 1$ Homolog (Zugriffsnummer: P52292). Identische Aminosäuren sind durch Bindestriche dargestellt, Deletionen werden durch Sterne angezeigt. Karyopherin $\alpha 3$ ist zu $74 \%$ identisch zu $\alpha 1$ und zu $87 \%$ ähnlich. Die durch Homologie identifizierte Karyopherin $\beta$ bindende (IBB) Domäne von der Xenopus Karyopherin $\alpha 3$ Variante wurde grau hinterlegt.
} 


\title{
3.4 Isolierung der in Xenopus neuen Karyopherin $\alpha$ Homologen $\alpha 4$ und
}

\section{$\alpha 5$}

Der anhand der EST Sequenz AW636855 erstellte Primer Alp430erF, der 39 Nukleotide „downstream“ des Startcodons in der 5' UTR von Karyopherin $\alpha 4$ liegt, und der anhand der EST Sequenz BF048642 entworfene Primer Alp533erF, der 17 Nukleotide „downstream“ vom Startcodon liegt, wurde benutzt, um die kodierende Sequenz mit dem „SMART RACE cDNA Amplification Kit“" zu amplifizieren und in den AT-Klonierungsvektor pGemT zu überführen. Für die geplanten Experimente wurden die kodierenden Sequenzen mit den in Tabelle 4 angegebenen Primern und Schnittstellen in die Vektoren pCS2+ und pCS2+MT überführt. Die erzeugten Plasmide wurden mit den in Tabelle 5 angegebenen Primern sequenziert.

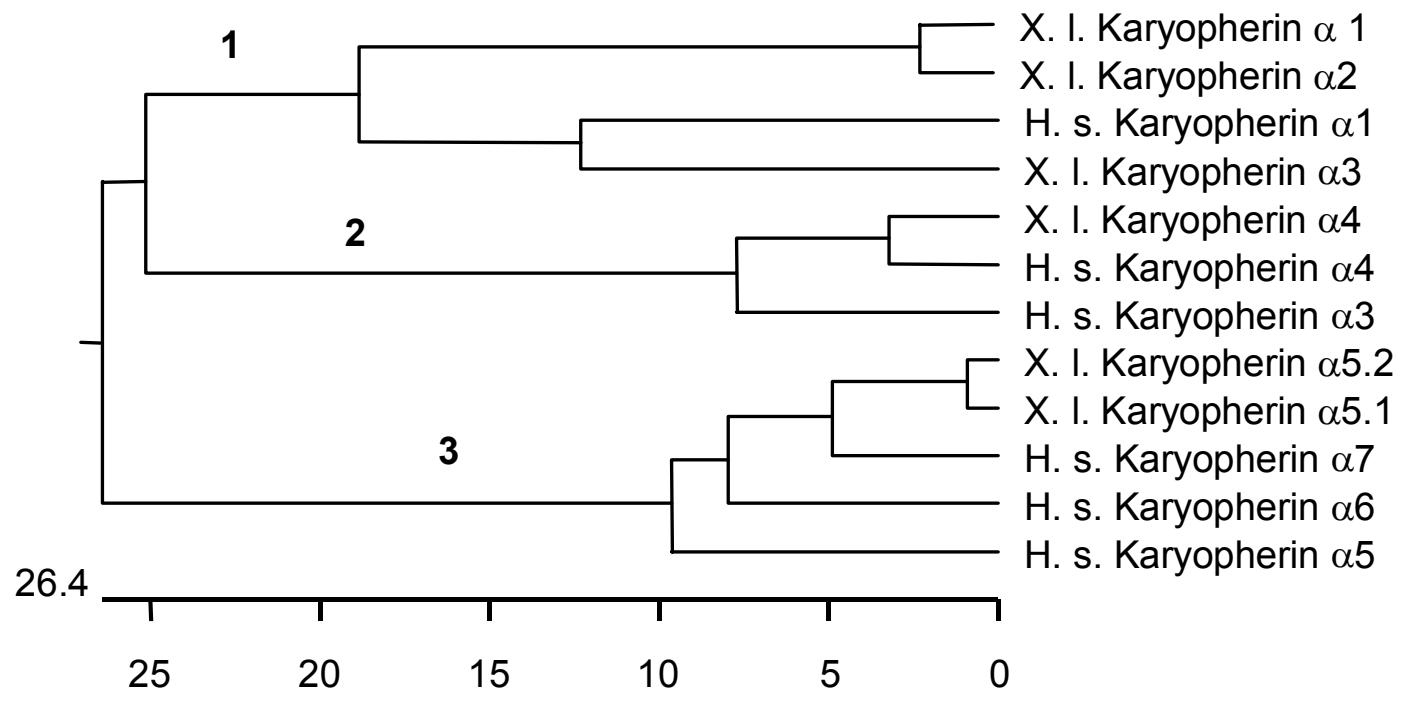

\begin{abstract}
Abbildung 14: Phylogenetischer Stammbaum der Karyopherin $\alpha$ Proteinfamilie.
Dargestellt sind die von Homo sapiens (H. s.) und Xenopus laevis (X. 1.) bekannten Karyopherin $\alpha$ Varianten $\alpha 1, \alpha 2$ und die neuen isolierten Varianten $\alpha 3, \alpha 4, \alpha 5.1$ und $\alpha 5$.2. Humanes Karyopherin $\alpha 2$ ist nicht bekannt. Für humane Karyopherin Varianten wurden Sequenzen mit folgenden Zugriffsnummen verwendet: $\alpha 1$,

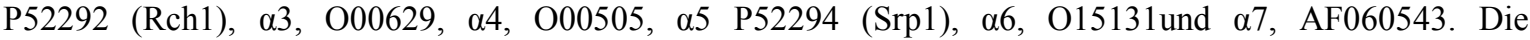
verschiedenen Klassen der Karyopherin $\alpha$ Familien sind in fetten schwarzen Ziffern angegeben.
\end{abstract}

Xenopus Karyopherin $\alpha 4$ besitzt eine relative Molekülmasse von 57774 Dalton. Das Protein besteht aus 521 Aminosäuren. Karyopherin $\alpha 4$ ist zu $\alpha 1 \mathrm{zu} 46 \%$ identisch und zu $64 \%$ ähnlich. Im Vergleich zum humanen Karyopherin $\alpha 4$ beträgt die Identität $93 \%$ und die Ähnlichkeit $95 \%$. Karyopherin $\alpha 4$ fällt somit in die zweite Karyopherinklasse. Die abgeleitete Sequenz von dem zweiten mit RACE isolierten Karyopherin, $\alpha 5.1$, besitzt eine relative Molekülmasse von 59812 Dalton. Das Protein besteht aus 537 Aminosäuren. Karyopherin $\alpha 5$ ist zu $\alpha 1$ zu 44 \% identisch und zu 61 \% ähnlich. Xenopus Karyopherin $\alpha 5.1$ 
ist zu humanem Karyopherin $\alpha 6 \mathrm{zu} 83 \%$ identisch und zu $90 \%$ ähnlich. $\mathrm{Zu}$ humanem Karyopherin $\alpha 7$ beträgt die Identität $90 \%$ und die Ähnlichkeit 93 \%. Xenopus Karyopherin a5.2 ist zu humanem Karyopherin $\alpha 6$ zu $82 \%$ identisch und zu $89 \%$ ähnlich. Zu humanem Karyopherin $\alpha 7$ beträgt die Identität $89 \%$ und die Ähnlichkeit $93 \%$. Das nächste humane Homolog $\mathrm{zu}$ den beiden $\alpha$ Allelen ist das in die dritte Karyopherin $\alpha$ Klasse fallende Karyopherin $\alpha 7$.

H.S. Karyopherin $\alpha 4$ MAENPSLENHRIKSFKNKGRDVETMRRHRNEVTVELRKNKRDEHLLKKRNVPQEESLEDS 60

$X .1$. Karyopherin $\alpha 4--D-A G-D-$

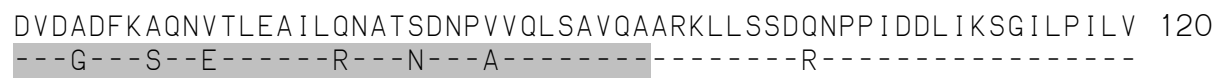

\begin{abstract}
Abbildung 15: Sequenzvergleich von Xenopus Karyopherin a4 mit dem humanen Karyopherin a4 Homolog.

Gegenüberstellung der neuen Karyopherin $\alpha$ Variante aus Xenopus, $\alpha 4$, und dem humanen Homolog Karyopherin $\alpha 4$. Identische Aminosäuren sind durch Bindestriche dargestellt. Die Karyopherin $\beta$ bindende Domäne liegt nach Homologie innerhalb der ersten 103 Aminosäuren. Xenopus Karyopherin $\alpha 4$ hat im Verhältnis zu humanem $\alpha 4$ eine Identität von $93 \%$ und $95 \%$ Ähnlichkeit. Sequenzen der Xenopus Karyopherin $\alpha 4$ Variante, die Homologien zur Karyopherin $\beta$ bindende Domäne (IBB) aufweisen, wurden grau hinterlegt.
\end{abstract}




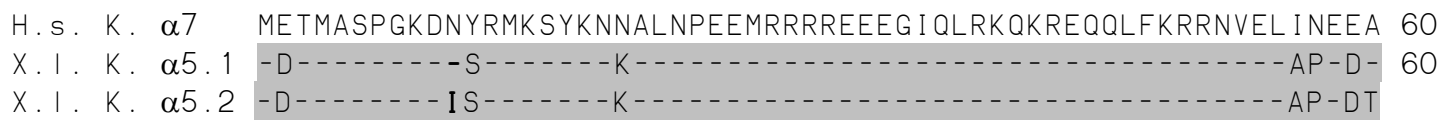

AMFDSLLMDSYVSSTT*GESVITREMVEMLFSDDSDLQLATTQKFRKLLSKEPSPPIDEV 119

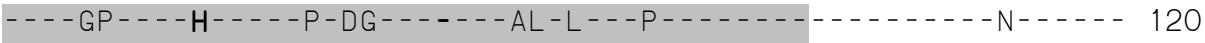

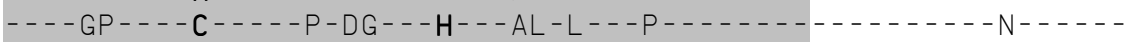

INTPRVVDRF VEFLKRNENCTLQFEAAWALTNIASGTSQQTKIVIEAGAVP IF I ELLNSD 179

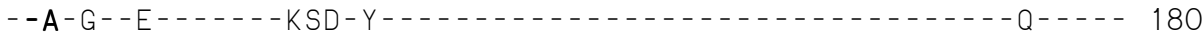

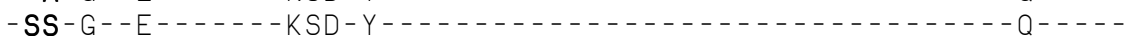

FEDVQEQAVWALGN I AGDSSVCRDYVLNCS I LNPLLTLLTKSTRLTMTRNAVWALSNLCR 239

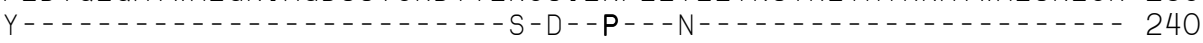

Y - - - - - - - - - - - - - - - - - - S-D- L - - - N- - - - - - - - - - - - - - -

GKNPPPEFAKVSPCLPVLSRLLFSSDSDLLADACWALSYLSDGPNEKI QAVIDSGVCRRL 299 - - - - D-D-- - - - - - - - - - - - - - - -

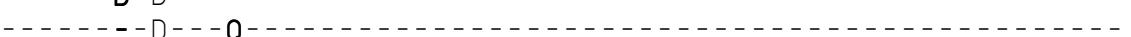

VELLMHNDYKVASPALRAVGN IVTGDDI QTQV I LNCSALPCLLHLLSSPKESIRKEACWT 359 - - - - - - - - - - - - - - - - - - - - - - - -

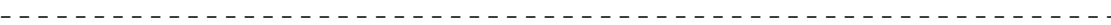

I SN I TAGNRAQ I QAV I DAN IFPVL I E ILQKAEFRTRKEAAWA I TNATSGGTPEQIRYLVS 419

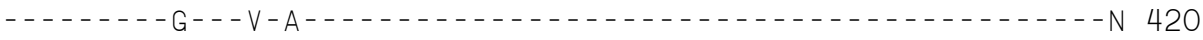

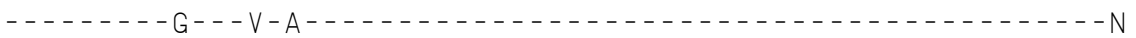

LGC IKPLCDLLTVMDSK I VQVALNGLEN I LRLGEQEGKRSGSGVNPYCGL IEEAYGLDK I 479 - - - - - - - - - - - - - - - - - - - A-HG-N-I---

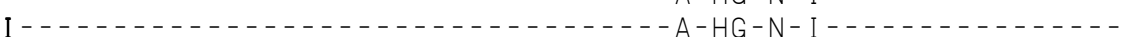

EFLQSHENQE I YQKAFDL I EHYFGVEDDDSSLAPQVDETQQQF IFQQPEAPMEGFQL 536 - - - - - - - - - - E------- E--PQ-V-S---S---Y--- T------- 537

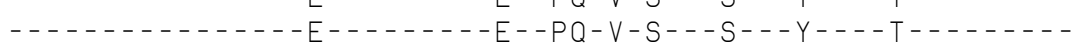

\section{Abbildung 16: Sequenzvergleich von Xenopus Karyopherin $\alpha 5.1$ und 5.2 mit dem humanen Karyopherin $\alpha 7$ Homolog.}

Gegenüberstellung der neuen Karyopherin $\alpha$ Varianten aus Xenopus, $\alpha 5.1$ und $\alpha 5.2$, mit ihrem humanen Homolog Karyopherin $\alpha$ 7. Die Karyopherin $\beta$ bindende Domäne liegt nach Homologie innerhalb der ersten 103 Aminosäuren. Der Vergleich der Xenopus Karyopherin $\alpha$ Variante $\alpha 5.1$ mit humanem Karyopherin $\alpha 7$ ergibt eine Identität von $90 \%$ und eine Ähnlichkeit von 93 \%. Vergleicht man die Xenopus Karyopherin $\alpha 5.2$ Variante mit ihrem humanen Homolog Karyopherin $\alpha 7$ beträgt die Identität $89 \%$ und die Ähnlichkeit $93 \%$. Der Unterschied innerhalb der Aminosäuresequenz der beiden Karyopherin $\alpha$ Allele $\alpha 5.1$ und $\alpha 5.2$ voneinander beträgt in Identität und Ähnlichkeit $2 \%$. Durch einen Stern ist die Position gekennzeichnet, an der in den Xenopus a Varianten eine zusätzliche Aminosäure vorkommt. Identische Aminosäuren sind durch einen Bindestrich dargestellt. Abweichungen in der Aminosäuresequenz der beiden Xenopus Varianten sind durch fettgedruckte Buchstaben hervorgehoben. Sequenzbereiche der Xenopus Karyopherin $\alpha 5$ Varianten, die Homologien zur Karyopherin $\beta$ bindende Domäne (IBB) zeigen, wurden grau hinterlegt.

\subsubsection{In vitro Translation der Konstrukte}

Um die Vollständigkeit und den Leserahmen der klonierten Karyopherin $\alpha$ Varianten zu testen, wurden die Varianten mit Reticulocytenlysat in einem gekoppelten $\mathrm{T}_{\mathrm{N}} \mathrm{T}$ Transkriptions-Translations-Ansatz exprimiert. Die Trennung auf einem 10 \%igen SDSPolyacrylamidgel zeigt die verschiedenen translatierten Varianten. Alle dargestellten Karyopherin $\alpha$ Varianten wurden im $\mathrm{T}_{\mathrm{N}} \mathrm{T}$ Reticulocytenlysat exprimiert. Die Proteine, welche 
von den primär erhaltenen Plasmiden exprimiert wurden, zeigen die erwartete Größe von 60 kd. Die Proteinausbeute liegt nach Herstellerangaben zwischen 0,1 und $0,5 \mathrm{pmol} / \mu \mathrm{l}$. Die Proteinstatistik des DNA-Star Softwarepakets ermittelt einen isoelektrischen Punkt für Karyopherin $\alpha 3$ von $\mathrm{pH} 5,294$ und eine Ladung von $-12,630$ bei $\mathrm{pH}$ 7. Karyopherin $\alpha 4$ trägt deutlich mehr negative Ladungen. Der isoelektrische Punkt liegt bei pH 4,711 und die Ladung bei pH 7 entspricht $-26,095$.

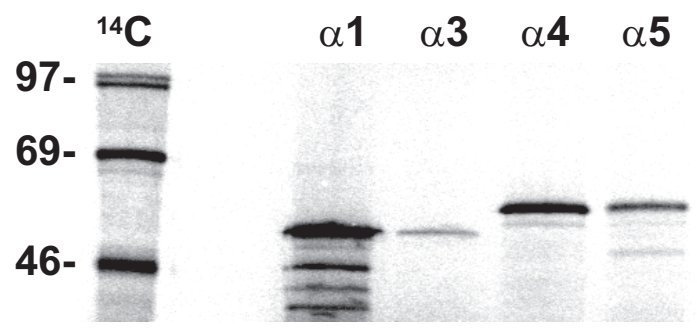

\begin{abstract}
Abbildung 17: Analyse der Karyopherin $\alpha 1, \alpha 3, \alpha 4$ und $\alpha 5$ Primärklone.
Alpha1 wurde als pCS2+ Karyopherin $\alpha 1$ mit SP6-RNA-Polymerase exprimiert. Karyopherin $\alpha 1$ und $\alpha 4$ liegen im pGEM®-T Vektor in SP6 Orientierung vor. Karyopherin $\alpha 3$ liegt im pBK-CMV Vektorplasmid vor und wurde mit T3-RNA-Polymerase exprimiert. Es wurde $1 \mu \mathrm{l}$ des $\mathrm{T}_{\mathrm{N}} \mathrm{T}$ Transkriptions-TranslationsAnsatzes der jeweiligen Variante aufgetragen.
\end{abstract}

Alle isolierten primären Klone der Karyopherin $\alpha$ Varianten sind in dem Reticulocytenlysatsystem exprimierbar und zeigen die erwarteten Proteingrößen von ca. $60 \mathrm{kd}$. Die isolierten Karyopherin $\alpha$ Varianten $\alpha 4$ und $\alpha 5$ sind entsprechend ihrer von der cDNA abgeleiteten Sequenz 2 kd größer als die Varianten $\alpha 1, \alpha 2$ und $\alpha 3$.

\title{
3.5 TFIIIA und Karyopherin $\alpha$
}

\subsubsection{RT-PCR Expressionsanalyse von Xenopus laevis Karyopherin $\alpha$ Varianten im Vergleich zu dem Zinkfingerprotein TFIIIA}

Zur Betrachtung des Expressionsverhaltens der verschiedenen $\alpha$ Varianten im Vergleich zu TFIIIA wurde zur räumlich-zeitlichen Auflösung mit Hilfe der RT-PCR Technik eine Analyse auf Gesamt-RNA von verschiedenen Oocytenstadien, Emryonalstadien und adulten Geweben durchgeführt. Die auf die reverse Transkription nachfolgende PCR-Reaktion erfolgte im Bereich der linearen Amplifikationsrate. Somit können die erhaltenen Signalstärken zueinander in Bezug gesetzt werden, und man erhält eine semi-quantitative Aussage über die Menge des Transkripts (Panitz, 1998). Histon H4 wird in der frühen Phase 
der Xenopus Embryonalentwicklung konstitutiv exprimiert (Niehrs et al., 1994). Durch die Kontrolle mit Histon $\mathrm{H} 4$ in Abbildung 18 bis 20 werden in dem verwendeten Ausgangsmaterial einheitliche RNA Mengen nachgewiesen. Die verwendete RNA wurde auf Kontamination mit genomischer DNA überprüft. Um Kontaminationen der verwendeten Komponenten auszuschließen, wurde in den jeweiligen Kontrollansätzen als Negativkontrolle $\mathrm{H}_{2} \mathrm{O}$ anstelle von RNA-Lösung in den Reaktionsansatz gegeben. Die $\mathrm{H}_{2} \mathrm{O}$ Negativkontrolle in der Abbildung 19 ist auch für die Abbildung 20 gültig, da diese Reaktionen gemeinsam angesetzt wurden.

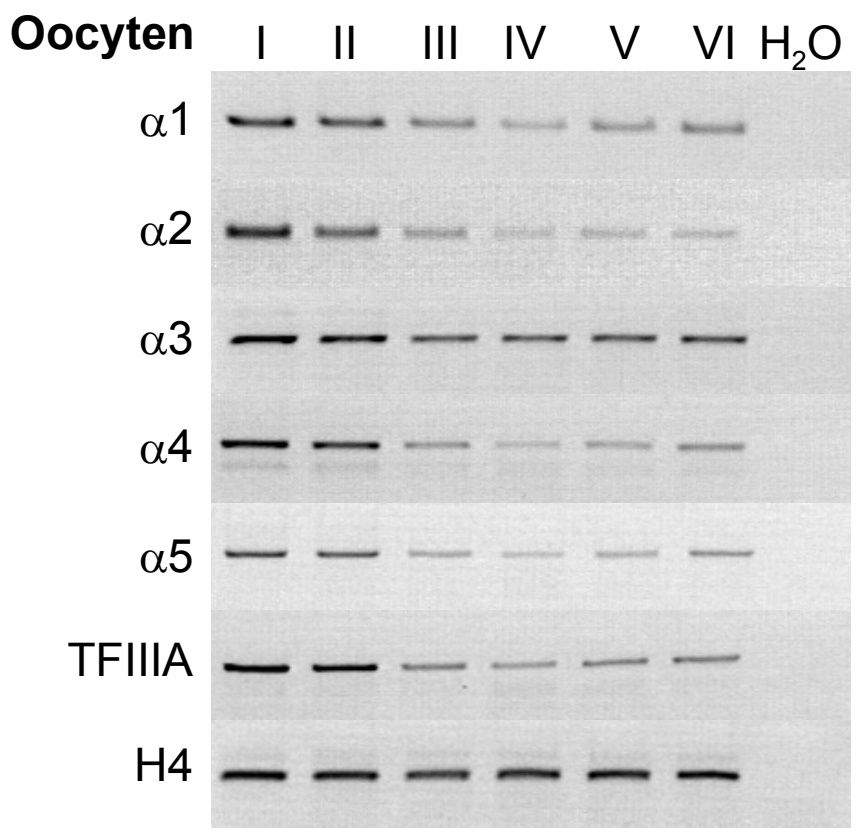

\begin{abstract}
Abbildung 18: Vergleichende Expressionsanalyse der Karyopherin Varianten $\alpha 1, \alpha 2, \alpha 3, \alpha 4, \alpha 5$ und TFIIIA während der Oogenese.

Für die reverse Transkription mit „random“ Hexameren wurden jeweils 50 ng stadienspezifischer Gesamt RNA pro Reaktion eingesetzt. Die PCR erfolgte mit den Primern für $\alpha 1$, XlAlpha1F1, XlAlpha1R1, $\alpha 2$, X1Alpha2F1, X1Alpha2R1, $\alpha 3$, Ialp3CDS1F, Ialp3CDS1R, $\alpha 4$, Ialp45'UTRF, Ialp4CDS1R, $\alpha 5$, Ialp5CDS1F, Ialp5CDSa1R und für TFIIIA mit den Primern TFIIIAfl und TFIIIArl (siehe Material und Methoden), die ein Amplifikationsprodukt von 200-350 Basenparen ergaben. Die Auftrennung der PCR Produkte erfolgte auf einem 2 \%igem Agarosegel. Für die Darstellung wurde eine Negativansicht der unter UV Licht (254nm) vorgenommenen Fragmentvisualisierung gewählt. In den Oocyten Stadien I und II zeigen alle $\alpha$ Varianten und TFIIIA eine erhöhte Expression. In den Stadien III bis VI ist bei der $\alpha 3$ Variante im Gegensatz zur Expression von $\alpha 1, \alpha 2, \alpha 4, \alpha 5$ und TFIIIA nur ein schwacher Abfall der Expressionsstärke zu sehen. Zur Kontrolle der eingesetzten Gesamt RNA Mengen wurden spezifische Primer für das Histon H4 verwendet.
\end{abstract}

In der RT-PCR Analyse der verschiedenen Karyopherin $\alpha$ Varianten ist eine deutliche Reduzierung von den Expressionsstärken der $\alpha 1, \alpha 2, \alpha 4, \alpha 5$ Varianten und TFIIIA während der Oogenese zu sehen. Generell zeigen alle untersuchten Gene während der frühen Oocytenstadien I und II eine starke Expression. Bei der Karyopherin $\alpha 3$ Variante tritt im 
Gegensatz zu der Expression anderer Karyopherin Varianten keine deutliche Reduzierung der Expressionsstärke auf. Während der Oogenese zeigen $\alpha 1, \alpha 2, \alpha 4, \alpha 5$ im Gegensatz zu $\alpha 3$ ein TFIIIA ähnliches Expressionsverhalten.

In der befruchteten Eizelle und den frühen Stadien 7 und 8 lassen sich alle untersuchten Transkripte nachweisen. Kurz nach Beginn der Midblastulatransition im Stadium 8, ab dem Stadium 9 bzw. 11 sind die maternalen Transkripte von $\alpha 2$ und TFIIIA nicht mehr nachweisbar. Das Signal der Karyopherin $\alpha 1$ Variante verschwindet vollständig mit dem Stadium 13. Im Stadium 11 liegt die geringste Transkriptanzahl der Karyopherinvariante $\alpha 4$ vor. Im Stadium 13 liegt die geringste Transkriptanzahl der Karyopherin Varianten $\alpha 3$ und $\alpha 5$ vor. Auf die Stadien 11 bzw. 13 folgend findet eine verstärkte, zygotische Transkription der Karyopherin $\alpha 4$ bzw. $\alpha 3$ und $\alpha 5$ Varianten statt. Deutlich erkennbar ist die verzögerte und schwächere zygotische Transkriptionsaktivierung der $\alpha 5$ Variante ab Stadium 16. Gegenüber der $\alpha 4$ Variante zeigt die $\alpha 3$ Variante ebenfalls eine verzögerte zygotische Transkriptionsaktivierung. Maternale TFIIIA mRNA ist ab Stadium 9 unter den hier gewählten Bedingungen nicht mehr nachweisbar. In den Stadien 28 bis 38 sind sehr schwache heterogene Transkripte zygotischer TFIIIA Expression zu erkennen.

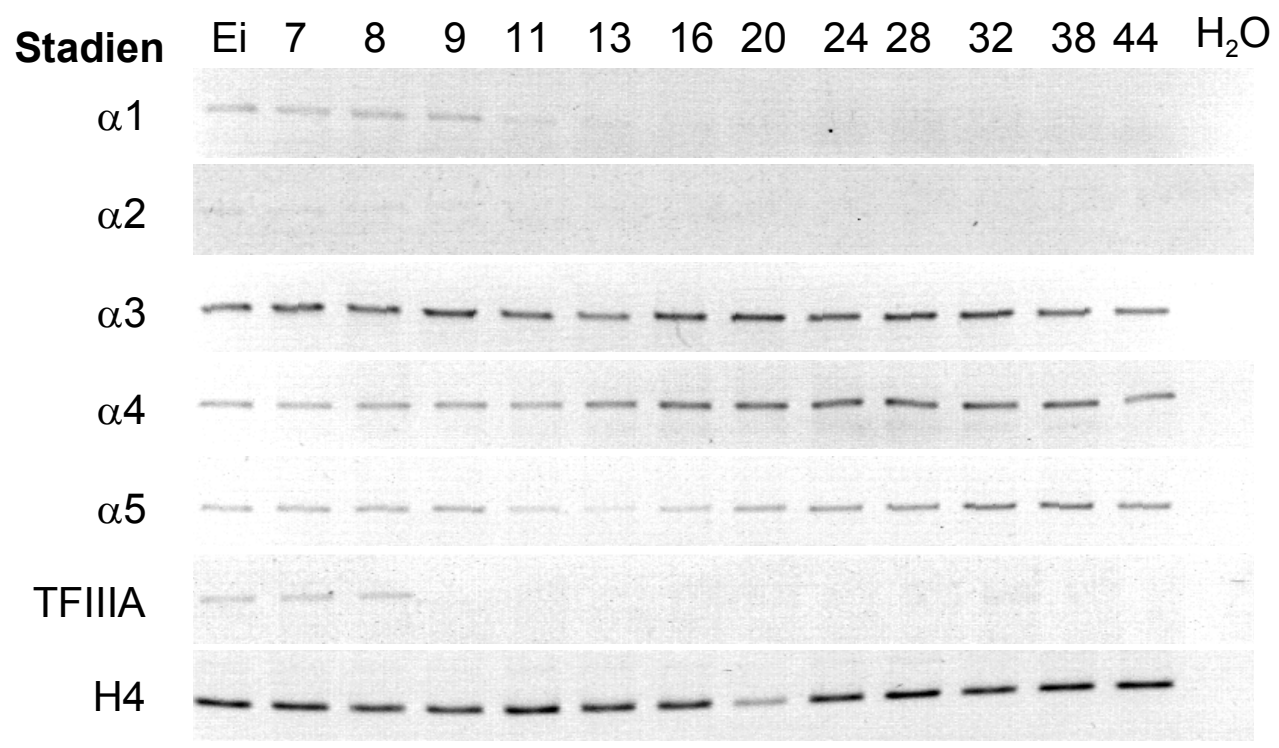

\footnotetext{
Abbildung 19: Vergleichende Expressionsanalyse der Karyopherin Varianten $\alpha 1, \alpha 2, \alpha 3, \alpha 4, \alpha 5$ und TFIIIA während der frühen Embryonalentwicklung von Xenopus laevis.

Die verwendeten Primer und angewandten Verfahren entsprechen der Beschreibung in Abbildung 18. Die beiden Karyopherin Varianten $\alpha 1, \alpha 2$ und TFIIIA sind nur bis zu den Stadien 8 - 9 in signifikanten Mengen nachweisbar. TFIIIA ist unter den hier gewählten Bedingungen in späteren Stadien 20 bis 44 ausserordentlich schwach zu sehen. Die Karyopherin $\alpha 3$ Variante ist in allen Stadien mit annähernd gleicher Intensität nachweisbar. Die Expression der Karyopherin $\alpha 4$ und $\alpha 5$ Varianten ist in den frühen Stadien Ei und 7 bis 13 schwächer als in den folgenden Stadien 20 bis 44. In der rechten Spur wurde den Reaktionsansätzen als Kontaminationskontrolle $\mathrm{H}_{2} \mathrm{O}$ anstelle von RNA hinzugefügt.
} 
Die $\alpha 1$ und $\alpha 2$ Varianten zeigen in den frühen embryonalen Stadien maternale Transkripte. Es findet aber keine zygotische Transkriptionsaktivierung statt. Die Varianten $\alpha 3, \alpha 4$ und $\alpha 5$ zeigen im Gegensatz zu $\alpha 1$ und $\alpha 2$ eine biphasische Expression. Die Expression von TFIIIA ist ebenfalls biphasisch, allerdings liegt hier in frühen Embryonalstadien eine sehr geringe Trankskriptanzahl heterogener mRNA vor (Shastry et al., 1984). Die Expression von TFIIIA korreliert mit den Werten von Analysen anderer Laboratorien (siehe 1.7). Das Expressionsverhalten von TFIIIA, $\alpha 1$ und $\alpha 2$ ist in Oocyten und den frühen Embryonalstadien identisch. Eine von diesem Befund abweichende Expression zeigen die Varianten Karyopherin $\alpha 3, \alpha 4$ und $\alpha 5$ mit ihrem biphasischen Expressionsverhalten.

Um die Limitierung der Expression auf einzelne Gewebe zu analysieren, wurden RT-PCR Analysen auf RNA Präpärationen von verschiedenen Geweben adulter Frösche durchgeführt. Bei der RT-PCR Analyse auf verschiedenen Geweben ist jede der analysierten Varianten stark im Ovar exprimiert. Im Pankreasgewebe lässt sich nur Karyopherin $\alpha 4$ mit sehr schwacher Expression nachweisen. Unter nicht kompetitiven Bedingungen sind die verwendeten Primerpaare für die $\alpha 1$ und $\alpha 2$ Variante nicht in der Lage zwischen den beiden Varianten zu unterscheiden (nicht gezeigt). Unter den kompetitiven Bedingungen der RTPCR Analyse hingegen wird ein spezifisches Produkt gebildet. Mit dem Primerpaar für den Nachweis der $\alpha 2$ Expression wird auf cDNA von Magengewebe ein Fragment von 480 Basenpaaren amplifiziert. Bei Karyopherin $\alpha 3$, welches in allen Embryonalstadien stark exprimiert wird, tritt ein sehr schwaches Signal in den meisten Geweben auf. Starke Signale sind nur in Testis und Ovar zu sehen. Karyopherin $\alpha 4$ und $\alpha 5$ zeigen in allen Geweben außer Pankreas ein deutliches Signal. Karyopherin $\alpha 4$ ist sehr schwach im Pankreas, stark in Muskel, Herz, Testis und Ovar exprimiert. Karyopherin $\alpha 5$ ist sehr schwach im Pankreas, stark in Muskel, Herz und Ovar exprimiert. Die PCR Produkte von TFIIIA geben in Testis und Ovar scharfe Banden. In den anderen Geweben sind heterogene Fragmente zu erkennen. Durch eine RT-PCR Analyse mit 40 Zyklen (nicht gezeigt) lässt sich eine Basislevelexpression von Karyopherin $\alpha 3$ in allen untersuchten Geweben nachweisen. 


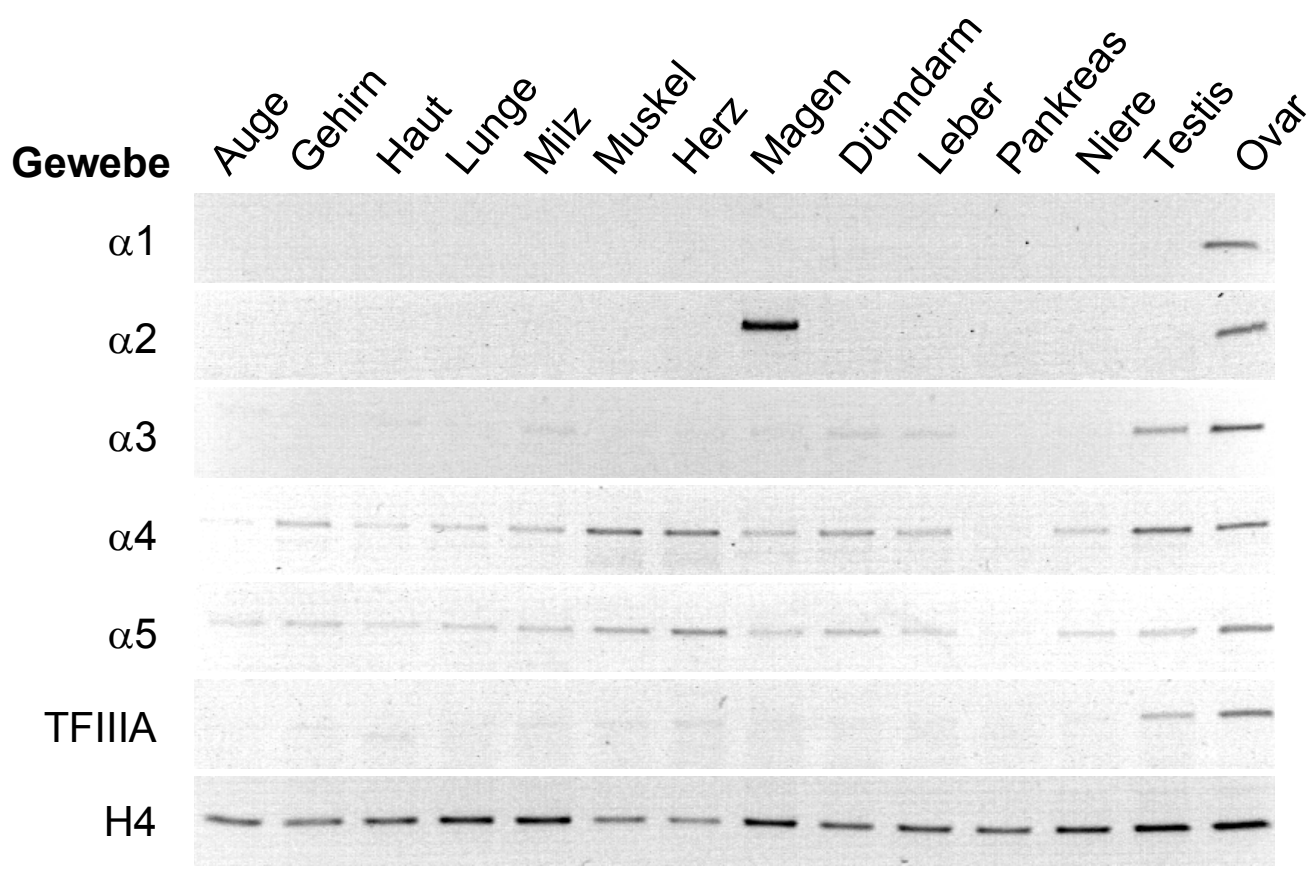

\begin{abstract}
Abbildung 20: Vergleichende Expressionsanalyse der Karyopherin Varianten $\alpha 1, \alpha 2, \alpha 3, \alpha 4, \alpha 5$ und TFIIIA in adulten Geweben von Xenopus laevis.

Für die reverse Transkription mit random Hexameren wurden jeweils $50 \mathrm{ng}$ gewebespezifischer Gesamt RNA pro Reaktion eingesetzt. Angewandte Verfahren und verwendete Primer sind in Abbildung 18 beschrieben. Im Ovar ist jede der analysierten Varianten stark exprimiert. Karyopherin $\alpha 1$ zeigt ausschließlich Expression auf RNA aus dem Ovar. Bei Karyopherin $\alpha 2$ ist in der Magenspur ein Fragment zu sehen, dass 300 Basenpaare größer ist als das erwartete PCR Produkt. Bei Karyopherin $\alpha 3$ tritt ein sehr schwaches Signal in Milz, Dünndarm und Leber auf. Starke Signale sind in Testis und Ovar zu sehen. Karyopherin $\alpha 4$ und $\alpha 5$ zeigen in allen Geweben ein Signal. Karyopherin $\alpha 4$ und $\alpha 5$ sind sehr schwach im Pankreas exprimiert. $\alpha 4$ ist stark in Muskel, Herz, Testis und Ovar und Karyopherin $\alpha 5$ ist stark in Muskel, Herz und Ovar exprimiert. Die PCR Produkte von TFIIIA geben in Testis und Ovar scharfe Banden. In den anderen Geweben sind sehr schwache heterogene PCR Produkte zu erkennen.
\end{abstract}

Die RT-PCR Analysen zeigen ein identisches Expressionsverhalten von Karyopherin $\alpha 1, \alpha 2$ und TFIIIA während der Oogenese und in den frühen Stadien der Embryonalentwicklung. Die Expression von Karyopherin $\alpha 3, \alpha 4$ und $\alpha 5$ ist im Gegensatz zu den Varianten $\alpha 1$ und $\alpha 2$ biphasisch. Da das Expressionsverhalten von Karyopherin $\alpha 1, \alpha 2$ und TFIIIA während der Oogenese und der frühen Embryonalentwicklung übereinstimmt, könnte TFIIIA ein Transportsubstrat der Karyopherin $\alpha 1$ und $\alpha 2$ Varianten sein.

\title{
3.5.2 Expressionsanalyse mit der ,whole mount" in situ Methode der Karyopherin $\alpha$ Varianten im Vergleich zu TFIIIA
}

Zur detaillierten Auflösung der räumlich-zeitlichen Expression der verschiedenen Karyopherin $\alpha$ Varianten im Vergleich zu TFIIIA während der Embryonalentwicklung wurde eine „whole mount“ in situ Analyse auf Oocyten Stadien und ausgewählten Embryonalstadien von Xenopus laevis durchgeführt. Während der Oogenese zeigen alle untersuchten Gene eine 
starke Expression in den Oocytenstadien I und II (Abbildung 21). Eine Reduzierung des Expressionssignals tritt bei TFIIIA vor allen anderen untersuchten Genen auf. In Stadium IV Oocyten ist in der Analyse von TFIIIA eine schwache Färbung zu erkennen. Die Transportadapter hingegen zeigen in diesem Stadium noch eine deutliche Färbung. Die Karyopherin $\alpha 3$ Variante zeigt während der Stadien III, IV und V die intensivste Färbung. Während der Embryonalentwicklung ist in der "whole mount" in situ Analyse keine Expression von TFIIIA und den Karyopherin $\alpha 1, \alpha 2$ Varianten detektierbar. Mit dem Neurula Stadium ist eine intensive Färbung des Augenfeldes und der Neuralleisten in einem Karyopherin $\beta 3$ ähnlichen Muster bei der $\alpha 3$ Variante zu sehen. Ein vergleichbares, aber deutlich schwächeres Muster tritt bei Karyopherin $\alpha 4$ auf. Karyopherin $\alpha 5$ zeigt die schwächste Expression in diesem Stadium. Das Auge, die Kiemenbögen und der posteriore Bereich der Schwanzknospen- und Schwanzspitzenstadien sind bei den Varianten $\alpha 4$ und $\alpha 5$ vergleichbar stark angefärbt, zeigen aber im Vergleich zu $\alpha 3$ eine deutlich schwächere Intensität. Im Kaulquappenstadium ist bei der $\alpha 3$ Variante eine starke Färbung im posterioren Bereich der Schwanzspitze zu erkennen. Durch die nicht gefärbten Zwischenräume der epidermalen Färbung lassen sich starke Färbungen in Organen des anterioren Embryos erkennen. Posterior weist die das Proctodeum umgebende Region eine starke Expression auf. In den Kaulquappenstadien ist das Herz bei $\alpha 3, \alpha 4$ und die Leber bei $\alpha 3, \alpha 4, \alpha 5$ deutlich angefärbt. Die Expression von Karyopherin $\alpha 1$ und $\alpha 2$ beschränkt sich auf die frühen Stadien der Oogenese. Ein ähnlicher Zustand ist für TFIIIA zu beobachten. Hingegen werden die Varianten $\alpha 3, \alpha 4$ und $\alpha 5$ zygotisch in unterschiedlichen Mengen exprimiert. Die Genaktivierung von $\alpha 5$ erreicht eine den Varianten $\alpha 3$ und $\alpha 4$ vergleichbare Stärke erst im Schwanzknospenstadium. 


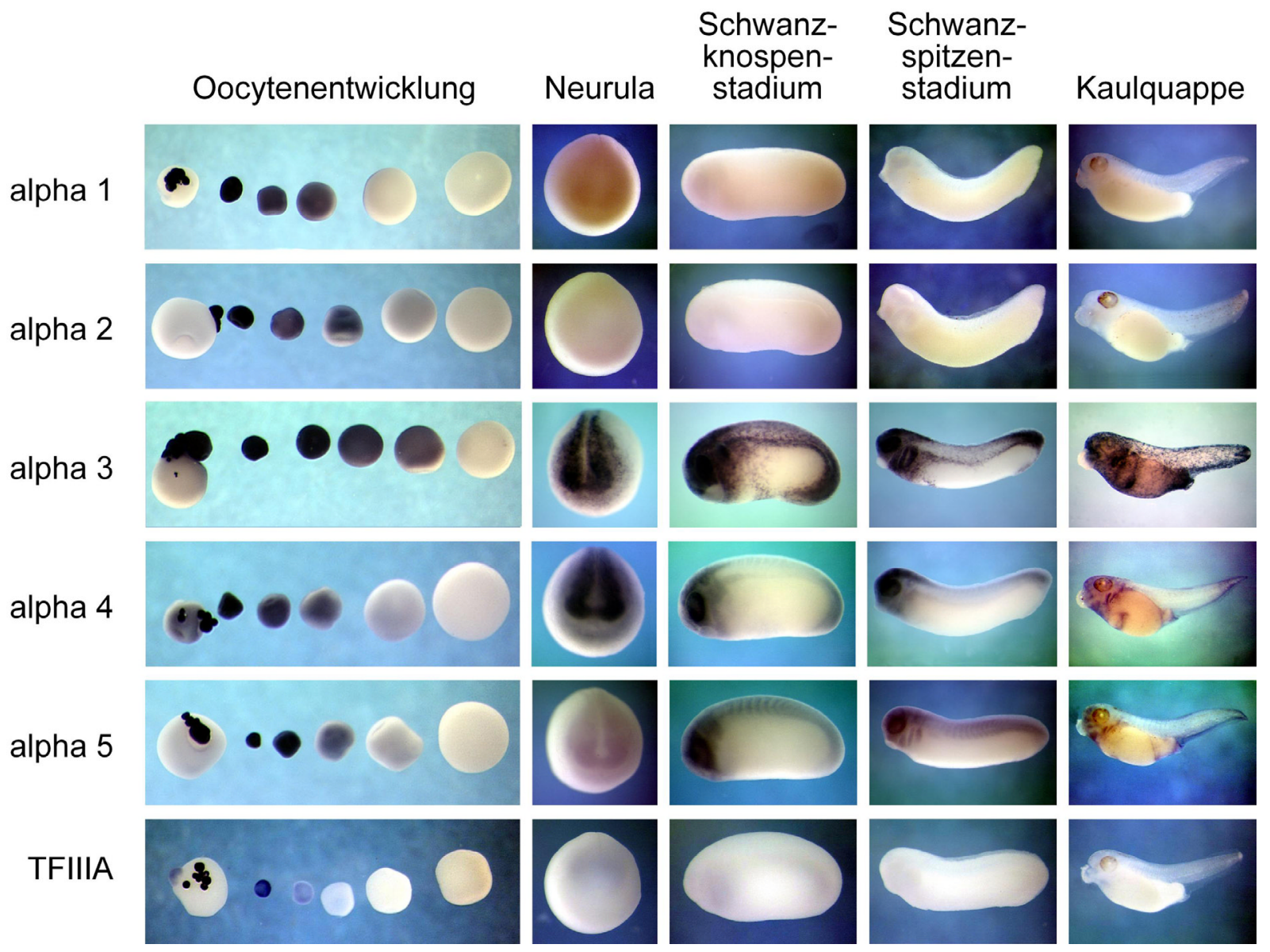

\begin{abstract}
Abbildung 21: Expressionsmusteranalyse mit der "whole mount“ in situ Technik zur räumlichzeitlichen Auflösung in der Oogenese und den frühen Entwicklungsstadien von Xenopus laevis. In der linken Spalte sind die verschiedenen Entwicklungsstufen der Oocyte während der Oogenese dargestellt. In Spalte 1 links sind Konglomerate von Stadium I Oocyten angeheftet an ältere Stadien mit starker Färbung zu sehen. TFIIIA RNA ist nur während der Stadien I und II stark in Oocyten exprimiert, ab der Stadium III Oocyte ist eine deutliche Reduzierung der Expression zu sehen. Die Expressionsstärken der Karyopherin $\alpha$ Varianten $\alpha 1, \alpha 2, \alpha 4$ und $\alpha 5$ nehmen in Oocyten später als TFIIIA ab. Eine Reduzierung der Expressionsstärke von Karyopherin $\alpha 3$ findet erst in älteren Oocytenstadien statt. Karyopherin $\alpha 1, \alpha 2$ und TFIIIA zeigen in embryonalen Stadien keine Färbung. Die Färbung von $\alpha 3$ ist ab dem Neurulastadium intensiver als die von $\alpha 4$ und $\alpha 5$. In den folgenden Schwanzspitzenstadien ist eine deutliche Färbung der Kiemenbogenregion zu sehen. Eine Kiemenbogenfärbung ist bei den $\alpha 4$ und $\alpha 5$ Varianten schwach ausgeprägt. Im Kaulquappenstadium ist eine epidermale Färbung der $\alpha 3$ Variante zu erkennen. Die Karyopherin Varianten $\alpha 4$ und $\alpha 5$ zeigen eine schwache Färbung in früh gebildeten Organen.
\end{abstract}

In Übereinstimmung mit den Resultaten der RT-PCR Analyse zeigen die Karyopherin Varianten $\alpha 3, \alpha 4$ und $\alpha 5$ ein in späten Stadien ausgeprägtes Expressionsmuster. Karyopherin $\alpha 3$ zeigt im Gegensatz zu anderen Varianten und TFIIIA eine ausgeprägte Expression in der Schwanzspitze und den Cilienzellen der Haut. Die Expression von Karyopherin $\alpha 1, \alpha 2$ Varianten und TFIIIA ist mit dieser Methode ab der späten Oogenese nicht mehr detektierbar. Dieses Ergebnis korreliert ebenfalls mit den Resultaten der RT-PCR Analyse, in der eine deutliche Reduktion der Expression von $\alpha 1, \alpha 2$ und TFIIIA ab Stadium III Oocyten zu sehen ist. Ab den Stadien 9 bis 11 ist eine Expression von $\alpha 1$, $\alpha 2$ sowohl in der RT-PCR Analyse als 
auch in der ,whole mount“ in situ Hybridisierung nicht mehr nachzuweisen. Die TFIIIA Expression wird in Übereinstimmung mit dem Expressionsprofil von $\alpha 1, \alpha 2$ ab dem Stadium III der Oogenese deutlich reduziert und ab Stadium 9 der Embryonalentwicklung auf kaum detektierbare Mengen herabgesetzt. Diese Korrelation im Expressionsprofil von TFIIIA und den Karyopherin Varianten $\alpha 1$ und $\alpha 2$ zeigt, dass sowohl ein Transportadapter als auch ein putatives Substrat (TFIIIA) in Bezug auf ihr zeitliches und räumliches Auftreten die Möglichkeit haben, miteinander zu interagieren. TFIIIA könnte somit ein Transportsubstrat von Karyopherin $\alpha 1$ und $\alpha 2$ sein.

\subsubsection{TFIIIA interagiert mit Karyopherin $\alpha$, aber nicht mit RanBP7, Karyopherin $\beta$, Karyopherin $\beta 3$ oder Transportin}

Die Expressionsprofile von TFIIIA und Karyopherin $\alpha 1$ und $\alpha 2$ zeigen eine starke Ähnlichkeit. Um zu testen, ob eine spezifische Interaktion von TFIIIA mit Karyopherin $\alpha 1$ vorliegt, wurde in einem in vitro Bindungsversuch das Bindungsverhalten von TFIIIA und verschiedener TFIIIA Mutanten, deren Importverhalten in Oocyten bekannt war (s.o.), an GST-Fusionsmutanten von verschiedenen Karyopherin $\beta$ verwandten Proteinen und Karyopherin $\alpha 1$ getestet. In TFIIIA konnten zwei transportkompetente Elemente identifiziert werden. Da nicht davon ausgegangen werden kann, dass beide Elemente denselben Transportfaktor (-adapter) binden, wurden Deletionsmutanten von TFIIIA in der Analyse eingesetzt. Die verwendeten GST-Fusionsproteine Karyopherin $\alpha 1$, Karyopherin $\beta$, RanBP7 und Transportin sind in Claußen et al. (1999) beschrieben. Karyopherin $\beta 3$ wurde von Maike Claußen entsprechend der anderen Transportfaktoren kloniert. Für die Analyse wurden mit

${ }^{35} \mathrm{~S}$ radioaktiv markierte TFIIIA Mutanten verwendet. Die 1/3- $\beta$-Gal-Mutanten 123, 789 und 678 (s.o.) wurden mit Nco I vor und hinter dem eingefügten $\beta$-Galaktosidase Anteil geschnitten und der verbleibende Vektor mit Zinkfingerinsert religiert. Die verwendeten pCS2+ TFIIIA, pCS2+ TFIIIA- $\triangle 56$ und pCS2+Nucleoplasmin Konstrukte wurden mir von Falko Rudt überlassen. Die klonierten Konstrukte wurden mit dem $\mathrm{T}_{\mathrm{N}} \mathrm{T}$-Reticulocytenlysat in einem gekoppelten Transkriptions-Translations-Ansatz exprimiert und in einem in vitro Interaktionsversuch eingesetzt. Die Expression der GST fusionierten Transportfaktoren wurde in E.coli XL1-blue durchgeführt. Die Zellen wurden durch Sonifizierung aufgeschlossen und die Fusionsproteine durch Bindung an GT-Sepharose immobilisiert. Nach zweimaligem Waschen des Pellets wurden die Ansätze in die für den Versuch benötigte Anzahl an Aliquots 
aufgeteilt. Im Bindungspuffer waren $2 \mathrm{mg} / \mathrm{ml}$ BSA zum blockieren unspezifischer Bindungsstellen enthalten.

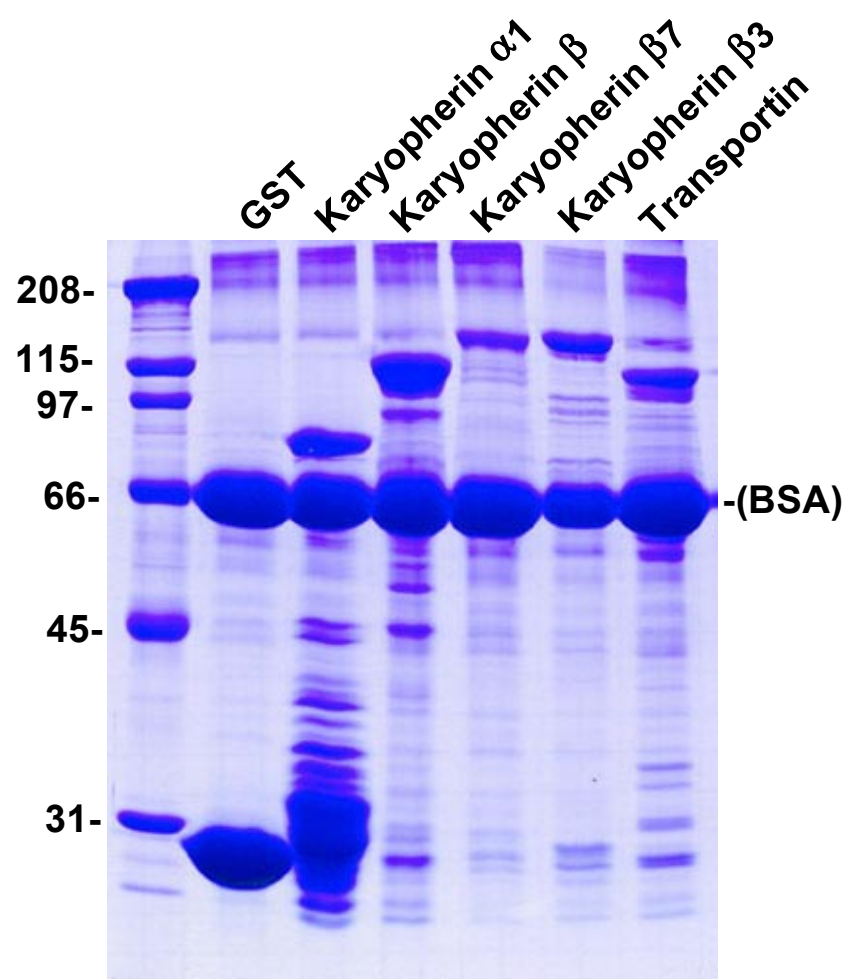

Abbildung 22: Zur Interaktion verwendete GST-Fusionsproteine.

Für die Analyse der Interaktion von TFIIIA, TFIIIA- $\Delta 56$, den Zinkfingern 123, 678, 789 und Nukleoplasmin wurden die GST-Fusionsproteine Karyopherin $\alpha 1$, Karyopherin $\beta$, Karyopherin $\beta 7$, Karyopherin $\beta 3$ und Transportin verwendet. Ein Aliquot der für die Interaktionsstudie verwendeten Glutathionagarose-GSTProtein Partikel wurde mittels SDS PAGE analysiert.

Den beladenen Pellets wurde in $600 \mu$ l Bindungspuffer $5 \mu 1$ des $\mathrm{T}_{\mathrm{N}} \mathrm{T}$-Reticulocytenlysates, in welchem die radioaktiven Substrate erstellt wurden, hinzugefügt. Nach $2 \mathrm{~h}$ Inkubation bei $4^{\circ} \mathrm{C}$ wurden ungebundene Komponenten durch sechs maliges Waschen mit Bindungspuffer entfernt und der Ansatz in SDS Puffer auf einem $10 \%$ Polyacrylamidgel elektrophoretisch aufgetrennt. 


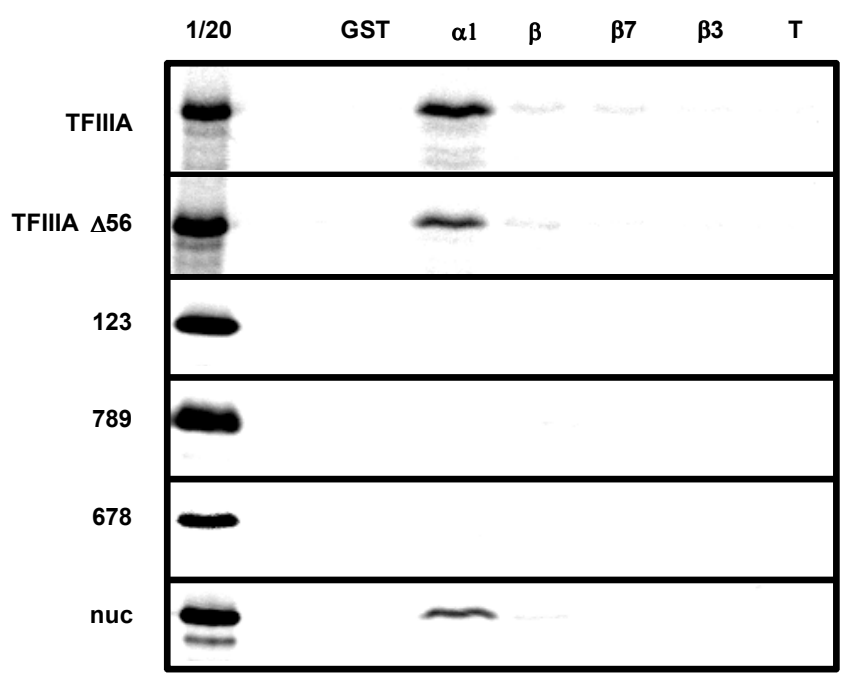

Abbildung 23: TFIIIA interagiert mit Karyopherin $\alpha$.

Analyse der Interaktion von TFIIIA, TFIIIA- $\triangle 56$, den Zinkfingern 123, 678, 789 und Nukleoplasmin mit den GST-Fusionsproteinen Karyopherin $\alpha 1$, Karyopherin $\beta$, Karyopherin $\beta 7$, Karyopherin $\beta 3$ und Transportin. In der linken Spur ist $1 / 20$-stel des eingesetzten mit ${ }^{35} \mathrm{~S}$-markierten Proteins aufgetragen.

Das als Spezifitätskontrolle in der Bindungsanalyse eingesetzte Nukleoplasmin bindet erwartungsgemäß ausschließlich an Karyopherin $\alpha 1$ und nicht an die Karyopherin $\beta$ verwandten Fusionsmutanten. Bei keiner der gezeigten Mutanten ist eine Interaktion mit dem GST-Fusionsanteil aufgetreten. TFIIIA und die TFIIIA- $\triangle 56$ Mutante wurden mit der GSTKaryopherin $\alpha 1$ Fusionsmutante aufgereinigt. Die Zinkfinger 123 und 678, welche in Oocyteninjektionen keine Transportaktivität aufweisen, wurden ebenso wenig von den Transportfaktoren gebunden wie das in Oocyten und HeLa Zellen transportkompetente Zinkfingerelement 789. Da die Zinkfinger 234 von dem GST-Fusionsanteil gebunden wurden (nicht gezeigt), ist die Darstellung der N-terminalen minimalen transportaktiven Zinkfingerregion in diesem Experiment nicht möglich. Für TFIIIA und die TFIIIA- $\Delta 56$ Mutante konnte jedoch eine spezifische Interaktion mit der Karyopherin $\alpha 1$ Variante nachgewiesen werden. Da das C-terminale Zinkfingermodul an keinem der eingesetzten Transportsubstrate bindet, es aber sowohl in Oocyten als auch in HeLa Zellen kernlokalisiert wird, könnte es wie das NLS 2 und 3 von L5 auf einem anderen Weg als das N-terminale NLS von TFIIIA in den Zellkern gelangen. Desweiteren interagiert das C-terminale NLS mit den Zinkfingern 789 hier nicht mit Karyopherin $\alpha 1$, wohl aber die TFIIIA Konstrukte, in denen das eingegrenzte C-terminale NLS enthalten ist.

\subsubsection{Interaktionsstudien von verschiedenen Karyopherin $\alpha$ Varianten}

Im letzten Abschnitt wurde gezeigt, dass radioaktiv markiertes TFIIIA und TFIIIA- $\Delta 56$ spezifisch mit immobilisiertem Karyopherin $\alpha 1$ interagiert. Diese Interaktion sollte sich in 
den folgenden Experimenten auch umgekehrt mit immobilisiertem TFIIIA- $\Delta 56$ und in Lösung befindlichem Karyopherin $\alpha$ zeigen lassen. Um eine mögliche Maskierung des NLS durch 5S RNA aus dem Reticulocytenlysat zu verhindern, wurde TFIIIA- $\Delta 56$ verwendet, welches nicht an 5S RNA bindet. Die oben gezeigten fast identischen Expressionsprofile von TFIIIA und den Karyopherin Varianten $\alpha 1$ und $\alpha 2$ weichen stark von denen der anderen Karyopherin $\alpha$ Varianten, $\alpha 3, \alpha 4$ und $\alpha 5, a b$. Dies weist auf eine mögliche spezifische Beziehung zwischen TFIIIA als Transportsubstrat und Karyopherin $\alpha 1$ und $\alpha 2$ als Transportadapter hin. Um das Bindungsverhalten von TFIIIA an die verschiedenen Karyopherin $\alpha$ Varianten zu testen, wurde frisch präpariertes immobilisiertes TFIIIA- $\Delta 56$ in einem Bindungsversuch mit ebenfalls frisch mit dem $\mathrm{T}_{\mathrm{N}} \mathrm{T}$ System erzeugten ${ }^{35} \mathrm{~S}$ markierten Karyopherin $\alpha$ Varianten inkubiert. Zur Kontrolle der Bindungsspezifität wurde GST alleine und als Positivkontrolle intaktes Nukleoplasmin eingesetzt.

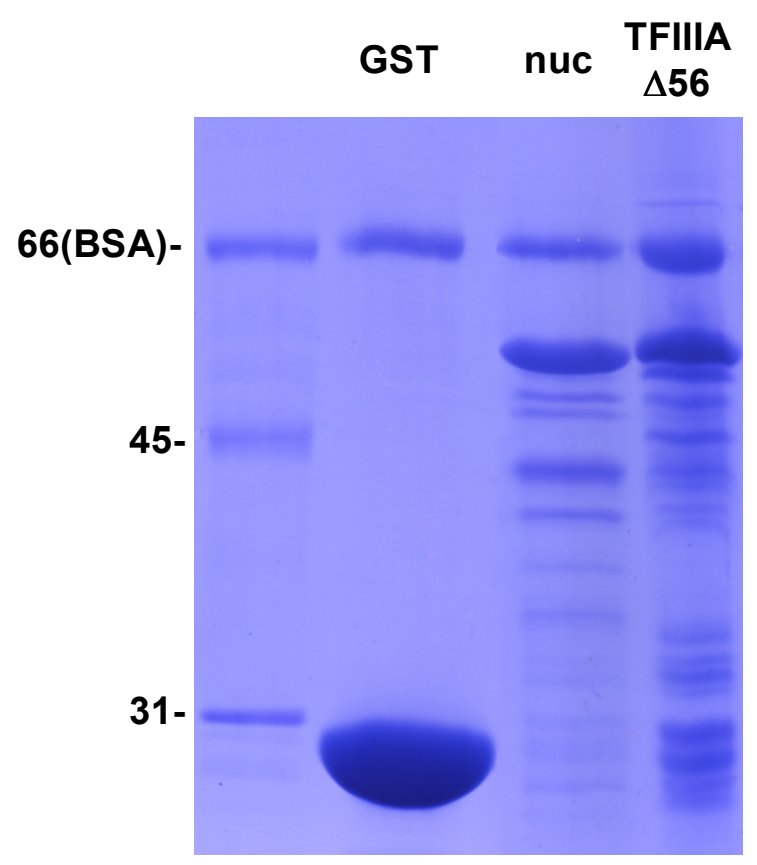

\footnotetext{
Abbildung 24: Bakterielle Expression der GST-Fusionsproteine mit Nukleoplasmin und TFIIIA- $\Delta 56$. Der verwendete Fusionsanteil GST wurde in BL21 Zellen, Nukleoplasmin (nuc) und TFIIIA- $\Delta 56$ wurden in BL21-DE3 Zellen exprimiert. Die Induktion erfolgte bei $30^{\circ} \mathrm{C}$ für $3 \mathrm{~h}$ mit $1 \mathrm{mM}$ IPTG. Der Zellaufschluss erfolgte mit einem Branson Sonifier mit folgenden Einstellungen: Leistung 3, Puls 60, 3 mal 30 Sekunden. Die Zelltrümmer wurden bei $10000 \mathrm{Upm}$ pelletiert und der Überstand für das Beladen der GT-Agarose eingesetzt. Das $10 \%$ ige mit Comassie angefärbte Gel zeigt die nach Abschluss des Experiments noch gebundenen, nicht radioaktiven Proteine. Aufgetragen wurden in Spur 1 der Größenstandard, in Spur 2 der GST-Fusionsanteil, in Spur 3 GST-Nukleoplasmin und in Spur 5 GST-TFIIIA- $\Delta 56$. Links angegeben sind die Größen des Standards in kd. Bei $66 \mathrm{kd}$ ist in allen Spuren das zur Abdeckung unspezifischer Bindungsstellen eingesetzte BSA zu sehen. Der als Kontrolle eingesetzte Fusionsanteil liegt im Gegensatz zu GST-Nukleoplasmin und GST-TFIIIA- $\Delta 56$, welche in äqivalenten Mengen gebunden wurden, in deutlichem Überschuss vor.
} 


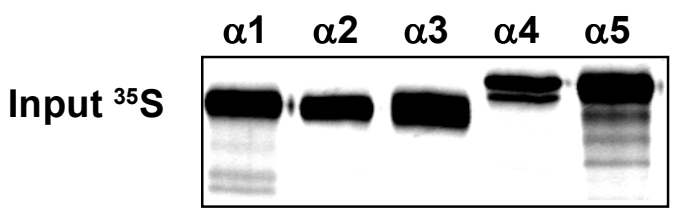

\begin{abstract}
Abbildung 25: Analyse der Karyopherin $\alpha$ Varianten.
Die Karyopherin $\alpha$ Varianten $\alpha 1, \alpha 3, \alpha 4$ und $\alpha 5$ lagen (s.o.) im pCS2+ Vektor vor und wurden mit SP6 RNAPolymerase, $\alpha 2$ mit T3 RNA-Polymerase mit Retikulocytenlysat in einer gekoppelten TranskriptionsTranslationsreaktion exprimiert. Äquivalente Mengen der radioaktiv markierten Karyopherin $\alpha$ Varianten wurden auf einem 10 \%igen Polyacrylamidgel zur Kontrolle der im Versuch (s.u.) eingesetzten Mengen aufgetrennt. Eingesetzte Mengen an Transkriptions-Translationsansatz: Karyopherin $\alpha 1$ : 1 $\mu 1, \alpha 2: 1,5 \mu 1, \alpha 3: 5$ $\mu 1, \alpha 4: 5 \mu 1, \alpha 5: 1,5 \mu 1$.
\end{abstract}

Die Karyopherin $\alpha 3, \alpha 4$ und $\alpha 5$ Varianten binden an keines der angebotenen Substrate. Karyopherin $\alpha 1$ und $\alpha 2$ binden nicht an den GST-Fusionsanteil, aber an das angebotene Nukleoplasmin und an TFIIIA- $\Delta 56$. TFIIIA kann somit mit Karyopherin $\alpha 1$ und $\alpha 2$ unter den hier gezeigten Bedingungen interagieren und ist folglich ein Transportsubstrat von Karyopherin $\alpha 1$ und $\alpha 2$.

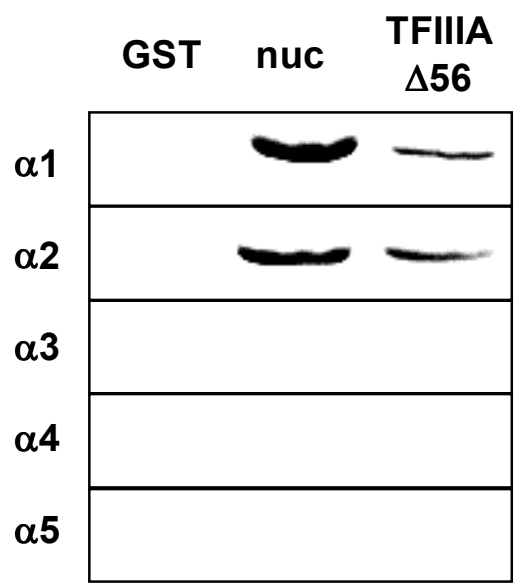

\begin{abstract}
Abbildung 26: Bindungsanalyse von GST-TFIIIA- $\Delta 56$ an verschiedene Karyopherin $\alpha$ Varianten. In der Bindungsanalyse wurden zu GT-Agarose, die mit GST, GST-Nukleoplasmin oder GST-TFIIIA- $\Delta 56$ beladen wurde, äquivalente Mengen der radioaktiv markierten Karyopherin $\alpha$ Varianten (siehe Abbildung 25) in Bindungspuffer hinzugefügt. Nach 2 Stunden Inkubation auf einem Drehrad wurden die Pellets sechs mal mit Bindungspuffer gewaschen. Die gebundenen Proteine wurden in SDS Puffer gelöst und auf einem 10 \%igen Polyacrylamidgel aufgetrennt.
\end{abstract}

In der Interaktionsstudie mit frisch angesetzten Transkriptions-Translationsansätzen und frisch angefertigten GST-Fusionsproteinen ist keine Bindung von den eingesetzten Transportadaptern Karyopherin $\alpha 3, \alpha 4$ und $\alpha 5$ an die angebotenen Transportsubstrate oder den zur Kontrolle eingesetzten Fusionsanteil GST aufgetreten. Karyopherin $\alpha 1$ und $\alpha 2$ zeigen keine Interaktion mit dem Fusionsanteil und binden somit spezifisch an Nukleoplasmin und TFIIIA- $\Delta 56$. Dieser Nachweis der spezifischen Interaktion von TFIIIA- $\Delta 56$ mit den 
Karyopherin $\alpha$ Varianten $\alpha 1$ und $\alpha 2$ korreliert, wie in der RT-PCR Analyse und der ,whole mount" in situ Analyse gezeigt, mit der gemeinsamen starken Expression während der frühen Phase der Oogenese. In den Versuchen, in denen Karyopherin $\alpha 1$ immobilisiert wurde und verschiedene TFIIIA Mutanten zur Bindungsanalyse verwendet wurden, wurde die Bindung von TFIIIA an Karyopherin $\alpha 1$ bestätigt. Eine Bindung von dem C-terminalen NLS 789 an Karyopherin $\alpha$ oder einen der angebotenen anderen Transportfaktoren trat jedoch nicht auf. Eine Analyse des Bindungsverhaltens des ersten NLS in den Zinkfingern 34 war aufgrund auftretender unspezifischer Bindungen an den GST-Fusionsanteil der eingesetzten Mutanten nicht möglich. Die Zinkfinger 34 sind jedoch das in den Oocyteninjektionen einzige, weitere transportkompetente Element von TFIIIA. Da TFIIIA in diesen Experimenten spezifisch an Karyopherin $\alpha 1$ bindet, bleibt als Interaktionsmotiv nur die Zinkfingerregion mit dem dritten und vierten Finger. Da das zweite NLS, die Zinkfinger 789, mit keinem der immobilisierten Transportfaktoren interagiert, wird es vermutlich auf einem anderen Importweg in den Zellkern transportiert. Möglicherweise interagiert dieses NLS mit einem der in der Durchmusterung einer embryonalen Augenbank identifizierten, neuen putativen Transportfaktoren. 


\title{
4 Diskussion
}

\subsection{Die Minimalstruktur der zwei NLS von TFIIIA}

In der vorliegenden Arbeit wurde die Minimalstruktur der transportaktiven Elemente von TFIIIA auf die Zinkfinger 34 und 789 eingegrenzt. Die Zinkfinger 123 bzw. 678 zeigen keine signifikante Kernlokalisierung. Dies zeigt, dass neben den allgemeinen Strukturelementen der Zinkfinger spezifische Signalsequenzen für die Vermittlung des Imports benötigt werden. Eine besondere Funktion ist den Zinkfingern 4 und 9 zuzuschreiben (Wischnewski, 1997). Sie besitzen neben der für die Ausbildung der Zinkfingerstruktur notwendigen Aminosäuren eine im Vergleich zu anderen Zinkfingern von TFIIIA hohe Anzahl an basischen Aminosäuren (Abbildung 27).

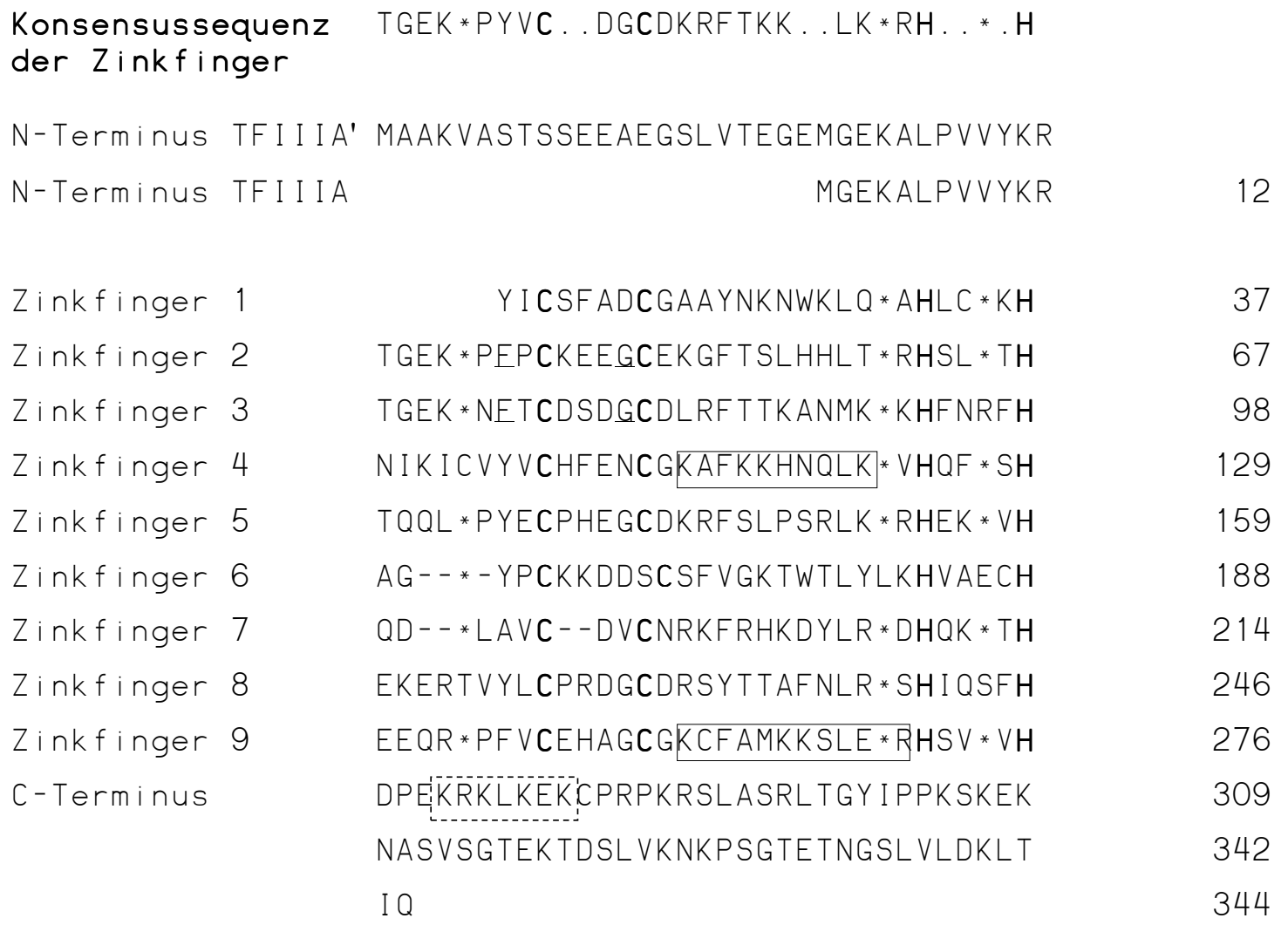

\begin{abstract}
Abbildung 27: Die Aminosäuresequenz von TFIIIA.
Die Aminosäuren sind so angeordnet, dass das sich neunmal wiederholende Motiv von Zinkfingern zu erkennen ist. Die Cysteine und Histidine, welche das Zinkfingermotiv (den HC-Link) bilden, sind fett dargestellt. Durch Sterne sind Positionen außerhalb des HC-Links gekennzeichnet, an denen in anderen Fingern zusätzliche Aminosäuren vorkommen. Das Fehlen von Aminosäuren wurde durch ein Minus (-) dargestellt. Mit durchgehender Linie eingefasste Aminosäuren geben Anhäufungen basischer Sequenzen innerhalb der Zinkfinger an, die mit unterbrochener Linie umrandete Sequenz gibt ein basisches Motiv im CTerminus an. Über den Zinkfingersequenzen sind die N-terminalen Sequenzen von TFIIIA und dem somatischen TFIIIA' angeordnet.
\end{abstract}


Die meisten der bisher beschriebenen Kerntransportsequenzen haben Motive basischer Natur. Unterschiedliches Bindungsverhalten von verschiedenen NLS an Transportfaktoren ist für L5 ebenso belegt wie die Nutzung grundlegend verschiedener Transportmechanismen. Nur das NLS1 bindet an RanBP7, Karyopherin $\beta$ und Karyopherin $\alpha 1$ (Claußen et al., 1999). Das NLS3 von L5 kann im Gegensatz zu NLS1 und NLS2 Ran unabhängig und unabhängig von cytosolischen Faktoren importiert werden (Rudt und Pieler, 2001). Die basischen Sequenzen im neunten Zinkfinger reichen nicht aus, um mit dem in Oocyten und HeLa Zellen transportkompetenten Zinkfingermodul 789 Bindung an Karyopherin $\alpha 1$ zu vermitteln. Für das zweite NLS von TFIIIA kann also angenommen werden, dass es einen anderen Transportweg als das C-terminale NLS von TFIIIA nutzt. Beide NLS sind in Oocyten und in transient transfizierten HeLa Zellen kernlokalisierungskompetent. Es kann also angenommen werden, dass für beide Fragmente in somatischen Zellen und in Oocyten Transportfaktoren existieren, die eine Kernlokalisierung ermöglichen.

Die Identifizierung der NLS von TFIIIA in den Zinkfingermodulen 34 und 789 steht in Übereinstimmung mit unserer Ausgangshypothese, dass Bindung von 5S RNA die NLS von TFIIIA maskiert. Eine Maskierung der NLS würde die cytoplasmatische Retention des 7S RNP Komplexes erklären. Beide NLS liegen flankierend der RNA bindenden Zinkfinger 4567. Die Zinkfinger 89 sind nicht signifikant an der Bindungsaktivität von TFIIIA an 5S RNA beteiligt (Setzer et al., 1996; Theunissen et al., 1998).

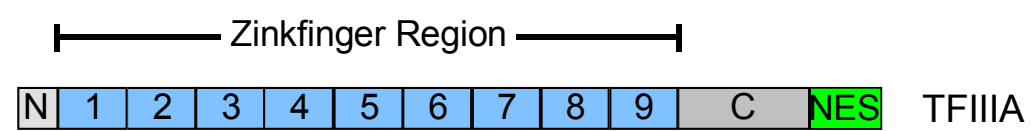

\begin{tabular}{|l|l|l|l|}
\hline 4 & 5 & 6 & 7 \\
\hline
\end{tabular}

5S RNA Bindung

\begin{tabular}{|l|l|}
\hline 3 & 4 \\
\hline
\end{tabular}

N-terminales NLS

\section{\begin{tabular}{l|l|l|l}
7 & 8 & 9 & C-terminales NLS
\end{tabular}}

Abbildung 28: Die TFIIIA Kerntransportsignale überlappen mit der 5S RNA bindenden Domäne. Schematische Darstellung der verschiedenen TFIIIA Domänen mit funktioneller Zuordnung. Die 5S RNA Bindung wird durch die Zinkfinger 4 bis 7 vermittelt. Das NLS1 wurde auf die Zinkfinger 34 und das NLS2 auf die Zinkfinger 789 eingegrenzt.

5S RNA Bindung an diese Finger hätte zur Folge, dass der vierte Zinkfinger für eine Interaktion mit Karyopherin $\alpha 1$ und $\alpha 2$ nicht mehr zugänglich wäre und somit der Import über 
diesen Karyopherin $\alpha$ vermittelten Weg nicht mehr möglich wäre. Eine Maskierung des Importsignals könnte die cytoplasmatische Retention von dem 7S RNP in Oocyten erklären. Dass ein solcher Mechanismus möglich ist, zeigt auch das gemeinsame Expressionsprofil von TFIIIA und den beiden Karyopherin $\alpha$ Varianten. Der Transportadapter und sein putatives Substrat werden im Verlauf der Oogenese zur selben Zeit stark exprimiert.

\subsection{TFIIIA bindet spezifisch an Karyopherin $\alpha 1$ und $\alpha 2$}

In den Bindungsstudien wurde mit Transportadapter oder Transportfaktoren beladene GTAgarose verwendet, um in vitro die Bindung von TFIIIA zu untersuchen. Die erste Analyse zeigte keine Bindung von TFIIIA an Karyopherin $\beta$, RanBP7, Transportin oder Karyopherin 33. Neben dem vollständigen Protein wurde die Bindung von verschiedenen TFIIIADeletionsmutanten untersucht. Nicht transportkompetente Zinkfinger konnten genausowenig wie auch das in Oocyteninjektionsexperimenten kernlokalisierte 789 Zinkfingerelement an die angebotenen Faktoren binden. Das N-terminale NLS ließ sich in diesem Experiment aufgrund unspezifischer Bindungsaktivität nicht analysieren. Es wurde von allen eingesetzten Transportfaktoren und dem GST-Fusionsanteil gebunden.

TFIIIA und die Deletionsmutante TFIIIA- $\Delta 56$ zeigen jedoch eine spezifische Affinität zu Karyopherin $\alpha 1$. Dieses Ergebnis korreliert mit Interaktionsstudien, in denen TFIIIA von einem Heteroproteinkomplex bestehend aus Karyopherin $\alpha$, Karyopherin $\beta$ und p62 präzipitiert werden kann (Percipalle et al., 1997). Da die Zinkfinger 789 von Karyopherin $\alpha 1$ nicht gebunden werden, ist es wahrscheinlich, dass die Interaktion durch das einzige weitere kernlokalisierungskompetente Zinkfingerelement in seiner Minimalstruktur bestehend aus den Fingern 34 vermittelt wird. Im Kontrollexperiment wurde gezeigt, dass die spezifische Affinität $\mathrm{zu} \alpha 1$ erhalten bleibt, wenn TFIIIA- $\Delta 56$ in immobilisierter Form dem gelösten Transportadapter als Substrat angeboten wird. Zusätzlich wurde gezeigt, dass die Bindung von TFIIIA auf die Karyopherin $\alpha 1$ und $\alpha 2$ Varianten beschränkt ist. Die Varianten $\alpha 3, \alpha 4$, und $\alpha 5$ zeigen keine Affinität zu TFIIIA. Dieses Ergebnis korreliert mit der in letzter Zeit häufig diskutierten selektiven Bindungsaktivität einiger Substrate an verschiedene $\alpha$ Karyopherine.

Die selektive Bindung an Karyopherin $\alpha 1$ und $\alpha 2$ konnte nur mit frisch präparierten Komponenten gezeigt werden. Wurden ältere Präparationen von GST-Fusionsproteinen verwendet (nicht gezeigt), zeigte zwar keine der Karyopherin $\alpha$ Varianten Affinität zu dem GST-Fusionsanteil, aber die Varianten $\alpha 3, \alpha 4$ und $\alpha 5$ wurden dann auch von Nukleoplasmin 
und TFIIIA signifikant gebunden. Es kann nicht davon ausgegangen werden, dass in einer in vitro Situation dieselben Konformationen eingenommen werden wie in vivo. Alle Komponenten mussten frisch präpariert werden, um die selektive Substratbindung der Karyopherin $\alpha 1$ und $\alpha 2$ Varianten darzustellen. Die komplexe in vivo Situation ist in den Interaktionstudien ebenso wenig berücksichtigt wie eine mögliche Konformationsänderung der Karyopherin $\alpha$ Varianten durch Bindung an Karyopherin $\beta$.

Karyopherin $\alpha$ abhängiger Import ist in Digitonin permeabilisierten HeLa Zellen mit der Xenopus Karyopherin $\alpha 2$ Variante und verschiedenen anderen humanen $\alpha$ Varianten bereits untersucht worden. Auch in dieser Analyse zeigen bei Verwendung von bei $-80^{\circ} \mathrm{C}$ gelagerten Karyopherin Varianten keine selektive Fähigkeit, den Import von klassischen NLS zu vermitteln, wenn nur ein Importsubstrat angeboten wird. Die Importeffizienz, welche durch die verschiedenen Varianten vermittelt wurde, war jedoch unterschiedlich ausgeprägt. Wurden verschiedene Importsubstrate angeboten, so war die Importeffizienz, die durch Xenopus Karyopherin $\alpha 2$ von Nukleoplasmin vermittelt wurde, dann am größten, wenn hnRNP K dem Importmix hinzugefügt wurde. Humanes Karyopherin $\alpha 1$ importiert unter diesen kompetitiven Bedingungen zwar hnRNP $\mathrm{K}$ effizient, nicht aber Nukleoplasmin (Köhler et al., 1999).

In dieser Analyse ist bei Verwendung von eingefrorenen Karyopherin $\alpha$ Varianten Nukleoplasmin in einer kompetitiven Situation ebenfalls nicht importiert worden. Dieser Befund stützt das in dieser Arbeit ermittelte selektive Bindungsverhalten von frisch präparierten Nukleoplasmin und TFIIIA- $\Delta 56$ an die Karyopherin $\alpha 1$ und $\alpha 2$ Varianten. Eine selektive Bindung würde auch in Übereinstimung mit den gemeinsamen Expressionsprofilen von TFIIIA und Karyopherin $\alpha 1$ und $\alpha 2$ stehen. Die Problematik des abweichenden Verhaltens unter den verschiedenen in vitro Bedingungen verdeutlicht die Notwendigkeit, in vivo Analysen zur weiteren Aufklärung der selektiven Substratspezifität von den verschiedenen Karyopherin $\alpha$ Varianten durchzuführen. In Experimenten, welche die gezielte Ausschaltung einzelner Karyopherin $\alpha$ Varianten in Oocyten oder dem lebenden Organismus ermöglichen, sollte sich die Redundanz im Bindungsverhalten der Karyopherin Varianten auflösen lassen. Ein gezieltes Ausschalten einzelner Proteine ist z.B. durch Antikörper, RNAi Experimente, Morpholino-Oligonukleotide oder Mutagenese möglich.

Die gezeigte Importkompetenz der 234 Deletionsmutante in HeLa Zellen könnte durch redundante Bindungsfähigkeit an andere Karyopherin Varianten oder weitere bisher noch nicht identifizierte Transportfaktoren erklärt werden. TFIIIA besitzt neben dem transportkompetenten 34 Zinkfingermodul ein weiteres transportaktives Modul, das nicht an 
Karyopherin $\alpha 1$ binden kann. Die Zinkfinger 789, die in Oocyten und in transienten Transfektionen von HeLa Zellen in den Zellkern importiert werden, könnten ein Transportsignal darstellen, welches dann vom Wildtypprotein genutzt wird, wenn die Karyopherin $\alpha 1$ und $\alpha 2$ Varianten nicht mehr zur Verfügung stehen. In in vitro Importstudien mit HeLa Zellen und Reticulocytenlysat wird das N-terminale NLS, die Zinkfinger 234 nicht aber das C-terminale NLS, die Zinkfinger 789, kernlokalisiert (F. Rudt, persönliche Mitteilung). Der auftretende Widerspruch zu den Ergebnissen der transienten Transfektionen von HeLa Zellen, in denen auch das 789 Zinkfingerelement kernlokalisiert wird, kann durch die unterschiedliche Dauer der für die Transportprozesse zur Verfügung stehenden Zeit erklärt werden. Die transfizierten HeLa Zellen wurden zwei Tage in Kultur gehalten. In den in vitro Importstudien ist der Transportprozeß nach 30 min abgebrochen worden. Die Ergebnisse, die unter den restriktiveren Bedingungen der in vitro Importstudien vorliegen, korrelieren mit den Interaktionsstudien dieser Arbeit. In HeLa Zellen ist dem 789 Zinkfingerelement aufgrund der in vitro Importstudien keine biologische Relevanz zuzuordnen. In Oocyten kann eine biologische Funktion aufgrund der Summe der importierten Deletionsmutanten nicht ausgeschlossen werden.

Da das C-terminale NLS 789 nicht mit Karyopherin $\alpha 1$ interagiert, ist es möglich, dass die Interaktion von TFIIIA mit Karyopherin $\alpha$ (siehe 3.5.3) auf das einzige weitere transportaktive Element von TFIIA, die transportaktiven Zinkfinger 34, zurückzuführen ist. Das mit basischen Aminosäuren angereicherte Zinkfingermodul des N-terminalen NLS, nicht aber das mit basischen Aminosäuren angereicherte Zinkfingermodul des C-terminalen NLS überlappt mit den Zinkfingern, die wesentlich an der 5S RNA Bindung von TFIIIA beteiligt sind.

Für das C-terminale NLS wurde in verschiedene Deletionsmutanten eine Kernlokalisierungskompetenz in Oocyten gezeigt. In transfizierten HeLa Zellen ist das 789 Zinkfingerelement kernlokalisiert. In der Sequenz des neunten Zinkfingers sind mehrere basische Aminosäuren enthalten. Eine der aktuellen Theorien zum nukleocytoplasmatischen Transport geht von der Notwendigkeit aus, dass hydrophile Proteinoberflächen durch die Bindung an Transportfaktoren verdeckt sein müssen, um Kerntransport zu ermöglichen (Ribbeck und Görlich, 2001). Eine Beteiligung weiterer Faktoren oder eine andersartige Maskierung der 789 Zinkfinger während des Transports in Oocyten wäre also eine Vorraussetzung für die Kernlokalisierung von TFIIIA. Dieser hydrophobe Zustand sollte auch im Karyopherin $\alpha / \beta$ Komplex vorliegen. Eine Interaktionstudie mit GST-Fusionsmutanten der Zinkfinger 34, 789 
und gelösten Transportfaktoren könnte Aufschluss darüber geben, welche der beiden Zinkfingerelemente den Kontakt zu Karyopherin $\alpha$ herstellen.

\subsection{Definition der Karyopherin $\beta 3$ Synexpressionsgruppe}

Expressionsmusteranalysen in Xenopus Embryonen mit zufällig ausgewählten cDNAs zeigten die Existenz von Gengruppen in koordinierter Expression, die in gemeinsamen Prozessen funktionieren. Diese Gengruppen wurden Synexpressionsgruppen genannt. Die biologischen Prozesse, in die solche Synexpressionsgruppen involviert sind, reichen von generellen zellulären Aktivitäten, wie ER-Import, bis hin zu spezifisch regulatorischen Prozessen, wie den BMP-4 oder Delta-1 Signalwegen (Niehrs und Pollet, 1999).

In unserem Labor wurde die Teilsequenz eines putativen Transportfaktors isoliert. Die Vervollständigung der Sequenz und eine ausführliche „whole mount“ in situ Analyse von Karyopherin $\beta 3$ zeigte ein differentielles Expressionsmuster. Der Vergleich zu Expressionsmustern von den ribosomalen Proteinen S8, S3A, L3, L6, L7A und L5, den transportassoziierten Proteinen RanTC4 und RanBP1 und den Expressionsmustern anderer Proteine, von denen angenommen wird, dass sie in den Transport ribosomaler Proteine involviert sind, zeigt gemeinsame Expressionscharakteristika dieser Gene. Die wesentlichen Merkmale sind eine starke Expression im Auge, den Kiemenbögen und der Schwanzspitze des Xenopus Embryos. Die Expression der genannten Gene ist ab dem Neurulastadium mit einem starken Signal im Augenfeld und in den sensorischen Schichten des Neuroektoderms detektierbar.

Diese Beobachtung eines gemeinsamen Expressionsprofils von Genen erfüllt die erste Bedingung für die Definition einer Synexpressionsgruppe. Proteine, die in Transportprozesse ribosomaler Proteine involviert sein könnten, und ribosomale Proteine selbst zeigen eine koordinierte Expression. Der funktionelle Zusammenhang wird durch den ribosomalen Transport hergestellt und erfüllt die zweite Bedingung für die Definition einer neuen Synexpressionsgruppe.

Aufgrund des charakteristischen Expressionsmusters dieser Gruppe sollte es über optische Selektion möglich sein, neue Gene $\mathrm{zu}$ identifizieren, die eine Funktion im ribosomalen Transport haben. Für eine solche Analyse wurde eine cDNA-Bank aus embryonalem Augengewebe hergestellt und in einer „whole mount“ in situ Analyse nach Karyopherin $\beta 3$ artigen Expressionsmustern durchsucht.

Für andere dem nukleocytoplasmatischen Transport assoziierte Gene, die nicht direkt in den Proteintransport ribosomaler Proteine involviert sind, wie SUMO-1 und p10 (NTF2) konnte 
ein Karyopherin $\beta 3$ entsprechendes Expressionsmuster nicht nachgewiesen werden. SUMO-1 und NTF2 sind in die Aufrechterhaltung des RanGDP/GTP Gradienten der Kernpore involviert. Dass sie kein ausgeprägtes Expressionsmuster zeigten, kann auf eine generell niedrigere Expression hinweisen, da weniger von diesen Komponenten benötigt wird. Möglicherweise liegt in den Embryonen eine besondere Situation vor, die zwar eine erhöhte Expression der Transportfaktoren benötigt, nicht aber die der anderen Komponenten der Transportmaschinerie. Hier würde eine Quantifizierung von Expressionsstärken in Embryonen und adulten Geweben zur Aufklärung dieses Ergebnisses beitragen.

\subsection{Die Karyopherin $\alpha$ Varianten}

Ausgehend von der Beobachtung, dass ribosomale Proteine, ihre putativen Transportfaktoren und dem Transportgeschehen assoziierte Proteine eine Synexpressionsgruppe bilden, wurden im Rahmen der Durchmusterung einer für diesen Zweck erstellten cDNA Bank aus embryonalem Augengewebe drei neue Karyopherin $\alpha$ Varianten isoliert. Eine vergleichende „whole mount“ in situ Analyse zeigte differentielle Expression für jede der Karyopherin $\alpha$ Varianten. Während der frühen Oogenese werden alle 5 Varianten wie auch TFIIIA exprimiert.

In der Embryonalentwicklung unterscheidet sich die Expression der Karyopherin Varianten deutlich. Karyopherin $\alpha 3$ wird im Gegensatz zu $\alpha 4$ und $\alpha 5$ in den Cilienzellen der Haut und deutlich stärker in den abdominalen Bereichen des Embryos exprimiert. Karyopherin $\alpha 3$ und $\alpha 4$ zeigen bereits im Neurulastadium eine ausgeprägte Expression. Mit $\alpha 3$ und $\alpha 4$ vergleichbare Expressionsstärken werden von der $\alpha 5$ Variante erst nach dem Neurulastadium erreicht. Interessant ist hier, dass die starke Transkriptionsaktivierung von $\alpha 3$ und $\alpha 4$ im Neurulastadium vor der Transkriptionsaktivierung der Karyopherin $\alpha 5$ Variante stattfindet. Diese geordnete starke Transkriptionsaktivierung könnte auf weitere spezifisch an bestimmte Karyopherin $\alpha$ Varianten bindende Proteine hinweisen, die von $\alpha 5$ gebunden werden, nicht aber von Karyopherin $\alpha 3$ und $\alpha 4$.

Mit Karyopherin $\alpha 3$ wird die zweite Klasse der Karyopherin $\alpha$ Familie erweitert. In Maus und Mensch konnte in dieser Klasse erst je eine Karyopherinvariante nachgewiesen werden. Xenopus hingegen besitzt mindestens zwei, Karyopherin $\alpha 1(\alpha 2)$ und das mit dieser Arbeit isolierte Karyopherin $\alpha 3$. Die Karyopherin Varianten $\alpha 1$ und $\alpha 2$ könnten in Xenopus eine besondere Bedeutung während der Oogenese haben. Ihre mRNA ist bis zum Beginn der Midblastulatransition, also bis zum Beginn der zygotischen Transkription, in RT-PCR 
Analysen nachweisbar, nimmt aber schon ab Stadium III Oocyten deutlich ab. Mit dieser Limitierung auf die maternale Transkription in Oocyten unterscheidet sich die Expression dieser beiden Varianten deutlich von der biphasischen Expression der Karyopherin Varianten $\alpha 3, \alpha 4$ und $\alpha 5$.

Die mit den PCR Analysen ermittelten Daten zeigen in der frühen Oogenese eine starke Expression von TFIIIA und den Karyopherin $\alpha 1$ und $\alpha 2$ Varianten. Die Signalstärke nimmt bei allen drei der getesteten mRNAs ab dem Stadium III ab. Diese Genexpression ist im Gegensatz zu anderen Varianten ab der Midblastulatransition nicht mehr detektierbar.

Das Expressionsprofil von $\alpha 1$ und $\alpha 2$ korreliert mit der starken maternalen Expression von TFIIIA sowohl in der RT-PCR Analyse als auch in der „whole mount“ in situ Analyse. Später, ab der Neurula auftretendes somatisches TFIIIA' wird in deutlich geringeren Mengen exprimiert (Shastry et al., 1984 und 3.5.1). Das gemeinsame Expressionsprofil von $\alpha 1, \alpha 2$ und TFIIIA macht Karyopherin $\alpha 1$ und $\alpha 2$ zu präferentiellen Kandidaten als Transportadapter von TFIIIA zu funktionieren.

In Drosophila und Caenorhabditis zeigte die Inaktivierung einzelner Karyopherin $\alpha$ Varianten einen morphologischen Effekt auf die Ovarien. Sterile homozygote Weibchen mit einer Transposon Insertion im Karyopherin $\alpha$ homologen Importin $\alpha 3$ Gen haben Defekte in den Ovarien und bilden weniger Ovariolen aus. Die Oogenese wird ab dem Stadium 7-10 unterbrochen und zwar $\mathrm{zu}$ einem Zeitpunkt, zu dem große Mengen an Importin $\alpha 3$ normalerweise in den Wildtyp Nährzellen vorhanden sind (Mathe et al., 2000). In C. elegans werden die Karyopherin $\alpha$ Homologen Ima-1, Ima-2 und Ima-3 in der Keimbahn exprimiert, aber nur Ima-3 wird auch im Soma exprimiert. RNA Interferenz (RNAi) Experimente zeigen, dass Ima-3 für das Fortschreiten der meiotischen Prophase I während der Oocytenentwicklung benötigt wird (Geles und Adam, 2001). Die Funktion der inaktivierten Karyopherin Varianten in Drosophila und Caenorhabditis konnte nicht durch andere Karyopherin $\alpha$ Varianten übernommen werden. Hier zeigt sich, dass im lebenden Organismus Karyopherin $\alpha$ Varianten für spezifische Transportfunktionen benötigt werden.

Obwohl der Hitzeschock Transkriptionsfaktor in frühen Embryonen schon vorhanden ist, kann eine Hitzeschock-Antwort nicht induziert werden. Der Hitzeschock Transkriptionsfaktor dHSF von Drosophila wird spezifisch von Importin $\alpha 3$ gebunden und kann erst mit der Expressionsaktivierung von Importin $\alpha 3$ in älteren Embryonen in den Zellkern gelangen. Die Hitzeschock-Antwort kann erst mit der Synthese von Importin $\alpha 3$ aktiviert werden (Fang et $a l .$, 2001). Neben einer hohen Redundanz im Bindungsverhalten, die für $\alpha$ Karyopherine in vitro beschrieben wurde (Köhler et al., 1997; Seki et al., 1997; Welch et al., 1999), gibt es in 
vivo auch Substrate, welche eine hohe Spezifität bei der Interaktion mit den Karyopherin $\alpha$ Varianten besitzen und wie der Hitzeschock Transkriptionsfaktor in ihrer nukleocytoplasmatischen Verteilung durch Karyopherine reguliert werden. Andernfalls dürfte die Inaktivierung einzelner Karyopherin Varianten in Drosophila und Caenorhabditis keinen morphologischen Effekt nach sich ziehen. Kandidaten für eine vergleichbare regulatorische Funktion im nukleocytoplasmatischen Transport von Xenopus sind die Karyopherin $\alpha 1$ und a2 Varianten. Sie könnten selektiv Proteine während der Oogenese in den Zellkern transportieren. Da die Karyopherin Varianten $\alpha 3, \alpha 4$ und $\alpha 5$ in allen Embryonalstadien nachweisbar waren, wäre eine regulatorische Funktion komplizierter und vermutlich konzentrationsabhängig. Ein mögliches Szenario wäre hier ein Transkriptionsfaktor, der wie TFIIIA NLS und NES (Kernexportsignalsequenz) Funktionen gleicher Effizienz trägt. Er könnte erst im Zellkern angereichert werden, wenn der Importfaktor in ausreichend hoher Konzentration vorliegt.

Das Expressionsmuster von Karyopherin $\alpha 3$ unterscheidet sich im Kaulquappenstadium deutlich von dem der anderen Karyopherin Varianten. Karyopherin $\alpha 3$ zeigt ein starkes Signal in einzelnen Zellen der Haut und eine erhöhte Expression in allen Geweben, in denen auch $\alpha 4$ und $\alpha 5$ exprimiert werden. Ein weiterer Kandidat für eine transportvermittelte regulatorische Funktion ist $\alpha 5$. Karyopherin $\alpha 5$ zeigt sowohl in der RT-PCR als auch in der ,whole mount“ in situ Analyse eine $\alpha 3$ und $\alpha 4$ gegenüber verzögerte schwächere Expression.

\subsection{Durchmusterung einer cDNA Bank aus embryonalem Augengewebe}

In der statistischen Auswertung der Klone, denen eine Funktion zugeordnet werden konnte, besteht ein generelles Problem der funktionellen Klassifizierung. Die Zuordnung zu einzelnen Gruppen wurde in Tabelle 10 basierend auf den Angaben zur ähnlichsten Sequenz aus den im BLAST benutzten Datenbanken vorgenommen. Die dort Angegebenen Kurzbeschreibungen mögen für eine statistische Übersicht hinreichend sein, können aber im Einzelfall nicht unbedingt ausreichen. Eine Beschränkung auf den Namen des Proteins allein reicht in der Bewertung nicht aus. Dies wird zum Beispiel durch das ,,non-histone chromosome protein 2 like 1" verdeutlicht, welches eine Komponente des U4,U6,U5 tri-snRNP ist und an den 5' „stem-loop“ von U4 snRNA bindet, also mit den Chromosomen nichts zu tun hat. Ein weiteres Problem stellt die Einordnung von Proteinen dar, die in mehrere Gruppen eingeordnet werden können dar. Histone wurden in die Gruppe DNA bindender Proteine eingeordnet, sie sind aber auch Mitglieder der Chromatingruppe. Eine Mehrfachnennung 
würde zu einem verfälschten Eindruck der Gesamtübersichten führen. Von der Seite der Chromatinproteine aus betrachtet wäre eine Einordnung in die Gruppe der DNA bindenden Proteine nicht gerechtfertigt, da viele dieser Proteine nicht direkt mit DNA interagieren, sondern die Chromatinstruktur über peripher angesiedelte Mechanismen beeinflussen. Diese Gruppe nicht zu nennen würde jedoch der Häufigkeit mit der Mitglieder der Chromatingruppe auftreten nicht gerecht werden.

Basierend auf der Beobachtung, dass ribosomale Proteine und ihre putativen Transportfaktoren eine Synexpressionsgruppe bilden, sollten in der Durchmusterung einer für diesen Zweck angefertigten cDNA-Bank aus embryonalem Augengewebe Klone isoliert werden, die in das Transportgeschehen ribosomaler Proteine involviert sind. Die nach optischer Selektion identifizierten Kandidaten wurden ansequenziert, und nach einer Datenbankanalyse (sofern möglich) wurde ihnen eine Identität zugeordnet. Als differentiell exprimiert wurden $28 \%$ von 989 analysierten Klonen gewertet. Eine ähnliche Häufigkeit mit 26 \% wurde von Gawantka et al. (Gawantka et al., 1998) in einer Analyse von einer Neurula cDNA Bank erzielt. Interessant ist auch der Vergleich von redundanten mehrfach auftretenden Sequenzen. Gawantka et al. hat fast doppelt so viele Klone analysiert und eine Redundanz von $40 \%$ erhalten. In der hier vorgestellten Analyse repräsentieren $10 \%$ der differentiell exprimierten Klone gleiche Gene (Tabelle 12). Dieser Unterschied könnte durch die Verwendung einer primären Phagenbank in dieser Arbeit erklärt werden. Gawantka verwendete eine amplifizierte cDNA Bank, was zu einer Anreicherung häufig exprimierter Gene führt. Während bei Gawantkas et al. Analyse selbst bei großzügiger Bewertung der Expressionsmuster aufgrund der unterschiedlichen Qualität der ,whole mount“" in situs maximal $12 \%$ der differentiell exprimierten Klone (ohne Redundante) in die Karyopherin Gruppe fallen, wurden in der hier vorgestellten Analyse $40 \%$ der analysierten Klone mit einem Karyopherin $\beta 3$ Muster identifiziert. Faktisch verdeutlicht wird die Anreicherung der Karyopherin $\beta 3$ artig exprimierten Klone durch einen Vergleich der isolierten Klone ribosomaler Proteine. In Gawantkas Analyse wurden 5 Klone (S2, S20, L29, L14 und L37) ribosomaler Gene isoliert, was einem Anteil der differentiell exprimierten Klone (ohne Redundante) von 1,8\% entspricht. Demgegenüber stehen 8,8\% isolierte Klone ribosomaler Proteine in dieser Arbeit. Allein durch die Auswahl einer Gewebe-spezifischen cDNA-Bank konnte die Ausbeute an Klonen ribosomaler Proteine um das Fünffache gesteigert werden. Die optische Selektion, welche ein notwendiger Schritt zur Identifizierung der differentiell exprimierten Klone ist, erhöht die Wahrscheinlichkeit einen ribosomalen Klon zu finden mit 
$16 \%$ um den Faktor 2 in der vorliegenden Arbeit, eine Anreicherung, die auch für in den nukleocytoplasmatischen Transport involvierte Proteine zu erwarten ist, da sie einen Teil der Synexpressionsgruppe darstellen.

Bei Betrachtung der Verteilung von Klonen ribosomaler Proteine innerhalb der Karyopherin $\beta 3$ Synexpressionsgruppe würde man ähnliche Ergebnisse erwarten. In der Tat stehen hier 14 $\%$ aus Gawantkas Analyse $16 \%$ Klonen ribosomaler Proteine aus der Karyopherin $\beta 3$ Synexpressionsgruppe dieser Arbeit gegenüber. Der Anteil an Klonen ribosomaler Proteine innerhalb der Karyopherin $\beta 3$ Synexpressionsgruppe ist somit gleich und zeigt im Bezug auf verschiedene Analysen Konsistenz.

Eine bezogen auf den experimentellen Ansatz vergleichbare Analyse ist die Durchmusterung einer embryonalen Schwanzspitzen cDNA Bank (Sölter, 1999). Hier wurde ein Gewebe analysiert, bei welchem eine Anreicherung von Klonen ribosomaler Gene zu erwarten ist, da das Expressionsmuster ribosomaler Gene ein verstärktes Signal in der Schwanzspitze zeigt. Die Signalintensität in der Schwanzspitze ist gegenüber der Signalintensität im embryonalem Augengewebe geringer. Aus der Analyse einer Schwanzspitzen cDNA Bank ging der partielle Klon von Karyopherin $\beta 3$ hervor, was einem Anteil bezogen auf die Gesamtzahl der differentiell exprimierten Gene von $0,5 \%$ entspricht. Die schwächere Signalintensität in der Schwanzspitze gegenüber dem Auge sollte auch eine unterschiedliche Verteilung der exprimierten Gengruppen widerspiegeln. Aufgrund der Gewebsspezifität würde man für Klone ribosomaler Gene bei Analyse einer Schwanzspitzen cDNA Bank eine höhere Ausbeute erwarten als in Gawantkas Analyse und einen geringeren Anteil als in der Analyse der vorliegenden Arbeit. Der Anteil von Klonen ribosomaler Gene bezogen auf die Gesamtanzahl der Klone mit einem Expressionsmuster liegt mit 2,8 \% erwartungsgemäß zwischen den Ausbeuten von Gawantka (1,8\%) und der vorliegenden Arbeit (8,8\%).

Für Klone ribosomaler Proteine wurde mit dem hier vorliegenden Ansatz eine Anreicherung erzielt. Wahrscheinlich gilt dies auch für in den nukleocytoplasmatischen Transport involvierte Proteine. Diese Frage ist jedoch noch nicht abschließend zu beantworten. Der Anteil der in das Transportgeschehen involvierten Proteine innerhalb der Synexpressionsgruppe liegt nach gesicherter Zuordnung einer Funktion bei $2 \%$. Aus der Analyse gingen zwei Klone hervor, die in den nukleocytoplasmatischen Transport involviert sind. Sam68, welches an Tap und die RNA Helicase A bindet, und Karyopherin $\alpha 3$. Der Anteil von $2 \%$ könnte jedoch wesentlich größer sein als hier zunächst erfasst. Von den 30 Klonen, denen keine Funktion zugeordnet werden konnte, besitzen 5 mit ihrer abgeleiteten Sequenz eine Homologie zur RCC1 Signatur und zeigen auch mit dem Dialign Programm 
Homologie zu einzelnen Bereichen Karyopherin $\beta$ verwandter Proteine. Sie könnten somit Mitglieder der Karyopherin $\beta$ Superfamilie sein, was den Anteil an der Synexpressionsgruppe auf $6 \%$ erhöhen würde. Von den Klonen wurde nur eine Teilsequenz für die Datenbankanalysen eingesetzt. Möglich ist demzufolge auch, dass der Bereich, welcher eine Zuordnung zur Superfamilie erlauben würde, in dieser Sequenz nicht enthalten war. Eine weitere Möglichkeit ist eine Beteiligung der Klone an der Ausbildung des Kernporenkomplexes. Die Bedeutung des Kernporenkomplexes für den nukleocytoplasmatischen Transport wird mit dem von cytosolischen Faktoren unabhängigen Import von dem L5 NLS3 erweitert. Da dieses NLS eine zugängliche Kernpore benötigt, ist ein Bestandteil des Kernporenkomplexes selbst in der Lage, Transport zu vermitteln. Die Sequenzen solcher Proteine konnten mit der PROSCAN bzw. Dialign Analyse noch nicht erfasst werden. Möglicherweise ist die Anzahl der in den nukleocytoplasmatischen Transport involvierten Proteine wesentlich größer als hier erfasst. Dies kann jedoch erst nach Vervollständigung der Kandidatenklone und weiteren Funktionsanalysen abschließend geklärt werden.

\subsection{Ausblick}

Eine Zusammenfassung in Synexpressionsgruppen, wie auch eine computergestützte Sequenzmusteranalyse können eine experimentelle Verifizierung der Funktion von Genen nicht ersetzen, aber sie erlauben eine Fokussierung der Analysen. Die 5 Kandidatenklone mit Sequenzmustern der Karyopherin $\beta$ Superfamilie sollten zunächst vervollständigt werden. Eine erneute Sequenzmusteranalyse könnte dann schon Hinweise auf eine mögliche Einordnung in eine der Klassen der Karyopherin $\beta$ Superfamilie geben. Zur Überprüfung der Funktion wären jedoch Interaktionsstudien mit Ran und eventuell auch mit Proteinen des Kernporenkomplexes notwendig. Sollten sich durch diese folgende Analyse weitere in den Kerntransport involvierte Proteine identifizieren lassen, lohnt sich auch eine weitere Betrachtung der Kandidaten, denen bisher noch keine Funktion zugeordnet werden konnte.

Die auftretende Redundanz im Bindungsverhalten von Karyopherin $\alpha$ Varianten erfordert die Entwicklung eines in vivo Systems, in dem sich der Effekt der $\alpha$ Varianten auf verschiedene Transportsubstrate untersuchen lässt. Aufgrund des mit dieser Arbeit gezeigten unterschiedlichen Verhaltens von frisch präparierten $\alpha$ Varianten und bei $-70{ }^{\circ} \mathrm{C}$ gelagerten Präparationen ist eine Neubewertung bisher erzielter in vitro Ergebnisse zur Substratspezifität von Karyopherin $\alpha$ Varianten unumgänglich. In Drosophila und Caenorhabditis wurde die 
Beteiligung der Transportadapter an entwicklungsregulatorischen Prozessen nachgewiesen. Xenopus bietet sich als klassischer Modellorganismus an, solche Prozesse zu untersuchen. Mit der Isolierung der Karyopherin Varianten wurden die Vorraussetzungen für solche Experimente geschaffen.

Das Zinkfingerprotein TFIIIA besitzt 2 NLS, für eines der beiden konnte hier ein putativer Transportadapter identifiziert werden. Für das zweite NLS muss ein Transportfaktor noch identifiziert werden. Um die Zuordnung des C-terminalen NLS (34) zu dem Transportadapter Karyopherin $\alpha \mathrm{zu}$ verifizieren, sollten Interaktionsstudien mit GST-Fusionen der Zinkfinger 34, 789 und den verschiedenen Karyopherin $\alpha$ Varianten durchgeführt werden. Wie für L5 beschrieben ist auch für NLS1 und NLS2 von TFIIIA nicht auszuschließen, dass grundlegend verschiedene Transportmechanismen für die Kernlokalisierung benutzt werden. 


\section{$5 \quad$ Zusammenfassung}

In der vorliegenden Arbeit wurden die minimalen transportkompetenten Strukturen des Transkriptionsfaktors IIIA auf die Zinkfinger 34 und 789 eingegrenzt. Die transportvermittelnden Zinkfingerregionen flankieren die RNA bindenden Zinkfinger 4567. Dieser Befund steht in Übereinstimmung mit unserer Arbeitshypothese. Die Bindung von 5S RNA an TFIIIA maskiert das NLS und führt so zur cytoplasmatischen Retention des 7S RNP Komplexes.

Mit den in Xenopus neuen Karyopherin $\alpha$ Varianten konnte gezeigt werden, dass TFIIIA- $\Delta 56$ bei Verwendung von frisch erstellten Karyopherin $\alpha$ Fusionsproteinen in vitro spezifisch an $\alpha 1$ und $\alpha 2$ binden kann. Beide Varianten zeigen in RT-PCR und ,whole mount“" Analysen ein Expressionsprofil, das dem von TFIIIA entspricht. Diese Bindung ist wahrscheinlich auf das Zinkfingerelement 34 zurückzuführen, da die Finger 789 im Gegensatz zu dem kompletten TFIIIA Protein keine Karyopherin $\alpha 1$ Interaktion zeigen und die Finger 34 das einzige weitere Element repräsentieren, welches Kerntransportkompetenz besitzt.

Aufgrund der identischen Expressionsmusterprofile von ribosomalen Proteinen, transportfaktorassoziierten Proteinen und Transportfaktoren wurde die Existenz einer neuen Synexpressionsgruppe nachgewiesen. Aus diesem Befund ging der experimentelle Ansatz hervor, neue in den Transport ribosomaler Proteine involvierte Gene durch optische Selektion auf das in der Synexpressionsgruppe auftretende Expressionsmuster zu isolieren. Für die Durchmusterung der angefertigten cDNA Bank aus embryonalem Augengewebe wurde ein maschinelles in situ Hybridisierungsverfahren angewendet. Dass der Ansatz der optischen Selektion zu einer Anreicherung der gewünschten Gene führt, zeigt der hohe Anteil der in der Durchmusterung isolierten Klone ribosomaler Gene. Aus der Analyse gingen zwei Klone hervor, die nachweislich in den Kerntransport involviert sind. Es wurden fünf weitere Kandidatenklone identifiziert, die eine RCC1 Signatur besitzen und in den nukleocytoplasmatischen Transport involviert sein könnten. 


\section{Literaturverzeichnis}

Altschul, S.F., Madden, T.L., Schaffer, A.A., Zhang, J., Zhang, Z., Miller, W. and Lipman, D.J. (1997) Gapped BLAST and PSI-BLAST: a new generation of protein database search programs.

Nucleic Acids Res 25, 3389-402.

Bannister, A.J., Miska, E.A., Görlich, D. and Kouzarides, T. (2000) Acetylation of importinalpha nuclear import factors by CBP/p300.

Curr Biol 10, 467-70.

Ben-Efraim, I. and Gerace, L. (2001) Gradient of increasing affinity of importin beta for nucleoporins along the pathway of nuclear import.

J Cell Biol 152, 411-7.

Birnboim, H.C. and Doly, J. (1979) A rapid alkaline extraction procedure for screening recombinant plasmid DNA.

Nucleic Acids Res 7, 1513-23.

Bordonne, R. (2000) Functional characterization of nuclear localization signals in yeast Sm proteins.

Mol Cell Biol 20, 7943-54.

Claußen, M., Rudt, F. and Pieler, T. (1999) Functional Modules in Ribosomal Protein L5 for Ribonucleoprotein Complex Formation and Nucleocytoplasmic Transport.

J Biol Chem 274, 33951-33958.

Cokol, M., Nair, R. and Rost, B. (2000) Finding nuclear localization signals.

EMBO Rep 1, 411-5.

Denning, D., Mykytka, B., Allen, N.P., Huang, L., Al, B. and Rexach, M. (2001) The nucleoporin Nup60p functions as a Gsp1p-GTP-sensitive tether for Nup2p at the nuclear pore complex.

J Cell Biol 154, 937-50.

Dürr, U. (1997) Isolierung und Charakterisierung von zum Drosophila melanogaster Zinkfinger Protein Schnurri homologen Proteinen aus dem Krallenfrosch Xenopus laevis. Diplomarbeit Universität Göttingen .

Eisen, M.B., Spellman, P.T., Brown, P.O. and Botstein, D. (1998) Cluster analysis and display of genome-wide expression patterns.

Proc Natl Acad Sci U S A 95, 14863-8.

Fang, X., Chen, T., Tran, K. and Parker, C.S. (2001) Developmental regulation of the heat shock response by nuclear transport factor karyopherin-alpha3.

Development 128, 3349-58. 
Fischer, U., Huber, J., Boelens, W.C., Mattaj, I.W. and Luhrmann, R. (1995) The HIV-1 Rev activation domain is a nuclear export signal that accesses an export pathway used by specific cellular RNAs.

Cell 82, 475-83.

Gawantka, V., Pollet, N., Delius, H., Vingron, M., Pfister, R., Nitsch, R., Blumenstock, C. and Niehrs, C. (1998) Gene expression screening in Xenopus identifies molecular pathways, predicts gene function and provides a global view of embryonic patterning.

Mech Dev 77, 95-141.

Geles, K.G. and Adam, S.A. (2001) Germline and developmental roles of the nuclear transport factor importin alpha3 in C. elegans.

Development 128, 1817-30.

Ginsberg, A.M., King, B.O. and Roeder, R.G. (1984) Xenopus 5S gene transcription factor, TFIIIA: characterization of a cDNA clone and measurement of RNA levels throughout development.

Cell 39, 479-89.

Görlich, D., Dabrowski, M., Bischoff, F.R., Kutay, U., Bork, P., Hartmann, E., Prehn, S. and Izaurralde, E. (1997) A novel class of RanGTP binding proteins.

J Cell Biol 138, 65-80.

Görlich, D. and Kutay, U. (1999) Transport between the cell nucleus and the cytoplasm. Annu Rev Cell Dev Biol 15, 607-60.

Hood, J.K., Casolari, J.M. and Silver, P.A. (2000) Nup2p is located on the nuclear side of the nuclear pore complex and coordinates Srp1p/importin-alpha export.

J Cell Sci 113, 1471-80.

Huber, J., Cronshagen, U., Kadokura, M., Marshallsay, C., Wada, T., Sekine, M. and Luhrmann, R. (1998) Snurportin1, a m3G-cap-specific nuclear import receptor with a novel domain structure.

EMBO J 17, 4114-26.

Ishidate, T., Yoshihara, S., Kawasaki, Y., Roy, B.C., Toyoshima, K. and Akiyama, T. (1997) Identification of a novel nuclear localization signal in Sam68.

FEBS Lett 409, 237-41.

Jäkel, S., Albig, W., Kutay, U., Bischoff, F.R., Schwamborn, K., Doenecke, D. and Görlich, D. (1999) The importin beta/importin 7 heterodimer is a functional nuclear import receptor for histone $\mathrm{H} 1$.

EMBO J 18, 2411-23.

Jäkel, S. and Görlich, D. (1998) Importin beta, transportin, RanBP5 and RanBP7 mediate nuclear import of ribosomal proteins in mammalian cells.

EMBO J 17, 4491-502. 
Jullien, D., Görlich, D., Laemmli, U.K. and Adachi, Y. (1999) Nuclear import of RPA in Xenopus egg extracts requires a novel protein XRIPalpha but not importin alpha.

EMBO J 18, 4348-58.

Kalderon, D., Richardson, W.D., Markham, A.F. and Smith, A.E. (1984) Sequence requirements for nuclear location of simian virus 40 large-T antigen.

Nature 311, 33-8.

Kamei, Y., Yuba, S., Nakayama, T. and Yoneda, Y. (1999) Three distinct classes of the alpha-subunit of the nuclear pore-targeting complex (importin-alpha) are differentially expressed in adult mouse tissues.

J Histochem Cytochem 47, 363-72.

Kataoka, N., Bachorik, J.L. and Dreyfuss, G. (1999) Transportin-SR, a nuclear import receptor for SR proteins.

J Cell Biol 145, 1145-52.

Kim, I.S., Kim, D.H., Han, S.M., Chin, M.U., Nam, H.J., Cho, H.P., Choi, S.Y., Song, B.J., Kim, E.R., Bae, Y.S. and Moon, Y.H. (2000) Truncated form of importin alpha identified in breast cancer cell inhibits nuclear import of p53.

J Biol Chem 275, 23139-45.

Köhler, M., Ansieau, S., Prehn, S., Leutz, A., Haller, H. and Hartmann, E. (1997) Cloning of two novel human importin-alpha subunits and analysis of the expression pattern of the importin-alpha protein family.

FEBS Lett 417, 104-8.

Köhler, M., Speck, C., Christiansen, M., Bischoff, F.R., Prehn, S., Haller, H., Görlich, D. and Hartmann, E. (1999) Evidence for distinct substrate specificities of importin alpha family members in nuclear protein import.

Mol Cell Biol 19, 7782-91.

Kutay, U., Bischoff, F.R., Kostka, S., Kraft, R. and Görlich, D. (1997) Export of importin alpha from the nucleus is mediated by a specific nuclear transport factor.

Cell 90, 1061-71.

Kutay, U., Hartmann, E., Treichel, N., Calado, A., Carmo-Fonseca, M., Prehn, S., Kraft, R., Görlich, D. and Bischoff, F.R. (2000) Identification of two novel RanGTP-binding proteins belonging to the importin beta superfamily.

J Biol Chem 275, 40163-8.

Kutay, U., Lipowsky, G., Izaurralde, E., Bischoff, F.R., Schwarzmaier, P., Hartmann, E. and Görlich, D. (1998) Identification of a tRNA-specific nuclear export receptor.

Mol Cell 1, 359-69.

Laemmli, U.K. (1970) Cleavage of structural proteins during the assembly of the head of bacteriophage $\mathrm{T} 4$.

Nature 227, 680-685. 
Lipowsky, G., Bischoff, F.R., Schwarzmaier, P., Kraft, R., Kostka, S., Hartmann, E., Kutay, U. and Görlich, D. (2000) Exportin 4: a mediator of a novel nuclear export pathway in higher eukaryotes.

EMBO J 19, 4362-71.

Mahajan, R., Delphin, C., Guan, T., Gerace, L. and Melchior, F. (1997) A small ubiquitinrelated polypeptide involved in targeting RanGAP1 to nuclear pore complex protein RanBP2.

Cell 88, 97-107.

Mathe, E., Bates, H., Huikeshoven, H., Deak, P., Glover, D.M. and Cotterill, S. (2000) Importin-alpha3 is required at multiple stages of Drosophila development and has a role in the completion of oogenesis.

Dev Biol 223, 307-22.

Mattaj, I.W. and De Robertis, E.M. (1985) Nuclear segregation of U2 snRNA requires binding of specific snRNP proteins.

Cell 40, 111-8.

Mattaj, I.W. and Englmeier, L. (1998) Nucleocytoplasmic transport: the soluble phase. Annu Rev Biochem 67, 265-306.

Matunis, M.J., Wu, J. and Blobel, G. (1998) SUMO-1 modification and its role in targeting the Ran GTPase-activating protein, RanGAP1, to the nuclear pore complex.

J Cell Biol 140, 499-509.

Michael, W.M., Eder, P.S. and Dreyfuss, G. (1997) The K nuclear shuttling domain: a novel signal for nuclear import and nuclear export in the hnRNP K protein.

EMBO J 16, 3587-98.

Mingot, J.M., Kostka, S., Kraft, R., Hartmann, E. and Görlich, D. (2001) Importin 13: a novel mediator of nuclear import and export.

EMBO J 20, 3685-94.

Miyamoto, Y., Imamoto, N., Sekimoto, T., Tachibana, T., Seki, T., Tada, S., Enomoto, T. and Yoneda, Y. (1997) Differential modes of nuclear localization signal (NLS) recognition by three distinct classes of NLS receptors.

J Biol Chem 272, 26375-81.

Moore, M.S. (1998) Ran and nuclear transport.

J Biol Chem 273, 22857-60.

Morgenstern, B. (1999) DIALIGN 2: improvement of the segment-to-segment approach to multiple sequence alignment.

Bioinformatics 15, 211-8.

Moroianu, J., Hijikata, M., Blobel, G. and Radu, A. (1995) Mammalian karyopherin alpha 1 beta and alpha 2 beta heterodimers: alpha 1 or alpha 2 subunit binds nuclear localization signal and beta subunit interacts with peptide repeat-containing nucleoporins.

Proc Natl Acad Sci U S A 92, 6532-6. 
Mullis, K.B. and Faloona, F.A. (1987) Specific synthesis of DNA in vitro via a polymerasecatalyzed chain reaction.

Methods Enzymol 155, 335-50.

Nachury, M.V., Ryder, U.W., Lamond, A.I. and Weis, K. (1998) Cloning and characterization of hSRP1 gamma, a tissue-specific nuclear transport factor.

Proc Natl Acad Sci U S A 95, 582-7.

Nakielny, S., Fischer, U., Michael, W.M. and Dreyfuss, G. (1997) RNA transport. Annu Rev Neurosci 20, 269-301.

Niehrs, C. and Pollet, N. (1999) Synexpression groups in eukaryotes.

Nature 402, 483-7.

Niehrs, C., Steinbeisser, H. and De Robertis, E.M. (1994) Mesodermal patterning by a gradient of the vertebrate homeobox gene goosecoid.

Science 263, 817-20.

Nieuwkoop, P.D. and Faber, P. (1967) Normal Table of Xenopus laevis (Daudin). 2nd edition.

North-Holland Publ. Co. Amsterdam .

Ohno, M., Fornerod, M. and Mattaj, I.W. (1998) Nucleocytoplasmic transport: the last 200 nanometers.

Cell 92, 327-36.

Ohno, M., Segref, A., Bachi, A., Wilm, M. and Mattaj, I.W. (2000) PHAX, a mediator of U snRNA nuclear export whose activity is regulated by phosphorylation.

Cell 101, 187-98.

Panitz, P. (1998) Isolierung und Charakterisierung der Zinkfinger-Proteine Xegr-1 und Xegr-3 in der frühen Embryonalentwicklung des Krallenfrosches Xenopus laevis.

Dissertation Universität Göttingen .

Percipalle, P., Clarkson, W.D., Kent, H.M., Rhodes, D. and Stewart, M. (1997) Molecular interactions between the importin alpha/beta heterodimer and proteins involved in vertebrate nuclear protein import.

J Mol Biol 266, 722-32.

Pieler, T. and Rudt, F. (1997) Nucleocytoplasmic transport of 5S ribosomal RNA.

Cell and Developmental Biology 8, 79-82.

Plafker, S.M. and Macara, I.G. (2000) Importin-11, a nuclear import receptor for the ubiquitin-conjugating enzyme, UbcM2.

EMBO J 19, 5502-13.

Pollard, V.W., Michael, W.M., Nakielny, S., Siomi, M.C., Wang, F. and Dreyfuss, G. (1996) A novel receptor-mediated nuclear protein import pathway.

Cell 86, 985-94. 
Prieve, M.G., Guttridge, K.L., Munguia, J. and Waterman, M.L. (1998) Differential importin-alpha recognition and nuclear transport by nuclear localization signals within the high-mobility-group DNA binding domains of lymphoid enhancer factor 1 and T-cell factor 1 .

Mol Cell Biol 18, 4819-32.

Reddy, T.R., Tang, H., Xu, W. and Wong-Staal, F. (2000) Sam68, RNA helicase A and Tap cooperate in the post-transcriptional regulation of human immunodeficiency virus and type D retroviral mRNA.

Oncogene 19, 3570-5.

Ribbeck, K. and Görlich, D. (2001) Kinetic analysis of translocation through nuclear pore complexes.

EMBO J 20, 1320-30.

Ribbeck, K., Lipowsky, G., Kent, H.M., Stewart, M. and Görlich, D. (1998) NTF2 mediates nuclear import of Ran.

EMBO J 17, 6587-98.

Robbins, J., Dilworth, S.M., Laskey, R.A. and Dingwall, C. (1991) Two interdependent basic domains in nucleoplasmin nuclear targeting sequence: identification of a class of bipartite nuclear targeting sequence.

Cell 64, 615-23.

Rout, M.P., Aitchison, J.D., Suprapto, A., Hjertaas, K., Zhao, Y. and Chait, B.T. (2000) The yeast nuclear pore complex: composition, architecture, and transport mechanism.

J Cell Biol 148, 635-51.

Rout, M.P., Blobel, G. and Aitchison, J.D. (1997) A distinct nuclear import pathway used by ribosomal proteins.

Cell 89, 715-25.

Rudt, F., Firmbach-Kraft, I., Petersen, M., Pieler, T. and Stick, R. (1996) Nucleoskeleton and nucleo-cytoplasmic transport in oocytes and early development of Xenopus laevis. Int J Dev Biol 40, 273-8.

Rudt, F. and Pieler, T. (1996) Cytoplasmic retention and nuclear import of 5S ribosomal RNA containing RNPs.

EMBO J 15, 1383-91.

Rudt, F. and Pieler, T. (2001) Cytosolic import factor- and Ran-independent nuclear transport of ribosomal protein L5.

Eur J Cell Biol 80, 661-8.

Sachdev, S., Bagchi, S., Zhang, D.D., Mings, A.C. and Hannink, M. (2000) Nuclear import of IkappaBalpha is accomplished by a ran-independent transport pathway.

Mol Cell Biol 20, 1571-82. 
Saiki, R.K., Scharf, S., Faloona, F., Mullis, K.B., Horn, G.T., Erlich, H.A. and Arnheim, N. (1985) Enzymatic amplification of beta-globin genomic sequences and restriction site analysis for diagnosis of sickle cell anemia.

Science 230, 1350-4.

Sambrook, J., Fritch, E.F. and Maniatis, T. (1989) Molecular cloning. A laboratory manual. C.S.H. Laboratory Press, New York.

Schwamborn, K. (1998) Der Transport des Histons H1ํ vom Cytoplasma in den Zellkern. Dissertation Universität Göttingen .

Schwamborn, K., Albig, W. and Doenecke, D. (1998) The histone H1(0) contains multiple sequence elements for nuclear targeting.

Exp Cell Res 244, 206-17.

Seedorf, M., Damelin, M., Kahana, J., Taura, T. and Silver, P.A. (1999) Interactions between a nuclear transporter and a subset of nuclear pore complex proteins depend on Ran GTPase.

Mol Cell Biol 19, 1547-57.

Seki, T., Tada, S., Katada, T. and Enomoto, T. (1997) Cloning of a cDNA encoding a novel importin-alpha homologue, Qip1: discrimination of Qip1 and Rch1 from hSrp1 by their ability to interact with DNA helicase Q1/RecQL.

Biochem Biophys Res Commun 234, 48-53.

Setzer, D.R., Menezes, S.R., Del Rio, S., Hung, V.S. and Subramanyan, G. (1996) Functional interactions between the zinc fingers of Xenopus transcription factor IIIA during 5S rRNA binding.

Rna 2, 1254-69.

Shastry, B.S., Honda, B.M. and Roeder, R.G. (1984) Altered levels of a 5 S gene-specific transcription factor (TFIIIA) during oogenesis and embryonic development of Xenopus laevis.

J Biol Chem 259, 11373-82.

Solsbacher, J., Maurer, P., Vogel, F. and Schlenstedt, G. (2000) Nup2p, a yeast nucleoporin, functions in bidirectional transport of importin alpha.

Mol Cell Biol 20, 8468-79.

Sölter, M. (1999) Identifizierung von Genen mit morphoregulatorischer Funktion in der frühen Embryogenese von Xenopus laevis aus einer Schwanzspitzen-cDNA-Bank. Diplomarbeit Universität Göttingen .

Spellman, P.T., Sherlock, G., Zhang, M.Q., Iyer, V.R., Anders, K., Eisen, M.B., Brown, P.O., Botstein, D. and Futcher, B. (1998) Comprehensive identification of cell cycleregulated genes of the yeast Saccharomyces cerevisiae by microarray hybridization. Mol Biol Cell 9, 3273-97. 
Ström, A.C. and Weis, K. (2001) Importin-beta-like nuclear transport receptors. Genome Biol 2.

Tabb, M.M., Tongaonkar, P., Vu, L. and Nomura, M. (2000) Evidence for separable functions of Srp1p, the yeast homolog of importin alpha (Karyopherin alpha): role for Srp1p and Sts $1 p$ in protein degradation.

Mol Cell Biol 20, 6062-73.

Theunissen, O., Rudt, F. and Pieler, T. (1998) Structural determinants in 5S RNA and TFIIIA for 7S RNP formation.

Eur J Biochem 258, 758-67.

Tsuji, L., Takumi, T., Imamoto, N. and Yoneda, Y. (1997) Identification of novel homologues of mouse importin alpha, the alpha subunit of the nuclear pore-targeting complex, and their tissue- specific expression.

FEBS Lett 416, 30-4.

Turner, D.L. and Weintraub, H. (1994) Expression of achaete-scute homolog 3 in Xenopus embryos converts ectodermal cells to a neural fate.

Genes Dev 8, 1434-47.

Welch, K., Franke, J., Köhler, M. and Macara, I.G. (1999) RanBP3 contains an unusual nuclear localization signal that is imported preferentially by importin-alpha3.

Mol Cell Biol 19, 8400-11.

Wischnewski, J. (1997) Identifizierung von Kernlokalisierungssignalsequenzen in Xenopus laevis TFIIIA.

Diplomarbeit Universität Göttingen .

Wischnewski, J., Sölter, M., Chen, Y., Hollemann, T. and Pieler, T. (2000) Structure and expression of Xenopus karyopherin-beta3: definition of a novel synexpression group related to ribosome biogenesis.

Mech Dev 95, 245-8.

Yaseen, N.R. and Blobel, G. (1997) Cloning and characterization of human karyopherin beta3.

Proc Natl Acad Sci U S A 94, 4451-6. 


\section{Anhang}

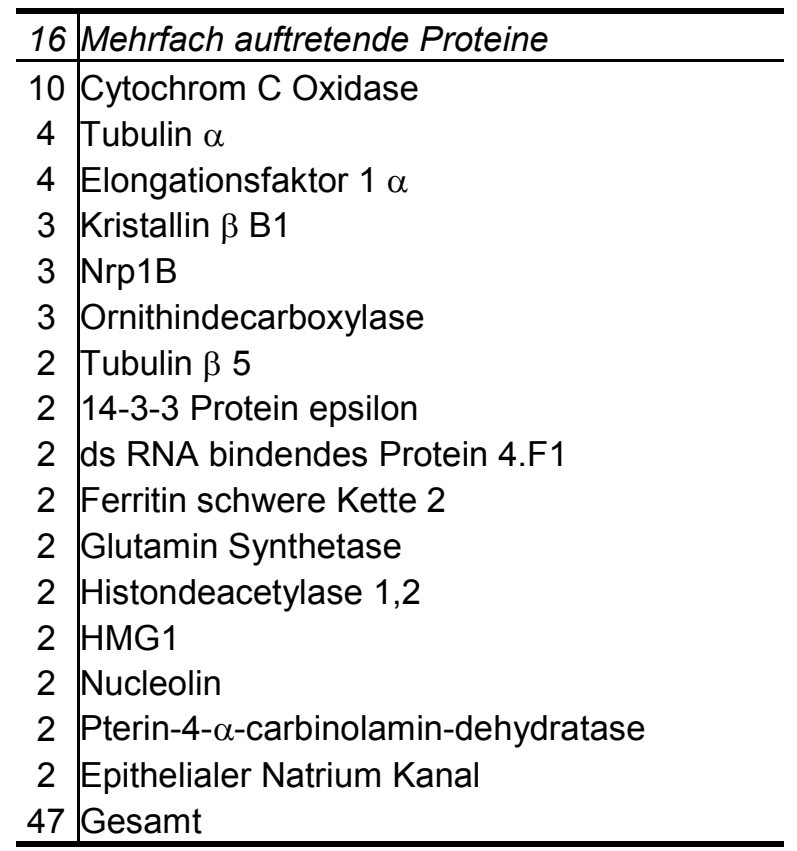

Tabelle 12: Mehrfach auftretende Proteine.

Nach Häufigkeit geordnete Auflistung von mehrfach auftretenden Sequenzen, die identische Gene repräsentieren.

\section{I. Karyopherin $\beta 3$}

ATGGCGGCCGAGCAGCAACAGTTCTACTTGCTCTTGGGTAACCTGCTCAGCCCTGAGAACGGCGCCAGAAAACAAGCAGAGGAAACTTAC M A A E Q O O O F GAGACCATCCCTGGGCCATCTAAAATCACATTTCTTTTGCAAGCTATAAGGAATGGAGCTGTTGCAGAAGAGGCAAGGCAGATGGCAGC T E T I I $P$ C G GTTTTACTGCGACGTCTCTTGTCCTCTGCATTTGAAGAAGTTTATCCATCCCTCCCTGTTGACCTCCAAACTGCCATTAGAAGCGAACTT $V \quad L \quad L \quad R \quad R \quad L \quad L \quad S \quad S$ A $F$ E E V Y P S L P V D L O T A I R S E L CTGCTTGCTATTCAAGTGGAATCTCAGTCGAGTATGCGCAAGAAGATATGTGACATTGTTGCTGAACTGGCCAGAAACCTAATTGATGAT

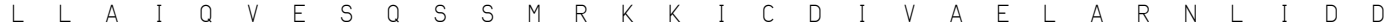
GACGGAAATAACCAGTGGCCTGAAGCTTTAAAATTTCTGTTTGACTCTGTAAGTTCGCAAGATGATGGACTGCGTGAAGCAGCATTACAC $\begin{array}{lllllllllllllllllllllllllllll}D & G & N & N & Q & W & P & E & A & L & K & F & L & F & D & S & V & S & S & Q & D & D & G & L & R & E & A & A & L\end{array}$ ATCTTCTGGAACTTCCCTGGAATTTTTGGAAACCAACAGCAGCATTACC TTGAAGTTGTCAAAAGAATGCTTGTGCAGTGCATGCAAGAG

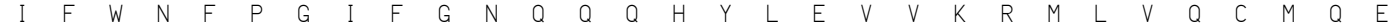
CAGAATCACCCTGTAATCAGAACTCTGTCTGCTAGAGCTGCTGGTGCATTTGTGCTTGCTAATGAGCACAATATTCCCCTGCTGAAGCAC $\begin{array}{lllllllllllllllllllllllllllllll}Q & N & H & P & V & I & R & T & L & S & A & R & A & A & G & A & F & V & L & A & N & E & H & N & I & P & L & L & K & H\end{array}$ TTCTCAGATTTGCTCCCAGGTTTACTGCAGTCTGTAAATGAATCCTGTTATCAGAATGACGACTCTGTCCTAAAATCACTGGTTGAGATT $\begin{array}{lllllllllllllllllllllllllllllllllllll}F & S & D & L & L & P & G & L & L & Q & S & V & N & E & S & C & Y & Q & N & D & D & S & V & L & K & S & L & V & E & I\end{array}$ GCAGACACTGTACCAAAATTTTTAAGACCACATCTAGAAGCAACC TTACAATTGAGCC TGAAGC TTTTTGCAGACAGATCCC TGAGCAAT

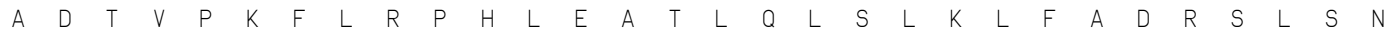
ATGCAGAGACAACTTGCCATGGAAGTCATTGTCACCCTTTCGGAGACTGCAGCAGCTATGTTAAGAAAGCATACGAGTATTGTTGCTCAG

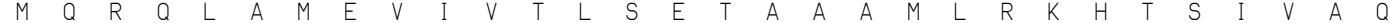
GCGATACCTCAGATGCTGGCAATGATGGTGGATTTAGAAGATGATGATGACTGGTCAAATGCAGACGAGCTTGAAGATGATGATTTTGAC $\begin{array}{llllllllllllllllllllllllllllll}A & I & P & Q & M & L & A & M & M & V & D & L & E & D & D & D & D & W & S & N & A & D & E & L & E & D & D & D & F & D\end{array}$ AGCAATGCAGTTGCGGGGGAAAGTGCCTTGGACAGAATGGCTTGTGGACTAGGGGGAAAATTGTTCTTCCAATGATCAAGGAGCACATT 1085 $S \quad N \quad A \quad V \quad A \quad G \quad E$ S A ATGCAAATGC TTCAAAACCC TGACTGGAAGTACAGGCATGCTGGTCTTATGGCATTGTCCGCCATTGGGGAAGGTTGTCACCAGCAGATG 1175

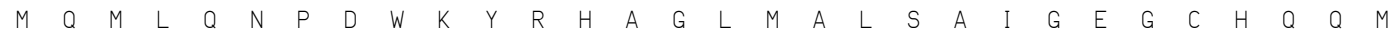
GAGGGCATTCTTAATGAGATGGTCAATTTTGTTCTGCTCTTCCTTCAAGATCCTCACCCTAGAGTACGTTATGCAGCATGTAATGCTATT 1265 E G I L N E M V GGCCAGATGGCTACTGACTTTGCTCCTGCTTTCCAGAAGAAGTTTCACGAAAAGGTGATAGCAAGTCTTCTGCAAACTATGGAAGACCAG 1355

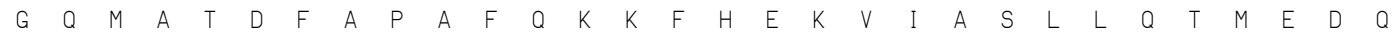
GCAAATCCACGAGTTCAGGCCCATGCAGCCGCTGCTCTAATTAACTTCACCGAAGACTGTCCAAAGTCTCTTCTGATTCCATATCTTGAT 1445 A N N P $R$ R V O O A AACCTTGTAAATCACTTGCACTCAATTATGGTGGTGAAACTGCAGGAGCTGATCCAGAAAGGAACAAAAC TTGTCTTGGAACAAGTTGTA 1535

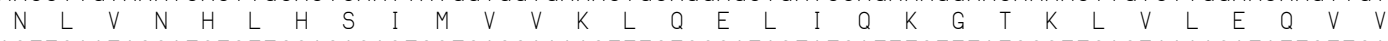
ACTTCAATAGCATCTGTTGCAGACACTGCTGAGGAAAAGTTTGTCCCATACTATGATTTGTTTATGCCTTCACTAAAACATATTGTTGAG 1625 $\begin{array}{llllllllllllllllllllllllllllllllllll}T & S & I & A & S & V & A & D & T & A & E & E & K & F & V & P & Y & Y & D & L & F & M & P & S & L & K & H & I & V & E\end{array}$ AACGCTGTACAGAAGGAACTTCGACTATTAAGAGGCAAAACTATTGAGTGCATCAGTTTGATCGGTTTGGCTGTTGGTAAAGAGAAGTTT 1715 


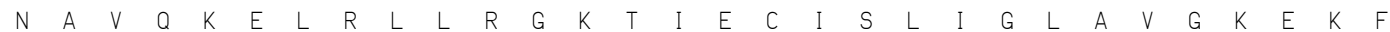
ATGCAAGATGCGTCTGATGTCATGCAGTTGTTGCTGAAGACACAAACTGATTTCAGTGATTTGGAAGATGATGACCCACAGATTTCCTAT 1805 $\begin{array}{llllllllllllllllllllllllllllll}M & Q & D & A & S & D & V & M & Q & L & L & L & K & T & Q & T & D & F & S & D & L & E & D & D & D & P & Q & I & S & Y\end{array}$ ATGATCTCTGCCTGGGCAAGAATGTGCAAAATCCTCGGAAAGGAATTTCAGCAATATCTTCCCGTGGTCATGGGCCCTTTGATGAAGACT 1895

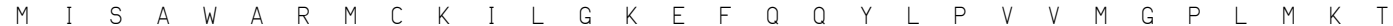
GCATCTATAAAACCTGAAGTGGCCCTACTTGATACGCAAGACATGGAAGGCATGGGAGAGGATGATGGCTGGGAGTTTGTTAATCTTGGT 1985

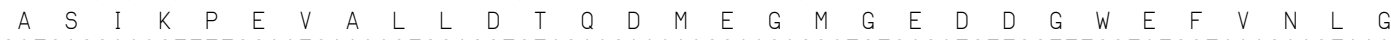
GATCAGCAAAGTTTTGGAATCAAAACTGCAGGTCTAGAAGAAAAAGCAACAGCATGTCAGATGTTGGTTTGCTATGCTAAAGAACTAAAA 2075 $\begin{array}{lllllllllllllllllllllllllllllll}D & 0 & O & S & F & G & I & K & T & A & G & L & E & E & K & A & T & A & C & O & M & L & V & C & Y & A & K & E & L & K\end{array}$ GAAGGATTTGCAGACTATACTGAACAAGTTGTGAAGCTAATGGTCCCGTTGTTAAAGTTCTATTTCCACGATGGTGTTAGAGTGGCAGCT 2165 E G F A GCAGAATCCATGCCACTACTTTTGGAATGCGCAAGAGTTCGTGGCCCAGAGTACTTGACCCAAATGTGGCATTTTATGTGTGATGCGCTT 2255 A $E$ S S M $M$ P $L$ ATCAAGGGAATCGGAACAGAACCAGACTCTGATGTTCTTTCAGAATTAATGCATTCCCTTGCTAAATGCATTGAGGTAATGGGTGATGGC 2345

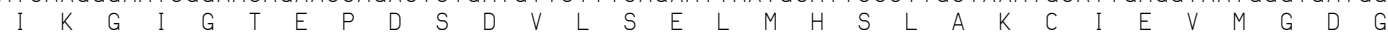
TGCATAAACAATGAACATTTTGAAGAGCTTGGTGGAATACTGAAGAGCAAACTAGAAGAGCACTTTAAAAACCAGGAACTCCGACAAGTG 2435 C I N N N AAAAGACAAGATGAAGATTATGATGAGCAAGTTGAGGAGTCATTACAAGATGAAGATGATAATGATGTTTACATTTTGACTAAAGTATCG 2525 $\begin{array}{llllllllllllllllllllllllllllll}K & R & Q & D & E & D & Y & D & E & Q & V & E & E & S & L & Q & D & E & D & D & N & D & V & Y & I & L & T & K & V & S\end{array}$ GACGTTTTGCACTCTATATTCAGCAGCTACAAAGAGAAGATCTTGCCCTGGTTTGAGCAGTTGTTACCATTGTTTGTTAACTTAATTTGT 2615

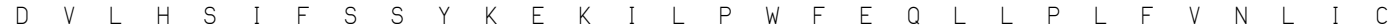
CCTAACAGGCCTTGGCCCGACAGACAATGGGGACTTTGTATTTTTGATGATGTAATAGAACATTGCAGCCCATCTTCCTTTAAATATGCA 2705 $\begin{array}{lllllllllllllllllllllllllllllll}P & N & R & P & W & P & D & R & Q & W & G & L & C & I & F & D & D & V & I & E & H & C & S & P & S & S & F & K & Y & A\end{array}$ GAGTATTTCCTAAGGCCACTGCTACAGTCAATTTGTGACAGCAGCCCTGAAGTTAGGCAAGCTGCTGCTTATGGTATTGGTGTAATGGCA 2795 $\begin{array}{lllllllllllllllllllllllllllllllll}E & Y & F & L & R & P & L & L & Q & S & I & C & D & S & S & P & E & V & R & Q & A & A & A & Y & G & I & G & V & M & A\end{array}$ CAATTTGGAGGTGACAATTATCGCCCCTTCTGCACAGAAGCTCTTCCACTGCTTGTCGGGGTTATCCAGGCTGCAGAGTCAAAAACCAAA 2885

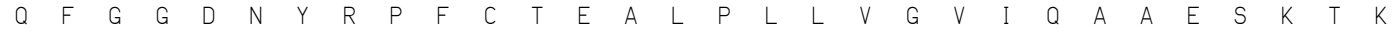
GAGAATATTAATGCAACGGAGAACTGCATTTCTGCAGTWGGCAAAATCATGAAGTTCCGACCAGACTGTATTAATGTGGAAGAGGTTCTG 2975 E N I I N A CCACACTGGTTGTCATGGCTGCCCTTGCATGAGGACAAAGAAGAGGCTGTTCACACTTATAACTTCCTTTGTGACCTCATTGAAAGCAAC 3065 $\begin{array}{llllllllllllllllllllllllllllll}P & H & W & L & S & W & L & P & L & H & E & D & K & E & E & A & V & H & T & Y & N & F & L & C & D & L & I & E & S & N\end{array}$ AATCCAATTGTCCTTGGACCTAACAATTCCAATTTACCCAAGATATTCAGTATAATAGCAGATGGAGGTGTCCATGAATCCATTAAAAAT 3155 $N$ N I V $L$ GAAGAAGTATGTGGAAACGGCTTGCAAATGTCATCCGTCAAGTTCAGGCCTCAGGAGTATTATTCACAGAATGTGTGTCACAGCTCAAT 3245

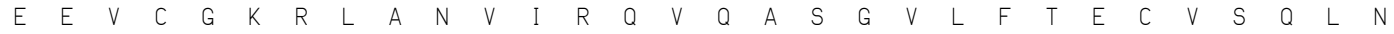
GCAGCCCAGCAGAAAGCTTTACAGGACCTGCTCAGCACTGCGTGAAGGCCTTCACCACTACATATCAGGACAACTAACATCAAATAAACT 3335 $\begin{array}{llllllllllllllllllll}A & A & Q & Q & K & A & L & 0 & D & L & L & S & T & A\end{array}$

TACCTCTTCTGTTTAGGTTTCTTGTTTTAGTTTTTGAGCAAAAAGAACAGTAGTGCTTATAGGCCAAGTTTTAGCAGgCCATCAAAAAC 3425 AGCGGGCAGAAAGCACTATGTATCAGACTTCATTGTCGAATGGATCGTTCTACAAGAGAGCTGCCCCCTGCAGACTCACAAATGGCTATA 3515 AAAGGATTATTTTTCTATCCTTATGTCTTCCCTCCTTATACATTTTCCACGTTTGTGGGTAGGGAGGGTTCACTTTGCCYGAGTTCCAAT 3605 AAATTAGGACTGTGGGTGCTACTTTTGGTTCATATGACAAATTCTTCCCATGCACTGGAAGTACTTTGCAGCACTTTTTGACATGGCACG 3695 ATCAATGTGGTTCCACCACGTGAGTTGATACAGTTAACATCTGTGCTTAGAATGATGTTGCCACAGTCAATAATGAACTCTGATATTTTA 3785 CTTAATAAGTGGGATAGAAAATTCCTTGTGCTTTGAAACATATCCCAAACCAAAGGTATGAAGGTATTGTGGAATTTTACGCACAGATT 3875 CATATTGGCATAAGGTTTTTTTTTTTGTGCCATCAGCTGTTTTCATAGGATTTATGGATTGAGGCAGGAAAATATTTAGCTTCTGGCCCT 3965 TGAATGTGAAAAATGTCTTTTGGCATGTCTTGCAACTCATTCACTCCTCAATAAACAACAATGAAATATCTCAACCAGCAAAAAAAAAAA 4055 AAAAAAA 4062

\author{
Abbildung 29: Karyopherin $\beta 3$ Sequenz. \\ Untranslatierte Region (UTR) und kodierende Sequenz von Karyopherin $\beta 3$. Darstellung der \\ kodierenden Nukleotide mit abgeleiteter Aminosäuresequenz. Nicht translatierte Nukleotide \\ repräsentieren 5 Nukleotide der 5'UTR und 775 Nukleotide identifizierter 3'UTR.
}




\section{X. l. Karyopherin $\alpha 3$}

ATGTCCAACAATGAGAATGGTGCCCGTCTCACTAGGTTCAAGAACAAGGGCAAGGACTCCACGGAAATGAGGAGGAGGAGGATTGAGGTG 90

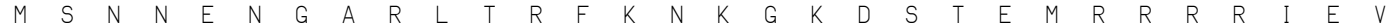
AACGTGGAGCTGCGTAAGGCCAAGAAAGATGATCAGATGCTAAAGAGGAGAAATGTCAGCACCTTCCCAGATGAGCCAACCTCTCCCCTC 180 $N \quad V \quad E \quad L \quad R \quad K \quad A \quad K \quad K \quad D \quad D \quad Q \quad M \quad L \quad K \quad R \quad R \quad N \quad V \quad S \quad T \quad F \quad P \quad D \quad E \quad P \quad T \quad S \quad P \quad L$ CAGGAGAAGAACCAGAATGGGCAGACCTCTTCACAGTGGAGTGTTGAGGAGATTGTCCGAGGTGTCGCCAACCCTAGCCTGGACATACAG 270

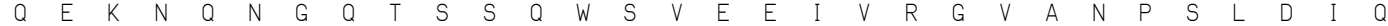
CTACAGGCCACACAGGCTGCAAGGAAACTTTTGTCCAGAGAGCGTGAGCCACCAATTGACCGCATCATTAAGGCTGGTCTCATTCCCAAG 360

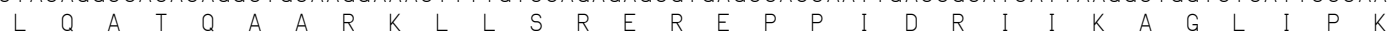
CTGGTAACTTTTCTGGCCCACTCTGACTGCAGCCCCATTCAGTTTGAGGCTGCCTGGGCTT TGACGAACATTGCTTCTGGAACTTCTGAT 450

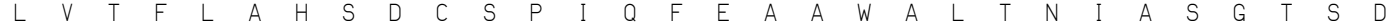
CAAACCAAGGCTGTTGTTGAAGGCGGTGGTGTCCCGGCCTTCATCTCTCTTTTGGCATCTCCTCATCCTCACATCAGCGAGCAGGCTGTG 540 Q T K A V V E G G G V P A F I S L L A S P H P H I S E Q A V TGGGCCTTGGGAAACATTGCAGGTGATGGATCTGCTTACAGAGATCTGGTTATTAAACATGGAGCTGTTGGGCCTCTGTTAGCTTTATTG 630

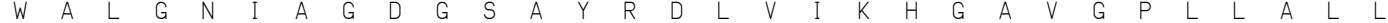
GCTGGTCCTGACCTCTCCACATTAGCTACTGGTTACCTCAGAAACGTTACATGGACTCTTTCAAACTTGTGCCGCAACAAGAATCCAGCC 720

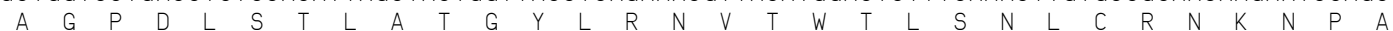
CCACCGCTGGATGCCATTCAGCAGATCTTGCCCACAATAGTGAGACTACTGCATCATGATGACCGAGAGGTACTGGCTGATACCTGCTGG 810

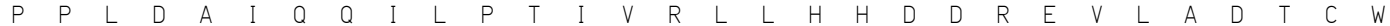
GCAGTGTCCTACCTCACTGATGGTTCAAATGACCGCATCGACGTGGTGGTCCGCACAGGCTTAGTCTCTCGCATTGTCCAGCTACTGGCC 900 A V S Y L T D G S N D R I D V V V R T G V V S R I V O L L A TGTGGAGAGCTGACAGTTGTGACCCCTTGTCTGAGAACTATTGGGAACATTGTGACTGGCACAGATGAGCAGACCCAAGTGGTTCTTGAC 990 $\begin{array}{llllllllllllllllllllllllllllll}C & G & E & L & T & V & V & T & P & C & L & R & T & I & G & N & I & V & T & G & T & D & E & 0 & T & 0 & V & V & L & D\end{array}$ GCTGGGGCTTTATCTGCCTTTACTGAGCTGCTCACGCACCACAAGAATAACATCCAGAAGGAAGCTGCCTGGACATTGTCCAACATTACT 1080 A G A L S A F T E L L T H H K N N I O K E A A W T L S N I T GCTGGGCGTCAGGACCAGATCCAGGAAGTGGTCAATTGTGGGCTAATTCCCTACCTCGTTGAAATCCTTAGGAAGGGTGACTACAAGACC 1170

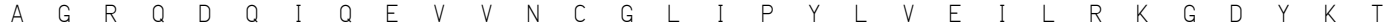
CAGAAAGAAGCTATTTGGGCAGTCACAAACTACACAAGTGGGGGAACAATAGATCAAATTATCTACCTCGTCCAATGTGGTATCATCGAG 1260 Q $K$ E A I W A V T N Y T S G G T I D Q I I Y L V O C G I I E CCTCTGTCAAATCTCCTGTCAGTCAAGGACAGCAAGACTGTGCTGGTCATGCTAGATGCATTCACCAATATATTTGCTGCTGCTGATAAG 1350

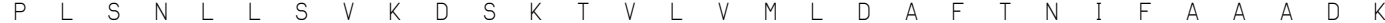
ATTGGGGAACTGAGAAGTGTGCCTAATGGTAGAGGAATGTGGTGGTCTTGACCGCATTGAGgCTTTGCAATCTCATGAGAATGAGCAG 1440

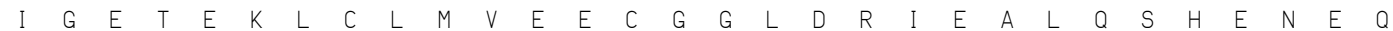
GTTTACAAAGCATCGGCTGCTCTCATTGAGAAATACTTCTCTGCAGAGGATGGAGAAGATGAATCATTGGCTCCTGAGACCACAGCCGAC 1530

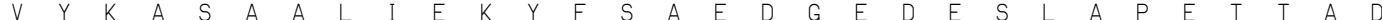
GGCTATGCTTTCCAGGTGGAAGGTGGAACTCACACTACATTTAACTTCTAAAACACTGCCATGTCTGTCCCCTTTTTTTCTATGTGAACC 1620 G Y A $\quad$ F $Q$ Q $V$ E G G T H T

TGCACTTTGTCTTATTTCAAGTGTCTTCTCCACACTGTAAATATACTGTGAATCTTAAATCTGTGTTCAAATTTAATAAAATGTTGTAAA 1710 TATATTCTTTTTAAATTTACAGCAGGCAGCAGCTGCCAGACCAGCCTTTCTCATTCAAACGCAAAGTAGCTGTGACCACCATAACCTCT 18O0 TAATGCAGAGATTTTATTGTTTTGGAACAATTCCAGCCACTGTCAGCACTTAGCACAATTTTAGATAAAGGGGTTTCTGAAAATAAATTG 1890 GTAATAAAAATT TGAGTTGTGATCCCCTGTGCCTTATATAAACCACTGTTTGTCTGGTCCTGGGTCCACTTATGTCCAGGTTCAGTAACT 1980 AATCCATAGACTTGCCATCTCTGCTCTGAGCCCCCTGTATAACTAAGAACTAGTCTTAGCTTGGAGGCTGCACACTGATGTTCTTTGTAC 2070 AGCCTCTTTATATTGCAACTGTTTACAATAAATTCCTTTTGGCAAAAAAAAAAAAAAAAAAAAAAAAAAAAAAAAAAAAAAAAAAAAAAA 2160 AAAAAAAAAAAAAAAAAAAAAAAAA 2187

\section{Abbildung 30 : Nukleotidsequenz mit abgeleiteter Proteinsequenz der kodierenden Nukleotide von Karyopherin $\alpha 3$ aus Xenopus laevis.}

UTR (untranslatierte Region) und kodierende Sequenz von Karyopherin $\alpha 3$. Über den kodierenden Nukleotiden ist die abgeleitete Aminosäuresequenz dargestellt. 


\section{X. l. Karyopherin $\alpha 4$}

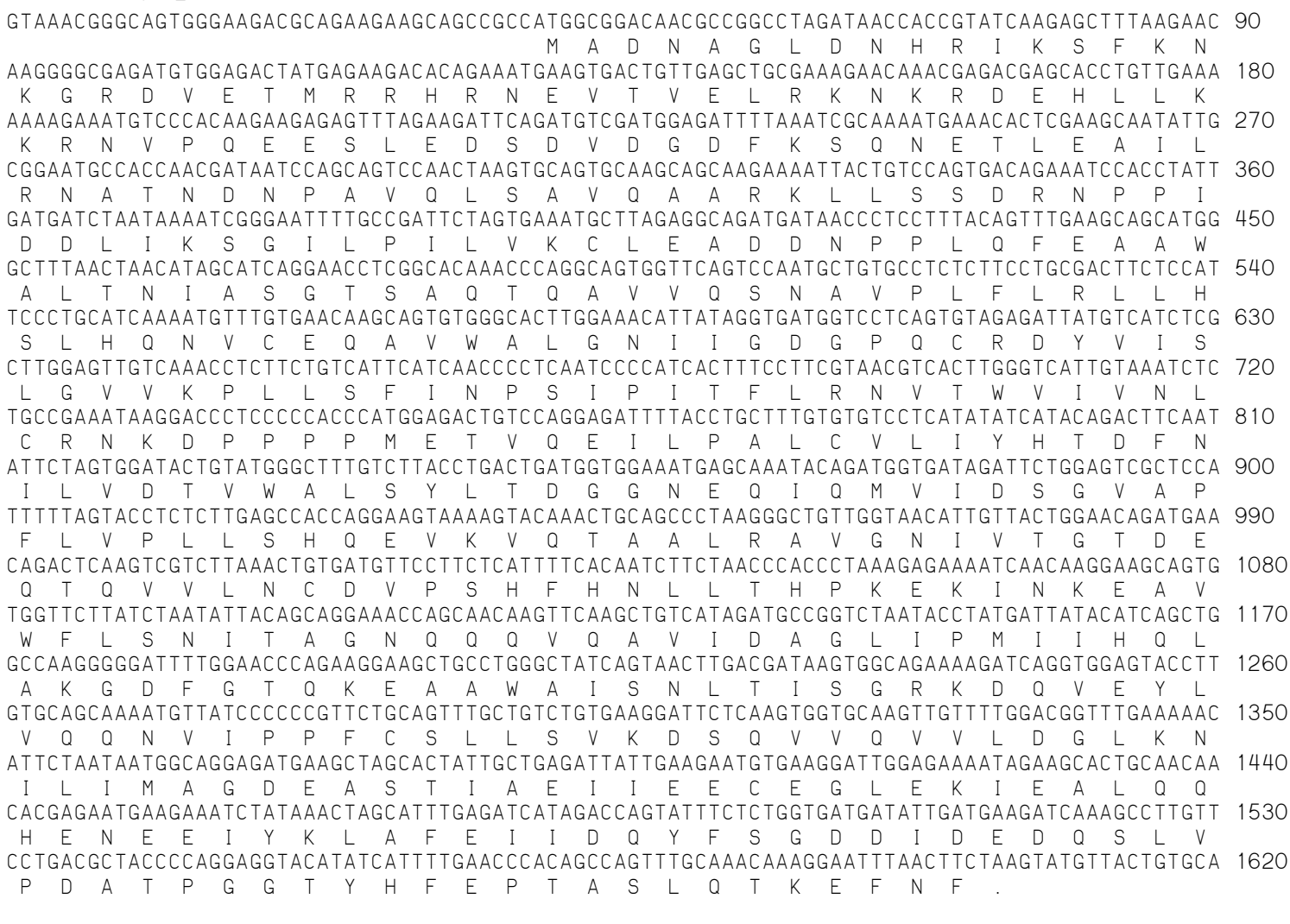

GCTTTTCTGTCCCTCAGCATACACCACCACCAGACACCAACCTGTTGAAGAAACATTAAAGGCTTAAAGGCCAAAAAAAAAAAAAAAAA 1710 AAAAAAAA 1719

\section{Abbildung 31 : Nukleotidsequenz mit abgeleiteter Proteinsequenz der kodierenden Nukleotide von Karyopherin $\alpha 4$ aus Xenopus laevis.}

Untranslatierte Region (UTR) und kodierende Sequenz von Karyopherin $\alpha 4$. Über den kodierenden Nukleotiden ist die abgeleitete Aminosäuresequenz dargestellt. 


\section{I. Karyopherin $\alpha 5.1$}

ATGGACACCATGGCAAGCCCCGGAAAGGACAACAGTCGGATGAAGAGCTACAAGAACAAGGCTCTGAACCCTGAAGAGATGCGCCGGCGT 90

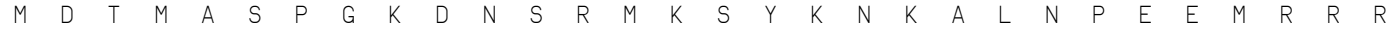
CGTGAGGAAGAAGGCATCCAGCTCCGGAAACAGAAGAGGGAACAACAGCTCTTTAAACGTCGGAATGTGGAGTTGGCTCCAGAGGATACC 180

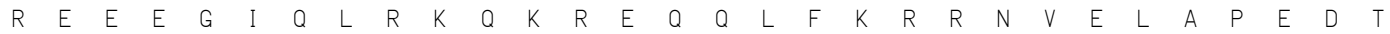
GCCATGTTTGACGGACCACTGATGGATTCTCATGTCAGCTCTACCACCCCTGGGGATGGAGTTATTACCCGCGAGATGGTAGCATTACT T 270 $\begin{array}{lllllllllllllllllllllllllllllll}A & M & F & D & G & P & L & M & D & S & H & V & S & S & T & T & P & G & D & G & V & I & T & R & E & M & V & A & L & L\end{array}$ CTCTCTGATGACCCTGACCTACAATTAGCTACTACACAGAAATTCAGAAAGCTCTTATCCAAAGAGCCAAATCCACCAATAGATGAGGTG 360

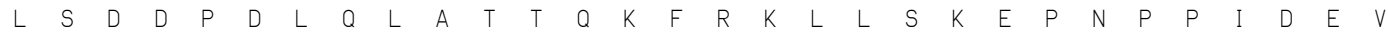
ATCAATGCCCCAGGAGTAGTAGAGCGATTTGTAGAATTTCTGAAGAAGAGTGACAACTATACACTACAGTTTGAAGCTGCCTGGGCCCT T 450

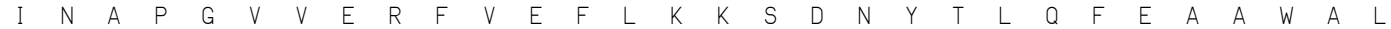
ACGAATATAGCTTCTGGAACCTCACAACAAACCAAAATCGTAATAGAAGCAGGGGCAGTTCCAATTTTCATTCAGCTGCTAAACTCTGAC 540

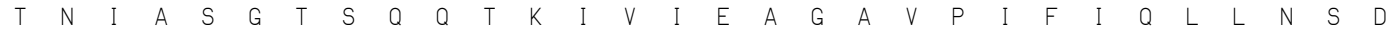
TATGAAGATGTACAAGAACAGGCTGTTTGGGCTCTGGGCAACATTGCAGGTGACAGTTCAGTGTGCAGAGACTATGTTCTAAGCTGTGAC 630

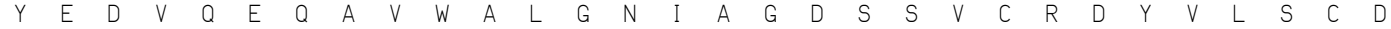
ATCCTTCCTCCTCTTCTCAATCTCCTTACCAAATCAACCCGTCTCACCATGACCCGAAATGCAGTCTGGGCCTTGTCTAACCTTTGTCGA 720

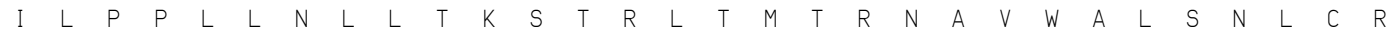
GGAAAGAACCCACCTCCAGACTTTGACAAGGTGTCTCCGTGTCTTCCTGTGCTGTCTCGTCTTCTATTCAGCAGTGATTCAGACCTGTTA 810

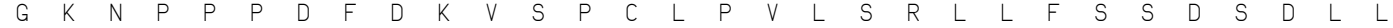
GCCGATGCCTGCTGGGCGCTTTCTTATCTCTCCGATGGCCCTAATGAGAAGATTCAGGCGGTCATAGACTCTGGAGTCTGCCGCAGGCTA 9OO

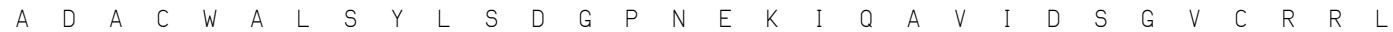
GTGGAGCTCCTAATGCACAATGATTACAAGGTGGCTTCTCCAGCACTCAGGGCTGTAGGAAATATTGTCACTGGAGATGATATCCAGACA 990

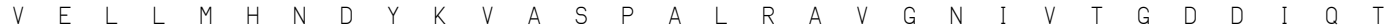
CAGGTCATCTTAAACTGTTCAGCTCTTCCCTGCCTCCTTCATCTTTTGAGCAGCCCAAAAGAGTCCATCCGGAAGGAGGCCTGCTGGACA 1080

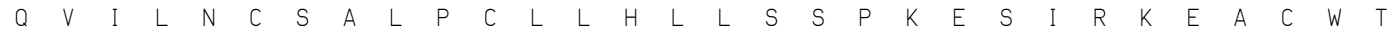
ATTTCAAACATTACTGCTGGCAACAGAGGCCAAATACAGGTTGTTGCTGATGCAAACATTTTTCCAGTTTTGATTGAGATTT TGCAAAAA 1170

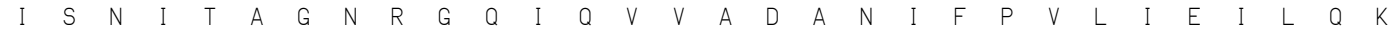
GCTGAATTTCGAACCCGAAAAGAGGCTGCATGGGCAATCACTAATGCAACATCTGGTGGCACACCAGAGCAAATCAGGTACCTGGTGAAC 1260

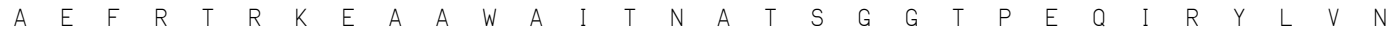
CTTGGCTGCATTAAACCTTTGTGTGACCTTCTCACAGTCATGGACTCAAAGATTGTTCAGGTTGCCCTAAATGGACTGGAAAATATACTA 1350

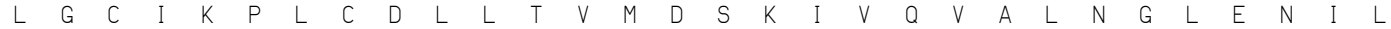
CGGCTTGGTGAGCAAGAAGCAAAGCATGGAGGCAATGGTATCAACCCATATTGTGGACTGATTGAAGAGGCATACGGTCTTGACAAAATA 1440

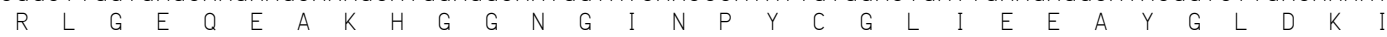
GAGTTCCTGCAGAGCCACGAGAACCAGGAAATCTACCAAAAAGCATTTGAATTGATAGAACATTACTTTGGAGTGGAGGAAGATGACCCT 1530 $\begin{array}{llllllllllllllllllllllllllllllllllllll}E & F & L & Q & S & H & E & N & Q & E & I & Y & Q & K & A & F & E & L & I & E & H & Y & F & G & V & E & E & D & D & P\end{array}$ CAGCTGGTCCCCTCTGTTGATGAATCTCAGCAGCAATATATCTTTCAGCAAACAGAAGCACCTATGGAAGGATTTCAGCTCTAA 1614

\section{X. l. Karyopherin $\alpha 5.2$}

ATGGACACCATGGCAAGCCCCGGAAAGGACATCAGTCGGATGAAGAGCTACAAGAACAAGGCTCTGAACCCTGAAGAGATGCGCCGGCGT 90

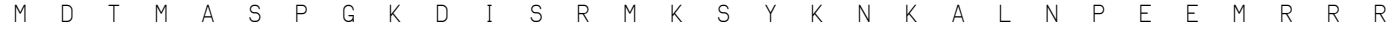
CGTGAGGAAGAAGGCATCCAGCTCCGCAAACAGAAGAGGGAGCAACAGCTCTTTAAACGACGTAATGTGGAGTTGGCTCCAGAAGATACC 180

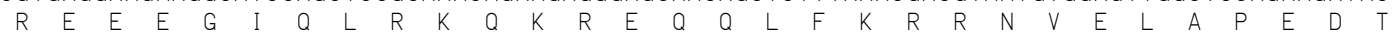
GCCATGTTTGATGGACCGCTGATGGATTCTTGTGTCAGCTCCACCACCCCTGGGGATGGTGTTATTACCCACGAGATGGTAGCATTGCT T 270

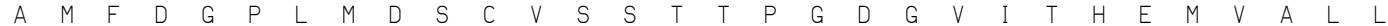
CTCTCTGATGACCCTGACCTACAGTTAGCTACTACACAGAAATTCAGAAAGCTCTTATCCAAAGAGCCAAATCCACCGATAGATGAGGTG 360

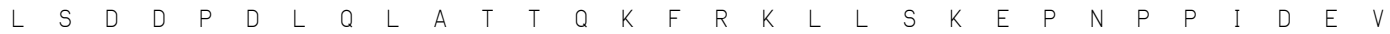
ATCAGT TCCCCAGgAGTAGTAGAGAGATTTGTAGAATTTCTGAAGAAGAGTGACAACTATACACTACAGTTTGAAGCTGCCTGGGCCCT T 450

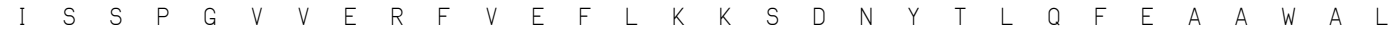
ACGAATATAGCTTCTGGCACCTCCCAACAAACCAAGATTGTAATAGAAGCAGGAGCAGTTCCAATCTTCATTCAGCTACTAAACTCTGAC 540

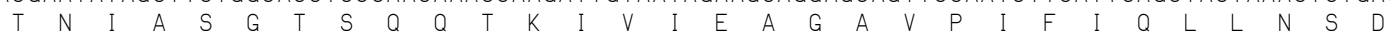
TATGAAGATGTGCAAGAACAGGCTGTTTGGGCTCTGGGCAACATCGCAGGTGACAGTTCAGTGTGCAGAGACTATGTTCTAAGCTGTGAC 630

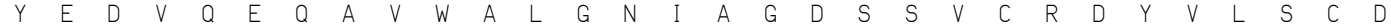
ATCCTTCTTCCTCTTCTCAACCTCCTTACAAAATCGACCCGTCTCACCATGACCCGGAATGCAGTCTGGGCCTTATCTAACCTTTGTCGA 720

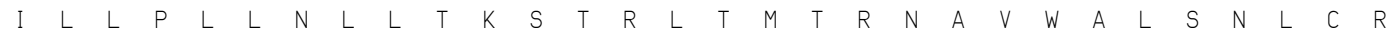
GGAAAGAACCCGCCTCCAGAGTTTGATAAGGTGTCTCAGTGTCTTCCTGTGCTGTCTCGCCTTCTATTCAGCAGTGATTCAGACCTGTTA 810

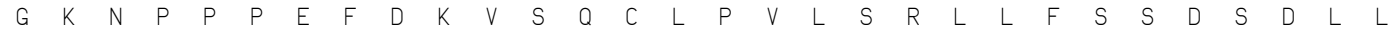
GCCGACGCCTGCTGGGCACTTTCTTATCTCTCTGATGGTCCTAATGAGAAGATCCAGGCAGTCATAGACTCAGGAGTCTGCCGCAGGCTG 900

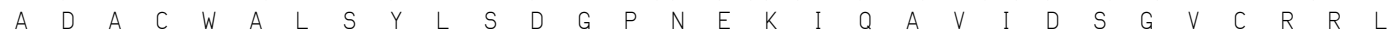
GTGGAGCTCCTAATGCACAATGATTACAAGGTGGCTTCTCCAGCACTCAGGGCTGTAGGAAATATTGTCACTGGAGATGATATCCAGACA 990

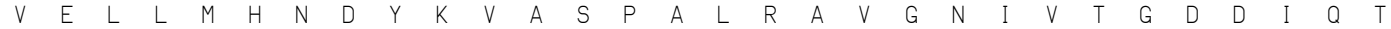
CAGGTCATCTTAAACTGTTCAGCTCTTCCCTGCCTCCTTCATCTTTTGAGCAGCCCAAAAGAGTCCATCCGGAAGGAGGCCTGCTGGACA 1080

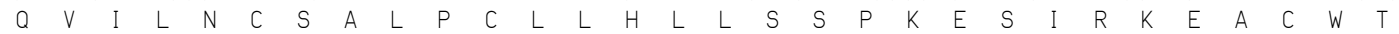
ATTTCAAACATTACTGCTGGCAACAGAGGCCAAATACAGGTTGTTGCTGATGCAAACATTTTTCCAGTTTTGATTGAGATTTTGCAAAAA 1170

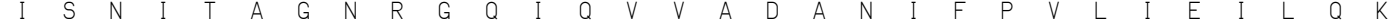
GCTGAATTTCGAACCCGAAAAGAGGCTGCATGGGCAATCACTAATGCAACATCTGGTGGCACACCAGAGCAAATCAGGTACCTGGTGAAC 1260

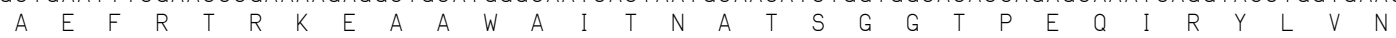
ATTGGCTGCATTAAACCTTTGTGTGACCTTCTCACAGTCATGGACTCAAAGATTGTTCAGGTTGCCCTAAATGGACTGGAAAATATACTA 1350

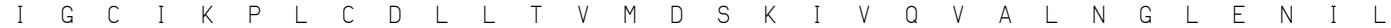
CGGCTTGGTGAGCAAGAAGCAAAGCATGGAGGCAATGGTATCAACCCATATTGTGGACTGATTGAAGAGGCATACGGTCTTGACAAAATA 1440

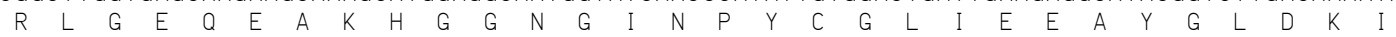
GAGT TCCTGCAGAGCCACGAGAACCAGGAAATCTACCAAAAAGCATTTGAATTGATAGAACATTACTT TGGAGTGGAGGAAGATGACCCT 1530

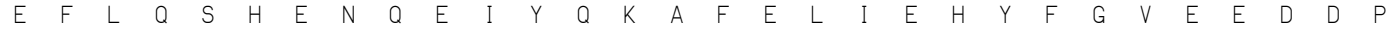
CAGCTGGTCCCCTCTGTTGATGAATCTCAGCAGCAATATATCTTTCAGCAAACAGAAGCACCTATGGAAGGATTTCAGCTCTAA 1614

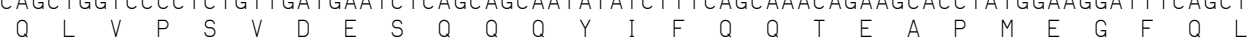

\footnotetext{
Abbildung 32: Nukleotidsequenz mit abgeleiteter Proteinsequenz der kodierenden Nukleotide von den Karyopherin $\alpha$ Varianten $\alpha 5.1$ und $\alpha 5.2$ aus Xenopus laevis.

Untranslatierte Region (UTR) und kodierende Sequenz von Karyopherin $\alpha 5.1$ und $\alpha 5.2$. Darstellung der kodierenden Nukleotide mit abgeleiteten Aminosäuresequenzen.
} 


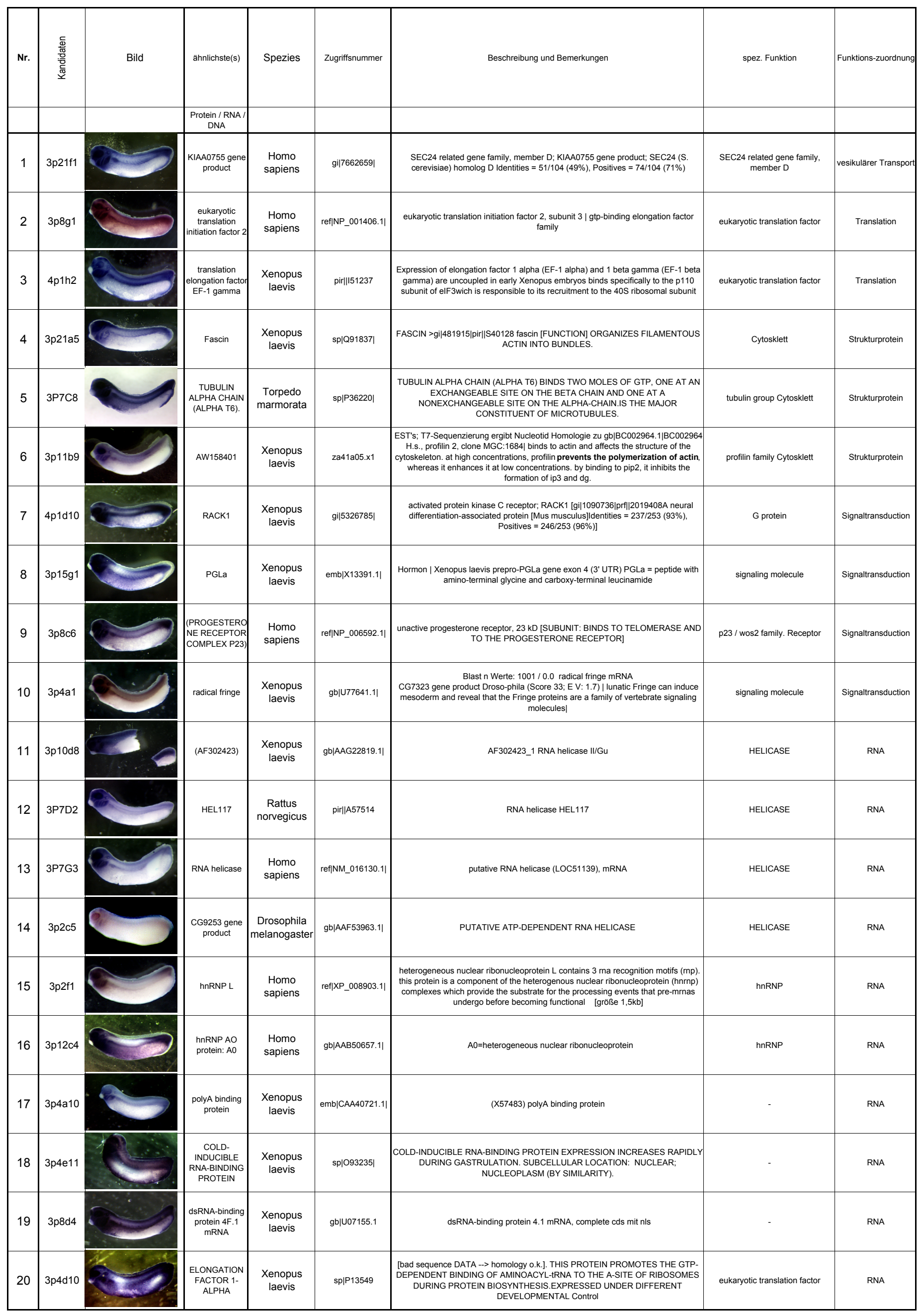




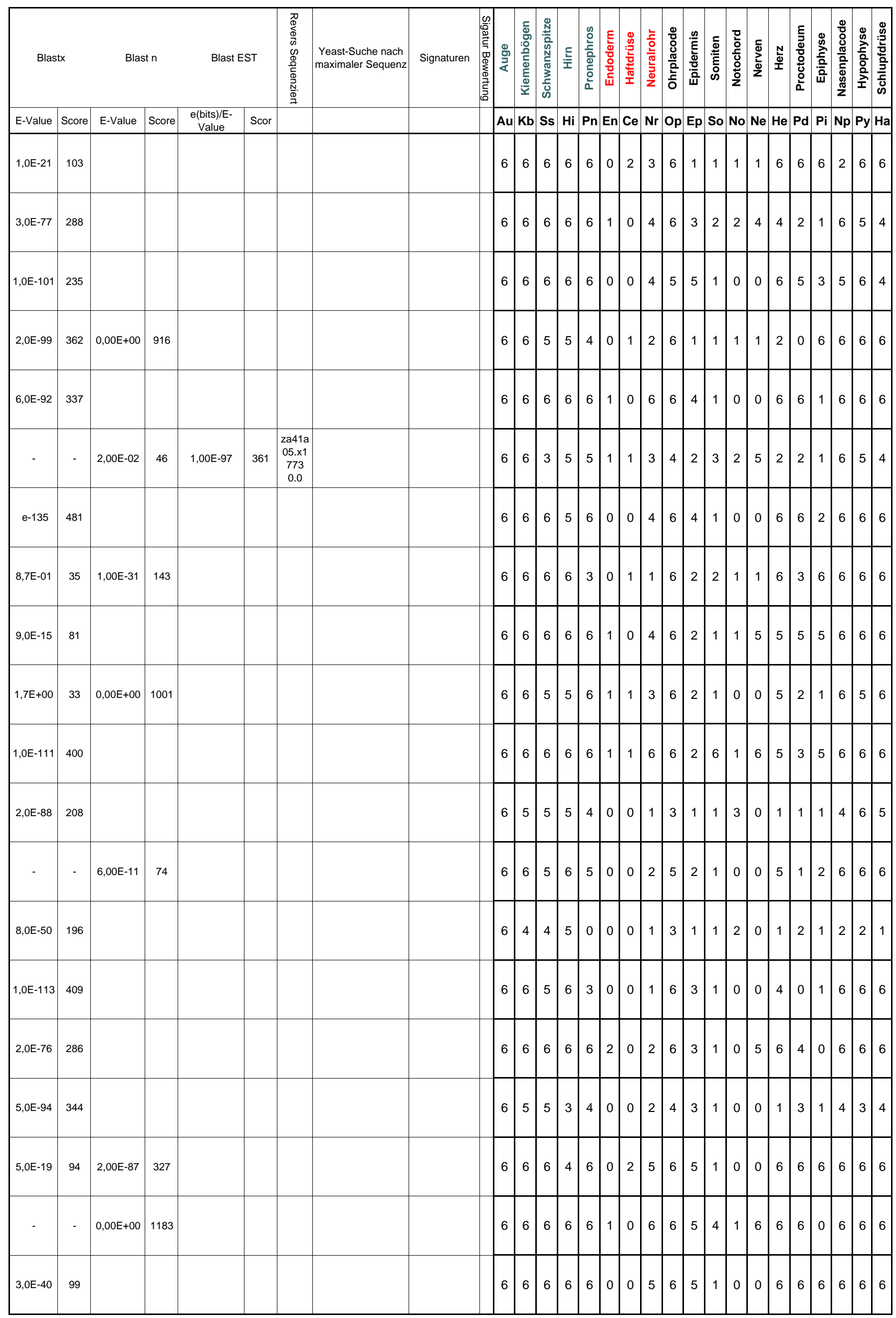




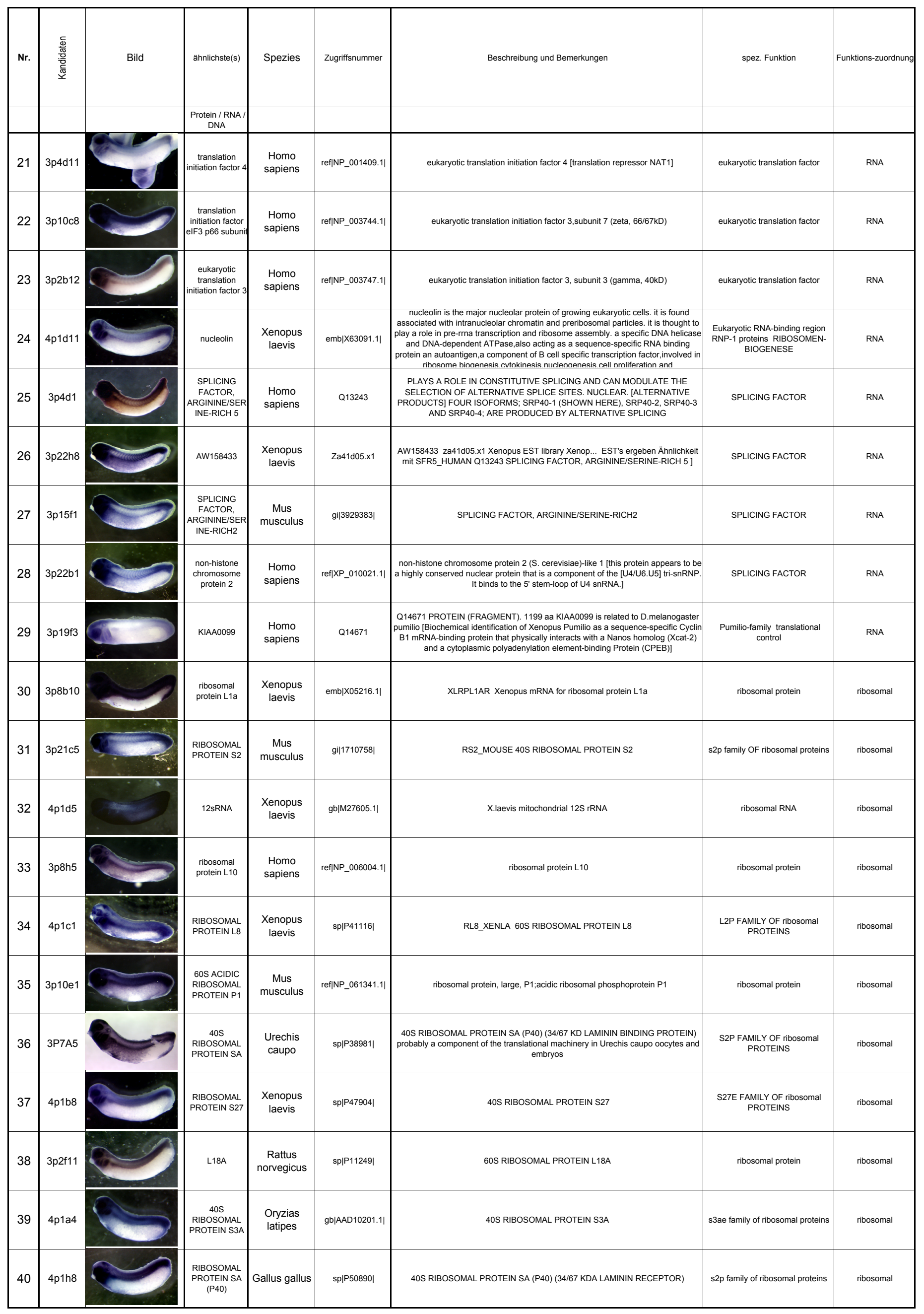




\begin{tabular}{|c|c|c|c|c|c|c|c|c|c|c|c|c|c|c|c|c|c|c|c|c|c|c|c|c|c|c|c|c|}
\hline Blas & & Blast & & Blast & & 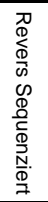 & $\begin{array}{c}\text { Yeast-Suche nach } \\
\text { maximaler Sequenz }\end{array}$ & Signaturen & 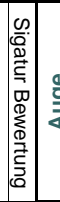 & बे & 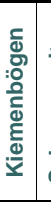 & 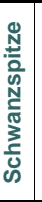 & 旁 & 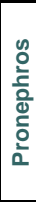 & 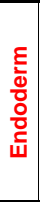 & 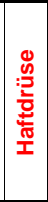 & 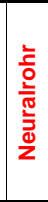 & 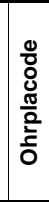 & $\mid \begin{array}{l}\frac{\mathscr{n}}{\mathbf{E}} \\
\frac{\mathbf{g}}{\mathbf{d}} \\
\frac{\mathbf{0}}{\mathbf{u}}\end{array}$ & 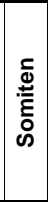 & $\mid \begin{array}{l}\mathbf{0} \\
\mathbf{0} \\
\mathbf{0} \\
\mathbf{0} \\
\mathbf{2}\end{array}$ & 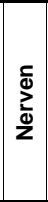 & & 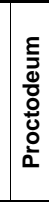 & 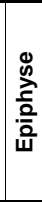 & 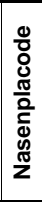 & 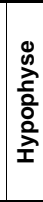 & 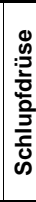 \\
\hline E-Value & Score & E-Value & Score & $\begin{array}{l}\text { e(bits)/E- } \\
\text { Value }\end{array}$ & Scor & & & & & $\mathrm{Au} \mathrm{K}$ & $\mathbf{K b} \mathbf{s}$ & Ss & $\mathrm{Hi}$ & $\mathrm{Pn}$ & En & $\mathrm{Ce}$ & $\mathrm{Nr}$ & Op & Ep & So & No & $\mathrm{Ne}$ & $\mathrm{He}$ & $P d$ & $\mathbf{P i}$ & Np & Py & $\mathrm{Ha}$ \\
\hline $2,0 \mathrm{E}-73$ & 276 & & & & & & & & & 65 & 5 & 5 & 5 & 3 & 0 & 0 & 1 & 3 & 2 & 1 & 1 & 0 & 3 & 1 & 2 & 4 & 4 & 2 \\
\hline $1,0 \mathrm{E}-101$ & 370 & & & & & & & & & $6 \mid 6$ & 6 & 6 & 6 & 6 & 1 & 1 & 6 & 6 & 2 & 6 & 1 & 6 & 6 & 5 & 5 & 6 & 6 & 6 \\
\hline $2,0 \mathrm{E}-49$ & 195 & & & & & & & & & $6 \mid 6$ & 6 & 5 & 6 & 4 & 1 & 0 & 2 & 6 & 1 & 1 & 0 & 0 & 5 & 1 & 0 & 6 & 6 & 6 \\
\hline- & - & $0,00 E+00$ & 684 & & & & & & & $6 \mid 6$ & 6 & 6 & 4 & 5 & 0 & 0 & 1 & 3 & 2 & 1 & 0 & 0 & 5 & 4 & 1 & 5 & 5 & 6 \\
\hline $4,0 \mathrm{E}-44$ & 177 & & & & & & & & & $6 \mid 6$ & 6 & 6 & 6 & 6 & 0 & 0 & 5 & 6 & 5 & 1 & 0 & 0 & 6 & 3 & 1 & 6 & 6 & 6 \\
\hline - & - & $2,00 \mathrm{E}-11$ & 76 & 0.0 & 797 & & \begin{tabular}{|c|} 
reffNP_012289.1| \\
Transcriptional activator \\
for allantioin an... 28 \\
2.8 \\
.8
\end{tabular} & & & \begin{tabular}{l|l}
6 & 6
\end{tabular} & 6 & 6 & 6 & 6 & 0 & 0 & 4 & 6 & 2 & 4 & 1 & 1 & 6 & 3 & 6 & 6 & 6 & 6 \\
\hline $2,0 \mathrm{E}-08$ & 60 & & & & & & & & & $6 \quad 6$ & 6 & 6 & 6 & 6 & 0 & 0 & 4 & 6 & 2 & 1 & 1 & 1 & 5 & 2 & 6 & 6 & 6 & 6 \\
\hline $2,0 \mathrm{E}-51$ & 203 & & & & & & & & & 6 & 6 & 6 & 6 & 6 & 0 & 0 & 1 & 6 & 1 & 1 & 1 & 1 & 6 & 4 & 6 & 6 & 6 & 6 \\
\hline $2,5 \mathrm{E}-95$ & 957 & & & & & & & & & $6 \mid 5$ & 5 & 4 & 3 & 3 & 0 & 0 & 1 & 5 & 1 & 1 & 1 & 1 & 2 & 3 & 2 & 3 & 3 & 3 \\
\hline $3,0 \mathrm{E}-20$ & 100 & $1,10 \mathrm{E}-01$ & 44 & & & & & & & 6 & 6 & 6 & 6 & 6 & 0 & 1 & 6 & 6 & 1 & 6 & 1 & 6 & 6 & 6 & 6 & 6 & 6 & 6 \\
\hline $2,0 \mathrm{E}-86$ & 319 & $1,00 E-119$ & 432 & & & & & & & 6 & 6 & 6 & 6 & 4 & 0 & 2 & 4 & 5 & 2 & 1 & 1 & 1 & 6 & 5 & 6 & 6 & 6 & 6 \\
\hline - & - & $0,00 E+00$ & 954 & & & & & & & $6 \mid 6$ & 6 & 6 & 6 & 6 & 0 & 5 & 0 & 6 & 6 & 1 & 6 & 0 & 6 & 6 & 6 & 6 & 6 & 6 \\
\hline $1,0 \mathrm{E}-110$ & 397 & & & & & & & & & 6 & 6 & 5 & 6 & 6 & 1 & 1 & 4 & 6 & 3 & 4 & 1 & 5 & 5 & 5 & 0 & 6 & 6 & 6 \\
\hline $1,0 \mathrm{E}-91$ & 324 & & & & & & & & & 46 & 6 & 6 & 4 & 6 & 0 & 0 & 3 & 4 & 5 & 1 & 0 & 0 & 5 & 5 & 1 & 6 & 5 & 2 \\
\hline $1,0 \mathrm{E}-23$ & 110 & & & & & & & & & 6 & 6 & 6 & 6 & 6 & 1 & 1 & 6 & 6 & 2 & 6 & 1 & 6 & 3 & 6 & 5 & 6 & 6 & 6 \\
\hline $3,0 \mathrm{E}-43$ & 102 & & & & & & & & & 6 & 6 & 6 & 6 & 6 & 1 & 1 & 6 & 6 & 4 & 1 & 0 & 0 & 6 & 6 & 1 & 6 & 6 & 6 \\
\hline $5,0 \mathrm{E}-37$ & 155 & & & & & & & & & $6 \quad 5$ & 5 & 6 & 3 & 5 & 0 & 0 & 3 & 3 & 2 & 1 & 0 & 0 & 3 & 1 & 2 & 4 & 4 & 2 \\
\hline $1,0 \mathrm{E}-52$ & 205 & & & & & & & & & 6 & 6 & 6 & 6 & 5 & 1 & 0 & 6 & 5 & 3 & 1 & 0 & 0 & 6 & 1 & 0 & 6 & 4 & 6 \\
\hline $1,0 \mathrm{E}-98$ & 359 & & & & & & & & & $6 \mid 5$ & 5 & 6 & 6 & 6 & 0 & 0 & 5 & 6 & 5 & 1 & 0 & 0 & 5 & 4 & 0 & 6 & 6 & 6 \\
\hline $3,0 \mathrm{E}-90$ & 333 & & & & & & & & & $6 \mid 6$ & 6 & 6 & 5 & 6 & 0 & 0 & 5 & 6 & 2 & 1 & 0 & 0 & 6 & 3 & 2 & 6 & 6 & 6 \\
\hline
\end{tabular}




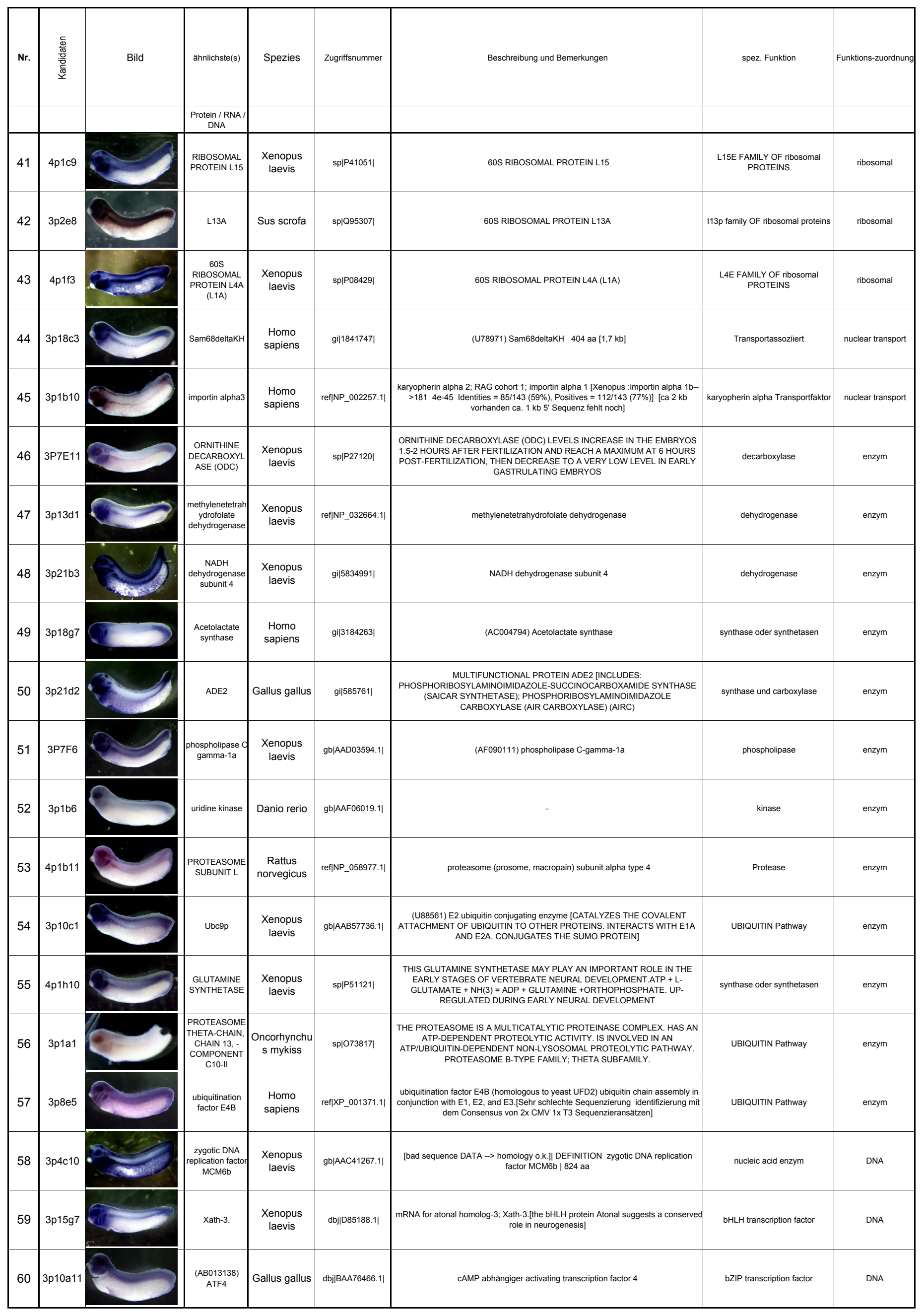




\begin{tabular}{|c|c|c|c|c|c|c|c|c|c|c|c|c|c|c|c|c|c|c|c|c|c|c|c|c|c|c|c|c|}
\hline Blast & & Blast & & Blast & & 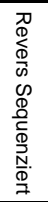 & $\begin{array}{c}\text { Yeast-Suche nach } \\
\text { maximaler Sequenz }\end{array}$ & Signaturen & 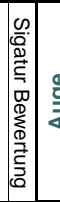 & 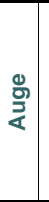 & 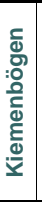 & 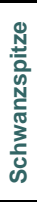 & 喜 & 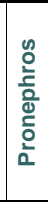 & 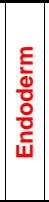 & 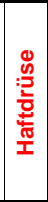 & 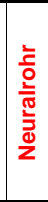 & 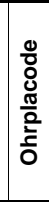 & 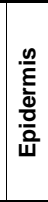 & 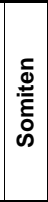 & $\mid \begin{array}{l}\mathbf{0} \\
\mathbf{0} \\
\mathbf{0} \\
\mathbf{0} \\
\mathbf{2}\end{array}$ & $\mid \begin{array}{l}\mathbf{c} \\
\stackrel{\mathbf{d}}{\mathbf{d}} \\
\mathbf{z} \\
\mathbf{z}\end{array}$ & 涉 & 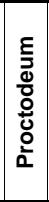 & 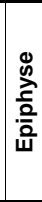 & 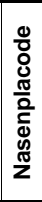 & & 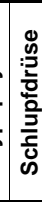 \\
\hline E-Value & Score & E-Value & Score & $\begin{array}{l}\text { e(bits)/E- } \\
\text { Value }\end{array}$ & Scor & & & & & $\mathrm{Au}$ & $\mathbf{K b}$ & Ss & $\mathrm{Hi}$ & Pn & En & $\mathrm{Ce}$ & $\mathrm{Nr}$ & Op & Ep & So & No & $\mathrm{Ne}$ & $\mathrm{He}$ & $\mathbf{P d}$ & $\mathbf{P i}$ & Np & & $\mathrm{Ha}$ \\
\hline $2,0 \mathrm{E}-92$ & 338 & & & & & & & & & 6 & 6 & 6 & 5 & 6 & 0 & 0 & 4 & 3 & 3 & 1 & 0 & 0 & 5 & 3 & 2 & 6 & 5 & 2 \\
\hline $9,0 \mathrm{E}-61$ & 233 & & & & & & & & & 6 & 6 & 6 & 6 & 6 & 0 & 0 & 6 & 6 & 3 & 1 & 6 & 0 & 6 & 2 & 0 & 6 & 6 & 6 \\
\hline $1,0 \mathrm{E}-90$ & 333 & & & & & & & & & 6 & 6 & 6 & 6 & 6 & 0 & 0 & 4 & 3 & 5 & 1 & 0 & 0 & 6 & 6 & 1 & 4 & 4 & 2 \\
\hline $5,0 \mathrm{E}-18$ & 92 & & & & & & & & & 6 & 6 & 5 & 6 & 5 & 0 & 1 & 1 & 6 & 1 & 2 & 1 & 1 & 6 & 2 & 2 & 6 & 6 & 6 \\
\hline $1,0 E-53$ & 209 & $1,50 \mathrm{E}-02$ & 46 & & & & & & & 6 & 6 & 5 & 6 & 6 & 1 & 0 & 2 & 4 & 2 & 1 & 1 & 3 & 1 & 1 & 2 & 5 & 5 & 4 \\
\hline $1,0 \mathrm{E}-112$ & 405 & & & & & & & & & 6 & 5 & 5 & 3 & 3 & 0 & 0 & 1 & 4 & 2 & 1 & 0 & 0 & 1 & 0 & 0 & 2 & 3 & 2 \\
\hline $4,0 E-93$ & 341 & & & & & & & & & 5 & 6 & 6 & 1 & 5 & 0 & 0 & 2 & 4 & 1 & 2 & 1 & 1 & 3 & 0 & 1 & 1 & 1 & 1 \\
\hline $9,0 \mathrm{E}-45$ & 181 & & & & & & & & & 6 & 6 & 6 & 6 & 6 & 0 & 4 & 6 & 6 & 2 & 2 & 1 & 1 & 6 & 5 & 6 & 6 & 6 & 6 \\
\hline $8,0 \mathrm{E}-59$ & 227 & & & & & & & & & 6 & 5 & 5 & 5 & 2 & 0 & 1 & 1 & 6 & 1 & 1 & 1 & 1 & 1 & 3 & 5 & 5 & 5 & 5 \\
\hline $8,0 \mathrm{E}-80$ & 297 & & & & & & & & & 6 & 6 & 6 & 5 & 6 & 0 & 1 & 2 & 6 & 1 & 1 & 1 & 1 & 2 & 5 & 3 & 6 & 6 & 6 \\
\hline $2,0 \mathrm{E}-89$ & 329 & $0,00 \mathrm{E}+00$ & 868 & & & & & & & 6 & 6 & 6 & 6 & 6 & 0 & 0 & 4 & 6 & 3 & 1 & 0 & 0 & 6 & 4 & 0 & 6 & 6 & 2 \\
\hline $5,0 \mathrm{E}-22$ & 104 & $3,00 E-03$ & 48 & & & & & & & 6 & 4 & 4 & 4 & 2 & 0 & 0 & 1 & 4 & 0 & 1 & 0 & 0 & 3 & 3 & 1 & 2 & 3 & 2 \\
\hline $9,0 \mathrm{E}-30$ & 122 & & & & & & & & & 6 & 5 & 4 & 4 & 6 & 1 & 0 & 1 & 3 & 2 & 1 & 0 & 0 & 2 & 1 & 2 & 3 & 3 & 3 \\
\hline $2,0 \mathrm{E}-91$ & 360 & & & & & & & & & 6 & 5 & 6 & 6 & 6 & 1 & 1 & 4 & 4 & 2 & 2 & 1 & 5 & 1 & 2 & 2 & 6 & 6 & 6 \\
\hline $1,0 E-108$ & 390 & & & & & & & & & 6 & 6 & 5 & 5 & 5 & 0 & 0 & 1 & 3 & 1 & 1 & 0 & 0 & 5 & 4 & 2 & 6 & 5 & 4 \\
\hline $6,0 \mathrm{E}-43$ & 174 & & & & & & & & & 6 & 5 & 5 & 4 & 4 & 0 & 0 & 0 & 3 & 0 & 1 & 0 & 0 & 1 & 0 & 1 & 1 & 2 & 1 \\
\hline $5,0 \mathrm{E}-13$ & 74 & & & & & & & & & 6 & 5 & 4 & 5 & 4 & 1 & 0 & 2 & 5 & 2 & 3 & 0 & 2 & 2 & 3 & 1 & 4 & 3 & 3 \\
\hline $4,0 \mathrm{E}-24$ & 111 & & & & & & & & & 6 & 6 & 6 & 4 & 6 & 0 & 0 & 4 & 5 & 5 & 1 & 0 & 0 & 6 & 6 & 1 & 6 & 6 & 5 \\
\hline - & - & $1,00 E-112$ & 412 & & & & & & & 6 & 5 & 5 & 5 & 5 & 0 & 1 & 2 & 4 & 1 & 1 & 1 & 1 & 3 & 4 & 4 & 4 & 4 & 4 \\
\hline $2,0 \mathrm{E}-21$ & 103 & & & & & & & & & 6 & 5 & 4 & 6 & 2 & 1 & 1 & 2 & 6 & 2 & 3 & 5 & 3 & 1 & 1 & 0 & 6 & 5 & 6 \\
\hline
\end{tabular}




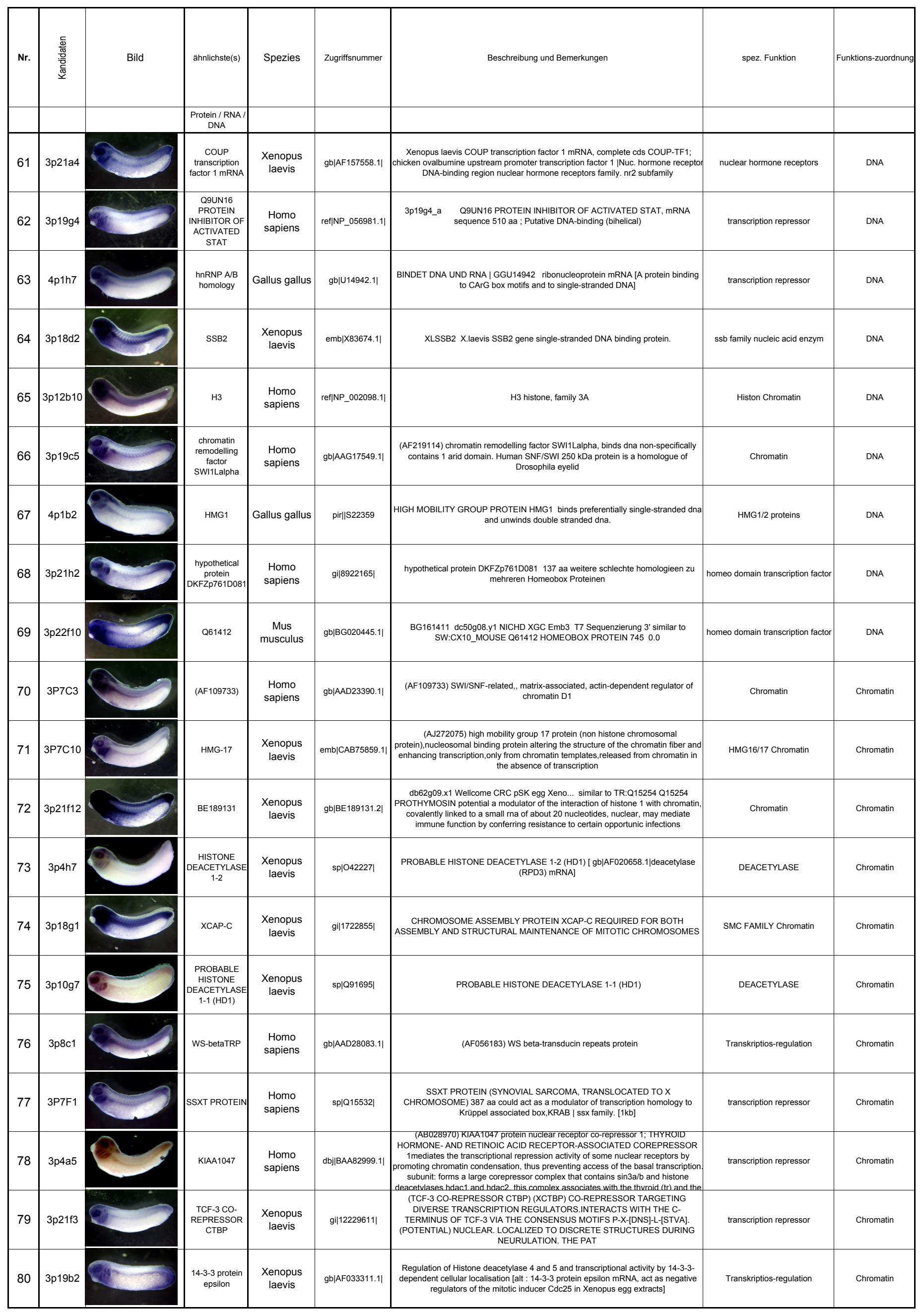




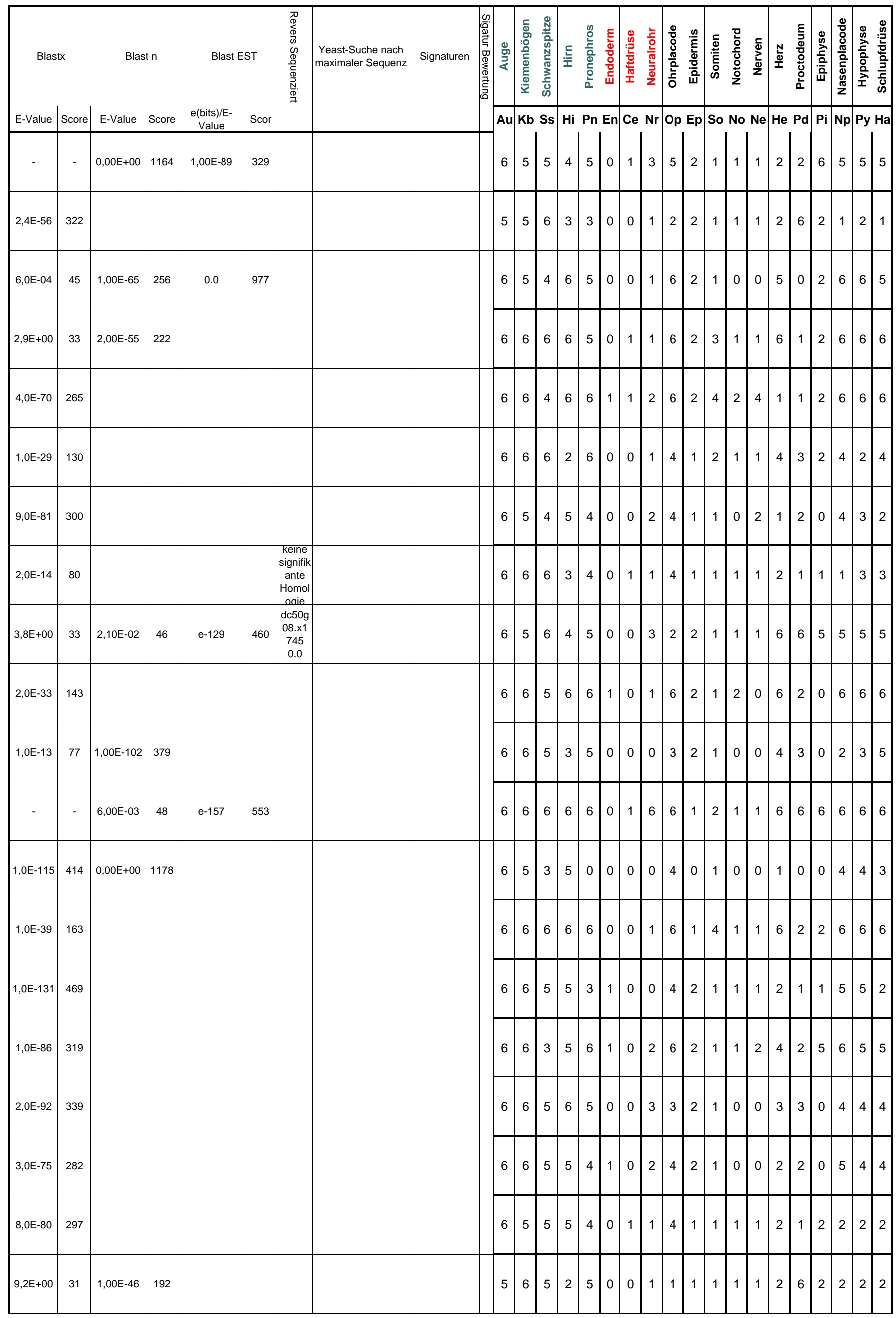




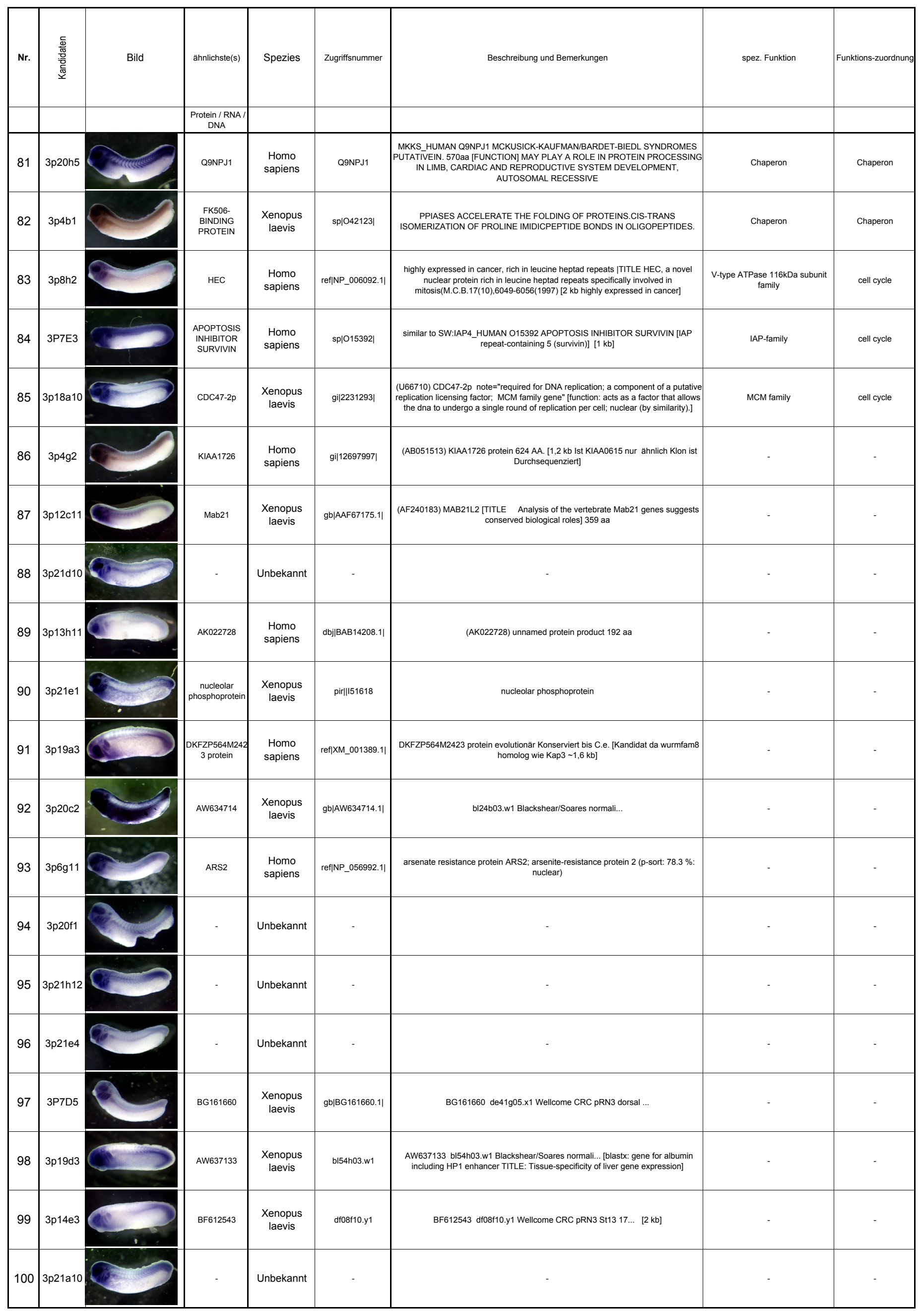









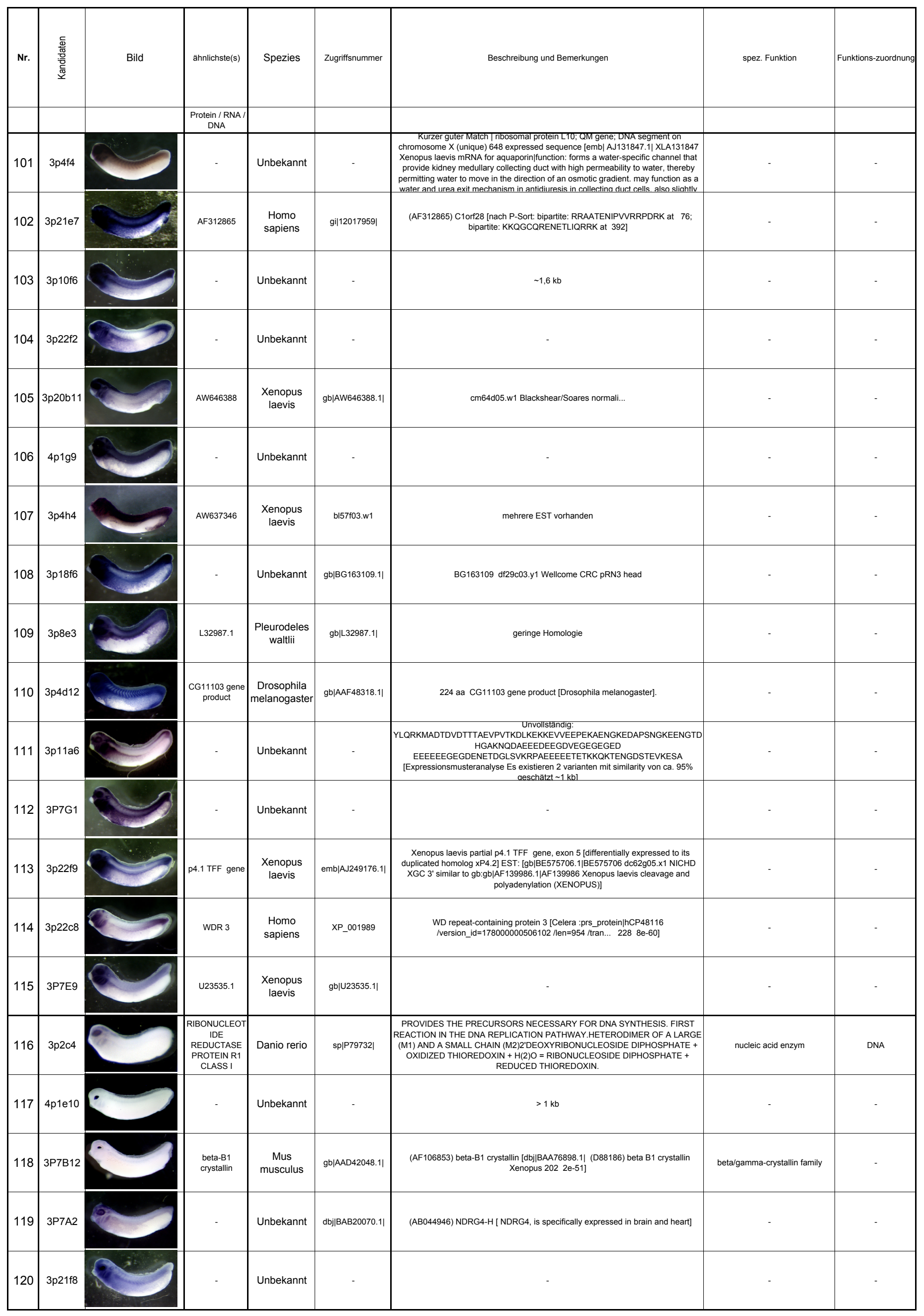




\begin{tabular}{|c|c|c|c|c|c|c|c|c|c|c|c|c|c|c|c|c|c|c|c|c|c|c|c|c|c|c|c|c|c|}
\hline \multicolumn{2}{|c|}{ Blastx } & \multicolumn{2}{|c|}{ Blast n } & \multicolumn{2}{|c|}{ Blast EST } & 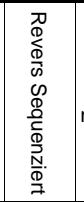 & $\begin{array}{c}\text { Yeast-Suche nach } \\
\text { maximaler Sequenz }\end{array}$ & Signaturen & 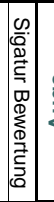 & $\underset{\Xi}{\Xi}$ & 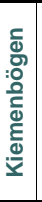 & 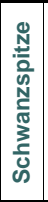 & 旁 & 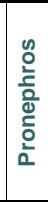 & \begin{tabular}{|l|}
$\frac{E}{0}$ \\
$\frac{d}{2}$ \\
$\frac{0}{0}$ \\
w \\
w
\end{tabular} & 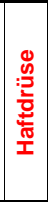 & 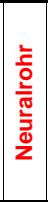 & 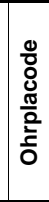 & 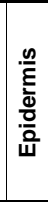 & 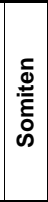 & 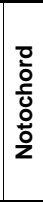 & 离 & & 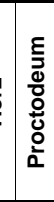 & 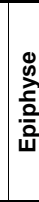 & 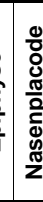 & 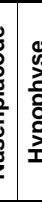 & 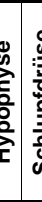 & \\
\hline E-Value & Score & E-Value & Score & $\begin{array}{l}\text { e(bits)/E- } \\
\text { Value }\end{array}$ & Scor & & & & & $\mathrm{Au}$ & $\mathbf{K b}$ & Ss & $\mathrm{Hi}$ & Pn & En & $\mathrm{Ce}$ & $\mathbf{N r}$ & Op & Ep & So & No & $\mathrm{Ne}$ & $\mathrm{He}$ & e $\mathbf{P d}$ & $\mathrm{Pi}$ & $\mathrm{i} \mid \mathbf{N}_{\mathrm{r}}$ & & y & \\
\hline $8,0 \mathrm{E}-04$ & 45 & $3,00 E-81$ & 280 & & & & & - & & 6 & 6 & 5 & 6 & 2 & 1 & 0 & 6 & 6 & 1 & 1 & 0 & 0 & 2 & 0 & 0 & 6 & 6 & 6 & 6 \\
\hline $3,0 \mathrm{E}-67$ & 255 & & & & & \begin{tabular}{|c|} 
de61e \\
$01 . y 1$ \\
1148 \\
0.0 \\
\end{tabular} & & $\begin{array}{c}\text { RCC1 ABC Ribo } \\
\text { kurzes peptid } 82.6 \\
\%: \text { nuclear }(34.8 \\
\%: \text { mitochondrial } \\
30.4 \% \text { : } \\
\text { cvtoolasmic } 17.4\end{array}$ & & 6 & 6 & 6 & 6 & 6 & 0 & 2 & 6 & 6 & 3 & 1 & 1 & 1 & 6 & 6 & 6 & 6 & 6 & $6 \mid 6$ & 6 \\
\hline- & - & $7,80 \mathrm{E}-02$ & 44 & $3,71 E+04$ & 38 & & & $\begin{array}{l}\text { RCC1 Ribo; } \\
\text { Kurzes Peptid }\end{array}$ & & 6 & 6 & 6 & 6 & 6 & 1 & 1 & 3 & 6 & 2 & 4 & 1 & 3 & 6 & 3 & 5 & 6 & 6 & $6 \mid 6$ & 6 \\
\hline $8,6 \mathrm{E}+00$ & 32 & $1,00 \mathrm{E}-06$ & 60 & $4,00 E-12$ & 72 & $\begin{array}{c}\text { Keine } \\
\text { signifik } \\
\text { ante } \\
\text { Homol } \\
\text { ogie }\end{array}$ & 274.7 & $\cdot$ & & 6 & 5 & 6 & 6 & 6 & 0 & 1 & 1 & 2 & 1 & 1 & 1 & 1 & 1 & 1 & 1 & 6 & 5 & 56 & 6 \\
\hline- & - & $7,40 \mathrm{E}+00$ & 38 & $3,00 E-46$ & 190 & & & - & & 6 & 6 & 6 & 6 & 4 & 0 & 1 & 5 & 5 & 1 & 1 & 1 & 3 & 5 & 1 & 6 & 6 & 6 & 66 & 6 \\
\hline- & - & - & - & $4,00 E-12$ & 72 & & & - & & 6 & 6 & 6 & 6 & 6 & 0 & 1 & 6 & 6 & 4 & 6 & 6 & 0 & 5 & 5 & 1 & 6 & 6 & 66 & 6 \\
\hline $1,7 \mathrm{E}+00$ & 34 & $2,80 \mathrm{E}-01$ & 42 & 0.0 & 882 & $\mid \begin{array}{c}\text { df72a0 } \\
7 . x 1 \\
714 \\
0.0\end{array}$ & & - & & 6 & 6 & 6 & 6 & 6 & 1 & 0 & 6 & 6 & 5 & 1 & 6 & 0 & 6 & 6 & 6 & 6 & 6 & \begin{tabular}{l|l}
6 & 6
\end{tabular} & 6 \\
\hline - & - & $2,50 \mathrm{E}-01$ & 30 & $5,00 \mathrm{E}-28$ & 121 & & & - & & 6 & 6 & 6 & 6 & 6 & 0 & 1 & 6 & 6 & 3 & 1 & 1 & 4 & 6 & 4 & 6 & 6 & 6 & 66 & 6 \\
\hline $7,0 \mathrm{E}-26$ & 123 & & & & & $\mid \begin{array}{c}\text { da } 87 \mathrm{~h} \\
11 . \mathrm{y} 1 \\
708 \\
0.0\end{array}$ & & Ribo & & 6 & 6 & 6 & 6 & 6 & 1 & 0 & 5 & 5 & 3 & 4 & 1 & 6 & 5 & 5 & 0 & 6 & 6 & $6 \mid 6$ & 6 \\
\hline $7,0 E-38$ & 157 & & & & & \begin{tabular}{|c|}
$\mathrm{dg} 10 \mathrm{e}$ \\
$01 . \mathrm{y} 1$ \\
674 \\
0.0 \\
\end{tabular} & & - & & 6 & 6 & 5 & 6 & 6 & 0 & 0 & 4 & 6 & 5 & 1 & 0 & 0 & 6 & 4 & 0 & 6 & 6 & \begin{tabular}{l|l}
6 & 6
\end{tabular} & 6 \\
\hline - & - & $5,00 \mathrm{E}-03$ & 48 & 0.0 & 674 & $\mid \begin{array}{c}\text { da29g } \\
02 . x 1 \\
821 \\
0.0\end{array}$ & & $\begin{array}{l}\text { RCC1 Ribo (69.6 } \\
\text { \%: nuclear 17.4 } \\
\text { \%: cyto-plasmic) }\end{array}$ & & 6 & 6 & 6 & 6 & 6 & 1 & 0 & 3 & 6 & 2 & 2 & 1 & 5 & 6 & 5 & 0 & 6 & 6 & $6 \mid$ & 6 \\
\hline $4,7 \mathrm{E}+00$ & 32 & $2,70 \mathrm{E}-01$ & 42 & 0.029 & 39 & \begin{tabular}{|c|} 
keine \\
signifik \\
ante \\
Homolo \\
gie \\
\end{tabular} & 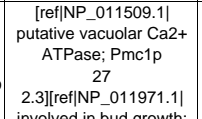 & - & & 6 & 6 & 6 & 5 & 6 & 0 & 0 & 6 & 6 & 4 & 1 & 0 & 0 & 6 & 5 & 0 & 6 & 6 & 6 & 4 \\
\hline - & - & $2,00 \mathrm{E}-18$ & 100 & $9,00 E-51$ & 200 & & & - & & 6 & 6 & 6 & 6 & 5 & 0 & 0 & 4 & 4 & 2 & 1 & 1 & 1 & 5 & 3 & 1 & 6 & 2 & 2 & 6 \\
\hline $3,0 E-58$ & 225 & & & & & & & ABC (Ribo) & & 6 & 6 & 6 & 6 & 3 & 0 & 0 & 1 & 6 & 1 & 4 & 1 & 1 & 5 & 1 & 6 & 6 & 6 & 6 & 6 \\
\hline $7,9 \mathrm{E}-02$ & 38 & $1,00 \mathrm{E}-98$ & 365 & e-111 & 404 & & & & & 6 & 6 & 3 & 5 & 6 & 0 & 1 & 1 & 6 & 2 & 1 & 0 & 0 & 5 & 1 & 0 & 6 & 5 & 5 & 6 \\
\hline $6,0 \mathrm{E}-41$ & 155 & & & & & & & & & 6 & 3 & 0 & 3 & 0 & 0 & 0 & 0 & 1 & 0 & 1 & 0 & 0 & 0 & 0 & 1 & 1 & 1 & 1 & 1 \\
\hline $5,7 \mathrm{E}+00$ & 32 & $3,70 \mathrm{E}+04$ & 40 & 0.13 & 42 & & & & & 6 & 0 & 0 & 0 & 0 & 0 & 0 & 1 & 0 & 0 & 1 & 0 & 1 & 0 & 0 & 0 & 0 & 0 & 0 & b \\
\hline $8,0 \mathrm{E}-58$ & 223 & & & & & & & & & 6 & 0 & 0 & 0 & 0 & 0 & 0 & 1 & 2 & 0 & 1 & 1 & 1 & 0 & 0 & 0 & 0 & 0 & 0 & 1 \\
\hline $8,0 \mathrm{E}-21$ & 69 & $1,00 \mathrm{E}-11$ & 78 & $2,00 E-63$ & 242 & & & & & 6 & 3 & 3 & 4 & 2 & 0 & 1 & 1 & 3 & 1 & 1 & 0 & 1 & 1 & 2 & 1 & 2 & 3 & 3 & 2 \\
\hline $\begin{array}{lll}- & - \\
\end{array}$ & - & $2,10 \mathrm{E}-02$ & 46 & $3,70 \mathrm{E}+04$ & 34 & & & & & 5 & 4 & 2 & 4 & 4 & 0 & 1 & 1 & 3 & 1 & 1 & 1 & 1 & 2 & 1 & 1 & 1 & 3 & 3 & 1 \\
\hline
\end{tabular}




\begin{tabular}{|c|c|c|c|c|c|c|c|c|}
\hline Nr. & 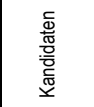 & Bild & ähnlichste(s) & Spezies & Zugriffsnummer & Beschreibung und Bemerkungen & spez. Funktion & Funktions-zuordnung \\
\hline & & & $\begin{array}{c}\text { Protein / RNA / } \\
\text { DNA }\end{array}$ & & & & & \\
\hline 121 & $3 p 15 c 5$ & & - & Unbekannt & - & - & - & - \\
\hline 122 & 3p8b4 & & - & Unbekannt & - & $1 \mathrm{~kb}$ & - & - \\
\hline 123 & $3 p 20 h 12$ & & $\begin{array}{c}\text { methionine } \\
\text { adenosyltransfer } \\
\text { ase II, alpha }\end{array}$ & $\begin{array}{l}\text { Homo } \\
\text { sapiens }\end{array}$ & gi|5174529| & methionine adenosyltransferase II, alpha & Transferase & enzym \\
\hline 124 & $3 p 19 b 7$ & & Pax6 & $\begin{array}{l}\text { Xenopus } \\
\text { laevis }\end{array}$ & $\mathrm{gb}|\mathrm{U} 77532.1|$ & Pax6 mRNA ; Dorsoventrale Musterbildung, ZNS. & homeo domain transcription factor & DNA \\
\hline 125 & $3 p 15 f 4$ & & $\begin{array}{l}\text { KIAA1341 } \\
\text { protein }\end{array}$ & $\begin{array}{l}\text { Homo } \\
\text { sapiens }\end{array}$ & gi|7243063| & $\begin{array}{l}\text { (AB037762) KIAA1341 protein } 620 \text { aa } \\
\text { (U13262) myelin gene expression factor ssDNA binding protein } 1862 \mathrm{e} \text { - } 46 \text { ] }\end{array}$ & transcription repressor & DNA \\
\hline 126 & $3 p 19 g 6$ & & $\begin{array}{l}\text { NEUROGENIC } \\
\text { DIFFERENTIAT } \\
\text { ION FACTOR } 1\end{array}$ & $\begin{array}{l}\text { Xenopus } \\
\text { laevis }\end{array}$ & Q91616 & $\begin{array}{l}\text { NDF1_XENLA NEUROGENIC DIFFERENTIATION FACTOR } 1 \\
\text { bHLH }==>\text { Neuro D }\end{array}$ & bHLH transcription factor & DNA \\
\hline 127 & $3 \mathrm{p} 18 \mathrm{e} 6$ & & - & Unbekannt & $\mathrm{gb}|\mathrm{BG} 018000.1|$ & dg31h04.x1 Xenopus laevis gastrula non normalized Xenopus laevis & - & - \\
\hline 128 & $3 p 21 g 7$ & & Idx & $\begin{array}{l}\text { Xenopus } \\
\text { laevis }\end{array}$ & pir|||151278 & $\begin{array}{l}\text { negative regulatory element Idx; XIdx, a dominant negative regulator of bHLH } \\
\text { function in early Xenopus embryos }\end{array}$ & transcription repressor & - \\
\hline 129 & 3p13b9 & & Symplekin & $\begin{array}{l}\text { Homo } \\
\text { sapiens }\end{array}$ & reffNP_004810.1| & $\begin{array}{l}\text { Symplekin; Huntingtin interacting protein [analyses have revealed that the protein } \\
\text { occurs in all these diverse cells in nucleoplasm, and only in those cells forming tight } \\
\text { junctions is it recruited. function in the nucleus as well as in the plaques] }\end{array}$ & Cytosklett & Strukturprotein \\
\hline 130 & $3 \mathrm{p} 1 \mathrm{e} 1$ & & $\begin{array}{l}\text { targeting protein } \\
\text { for Xk1p2; TPX2 }\end{array}$ & $\begin{array}{l}\text { Xenopus } \\
\text { laevis }\end{array}$ & gb|AAF81694.1| & $\begin{array}{c}\text { Cellcycle, Cytosklett| mediates binding of Xklp2 to microtubules; stabilizes spindle } \\
\text { poles; stage Oocyte }\end{array}$ & Cytosklett & Strukturprotein \\
\hline 131 & $3 p 1 c 6$ & & U1 SNRNP A & $\begin{array}{l}\text { Xenopus } \\
\text { laevis }\end{array}$ & sp|P45429| & $\begin{array}{l}\text { U1 SMALL NUCLEAR RIBONUCLEOPROTEIN A (U1 SNRNP A PROTEIN) } \\
\text { [Nuclear Import of the U1A Splicesome Protein Is Mediated by Importin alpha /beta } \\
\text { and Ran in living Mammalian Cells] }\end{array}$ & $\begin{array}{l}\text { Eukaryotic RNA-binding region } \\
\text { RNP-1 proteins }\end{array}$ & RNA \\
\hline 132 & $3 \mathrm{p} 2 \mathrm{~h} 6$ & & $\begin{array}{l}\text { TRNA-RIBOSYL } \\
\text { TRANSFERASE }\end{array}$ & $\begin{array}{c}\text { Oryctolagus } \\
\text { cuniculus }\end{array}$ & sp|P40826| & $\begin{array}{l}\text { tRNA-GUANINE TRANSGLYCOSYLASE SYNTHESIZE QUEUOSINE } \\
\text { (NUCLEOSIDE Q) BY THE IRREVERSIBLE BASE-FOR-BASE EXCHANGE OF } \\
\text { QUEUINE (Q BASE) FOR GUANINE AT TRNA POSITION } 34 .\end{array}$ & Transferase & RNA \\
\hline 133 & $3 p 1 a 6$ & & $\begin{array}{c}\text { (DKFZP564M24 } \\
\text { 23), mRNA }\end{array}$ & $\begin{array}{l}\text { Homo } \\
\text { sapiens }\end{array}$ & ref|NM_015640.1| & $\begin{array}{c}\text { DKFZP564M2423 protein (DKFZP564M2423), mRNA Length = 2201; PAI-1 mRNA- } \\
\text { binding protein; actin binding LIM protein }\end{array}$ & - & RNA \\
\hline 134 & $3 \mathrm{p} 4 \mathrm{~h} 3$ & & $\begin{array}{l}\text { (L10911) } \\
\text { splicing factor }\end{array}$ & $\begin{array}{c}\text { Homo } \\
\text { sapiens }\end{array}$ & gb|AAA16347.1| & Putative splicing factor with RNA-binding domains and unique arginine/serine motiv & SPLICING FACTOR & RNA \\
\hline 135 & $3 p 9 e 12$ & & $\begin{array}{l}\text { XFG 5-1 and } \\
\text { XFG 5-2 }\end{array}$ & $\begin{array}{l}\text { Xenopus } \\
\text { laevis }\end{array}$ & emb|X71067.1| & XFG 5-1 and XFG 5-2 & zinc finger & RNA \\
\hline 136 & $3 p 4 f 3$ & & (AF218007) & $\begin{array}{l}\text { Homo } \\
\text { sapiens }\end{array}$ & gb|AAG17249.1| & $\begin{array}{l}\text { unknown protein Homo sapiens (HASJ4442), mRNA similar to putative } \\
\text { methyltransferase | Titel: Novel Human cDNA clones with function of inhibiting } \\
\text { cancer cell growth. }\end{array}$ & Transferase & enzym \\
\hline 137 & 3P7D10 & & $\begin{array}{c}\text { DNA } \\
\text { methyltransferas } \\
\text { e } 1\end{array}$ & $\begin{array}{l}\text { Xenopus } \\
\text { laevis }\end{array}$ & gb|AAF06333.1| & (AF192996) DNA methyltransferase 1 & Transferase & DNA \\
\hline 138 & $3 p 19 a 2$ & & SSB1 & $\begin{array}{l}\text { Xenopus } \\
\text { laevis }\end{array}$ & emb|x83673.1| & X.laevis SSB1 gene ; mitochondrial protein; single-stranded DNA binding protein & ssb family & DNA \\
\hline 139 & $4 \mathrm{p} 1 \mathrm{~d} 3$ & & $\mathrm{H} 2 \mathrm{~A}$ & $\begin{array}{l}\text { Homo } \\
\text { sapiens }\end{array}$ & ref|NP_036544.1| & $\begin{array}{c}\text { ref|NP_036544.1| purine-rich element binding protein B (h2A histone family, } \\
\text { member Z) }\end{array}$ & Histon & DNA \\
\hline 140 & $4 \mathrm{p} 1 \mathrm{f} 1$ & & $\begin{array}{c}\text { HIRA interacting } \\
\text { protein } 4\end{array}$ & $\begin{array}{l}\text { Homo } \\
\text { sapiens }\end{array}$ & ref|NP_005871.1| & $\begin{array}{l}412 \text { aa, HIRA interacting protein } 4 \text { (dnaJ-like) HIRA protein shares sequence } \\
\text { similarity with Hir1p and Hir2p, the two corepressors of histone gene } \\
\text { transcription(yeast); DnaJ molecular chaperone homology domain }\end{array}$ & DnaJ subfamily A & Chaperon \\
\hline
\end{tabular}




\begin{tabular}{|c|c|c|c|c|c|c|c|c|c|c|c|c|c|c|c|c|c|c|c|c|c|c|c|c|c|c|c|c|c|}
\hline Blas & & Blas & & Blast $\mathrm{E}$ & & 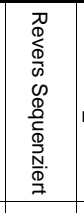 & $\begin{array}{c}\text { Yeast-Suche nach } \\
\text { maximaler Sequenz }\end{array}$ & Signaturen & 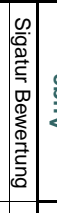 & $\begin{array}{l}\text { Ð } \\
\stackrel{\Xi}{\rightleftarrows}\end{array}$ & 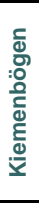 & 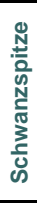 & 喜 & 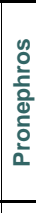 & 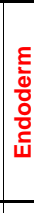 & 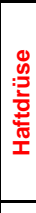 & 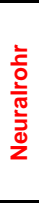 & 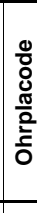 & 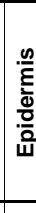 & & $\begin{array}{l}\text { 호 } \\
\text { 등 } \\
\text { 을 }\end{array}$ & & $\frac{N}{\mathbb{N}}$ & 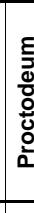 & & & 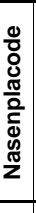 & 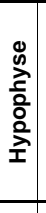 & 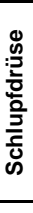 \\
\hline E-Value & Score & E-Value & Score & $\begin{array}{l}\text { e(bits)/E- } \\
\text { Value }\end{array}$ & Scor & & & & & $\mathrm{Au}$ & $\mathbf{K b}$ & Ss & $\mathrm{Hi}$ & $\mathrm{Pn}$ & En & $\mathrm{Ce}$ & $\mathrm{Nr}$ & Op & $\mathrm{E}$ & $\mathrm{Sc}$ & $N$ & $\mathrm{~N}$ & $\mathrm{H}$ & $\mathbf{P}$ & $F$ & & $\mathrm{~Np}$ & Py & $\mathrm{Ha}$ \\
\hline $9,0 \mathrm{E}-01$ & 35 & $4,00 \mathrm{E}-04$ & 52 & $2,00 E-33$ & 143 & & & & & 5 & 4 & 2 & 3 & 3 & 0 & 1 & 1 & 3 & 2 & 1 & 0 & 1 & 1 & 1 & 2 & & 3 & 3 & 3 \\
\hline $5,2 E+00$ & 32 & $3,69 \mathrm{E}+04$ & 40 & 0.39 & 40 & & & & & 6 & 5 & 2 & 2 & 5 & 1 & 0 & 3 & 4 & 1 & 4 & 2 & 3 & 1 & 5 & . & & 2 & 2 & 2 \\
\hline $3,0 \mathrm{E}-13$ & 77 & & & & & & & & & 6 & 5 & 4 & 4 & 1 & 1 & 1 & 1 & 3 & 1 & 1 & 1 & 1 & 2 & 3 & 5 & & 3 & 3 & 3 \\
\hline $3,2 E+00$ & 38 & $9,00 \mathrm{E}-88$ & 329 & & & & & & & 6 & 6 & 2 & 4 & 1 & 0 & 0 & 1 & 1 & 1 & 1 & 1 & 1 & 1 & 1 & 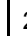 & & 3 & 3 & 3 \\
\hline $7,0 \mathrm{E}-47$ & 187 & & & & & $\mid \begin{array}{c}\text { da07h } \\
11 . x 1 \\
577 \mathrm{e}- \\
164\end{array}$ & & & & 6 & 5 & 4 & 3 & 5 & 0 & 1 & 2 & 3 & 1 & 1 & 1 & 1 & 2 & 1 & 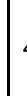 & & 4 & 3 & 2 \\
\hline $6,9 \mathrm{E}-54$ & 566 & & & & & & & & & 6 & 4 & 3 & 5 & 4 & 2 & 1 & 3 & 2 & 3 & 2 & 1 & 4 & 1 & 6 & 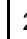 & & 1 & 3 & 2 \\
\hline $2,2 \mathrm{E}+00$ & 34 & $9,80 \mathrm{E}-02$ & 44 & $2,00 \mathrm{E}-97$ & 355 & & & & & 6 & 4 & 4 & 3 & 2 & 0 & 1 & 1 & 2 & 1 & 1 & 1 & 1 & 2 & 1 & 2 & & 2 & 1 & 1 \\
\hline $2,0 \mathrm{E}-56$ & 219 & & & & & & & & & 6 & 3 & 4 & 5 & 3 & 0 & 0 & 5 & 1 & 1 & 1 & 1 & 1 & 5 & 5 & . & & 2 & 1 & 1 \\
\hline $8,0 \mathrm{E}-70$ & 264 & & & & & & & & & 5 & 4 & 4 & 4 & 4 & 0 & 0 & 1 & 4 & 0 & 0 & 0 & 1 & 0 & 1 & 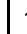 & 1 & 4 & 4 & 4 \\
\hline $3,0 \mathrm{E}-62$ & 238 & & & & & & & & & 5 & 4 & 3 & 4 & 0 & 0 & 0 & 1 & 3 & 1 & 1 & 2 & 0 & 2 & 0 & ( & 0 & 3 & 3 & 3 \\
\hline $7,0 \mathrm{E}-37$ & 153 & & & & & & & & & 5 & 4 & 3 & 4 & 4 & 0 & 0 & 0 & 3 & 0 & 1 & 0 & 0 & 1 & 2 & 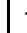 & 1 & 1 & 3 & 2 \\
\hline $1,0 \mathrm{E}-43$ & 175 & & & & & & & & & 5 & 4 & 1 & 4 & 5 & 0 & 0 & 0 & 2 & 0 & 1 & 2 & 3 & 0 & 0 & ( & & 0 & 1 & 2 \\
\hline $2,0 \mathrm{E}-45$ & 188 & & & & & & & & & 5 & 4 & 0 & 4 & 2 & 0 & 0 & 1 & 3 & 1 & 1 & 0 & 0 & 1 & 0 & 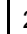 & 2 & 1 & 2 & 2 \\
\hline $4,0 \mathrm{E}-64$ & 244 & & & & & & & & & 5 & 3 & 0 & 2 & 5 & 0 & 0 & 0 & 3 & 0 & 1 & 2 & 0 & 1 & 0 & ( & 0 & 1 & 2 & 2 \\
\hline $3,7 \mathrm{E}+04$ & 33 & $8,00 \mathrm{E}-49$ & 200 & & & & & & & 5 & 2 & 1 & 2 & 0 & 0 & 0 & 1 & 1 & 1 & 0 & 0 & 0 & 1 & 1 & . & & 2 & 2 & 1 \\
\hline $1,0 \mathrm{E}-47$ & 189 & $1,00 \mathrm{E}-03$ & 50 & & & & & & & 5 & 3 & 3 & 4 & 1 & 0 & 0 & 0 & 2 & 0 & 1 & 2 & 0 & 3 & 0 & 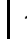 & & 2 & 4 & 1 \\
\hline $1,0 \mathrm{E}-116$ & 416 & $0,00 \mathrm{E}+00$ & 1197 & & & & & & & 6 & 6 & 0 & 4 & 4 & 0 & 0 & 0 & 3 & 1 & 1 & 3 & 0 & 1 & 0 & ( & & 2 & 3 & 3 \\
\hline 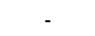 & - & $3,00 \mathrm{E}-32$ & 145 & & & & & & & 5 & 4 & 4 & 4 & 2 & 0 & 0 & 1 & 1 & 1 & 1 & 1 & 1 & 1 & 1 & 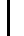 & & 1 & 1 & 1 \\
\hline $3,0 \mathrm{E}-56$ & 219 & & & & & & & & & 6 & 2 & 0 & 1 & 3 & 0 & 0 & 0 & 3 & 0 & 1 & 2 & 0 & 1 & 1 & 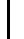 & & 1 & 1 & 1 \\
\hline $1,0 \mathrm{E}-91$ & 336 & & & & & & & & & 5 & 3 & 3 & 3 & 4 & 0 & 0 & 0 & 4 & 1 & 1 & 1 & 0 & 1 & 1 & & & 2 & 2 & 1 \\
\hline
\end{tabular}




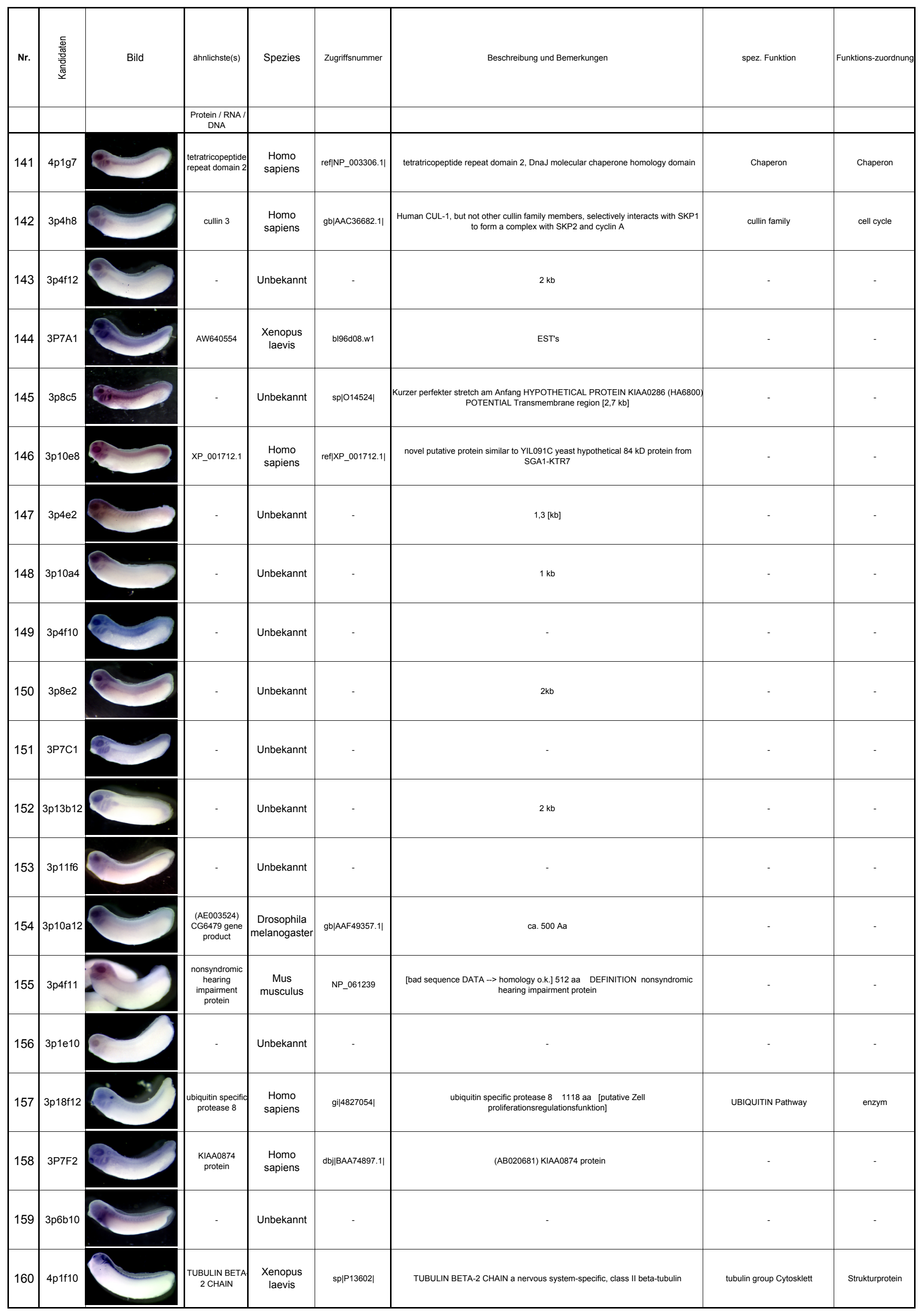




\begin{tabular}{|c|c|c|c|c|c|c|c|c|c|c|c|c|c|c|c|c|c|c|c|c|c|c|c|c|c|c|c|c|c|}
\hline Blas & & Blas & & Blast & & 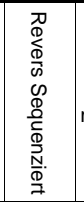 & $\begin{array}{c}\text { Yeast-Suche nach } \\
\text { maximaler Sequenz }\end{array}$ & Signaturen & 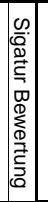 & 莺 & 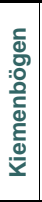 & 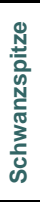 & 薹 & 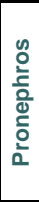 & 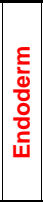 & 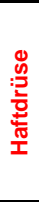 & 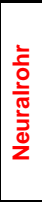 & 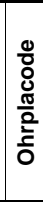 & 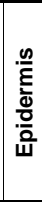 & 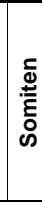 & & 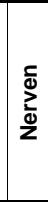 & $\frac{N}{\frac{N}{T}}$ & 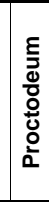 & 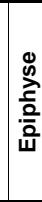 & 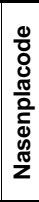 & & & \\
\hline E-Value & Score & E-Value & Score & $\begin{array}{l}\text { e(bits)/E- } \\
\text { Value }\end{array}$ & Scor & & & & & $\mathrm{Au}$ & $\mathbf{K b}$ & Ss & $\mathrm{Hi}$ & $\mathrm{Pn}$ & En & $\mathrm{Ce}$ & $\mathrm{Nr}$ & Op & Ep & So & No & $\mathrm{Ne}$ & $\mathrm{He}$ & $P d$ & $\mathrm{Pi}$ & $\mathrm{Np}$ & & $\mathrm{He}$ & \\
\hline $4,0 \mathrm{E}-97$ & 354 & & & & & & & & & 6 & 5 & 1 & 3 & 1 & 1 & 0 & 1 & 2 & 1 & 1 & 0 & 0 & 2 & 0 & 2 & 1 & 1 & 2 & \\
\hline $1,0 \mathrm{E}-80$ & 299 & & & & & & & & & 5 & 4 & 1 & 4 & 3 & 0 & 0 & 0 & 4 & 0 & 1 & 1 & 0 & 1 & 1 & 1 & 2 & 3 & 3 & \\
\hline $3,3 \mathrm{E}+00$ & 33 & $3,69 \mathrm{E}+04$ & 40 & 0.096 & 42 & $\begin{array}{c}\text { df89b0 } \\
6 . y 1 \\
654 \\
0.0\end{array}$ & & & & 5 & 4 & 3 & 4 & 3 & 0 & 0 & 0 & 6 & 1 & 1 & 0 & 0 & 5 & 2 & 6 & 6 & 3 & 5 & \\
\hline - & - & $9,70 \mathrm{E}-01$ & 40 & $1,00 \mathrm{E}-59$ & 234 & & & & & 6 & 5 & 1 & 5 & 5 & 0 & 1 & 2 & 3 & 2 & 1 & 2 & 1 & 2 & 1 & 4 & 5 & 4 & 4 & \\
\hline $2,0 \mathrm{E}-03$ & 43 & $2,90 \mathrm{E}-01$ & 42 & & & & & & & 6 & 5 & 2 & 5 & 5 & 1 & 0 & 2 & 5 & 2 & 2 & 2 & 2 & 2 & 1 & 1 & 2 & 3 & 3 & \\
\hline $1,0 \mathrm{E}-114$ & 371 & & & & & & & & & 5 & 4 & 5 & 4 & 1 & 1 & 0 & 2 & 4 & 1 & 2 & 4 & 2 & 1 & 2 & 2 & 4 & 4 & 2 & \\
\hline - & - & $1,00 \mathrm{E}-03$ & 50 & $9,00 \mathrm{E}-05$ & 52 & & & & & 6 & 4 & 1 & 5 & 1 & 0 & 1 & 1 & 5 & 1 & 1 & 0 & 0 & 4 & 0 & 5 & 4 & 5 & 5 & \\
\hline - & - & $2,00 \mathrm{E}-11$ & 76 & $2,00 \mathrm{E}-12$ & 78 & & & & & 6 & 4 & 1 & 5 & 3 & 0 & 1 & 1 & 5 & 1 & 0 & 1 & 1 & 1 & 1 & 2 & 3 & 4 & 6 & \\
\hline - & - & $8,00 \mathrm{E}-06$ & 56 & $3,00 \mathrm{E}-07$ & 60 & & & & & 6 & 4 & 3 & 3 & 2 & 0 & 1 & 2 & 4 & 3 & 1 & 0 & 0 & 1 & 2 & 2 & 2 & 3 & 2 & \\
\hline $3,3 \mathrm{E}+00$ & 33 & $7,60 \mathrm{E}-02$ & 44 & $4,00 \mathrm{E}-04$ & 50 & $\mid \begin{array}{c}\text { za } 40 \mathrm{~g} \\
12 . \mathrm{x} \\
196 \\
2 \mathrm{e}-49\end{array}$ & & & & 6 & 4 & 2 & 5 & 4 & 1 & 0 & 1 & 4 & 1 & 1 & 1 & 2 & 1 & 1 & 1 & 2 & 2 & 2 & \\
\hline - & - & $2,10 \mathrm{E}-02$ & 46 & 0.12 & 42 & \begin{tabular}{|c|} 
keine \\
signifik \\
ante \\
Homolo \\
gie
\end{tabular} & & & & 5 & 4 & 4 & 4 & 3 & 1 & 0 & 1 & 3 & 2 & 1 & 0 & 0 & 1 & 2 & 1 & 2 & 2 & 2 & \\
\hline - & - & $2,30 \mathrm{E}-02$ & 46 & 0.025 & 44 & \begin{tabular}{|c|} 
dab64 \\
g02.x1 \\
174 \\
$5 e-43$
\end{tabular} & \begin{tabular}{|c|c|} 
reffNP_012745.1| Lst4p \\
281.8
\end{tabular} & & & 5 & 4 & 3 & 4 & 4 & 0 & 0 & 0 & 4 & 0 & 0 & 0 & 1 & 1 & 1 & 1 & 3 & 2 & 2 & \\
\hline $6,2 \mathrm{E}+00$ & 32 & $7,80 \mathrm{E}-02$ & 44 & 0.009 & 46 & & & & & 6 & 1 & 2 & 2 & 1 & 0 & 1 & 1 & 4 & 2 & 1 & 1 & 5 & 1 & 0 & 1 & 2 & 2 & 1 & \\
\hline $3,0 \mathrm{E}-26$ & 119 & $3,10 \mathrm{E}-01$ & 42 & & & & & & & 6 & 2 & 0 & 5 & 0 & 1 & 1 & 1 & 3 & 1 & 1 & 1 & 1 & 1 & 1 & 2 & 3 & 2 & 2 & \\
\hline $2,0 \mathrm{E}-11$ & 70 & & & & & & & & & 5 & 5 & 1 & 3 & 3 & 0 & 0 & 1 & 2 & 0 & 1 & 0 & 0 & 1 & 1 & 1 & 2 & 2 & 2 & \\
\hline - & - & $7,60 \mathrm{E}-02$ & 44 & 0.10 & 42 & & & & & 5 & 3 & 1 & 3 & 0 & 0 & 0 & 0 & 1 & 0 & 1 & 0 & 0 & 1 & 0 & 2 & 1 & 2 & 1 & \\
\hline $3,0 \mathrm{E}-73$ & 275 & & & & & & & & & 1 & 1 & 0 & 1 & 1 & 0 & 5 & 1 & 5 & 0 & 1 & 2 & 1 & 1 & 1 & 1 & 1 & 1 & 1 & \\
\hline $4,0 \mathrm{E}-20$ & 99 & & & & & & & & & 4 & 3 & 3 & 2 & 1 & 0 & 5 & 1 & 2 & 1 & 1 & 1 & 1 & 1 & 1 & 1 & 2 & 2 & 1 & \\
\hline $3,7 \mathrm{E}+00$ & 33 & - & - & 0.034 & 44 & & \begin{tabular}{|c|} 
ref|NP_015064.1| \\
medium subunit of the \\
clathrin-associated ... \\
$28 \quad 1.5$
\end{tabular} & & & 2 & 4 & 1 & 2 & 1 & 0 & 0 & 1 & 5 & 1 & 1 & 2 & 2 & 6 & 1 & 2 & 4 & 1 & 1 & \\
\hline $1,0 \mathrm{E}-86$ & 320 & & & & & & & & & 1 & 0 & 0 & 6 & 0 & 0 & 0 & 6 & 0 & 0 & 1 & 0 & 6 & 0 & 0 & 1 & 0 & 1 & 0 & \\
\hline
\end{tabular}




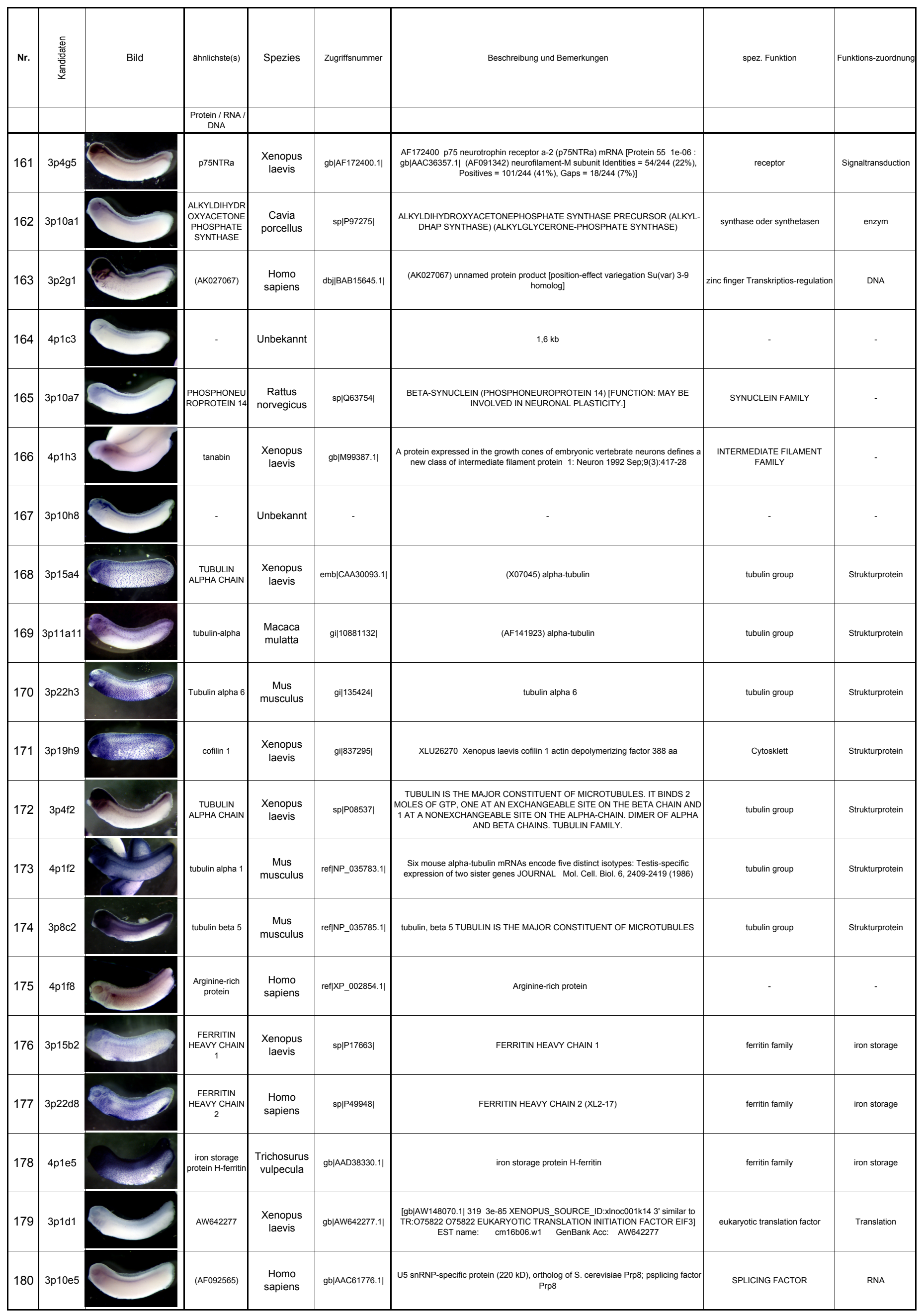




\begin{tabular}{|c|c|c|c|c|c|c|c|c|c|c|c|c|c|c|c|c|c|c|c|c|c|c|c|c|c|c|c|c|}
\hline Blast & & Blast & & Blast & & 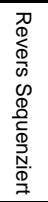 & $\begin{array}{c}\text { Yeast-Suche nach } \\
\text { maximaler Sequenz }\end{array}$ & Signaturen & 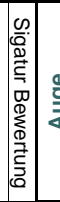 & बे & 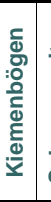 & 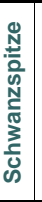 & 旁 & 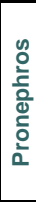 & 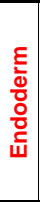 & 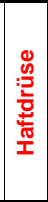 & 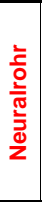 & \begin{tabular}{|l}
0 \\
0 \\
0 \\
$\frac{0}{0}$ \\
$\frac{0}{2}$ \\
ठ
\end{tabular} & 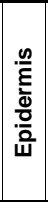 & 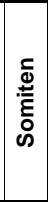 & $\begin{array}{l}\text { 후 } \\
\text { o } \\
0 \\
\text { o } \\
\text { z }\end{array}$ & $\mid \begin{array}{l}\mathbf{c} \\
\stackrel{\mathbf{d}}{\mathbf{d}} \\
\mathbf{e} \\
\mathbf{z}\end{array}$ & 涉 & 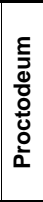 & 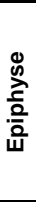 & 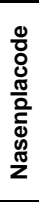 & & 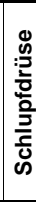 \\
\hline E-Value & Score & E-Value & Score & $\begin{array}{l}\text { e(bits)/E- } \\
\text { Value }\end{array}$ & Scor & & & & & $\mathrm{Au} \mathrm{K}$ & $\mathbf{K b} \mathbf{s}$ & Ss & $\mathrm{Hi}$ & $\mathrm{Pn}$ & En & $\mathrm{Ce}$ & $\mathrm{Nr}$ & Op & Ep & So & No & $\mathrm{Ne}$ & $\mathrm{He}$ & Pd & $\mathbf{P i}$ & $\mathrm{Np}$ & & $\mathrm{Ha}$ \\
\hline $3,0 \mathrm{E}-06$ & 53 & $9,00 \mathrm{E}-45$ & 186 & & & & & & & $6 \mid c$ & 0 & 1 & 6 & 1 & 1 & 0 & 6 & 5 & 1 & 1 & 0 & 6 & 1 & 0 & 1 & 5 & 4 & 6 \\
\hline $7,0 \mathrm{E}-69$ & 260 & & & & & & & & & $1 \mid 1$ & 1 & 0 & 1 & 0 & 0 & 1 & 6 & 1 & 1 & 1 & 1 & 6 & 1 & 0 & 1 & 1 & 3 & 1 \\
\hline $1,0 \mathrm{E}-53$ & 210 & & & & & & & & & $6 \mid 6$ & 6 & 0 & 6 & 0 & 0 & 0 & 6 & 6 & 0 & 1 & 1 & 6 & 5 & 0 & 2 & 6 & 6 & 6 \\
\hline- & - & $1,80 \mathrm{E}-02$ & 46 & 0.006 & 46 & & & & & $0 \mid c$ & 0 & 0 & 0 & 0 & 0 & 1 & 5 & 0 & 0 & 1 & 1 & 6 & 0 & 0 & 2 & 0 & 0 & 1 \\
\hline $2,0 E-37$ & 156 & & & & & & & & & $1 \mid 1$ & 1 & 0 & 1 & 0 & 0 & 0 & 6 & 1 & 1 & 1 & 1 & 6 & 1 & 0 & 1 & 1 & 5 & 1 \\
\hline $2,4 \mathrm{E}+00$ & 33 & $6,00 \mathrm{E}-18$ & 98 & 0.38 & 40 & & & & & $1 \mid 1$ & 1 & 0 & 5 & 0 & 3 & 0 & 5 & 0 & 1 & 1 & 0 & 6 & 1 & 1 & 1 & 1 & 1 & 1 \\
\hline- & - & $1,00 \mathrm{E}-06$ & 60 & $5,00 E-13$ & 80 & & & & & $1 \mid 1$ & 1 & 1 & 5 & 0 & 1 & 1 & 6 & 6 & 1 & 1 & 1 & 6 & 1 & 0 & 1 & 1 & 5 & 1 \\
\hline $4,0 \mathrm{E}-73$ & 274 & $1,00 \mathrm{E}-163$ & 581 & & & & & & & 52 & 2 & 0 & 3 & 1 & 0 & 0 & 4 & 3 & 4 & 1 & 1 & 1 & 1 & 1 & 2 & 3 & 1 & 1 \\
\hline $1,0 \mathrm{E}-132$ & 473 & & & & & & & & & 43 & 3 & 2 & 2 & 2 & 1 & 1 & 1 & 2 & 5 & 1 & 1 & 2 & 3 & 3 & 6 & 3 & 4 & 2 \\
\hline $1,0 \mathrm{E}-117$ & 421 & & & & & & & & & $2 \mid 4$ & 4 & 1 & 2 & 1 & 0 & 0 & 1 & 1 & 5 & 1 & 1 & 1 & 6 & 5 & 2 & 1 & 3 & 1 \\
\hline - & - & $0,00 \mathrm{E}+00$ & 771 & & & & & & & 62 & 2 & 0 & 5 & 1 & 0 & 0 & 1 & 4 & 5 & 1 & 1 & 2 & 3 & 4 & 3 & 2 & 3 & 3 \\
\hline $3,0 \mathrm{E}-70$ & 264 & & & & & & & & & $6 \mid 6$ & 6 & 1 & 6 & 2 & 0 & 1 & 6 & 6 & 1 & 1 & 1 & 6 & 5 & 0 & 6 & 6 & 6 & 6 \\
\hline $1,0 \mathrm{E}-109$ & 395 & & & & & & & & & $6 \quad 5$ & 5 & 6 & 6 & 6 & 1 & 0 & 6 & 6 & 3 & 1 & 1 & 0 & 5 & 0 & 6 & 6 & 6 & 6 \\
\hline $6,0 \mathrm{E}-43$ & 174 & & & & & & & & & 6 & 6 & 6 & 6 & 6 & 1 & 1 & 6 & 6 & 2 & 4 & 1 & 6 & 6 & 6 & 5 & 6 & 6 & 6 \\
\hline $1,0 \mathrm{E}-38$ & 160 & & & & & & & & & 32 & 2 & 2 & 1 & 5 & 2 & 0 & 3 & 3 & 4 & 1 & 0 & 0 & 1 & 2 & 2 & 5 & 3 & 6 \\
\hline $1,0 \mathrm{E}-97$ & 356 & & & & & & & & & \begin{tabular}{l|l}
2 & 1
\end{tabular} & 1 & 1 & 1 & 1 & 0 & 1 & 1 & 1 & 4 & 1 & 1 & 6 & 1 & 1 & 1 & 1 & 1 & 5 \\
\hline $3,0 \mathrm{E}-89$ & 328 & & & & & & & & & 32 & 2 & 1 & 1 & 1 & 2 & 3 & 1 & 2 & 3 & 1 & 1 & 1 & 1 & 6 & 1 & 1 & 2 & 5 \\
\hline $1,0 \mathrm{E}-65$ & 249 & & & & & & & & & \begin{tabular}{l|l}
6 & 6
\end{tabular} & 6 & 6 & 6 & 6 & 0 & 6 & 6 & 6 & 5 & 1 & 6 & 0 & 6 & 6 & 6 & 6 & 6 & 6 \\
\hline $7,7 \mathrm{E}+00$ & 31 & $7,00 \mathrm{E}-01$ & 40 & e-126 & 454 & & & & & \begin{tabular}{l|l}
2 & 1
\end{tabular} & 1 & 2 & 2 & 0 & 0 & 0 & 1 & 0 & 1 & 1 & 2 & 0 & 1 & 2 & 1 & 1 & 1 & 1 \\
\hline 1,0E-114 & 410 & & & & & & & & & \begin{tabular}{l|l}
3 & 2 \\
\end{tabular} & 2 & 1 & 2 & 1 & 1 & 1 & 1 & 2 & 1 & 1 & 5 & 1 & 1 & 0 & 1 & 2 & 2 & 1 \\
\hline
\end{tabular}




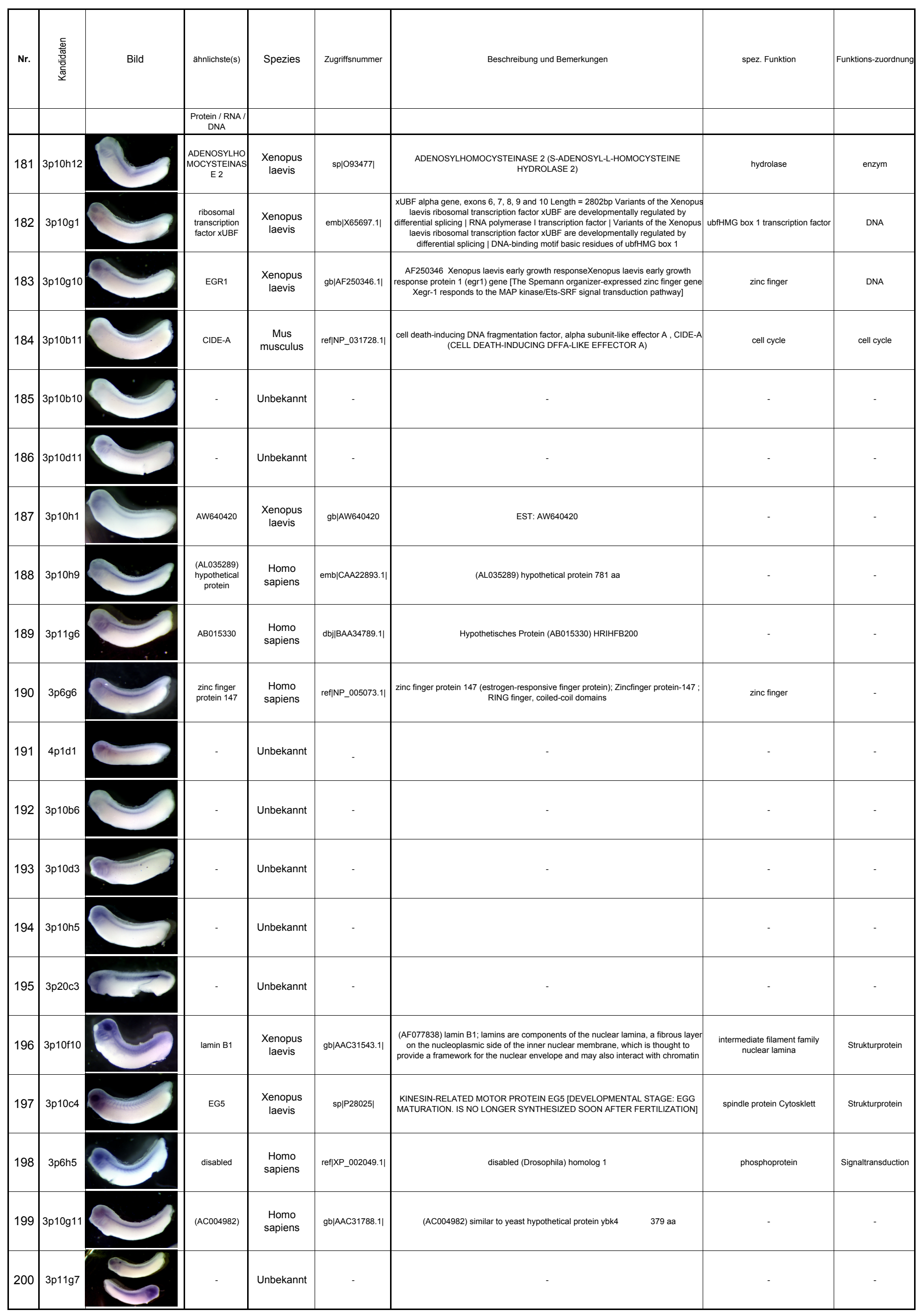




\begin{tabular}{|c|c|c|c|c|c|c|c|c|c|c|c|c|c|c|c|c|c|c|c|c|c|c|c|c|c|c|c|c|}
\hline Blast & & Blas & & Blast & & 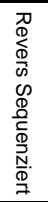 & $\begin{array}{c}\text { Yeast-Suche nach } \\
\text { maximaler Sequenz }\end{array}$ & Signaturen & 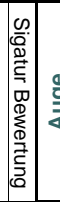 & बे & 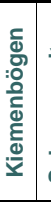 & 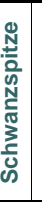 & 产 & 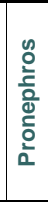 & 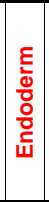 & 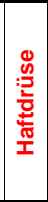 & 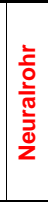 & 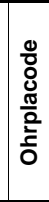 & 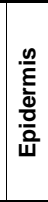 & 离 & 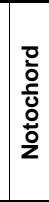 & 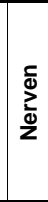 & & 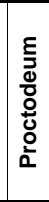 & 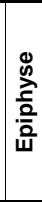 & 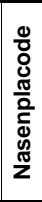 & & 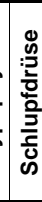 \\
\hline E-Value & Score & E-Value & Score & $\begin{array}{l}\text { e(bits)/E- } \\
\text { Value }\end{array}$ & Scor & & & & & $\mathrm{Au} K$ & $\mathbf{K b} s$ & Ss & $\mathrm{Hi}$ & Pn & En & $\mathrm{Ce}$ & $\mathrm{Nr}$ & Op & Ep & So & No & $\mathrm{Ne}$ & $\mathrm{He}$ & $\mathrm{Pd}$ & $\mathbf{P i}$ & Np & & $\mathrm{Ha}$ \\
\hline $1,0 \mathrm{E}-113$ & 406 & & & & & & & & & 12 & 2 & 1 & 1 & 1 & 1 & 1 & 1 & 1 & 1 & 1 & 5 & 1 & 1 & 0 & 1 & 1 & 1 & 1 \\
\hline- & - & $9,00 \mathrm{E}-85$ & 319 & & & & & & & 2 & 2 & 1 & 2 & 2 & 1 & 1 & 1 & 4 & 1 & 1 & 5 & 1 & 1 & 0 & 1 & 2 & 2 & 1 \\
\hline - & - & $0,00 E+00$ & 1106 & & & & & & & 2 & 2 & 1 & 1 & 1 & 1 & 1 & 1 & 4 & 1 & 1 & 5 & 1 & 1 & 0 & 1 & 2 & 2 & 1 \\
\hline $6,0 \mathrm{E}-48$ & 191 & & & & & & & & & $0 \mid c$ & 0 & 0 & 0 & 0 & 1 & 0 & 1 & 0 & 1 & 0 & 5 & 1 & 1 & 0 & 1 & 0 & 0 & 0 \\
\hline $3,4 \mathrm{E}+00$ & 33 & $3,10 \mathrm{E}-01$ & 42 & 0.027 & 44 & & & & & $0 \mid c$ & 0 & 1 & 0 & 0 & 0 & 0 & 1 & 0 & 1 & 0 & 5 & 1 & 1 & 0 & 0 & 0 & 0 & 1 \\
\hline $3,3 \mathrm{E}-01$ & 36 & $2,00 \mathrm{E}-14$ & 86 & $3,00 \mathrm{E}-27$ & 127 & & & & & 2 & 2 & 1 & 1 & 1 & 1 & 1 & 1 & 5 & 1 & 1 & 5 & 1 & 1 & 0 & 1 & 1 & 1 & 1 \\
\hline $4,7 \mathrm{E}+00$ & 32 & $2,00 \mathrm{E}-02$ & 46 & e-153 & 545 & & & & & 2 & 2 & 1 & 1 & 1 & 1 & 1 & 1 & 1 & 1 & 1 & 5 & 1 & 1 & 1 & 1 & 2 & 1 & 1 \\
\hline $9,0 \mathrm{E}-18$ & 91 & $3,69 \mathrm{E}+04$ & 40 & & & & & & & \begin{tabular}{l|l}
1 & 1
\end{tabular} & 1 & 1 & 1 & 1 & 0 & 1 & 1 & 1 & 1 & 1 & 6 & 1 & 1 & 0 & 3 & 1 & 1 & 1 \\
\hline $5,0 \mathrm{E}-05$ & 49 & & & & & & & & & 23 & 3 & 1 & 2 & 1 & 1 & 1 & 1 & 2 & 1 & 2 & 6 & 3 & 1 & 0 & 1 & 2 & 2 & 1 \\
\hline $2,0 \mathrm{E}-26$ & 120 & & & & & & & & & \begin{tabular}{l|l}
2 & 1
\end{tabular} & 1 & 1 & 1 & 0 & 1 & 1 & 1 & 1 & 1 & 1 & 5 & 1 & 0 & 0 & 1 & 1 & 1 & 1 \\
\hline $4,0 E+00$ & 32 & $2,80 \mathrm{E}-01$ & 42 & 0.095 & 42 & & & & & 42 & 2 & 0 & 1 & 2 & 0 & 0 & 1 & 2 & 1 & 1 & 2 & 0 & 1 & 1 & 1 & 1 & 1 & 1 \\
\hline $8,0 E+00$ & 32 & $7,90 \mathrm{E}-02$ & 44 & 0.58 & 40 & & & & & \begin{tabular}{l|l}
0 & 1
\end{tabular} & 1 & 0 & 1 & 0 & 0 & 0 & 1 & 1 & 1 & 0 & 5 & 1 & 1 & 0 & 1 & 1 & 1 & 1 \\
\hline - & - & $3,69 \mathrm{E}+04$ & 40 & 0.14 & 42 & & & & & 2 & 2 & 1 & 2 & 1 & 1 & 0 & 1 & 5 & 1 & 1 & 5 & 1 & 1 & 0 & 1 & 2 & 1 & 1 \\
\hline $2,1 \mathrm{E}+00$ & 33 & $3,10 \mathrm{E}-01$ & 42 & 0.42 & 40 & & & & & 2 & 2 & 1 & 2 & 0 & 1 & 1 & 1 & 2 & 1 & 1 & 5 & 1 & 1 & 0 & 1 & 2 & 1 & 1 \\
\hline- & - & $3,80 \mathrm{E}-01$ & 42 & 0.25 & 36 & & & & & \begin{tabular}{l|l}
1 & 1
\end{tabular} & 1 & 0 & 2 & 1 & 0 & 1 & 1 & 2 & 0 & 0 & 6 & 1 & 1 & 0 & 1 & 1 & 1 & 1 \\
\hline $2,0 \mathrm{E}-56$ & 219 & $0,00 E+00$ & 1168 & & & & & & & 63 & 3 & 2 & 3 & 2 & 1 & 0 & 2 & 3 & 1 & 2 & 5 & 2 & 0 & 1 & 2 & 3 & 3 & 2 \\
\hline $7,0 \mathrm{E}-99$ & 360 & & & & & & & & & $6 \mid 4$ & 4 & 2 & 4 & 2 & 1 & 1 & 1 & 4 & 1 & 2 & 5 & 1 & 1 & 0 & 1 & 2 & 3 & 3 \\
\hline $4,0 \mathrm{E}-68$ & 258 & & & & & & & & & 43 & 3 & 1 & 2 & 1 & 0 & 1 & 2 & 4 & 0 & 2 & 5 & 2 & 0 & 0 & 2 & 4 & 3 & 1 \\
\hline $4,0 E-78$ & 291 & & & & & & & & & 32 & 2 & 1 & 2 & 1 & 1 & 1 & 1 & 2 & 1 & 1 & 6 & 1 & 1 & 0 & 2 & 2 & 2 & 1 \\
\hline $5,6 \mathrm{E}-01$ & 35 & $7,90 \mathrm{E}-02$ & 44 & 0.54 & 40 & & & & & $5 \mid 3$ & 3 & 1 & 4 & 0 & 1 & 1 & 1 & 6 & 1 & 3 & 6 & 5 & 1 & 0 & 1 & 2 & 2 & 2 \\
\hline
\end{tabular}




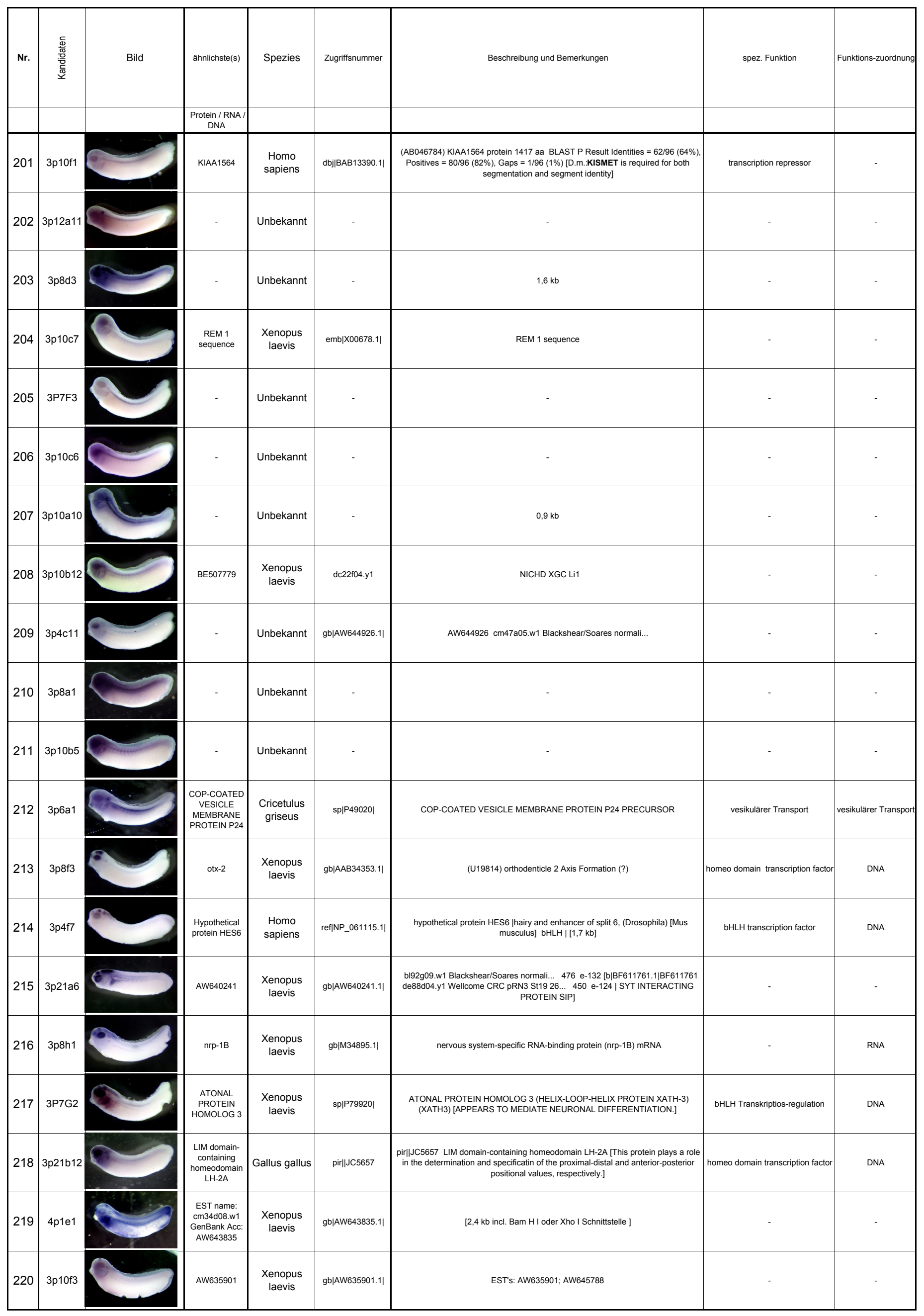




\begin{tabular}{|c|c|c|c|c|c|c|c|c|c|c|c|c|c|c|c|c|c|c|c|c|c|c|c|c|c|c|c|c|c|c|}
\hline Blas & & Blas & & Blast $\mathrm{E}$ & & 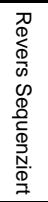 & $\begin{array}{c}\text { Yeast-Suche nach } \\
\text { maximaler Sequenz }\end{array}$ & Signaturen & 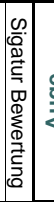 & $\begin{array}{l}\stackrel{Ð}{\Xi} \\
\stackrel{\Xi}{\varangle}\end{array}$ & 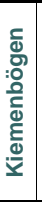 & 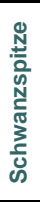 & 롣 & 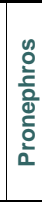 & 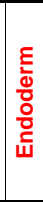 & 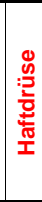 & 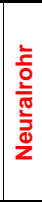 & 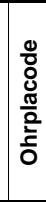 & 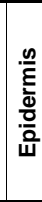 & & & & $\stackrel{\mathbf{D}}{\mathbf{D}}_{\mathbf{d}}^{\mathbf{d}}$ & $\frac{\mathbf{N}}{\mathbf{\Phi}}$ & 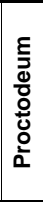 & 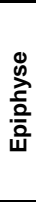 & 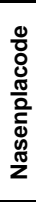 & & 总 & \\
\hline E-Value & Score & E-Value & Score & $\begin{array}{l}\text { e(bits)/E- } \\
\text { Value- }\end{array}$ & Scor & & & & & $\mathrm{Au}$ & $\mathbf{K b}$ & Ss & $\mathrm{Hi}$ & Pn & En & $\mathrm{Ce}$ & $\mathrm{Nr}$ & $O p$ & $E p$ & Sc & $\mathrm{ON}$ & Jo 1 & $\mathrm{Ne}$ & $\mathrm{He}$ & Pd & $\overrightarrow{P i}$ & $\mathrm{~Np}$ & & $\mathrm{He}$ & \\
\hline $3,0 \mathrm{E}-27$ & 122 & $5,00 \mathrm{E}-03$ & 48 & $1,00 \mathrm{E}-04$ & 52 & & \begin{tabular}{|c|} 
reff|NP_014948.1| \\
ATPase component of a \\
two subunit chromatin \\
rem... $1442 \mathrm{e}-34$
\end{tabular} & & & 4 & 4 & 1 & 1 & 1 & 1 & 1 & 1 & 1 & 1 & 1 & 5 & 5 & 1 & 1 & 0 & 2 & 2 & 1 & 2 & \\
\hline $6,2 \mathrm{E}+00$ & 32 & $2,00 \mathrm{E}-08$ & 66 & 0.14 & 42 & & & & & 4 & 4 & 0 & 3 & 1 & 1 & 1 & 1 & 6 & 1 & 1 & 5 & 5 & 3 & 1 & 0 & 1 & 2 & 2 & 2 & \\
\hline $5,6 \mathrm{E}+00$ & 32 & $3,69 E+04$ & 40 & 0.002 & 48 & & $\begin{array}{c}\text { emb|CAB57250.1] } \\
\text { (AJ270223) putative } \\
\text { ubiquititn carrier [Ento... } \\
400.094\end{array}$ & & & 6 & 6 & 1 & 6 & 6 & 1 & 1 & 2 & 6 & 1 & 2 & 5 & 5 & 2 & 4 & 0 & 6 & 5 & 6 & 6 & \\
\hline $7,7 \mathrm{E}+00$ & 32 & $1,00 E-31$ & 143 & & & & & & & 5 & 3 & 0 & 2 & 1 & 1 & 1 & 1 & 3 & 1 & 1 & 5 & 5 & 1 & 1 & 0 & 2 & 3 & 2 & 1 & \\
\hline $2,8 \mathrm{E}+00$ & 33 & $3,10 \mathrm{E}-01$ & 42 & $1,70 \mathrm{E}+00$ & 38 & & & & & 2 & 1 & 0 & 1 & 0 & 0 & 0 & 0 & 1 & 0 & 1 & 6 & 6 & 0 & 0 & 0 & 0 & 1 & 1 & 1 & \\
\hline - & - & $3,00 \mathrm{E}-10$ & 72 & $8,00 \mathrm{E}-25$ & 119 & & & & & 5 & 2 & 0 & 2 & 1 & 0 & 1 & 1 & 2 & 1 & 1 & 6 & 6 & 1 & 1 & 0 & 1 & 2 & 2 & 2 & \\
\hline - & - & $3,00 E-10$ & 72 & 0.11 & 42 & & & & & 5 & 4 & 1 & 4 & 1 & 1 & 1 & 2 & 4 & 0 & 2 & 6 & 6 & 2 & 1 & 0 & 2 & 2 & 2 & 2 & \\
\hline $4,3 \mathrm{E}-01$ & 36 & $7,90 \mathrm{E}-02$ & 44 & $e-168$ & 595 & & & & & 5 & 4 & 1 & 2 & 1 & 1 & 1 & 1 & 3 & 1 & 2 & 5 & 5 & 1 & 1 & 0 & 1 & 4 & 1 & 1 & \\
\hline $2,1 \mathrm{E}+00$ & 34 & $2,00 \mathrm{E}-08$ & 66 & $1,00 \mathrm{E}-150$ & 531 & & & & & 5 & 2 & 0 & 1 & 0 & 0 & 0 & 0 & 1 & 0 & 1 & 4 & 4 & 0 & 1 & 0 & 2 & 1 & 1 & 1 & \\
\hline - & - & $5,30 \mathrm{E}-01$ & 40 & $3,70 \mathrm{E}+04$ & 38 & & & & & 6 & 4 & 1 & 6 & 3 & 1 & 1 & 1 & 6 & 1 & 2 & & 5 & 3 & 2 & 0 & 5 & 6 & 6 & 4 & \\
\hline $6,2 \mathrm{E}+00$ & 32 & $5,00 \mathrm{E}-03$ & 48 & $4,00 \mathrm{E}-48$ & 196 & & & & & 6 & 5 & 3 & 6 & 2 & 1 & 1 & 2 & 4 & 1 & 3 & & 5 & 1 & 1 & 0 & 2 & 6 & 6 & 4 & \\
\hline $2,0 \mathrm{E}-83$ & 309 & & & & & & & & & 2 & 2 & 0 & 2 & 5 & 0 & 5 & 1 & 4 & 0 & 2 & & 6 & 2 & 1 & 0 & 2 & 3 & 1 & 1 & \\
\hline $8,0 \mathrm{E}-09$ & 61 & $1,00 \mathrm{E}-157$ & 559 & & & & & & & 6 & 0 & 0 & 6 & 0 & 0 & 0 & 0 & 1 & 0 & 0 & & 1 & 0 & 0 & 0 & 6 & 1 & 1 & 1 & \\
\hline $3,0 \mathrm{E}-45$ & 182 & & & & & & & & & 4 & 0 & 3 & 5 & 0 & 0 & 0 & 0 & 0 & 0 & 1 & & 0 & 0 & 0 & 0 & 5 & 0 & 1 & 1 & \\
\hline - & - & $3,60 \mathrm{E}-01$ & 42 & e-132 & 476 & & & & & 6 & 1 & 0 & 6 & 3 & 0 & 0 & 2 & 1 & 0 & 1 & & 2 & 1 & 1 & 0 & 6 & 0 & 1 & 0 & \\
\hline $2,0 \mathrm{E}-05$ & 50 & $1,00 \mathrm{E}-145$ & 521 & & & & & & & 6 & 0 & 1 & 3 & 0 & 0 & 0 & 4 & 5 & 1 & 0 & & 1 & 1 & 1 & 1 & 6 & 2 & 2 & 1 & \\
\hline $2,0 \mathrm{E}-75$ & 283 & & & & & & & & & 6 & 5 & 0 & 5 & 5 & 0 & 0 & 0 & 5 & 0 & 1 & & 5 & 1 & 6 & 0 & 6 & 5 & 5 & 5 & \\
\hline $6,0 \mathrm{E}-31$ & 135 & $5,00 \mathrm{E}-37$ & 161 & & & & & & & 6 & 4 & 0 & 5 & 1 & 0 & 1 & 1 & 4 & 0 & 1 & & 2 & 1 & 2 & 0 & 6 & 2 & 5 & 5 & \\
\hline $4,3 \mathrm{E}+00$ & 32 & $1,00 \mathrm{E}-03$ & 50 & 0.0 & 708 & & & & & 2 & 5 & 6 & 4 & 3 & 0 & 0 & 3 & 2 & 4 & 1 & & 0 & 0 & 5 & 3 & 1 & 1 & 6 & 1 & \\
\hline $8,6 \mathrm{E}-02$ & 38 & $3,10 \mathrm{E}-01$ & 42 & 0.0 & 965 & & & & & 3 & 3 & 1 & 2 & 0 & 1 & 1 & 1 & 4 & 1 & 1 & & 1 & 1 & 1 & 0 & 6 & 2 & 2 & 1 & \\
\hline
\end{tabular}




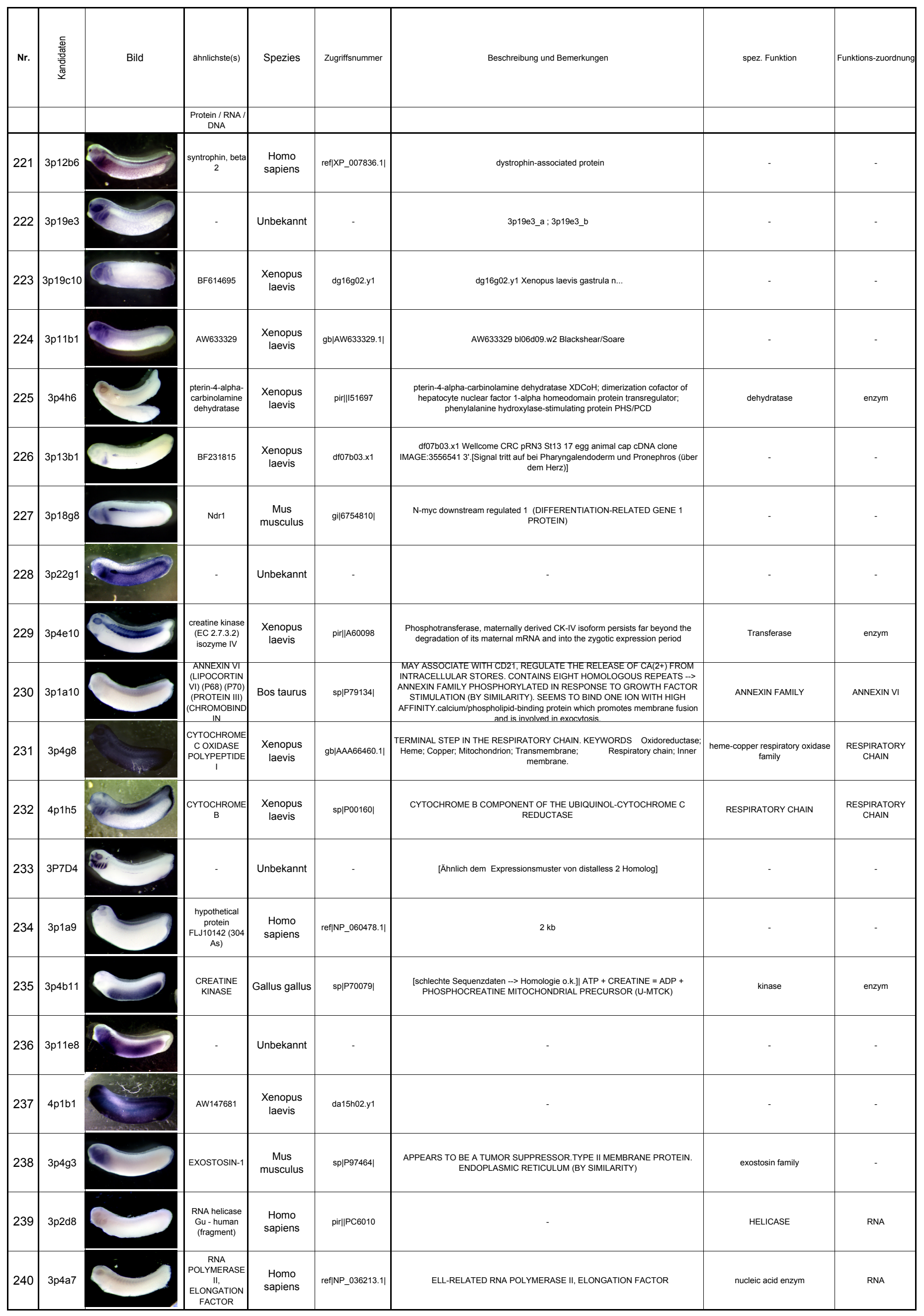




\begin{tabular}{|c|c|c|c|c|c|c|c|c|c|c|c|c|c|c|c|c|c|c|c|c|c|c|c|c|c|c|c|c|c|}
\hline Blas & & Blas & & Blast & & 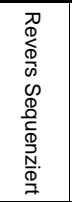 & $\begin{array}{c}\text { Yeast-Suche nach } \\
\text { maximaler Sequenz }\end{array}$ & Signaturen & 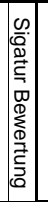 & $\begin{array}{l}\stackrel{Ð}{\Xi} \\
\stackrel{\Xi}{\varangle}\end{array}$ & 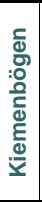 & 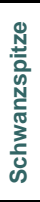 & 咅 & 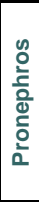 & 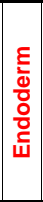 & 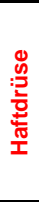 & 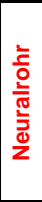 & 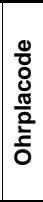 & 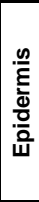 & 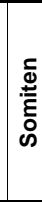 & & 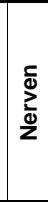 & & 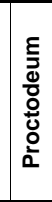 & 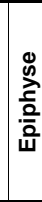 & 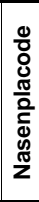 & & & \\
\hline E-Value & Score & E-Value & Score & $\begin{array}{l}\text { e(bits)/E- } \\
\text { Value }\end{array}$ & Scor & & & & & $\mathrm{Au}$ & $\mathbf{K b}$ & Ss & $\mathrm{Hi}$ & $\mathrm{Pn}$ & En & $\mathrm{Ce}$ & $\mathrm{Nr}$ & Op & Ep & So & No & $\mathrm{Ne}$ & $\mathrm{He}$ & $\mathrm{Pd}$ & $\mathrm{Pi}$ & $\mathrm{Np}$ & & $\mathrm{y} \mathrm{He}$ & \\
\hline $1,0 \mathrm{E}-48$ & 193 & & & & & & & & & 2 & 6 & 4 & 2 & 4 & 1 & 0 & 6 & 5 & 5 & 1 & 2 & 4 & 6 & 1 & 0 & 2 & 6 & 1 & \\
\hline - & - & $8,90 \mathrm{E}-02$ & 44 & 0.22 & 36 & & & & & 6 & 5 & 5 & 2 & 2 & 1 & 0 & 2 & 4 & 1 & 1 & 2 & 5 & 2 & 2 & 2 & 2 & 6 & 2 & \\
\hline $3,3 E+00$ & 33 & $2,30 \mathrm{E}-02$ & 46 & $e-136$ & 490 & & & & & 5 & 4 & 5 & 3 & 3 & 0 & 0 & 0 & 2 & 1 & 1 & 1 & 1 & 1 & 2 & 2 & 2 & 1 & 3 & \\
\hline - & - & $7,90 \mathrm{E}-02$ & 44 & 0.0 & 1120 & & & & & 5 & 4 & 1 & 3 & 1 & 1 & 1 & 1 & 5 & 1 & 1 & 2 & 3 & 1 & 2 & 1 & 3 & 5 & 1 & \\
\hline $3,0 \mathrm{E}-37$ & 155 & & & & & & & & & 5 & 0 & 0 & 3 & 6 & 0 & 0 & 0 & 0 & 0 & 1 & 0 & 4 & 0 & 0 & 0 & 0 & 2 & 1 & \\
\hline 2,0E-09 & 64 & $3,40 \mathrm{E}-01$ & 42 & $2,00 E-96$ & 357 & & & & & 0 & 0 & 0 & 0 & 6 & 0 & 0 & 0 & 0 & 0 & 0 & 1 & 0 & 6 & 0 & 0 & 0 & 1 & 0 & \\
\hline $7,0 \mathrm{E}-92$ & 337 & $3,00 \mathrm{E}-23$ & 115 & & & & & & & 1 & 3 & 0 & 1 & 6 & 0 & 1 & 1 & 1 & 0 & 1 & 4 & 1 & 3 & 0 & 1 & 1 & 1 & 1 & \\
\hline - & - & $3,70 \mathrm{E}+04$ & 40 & 0.019 & 40 & & & & & 2 & 6 & 1 & 0 & 6 & 1 & 0 & 1 & 1 & 2 & 1 & 1 & 1 & 6 & 2 & 1 & 1 & 1 & 1 & \\
\hline 2,0E-99 & 362 & & & & & & & & & 5 & 0 & 0 & 2 & 1 & 0 & 4 & 1 & 2 & 0 & 6 & 5 & 0 & 5 & 0 & 0 & 0 & 2 & 1 & \\
\hline $5,0 \mathrm{E}-44$ & 177 & & & & & & & & & 0 & 0 & 0 & 1 & 0 & 0 & 0 & 2 & 0 & 0 & 1 & 1 & 0 & 0 & 0 & 0 & 0 & 1 & 1 & \\
\hline $2,0 \mathrm{E}-56$ & 219 & & & & & & & & & 6 & 6 & 6 & 6 & 6 & 0 & 4 & 6 & 6 & 6 & 1 & 6 & 0 & 6 & 6 & 6 & 6 & 6 & 6 & \\
\hline $1,0 \mathrm{E}-102$ & 370 & & & & & & & & & 2 & 5 & 5 & 2 & 3 & 1 & 0 & 3 & 1 & 3 & 1 & 0 & 0 & 1 & 6 & 2 & 1 & 2 & 4 & \\
\hline - & - & $2,40 \mathrm{E}-02$ & 46 & 0.11 & 42 & & & & & 5 & 6 & 0 & 0 & 0 & 0 & 0 & 0 & 6 & 0 & 1 & 1 & 1 & 0 & 0 & 0 & 6 & 5 & 4 & \\
\hline $6,0 \mathrm{E}-41$ & 167 & $1,40 \mathrm{E}-02$ & 46 & & & & & & & 0 & 0 & 0 & 1 & 0 & 0 & 0 & 1 & 0 & 0 & 1 & 0 & 2 & 0 & 0 & 2 & 0 & 6 & 1 & \\
\hline $2,0 \mathrm{E}-14$ & 79 & & & & & & & & & 0 & 0 & 0 & 0 & 0 & 6 & 0 & 0 & 0 & 0 & 1 & 0 & 0 & 0 & 0 & 0 & 0 & 0 & 0 & \\
\hline $3,2 \mathrm{E}+00$ & 33 & $7,40 \mathrm{E}-01$ & 40 & $1,90 \mathrm{E}+00$ & 38 & & & & & 2 & 6 & 0 & 2 & 6 & 6 & 0 & 1 & 5 & 0 & 1 & 0 & 0 & 6 & 0 & 0 & 2 & 1 & 1 & \\
\hline - & - & $3,00 \mathrm{E}-01$ & 42 & e-160 & 567 & $\begin{array}{c}\text { da } 15 \mathrm{~h} \\
02 . x 1 \\
971 \\
0.0\end{array}$ & & & & 6 & 6 & 6 & 6 & 5 & 3 & 2 & 2 & 6 & 5 & 1 & 6 & 0 & 6 & 6 & 6 & 6 & 6 & 6 & \\
\hline $4,0 \mathrm{E}-29$ & 127 & & & & & & & & & 6 & 6 & 2 & 5 & 3 & 0 & 0 & 0 & 3 & 0 & 1 & 0 & 0 & 1 & 1 & 0 & 4 & 3 & 3 & \\
\hline $9,0 \mathrm{E}-21$ & 100 & & & & & & & & & 3 & 3 & 1 & 1 & 0 & 0 & 0 & 0 & 1 & 0 & 1 & 0 & 0 & 1 & 1 & 0 & 1 & 1 & 1 & \\
\hline $6,0 \mathrm{E}-23$ & 106 & & & & & & & & & 2 & 0 & 0 & 1 & 0 & 0 & 0 & 0 & 0 & 0 & 1 & 0 & 0 & 0 & 0 & 0 & 0 & 1 & 1 & \\
\hline
\end{tabular}




\begin{tabular}{|c|c|c|c|c|c|c|c|c|}
\hline Nr. & 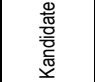 & Bild & ähnlichste(s) & Spezies & Zugriffsnummer & Beschreibung und Bemerkungen & spez. Funktion & Funktions-zuordnung \\
\hline & & & $\begin{array}{c}\text { Protein / RNA / } \\
\text { DNA }\end{array}$ & & & & & \\
\hline 241 & 3p9e7 & & $\begin{array}{c}\text { NADH } \\
\text { dehydrogenase } \\
\text { subunit } 5\end{array}$ & $\begin{array}{l}\text { Xenopus } \\
\text { laevis }\end{array}$ & ref|NP_008144.1| & ND5_10422 NADH dehydrogenase subunit 5 & dehydrogenase & enzym \\
\hline 242 & 3p9b11 & & $\begin{array}{c}\text { NADH } \\
\text { dehydrogenase }\end{array}$ & $\begin{array}{l}\text { Homo } \\
\text { sapiens }\end{array}$ & reff|NP_004997.1| & NADH dehydrogenase (ubiquinone) Fe-S protein & dehydrogenase & enzym \\
\hline 243 & $3 p 4 f 5$ & & \begin{tabular}{|c|} 
transcription \\
elongation factor \\
TFIIS
\end{tabular} & $\begin{array}{l}\text { Xenopus } \\
\text { laevis }\end{array}$ & emb|X97660.1| & XTFIIS. oA gene, exon 3 & zinc finger transcription factor & DNA \\
\hline 244 & $3 \mathrm{p} 10 \mathrm{e} 4$ & & $\begin{array}{l}\text { TXz.1 } \\
\text { transposase } \\
\text { pseudogene }\end{array}$ & $\begin{array}{c}\text { Pleuronectes } \\
\text { platessa }\end{array}$ & $\mathrm{gb}|\mathrm{U} 43659.1|$ & $\begin{array}{c}\text { [transposase emb|CAB51372.1| Schwacher Match zieht sich durch die ganze } \\
\text { Famielie] [gb|U43659.1|XLU43659 Xenopus laevis transposon TXz.1 transposase } \\
\text { pseudogene] }\end{array}$ & Transposase & DNA \\
\hline 245 & $3 p 4 b 12$ & & $\begin{array}{l}\text { HOMEOBOX } \\
\text { PROTEIN } \\
\text { SMOX-3 }\end{array}$ & $\begin{array}{c}\text { Schistosoma } \\
\text { mansoni }\end{array}$ & $\mathrm{sp}|\mathrm{Q} 26602|$ & $\begin{array}{c}\text { Match über die Homeobox (S.C. Homeobox-domain containing transcription fractor) } \\
==>\text { Homeobox mit strengstem Consensus zu Helix (3)/4 Consensus von } \\
\text { Homeobox Genen [3kb] }\end{array}$ & homeo domain transcription factor & DNA \\
\hline 246 & $4 \mathrm{p} 1 \mathrm{f5}$ & & $\begin{array}{c}\text { heterochromatin } \\
\text { protein } 1 \\
\text { gamma }\end{array}$ & $\begin{array}{l}\text { Xenopus } \\
\text { laevis }\end{array}$ & gb|AAC60299.1| & $\begin{array}{l}\text { TITLE Association of the origin recognition complex with heterochromatin and HP1 in } \\
\text { higher eukaryotes Cell } 91(3), 311-323(1997)\end{array}$ & Chromatin & Chromatin \\
\hline 247 & $3 p 1 e 6$ & & AW645913 & $\begin{array}{l}\text { Xenopus } \\
\text { laevis }\end{array}$ & cm58g11.w1 & {$[2 \mathrm{~kb}]$} & - & - \\
\hline 248 & $3 p 13 g 10$ & & - & Unbekannt & - & - & - & - \\
\hline 249 & $4 \mathrm{p} 1 \mathrm{b3}$ & & AW636607 & $\begin{array}{l}\text { Xenopus } \\
\text { laevis }\end{array}$ & gb|AW636607.1| & \begin{tabular}{|c|} 
bl48f10.w1 | Frame in guter Qualität |1.) Identities $=41 / 184(22 \%)$, Positives $=$ \\
$78 / 184(42 \%)$, Gaps $=10 / 184(5 \%)|| 2$.$) Identities =31 / 131(23 \%)$, Positives $=59 / 131$ \\
(44\%)||||3.)D-Titin [Drosophila melanogaster] Protein 2 Mda
\end{tabular} & - & - \\
\hline 250 & 3P7A12 & & AW640142 & $\begin{array}{l}\text { Xenopus } \\
\text { laevis }\end{array}$ & AW640142 & AW640142 bl91g07.w1 EST's & - & - \\
\hline 251 & 3P7A4 & & - & Unbekannt & - & - & - & - \\
\hline 252 & 3p1b3 & & FLJ00069 & $\begin{array}{l}\text { Homo } \\
\text { sapiens }\end{array}$ & dbj|BAB15766.1| & (AK024476) FLJ00069 protein & - & - \\
\hline 253 & $3 \mathrm{p} 4 \mathrm{e} 12$ & & - & Unbekannt & - & $\begin{array}{l}\text { [schlechte Sequenz evtl gb|U81291.1] oviductin mRNA, the X.I. oviductal protease } \\
\text { that processes egg envelope glycoprotein gp } 43 \text {, increases sperm binding to } \\
\text { envelopes and is translated as part of an unusual mosaic protein composed of two } \\
\text { protease and several CUB domains }\end{array}$ & - & - \\
\hline
\end{tabular}




\begin{tabular}{|c|c|c|c|c|c|c|c|c|c|c|c|c|c|c|c|c|c|c|c|c|c|c|c|c|c|c|c|c|}
\hline Blast & & Blas & & Blast & & 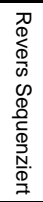 & $\begin{array}{c}\text { Yeast-Suche nach } \\
\text { maximaler Sequenz }\end{array}$ & Signaturen & 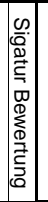 & $\underset{\stackrel{Ð}{\rightleftarrows}}{\stackrel{\Xi}{\rightleftarrows}}$ & 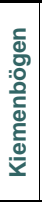 & 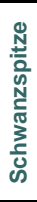 & 点 & 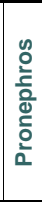 & 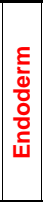 & 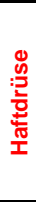 & 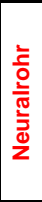 & $\begin{array}{l}\frac{0}{0} \\
0 \\
\frac{0}{0} \\
\frac{0}{2} \\
\text { t }\end{array}$ & 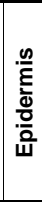 & 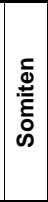 & 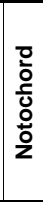 & \begin{tabular}{|l|}
$\mathbf{c}$ \\
$\mathbf{d}$ \\
$\mathbf{d}$ \\
$\mathbf{z}$
\end{tabular} & $\frac{\mathrm{N}}{\mathrm{N}}$ & 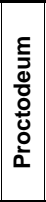 & 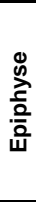 & 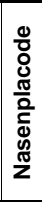 & 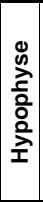 & 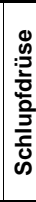 \\
\hline E-Value & Score & E-Value & Score & $\begin{array}{l}\text { e(bits)/E- } \\
\text { Value }\end{array}$ & Scor & & & & & $\mathrm{Au}$ & $\mathbf{K b}$ & Ss & $\mathrm{Hi}$ & Pn & En & $\mathrm{Ce}$ & $\mathrm{Nr}$ & Op & Ep & So & No & $\mathrm{Ne}$ & $\mathrm{He}$ & $\mathbf{P d}$ & $\mathbf{P i}$ & Np & & $\mathrm{Ha}$ \\
\hline $4,0 E-88$ & 325 & & & & & & & & & 5 & 0 & 0 & 1 & 0 & 0 & 0 & 1 & 1 & 1 & 1 & 0 & 1 & 1 & 1 & 1 & 2 & 2 & 1 \\
\hline $1,0 \mathrm{E}-85$ & 317 & & & & & & & & & 4 & 4 & 2 & 4 & 1 & 2 & 0 & 2 & 4 & 3 & 1 & 2 & 2 & 4 & 3 & 0 & 5 & 4 & 4 \\
\hline - & - & $1,00 \mathrm{E}-34$ & 153 & & & & & & & 5 & 3 & 0 & 3 & 0 & 0 & 0 & 0 & 1 & 0 & 1 & 0 & 0 & 2 & 0 & 2 & 2 & 3 & 1 \\
\hline $2,5 \mathrm{E}-01$ & 37 & $1,00 \mathrm{E}-74$ & 285 & & & & & & & 4 & 3 & 2 & 3 & 1 & 1 & 1 & 1 & 2 & 2 & 2 & 5 & 1 & 1 & 1 & 2 & 3 & 3 & 2 \\
\hline $7,6 \mathrm{E}-02$ & 38 & $7,50 \mathrm{E}-02$ & 44 & 0.099 & 42 & & & & & 2 & 1 & 0 & 1 & 0 & 0 & 0 & 0 & 0 & 0 & 1 & 1 & 0 & 1 & 0 & 1 & 1 & 0 & 1 \\
\hline $3,0 \mathrm{E}-52$ & 205 & & & & & & & & & 5 & 5 & 2 & 1 & 2 & 0 & 0 & 0 & 1 & 0 & 1 & 0 & 0 & 3 & 0 & 1 & 2 & 2 & 2 \\
\hline $2,0 \mathrm{E}+00$ & 32 & $1,70 \mathrm{E}-01$ & 42 & 0.0 & 928 & & & & & 5 & 4 & 2 & 3 & 2 & 0 & 0 & 0 & 2 & 0 & 1 & 0 & 0 & 1 & 2 & 1 & 1 & 1 & 1 \\
\hline - & - & $2,00 \mathrm{E}-14$ & 86 & $8,00 E-15$ & 86 & & \begin{tabular}{|c|} 
reffNP_013413.1| \\
regulatory protein of \\
adenylate cyclase; $\mathrm{C} . .$. \\
$28 \mathrm{1} 1.4$
\end{tabular} & & & 5 & 5 & 4 & 4 & 3 & 1 & 0 & 1 & 4 & 1 & 1 & 1 & 1 & 1 & 1 & 2 & 3 & 3 & 3 \\
\hline $1,0 \mathrm{E}-02$ & 41 & $2,70 \mathrm{E}-01$ & 42 & 0.0 & 654 & & & & & 4 & 2 & 2 & 2 & 1 & 0 & 0 & 1 & 3 & 1 & 1 & 0 & 0 & 1 & 0 & 2 & 1 & 2 & 1 \\
\hline - & - & $7,50 \mathrm{E}-02$ & 44 & 0.0 & 866 & & & & & 3 & 4 & 1 & 1 & 2 & 1 & 0 & 1 & 3 & 1 & 1 & 2 & 0 & 1 & 1 & 0 & 1 & 1 & 1 \\
\hline - & - & $3,10 \mathrm{E}-01$ & 42 & $3,71 \mathrm{E}+04$ & 38 & & & & & 2 & 4 & 2 & 2 & 2 & 0 & 0 & 0 & 3 & 1 & 1 & 0 & 0 & 1 & 1 & 2 & 1 & 2 & 1 \\
\hline $7,0 \mathrm{E}-64$ & 240 & & & & & & & & & 1 & 0 & 0 & 1 & 0 & 0 & 0 & 0 & 0 & 0 & 1 & 1 & 0 & 0 & 1 & 1 & 0 & 1 & 1 \\
\hline - & - & $2,00 \mathrm{E}-04$ & 52 & $\begin{array}{ll}42 & 0.069\end{array}$ & & & & & & 0 & 0 & 0 & 0 & 0 & 0 & 1 & 4 & 0 & 0 & 1 & 1 & 5 & 0 & 0 & 2 & 0 & 0 & 1 \\
\hline
\end{tabular}


Tabelle 13: Auszug aus der Rohdatentabelle zur Durchmusterung einer cDNA Bank aus embryonalem Augengewebe.

Die Expressionsstärken der analysierten Klone in den verschiedenen embryonalen Geweben wurden entsprechend ihrer Intensität mit den Zahlen 1 bis 6 bewertet (1: sehr schwach, 2: schwach, 3: mittlere Expressionsstärke, 4: stärkere Expression: 5 starke Expression und 6: sehr starke Expression). Anhand der so erhaltenen Expressionsmatrix wurden die Klone nach verschiedenen Vektoren (Tabelle 14), die die Karyopherin $\beta 3$ Synexpressionsgruppe definieren, in aufeinanderfolgenden Durchgängen sortiert. Nachdem die Karyopherin $\beta 3$ Synexpressionsgruppe abgegrenzt wurde, erfolgte zur besseren Übersicht ein Sortierschritt nach der zugeordneten Funktion. Die Funktionszuordnung erfolgte auf der Grundlage von Sequenzhomologien der partiell sequenzierten Klone zu Sequenzen aus Protein- und Nukleotiddatenbanken. Mit Klonen, die andere Expressionsmuster zeigten, wurde mit geigneten Vektoren (Tabelle 15) entsprechend verfahren. Klone die mit diesem Verfahren nicht eingeordnet werden konnten wurden manuell sortiert. Die ersten 115 Klone wurden der Karyopherin $\beta 3$ Synexpressionsgruppe zugeordnet. Die restlichen Klone zeigen ein anderes Expressionsmuster.

\begin{tabular}{|c|c|c|}
\hline Vektor I & Vektor II & Vektor III \\
\hline $\begin{array}{c}\mathrm{Au}, \mathrm{Kb}, \mathrm{Ss}, \mathrm{Hi}, \\
\mathrm{En}, \mathrm{Ce}\end{array}$ & $\begin{array}{c}\mathrm{Au}, \mathrm{Kb}, \mathrm{Ss}, \mathrm{Hi}, \mathrm{Pn}, \\
\mathrm{En}, \mathrm{Ce}, \mathrm{Nr}\end{array}$ & $\begin{array}{c}\mathrm{Au}, \mathrm{Kb}, \mathrm{Ss}, \mathrm{Hi}, \mathrm{Pn}, \mathrm{Op}, \mathrm{Pi}, \mathrm{Np}, \mathrm{Ha}, \\
\mathrm{En}, \mathrm{Ce}, \mathrm{Nr}, \mathrm{Ep}, \mathrm{So}, \mathrm{He}, \mathrm{Pd}, \mathrm{Pi}\end{array}$ \\
\hline
\end{tabular}

Tabelle 14: Zur Gruppierung der Karyopherin $\beta 3$ Synexpressionsgruppe verwendete Vektoren.

Für die Bezeichnung der verschiedenen Gewebe wurden folgende Abkürzungen verwendet: Au, Auge, Kb, Kiemenbögen, Ss, Schwanzspitze, Hi, Gehirn, Pn, Pronephros, En, Endoderm, Ce, Haftdrüse, Nr, Neuralrohr, Op, Ohrplacode, Ep, Epidermis, So, Somiten, No, Notochord, Ne, Nerven, He, Herz, Pd, Proctodeum, Pi, Epiphyse, Np, Nasenplacode, Py, Hypophyse, Ha, Schlupfdrüse. Ein Vektor setzt sich aus der Summe von positiven Werten (grün dargestellten Geweben) und negativen Werten (rot dargestellten Geweben) zusammen.

\begin{tabular}{|c|c|c|c|c|}
\hline Augen & $\begin{array}{l}\text { Hirn Augen } \\
\text { Neuralrohr }\end{array}$ & $\begin{array}{l}\text { Epiphyse } \\
\text { Hypophyse }\end{array}$ & $\begin{array}{c}\text { Kopf Notochord } \\
\text { Augen }\end{array}$ & $\begin{array}{c}\text { Ohrplacode } \\
\text { Haftdrüse }\end{array}$ \\
\hline $\begin{array}{c}\mathrm{Au}, \mathrm{Kb}, \mathrm{Ss}, \mathrm{Hi} \text {, } \\
\mathrm{Pn}, \mathrm{En}, \mathrm{Ce}, \mathrm{Nr}, \\
\mathrm{Op}, \mathrm{Ep}, \mathrm{So}, \mathrm{No} \text {, } \\
\mathrm{Ne}, \mathrm{He}, \mathrm{Pd}, \mathrm{Pi}, \\
\mathrm{Np}, \mathrm{Py}, \mathrm{Ha}\end{array}$ & $\begin{array}{c}\mathrm{Au}, \mathrm{Kb}, \mathrm{Ss}, \mathrm{Hi} \text {, } \\
\text { En, Ce, Nr, Ep, } \\
\mathrm{So}, \mathrm{No}, \mathrm{Ne}, \mathrm{He} \text {, } \\
\mathrm{Pd}\end{array}$ & $\begin{array}{c}\mathrm{Au}, \mathrm{Kb}, \mathrm{Ss}, \mathrm{Hi}, \\
\mathrm{Pn}, \mathrm{En}, \mathrm{Ce}, \mathrm{Nr}, \\
\mathrm{Op}, \mathrm{Ep}, \mathrm{So}, \mathrm{No}, \\
\mathrm{Ne}, \mathrm{He}, \mathrm{Pd}, \mathrm{Pi}, \\
\text { Np, Py, Ha }\end{array}$ & $\begin{array}{c}\mathrm{Au}, \mathrm{Kb}, \mathrm{Ss}, \mathrm{Hi}, \\
\mathrm{Pn}, \mathrm{En}, \mathrm{Ce}, \mathrm{Nr}, \\
\mathrm{Ep}, \mathrm{So}, \mathrm{No}, \mathrm{Ne}, \\
\mathrm{He}, \mathrm{Pd}, \mathrm{Np},\end{array}$ & $\mathrm{Ce}, \mathrm{Op}$ \\
\hline
\end{tabular}

Tabelle 15: Zur Gruppierung von Genen mit anderen Expressionsmustern verwendete Vektoren. Die verwendeten Abkürzungen entsprechen denen aus Tabelle 14. Ein Vektor setzt sich aus der Summe von positiven Werten (grün dargestellten Geweben) und negativen Werten (rot dargestellten Geweben) zusammen. 


\section{Danksagung}

Herrn Prof. Dr. T. Pieler möchte ich für die guten Arbeitsmöglichkeiten danken. Bei Frau Prof. Dr. M. Schäfer bedanke ich für die bereitwillige Übernahme der Begutachtung dieser Arbeit. Frau Prof. Dr. C. Gatz danke ich für die Übernahme des Korefferats. Für zur Verfügung gestellte cDNAs geht mein Dank an Marry Dasso für RanBP1, Ducan Sparrow für XSUMO-1, Dirk Görlich für Karyopherin $\alpha 1$ und Karyopherin $\alpha 2$ und an Gideon Dreyfuss für Transportin. Bei Klaus Schwamborn bedanke ich mich für das modifizierte pSV-beta Plasmid, bei Falko Rudt und Maike Claußen für den regen Tausch der Plasmide aus unserem Labor. Marion Sölter danke ich für den partiellen Karyopherin beta-3 Klon. Yong Long Chen danke ich für die Sequenz von Ran-TC4. Bei Gudrun Kracht, Tina Berneking, Ulrike Strube, Regina Buhl, Andreas Nolte und ganz besonders Helma Füllgrabe möchte ich mich für die technische Unterstützung bedanken. Dr. Falko Rudt, Dr. Kirstie Murdoch und Susanne Loop danke ich für die zur Verfügung gestellten Protokolle. Bei den Mitarbeitern und Marion Sölter, Susanne Loop, Marco Winkler, Tina Berneking, Bettina Spielbauer und Katja Horvay bedanke ich mich für das besonders angenehme Arbeitsklima. Bei Werner Ochotzki und der Werkstadt bedanke ich mich für die gute Kooperation. 


\section{Lebenslauf}

Name: $\quad$ Wischnewski

Vorname: Jörg

Geburtsdatum: $\quad$ 15. März. 1968

Geburtsort: Hannover

Nationalität: Deutsch

\section{Ausbildung}

1974

1974-1978

1978-1980

1980-1984

1984-1987

1987-1989

1989-1990

$10 / 1990$

10/1992

07/1994-09/1994

$11 / 1995$

11/1995-07/1997

08/1997-03/2002
Einschulung in die Albert Schweitzer Schule, Hannover

Grundschule Mariensee

Orientierungsstufe Süd, Neustadt a. Rbge.

Realschule, Neustadt a. Rbge.

Kooperative Gesamtschule, Neustadt a. Rbge., mit Abiturabschluß am 27.05.87

Zivildienst, Diakoniestation Neustadt a. Rbge.

Aushilfstätigkeiten

Beginn des Studiums der Biologie an der Georg-August-Universität zu Göttingen

Diplomvorprüfung in den Fächern Zoologie, Genetik, Anorganische Chemie und Physikalische Chemie

Laborpraktikum am Max-Planck-Institut für Biophysikalische Chemie, Abt. Molekulare Zellbiologie, Prof. Dr. Peter Gruss, Göttingen Hauptdiplomprüfung in den Fächern Entwicklungsbiologie, Zoologie und Chemie

Diplomarbeit mit dem Titel „Identifizierung von Kernlokalisierungssignalsequenzen in Xenopus laevis TFIIIA“ am Institut für Biochemie und Molekulare Zellbiologie der Georg-August-Universität Göttingen in der Abteilung von Herrn Prof. Dr. T. Pieler

Anfertigung der hier vorliegenden Dissertation mit dem Titel „Analyse der differentiellen Expression von Transportfaktoren und deren Funktion bei dem nukleocytoplasmatischen Transport von TFIIIA“ am Institut für Biochemie und Molekulare Zellbiologie der Georg-AugustUniversität Göttingen in der Abteilung von Herrn Prof. Dr. T. Pieler 
